\title{
Learning to Dive \\ The Digital Restitution of Lot 3317
}

by

\section{Kyle Thomas David Tousant}

A thesis submitted to the Faculty of Graduate and Postdoctoral Affairs in partial fulfillment of the requirements for the degree of

\section{Master of Architecture}

\section{Carleton University \\ Ottawa, Ontario}

(C) 2018

Kyle Thomas David Tousant 


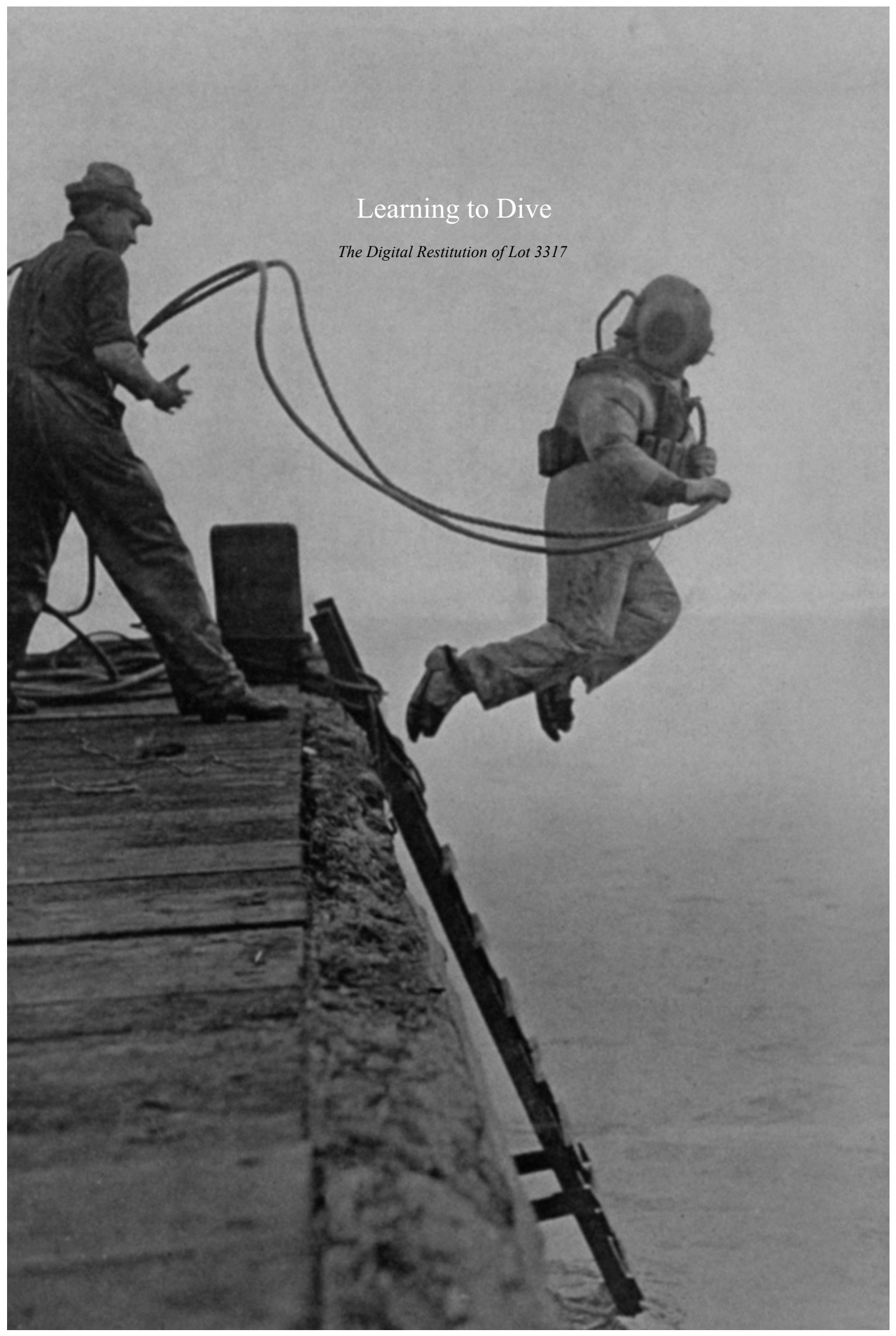




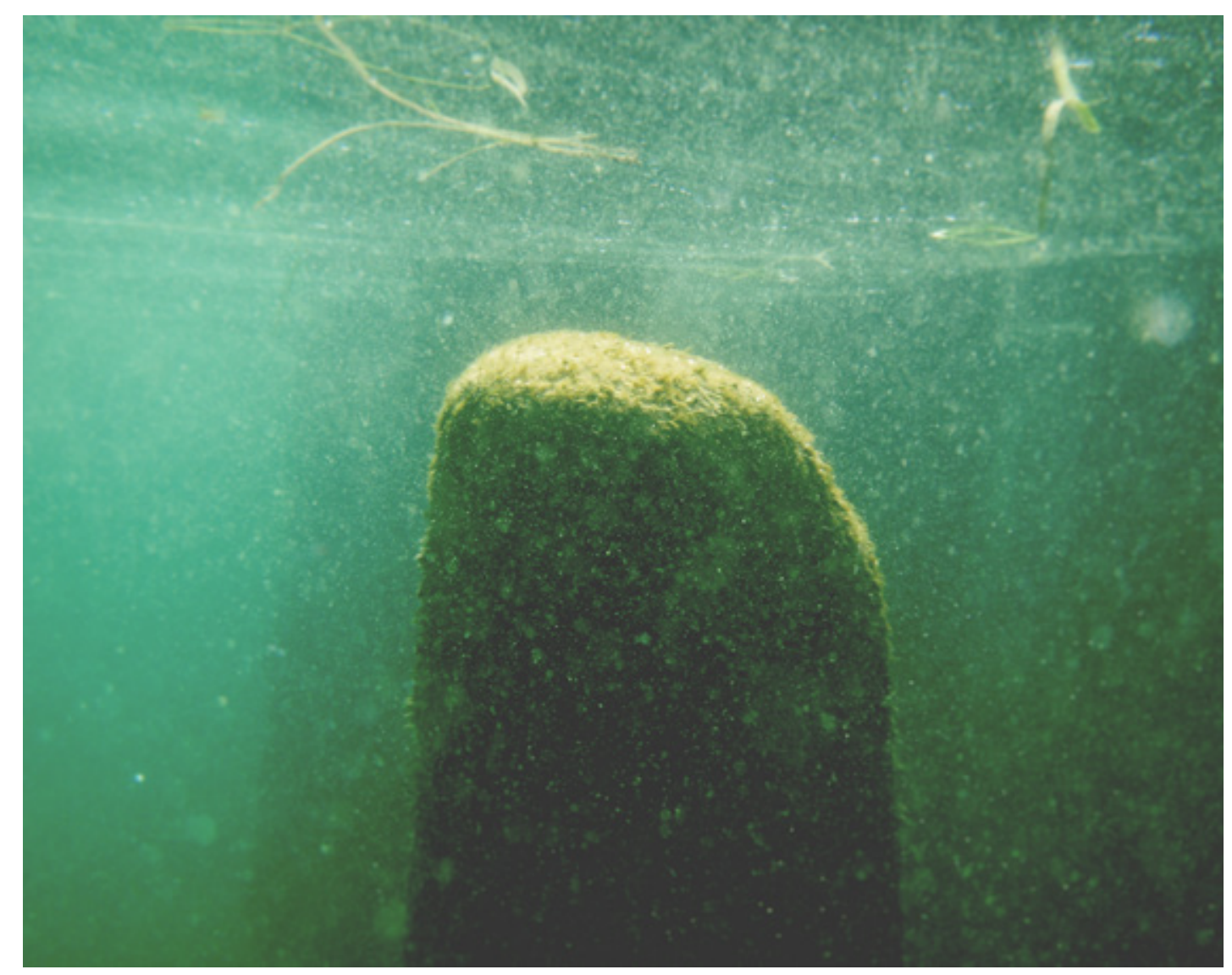

Fence Post

The St. Lawrence Seaway has been of importance to me since I was very young. I have very fond memories of boating, swimming and fishing along its shorelines, from the Prescott Marina all the way down to Cardinal and Iroquois a distance of approximately $25 \mathrm{~km}$. I was fascinated by the old canals and the large ships that slowly passed in the distance. I often wondered where they were going or what they might have on board. Once in a while, when my grandfather, father and I were fishing, we would watch the ships pull into the Port of Johnstown. We sat just west of old Gallops Canal, almost directly below the Oldenburg-Prescott International Bridge, watching as our boat slowly floated east towards "the old north channel". There is a large grain elevator there, my grandfather helped build it, and he says that it once sat on large wooden piles that reached deep down to the very bottom of the river. From that point on, I wondered what could be found down there. 


\section{Abstract}

This project heuristically explores the history of the St. Lawrence Seaway and of the villages displaced by the construction of various locks, channels and canals prior to its opening in 1958. The completion of the work ensured secure passage of ocean going vessels and was critical to the expansion of the Canadian economy.

This thesis begins with a review of the techniques involved in the digital restitution of sub-merged artefacts, followed by the replication of a chosen site. As a proof of concept, the data will then be used as a model to explore methods in creating and validating heritage values, while valourizing assets as a cultural resources for use in the future.

More importantly, the content produced will demonstrate that there are benefits in maintaining a link between the lost villages and the historical lore of existing communities. As a design paradigm, this project will invite individuals to reflect on the physical, representational and political attributes that the St. Lawrence Seaway and Power Project helped define. 

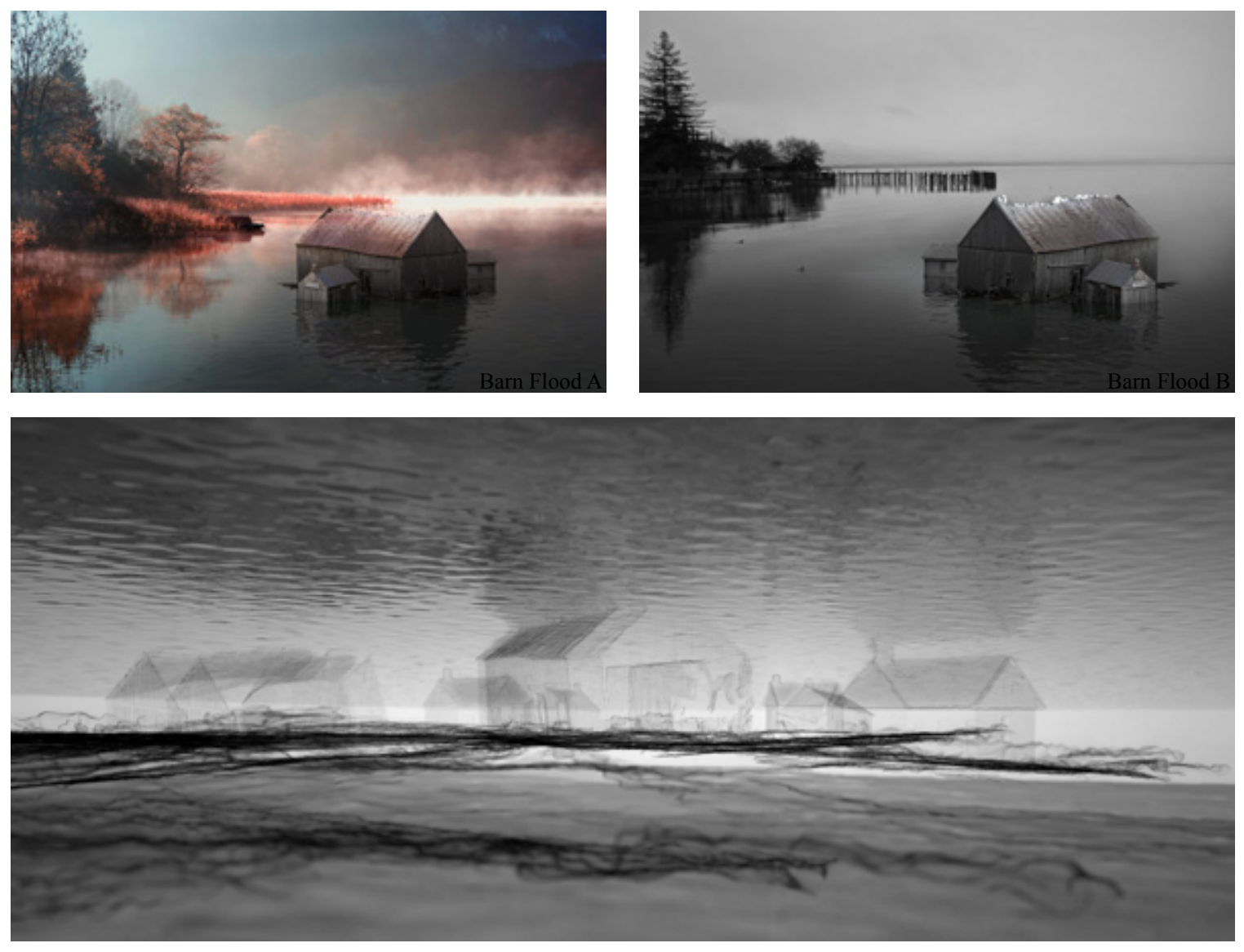


\section{Acknowledgments}

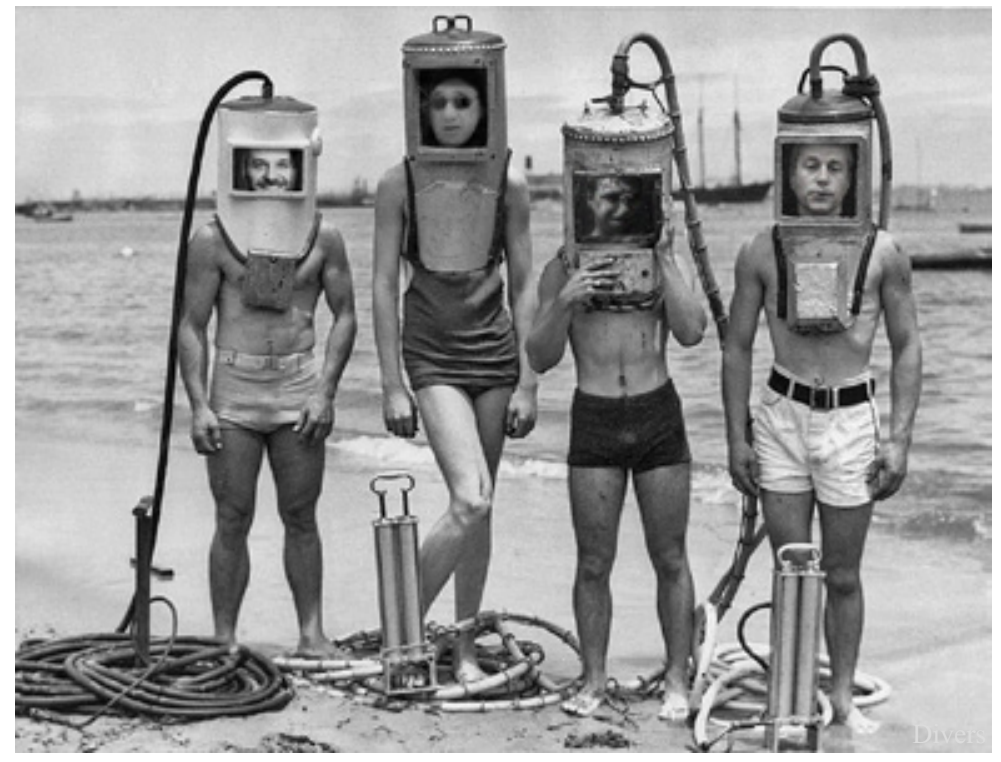

This thesis is dedicated to my grandparents, Gordon and Eleanor Tousant for their unconditional love and support. I would like to thank my brother, Issac StoreyTousant, for the use of his boat and Rob Duncan for his invaluable camaraderie and emotional support.

In addition, I would like to thank my advisor, Dr. Stephen Fai, for his guidance and support throughout this project, and the Carleton Immerse Media Studio Lab (CIMS), for providing academic and occupational opportunities. CIMS has empowered me to foster, develop and further my interest in heritage documentation while completing my Master's Degree.

I would also like to thank Keith Duncan for his editing help with this document and to extend many thanks to all of my friends and colleagues at CIMS. Their passion and interest in my re-search has been a strong source of encouragement, while providing uplifting spirits and a motivational atmosphere. 


\section{Table of Contents}

\subsection{Geographical Context}

1.1 Introduction to the Great Lakes-St. Lawrence Seaway 14

1.2 Introduction to the St. Lawrence River 15

1.3 The Power of the St. Lawrence 16

\subsection{Historical Context}

2.1 Early Canada - St. Lawrence 16

2.2 The St. Lawrence Seaway and Power Project 17

2.3 Lake St. Lawrence 19

2.4 The International Rapids Power Development Act 19

2.5 The Displacement and Destruction 24

2.6 New Homes 25

\subsection{Socio-Environmental Context}

3.1 Regional Changes 26

3.2 The Community 26

3.3 Dysfunctional 31

3.4 Valourization - Heritage Conservation Districts 33

3.5 Under Water 34

3.6 The Sunken Villages 35

3.7 Accessibility 43

\subsection{Generating Assets}

4.1 Creating value in Assets through tourism 46

4.2 Re-Habilitation 46

4.3 Data Acquisition 47

\subsection{Developing Assets}

5.1 Canadian Inventory of Historic Buildings 49

5.2 Identifying Lot 331750

5.4 Site Access by Boat 57

5.5 Digital Restitution through Photogrammetry 57

\subsection{Speculative Reconstruction}

6.1 The Barn 63

6.2 The English Barn 64

6.3 The Speculative Construction 66

6.4 Asset No.2 A Speculative Reconstruction 67

\subsection{First Person Experience in HMD}

7.1 The Experience 68

7.2 Firt Person Interpretation 70

7.4 VH Experiences of Lot 331772

\subsection{Digital Re-Habilitation Appendix:}

9.1 West Section of Site 75

9.2 Passive Panorami Experiences 78

9.3 Speculative Reconstructions 86

\subsection{Identifying Assets}

10.1 Identifying Assets: Introduction 99

10.2 Identifying Assets Part 1: 100

The Monument of Chryslers Battle Field 100

10.3 Identifying Assets Part 1: The Christ's Church 101

10.4 Identifying Assets Part 1: Cook's Tavern 107

10.5 Identifying Assets Part 2115

\subsection{Introduction}

11.1 Introduction to Diving + Data Acquisition 117

11.2 Introduction to Photogrammetry Process 118

11.3 Underwater Survey Safety Considerations 118

\subsection{Site Acquisition}

12.1 Site Access by Boat 122

12.2 Capturing Data 122

\subsection{Capturing Data}

13.1 Multimedia Photogrammetry 123

13.2 Camera Comparison 125

13.3 Camera Results 129

13.4 Working Distance 129

13.5 Network Design 130

13.6 Targets 131

2.9 Placing Targets 132

\subsection{Digital Restitution}

14.1 Alignment \& Camera Calibration 135

14.2 Alignment - Image processing 136

14.3 Alignment - Camera Calibrations 137

3.4 Building Dense Clouds 144

3.5 Building Meshes 145

3.6 Building Textures 146

\subsection{Stereo Images}

15.1 Gopro-Stereo 149

\section{Dive Log}

CORNER 138 DIVGii $140 \quad$ DIViii 143

DIV 138 DIVGe $141 \quad$ DIVGo_01 150

DIVGi 139 OCT 232017141 DIVGo_02 150

DIVii 139 DIVi 142 DIV_03_STEREO 150 


\section{List of Illustrations}

Fence Post

Tousant, Kyle. 2018

Barn Flood A

Tousant, Kyle. 2018

Untextured Mesh

Tousant, Kyle. 2018

Barn Flood B

Tousant, Kyle. 2018

Divers

www.pinterest.co.uk/LifeBuzzNews/history. 2018

Point Cloud

Tousant, Kyle. 2018

Great Lakes-St. Lawrence Seaway

Google Maps, Google, www.google.com.br/maps.

Great Lakes-St. Lawrence Seaway Project

danielmacfarlane.wordpress.com/2013/12/20/

montreal-and-the-st-lawrence

St. Lawrence Seaway River

lostvillages.ca/

Opening Day of St. Lawrence Seaway Project

lostvillages.ca

1958 Lake St. Lawrence - Pre-Flood

lostvillages.ca/

The Construction of Moses-Saunders Power Dam 18

lostvillages.ca/

1958 Lake St. Lawrence - Post-Flood

lostvillages.ca/

1958 Lake St. Lawrence - After-Flood

lostvillages.ca/

The Flood Running Over Former Lock No.22

Interpretive Manual, Upper Canada Village, Internal Document.

Removal of Debris

Interpretive Manual, Upper Canada Village, Internal Document

Water Running Over The King's Highway

Interpretive Manual, Upper Canada Village, Internal Document.

Re-Locating The Christ's Church

Interpretive Manual, Upper Canada Village, Internal Document.

Re-Locating The Cook's Tavern

ent.

Interpretive Manual, Upper Canada Village, Internal Document.

Map Identifying The Lost Villages

lostvillages.ca/

Map Identifying The Lost Villages

lostvillages.ca/

Moulinette Home 1920

Interpretive Manual, Upper Canada Village, Internal Document.

Osnabruck Book 2 Archive

Interpretive Manual, Upper Canada Village, Internal Document.

Osnabruck Book 2 Archive

Interpretive Manual, Upper Canada Village, Internal Document.

Osnabruck Book 2 Archive

Interpretive Manual, Upper Canada Village, Internal Document.

Morrisburg Lock No.21

Interpretive Manual, Upper Canada Village, Internal Document.

Morrisburg Lock No.21

Google Maps, Google, www.google.com.br/maps.

Potential Heritage Sites

Google Maps, Google, www.google.com.br/maps.

Tousant, Kyle. 2018

15
3 Long Sault Parkway

43

Tousant, Kyle. 2018

5 Aerial Images of Long Sault Parkway

5 sunkenvillages.ca

Lock 221952

5 helbig, luis. "the sunken villages story." sunken villages,

unkenvillages.ca

Diving Map

http://www.neptune-scuba.info/ca/ca-en.html

Diagram of Lock 22

http://www.neptune-scuba.info/ca/ca-en.html

14 Diver at Lock 22

https://www.canadiangeographic.ca/article/shipwreck-hunter 45

Lot 3317

Tousant, Kyle. 2018

Aerial Image 1958

helbig, luis. "the sunken villages story." sunken villages,

Aerial Image 2018

18 Thelbig, luis. "the sunken villages story." sunken villages,

sunkenvillages.ca

HEPCO Zoning

Interpretive Manual, Upper Canada Village, Internal Document.

18 Nautical Map

18 GIS Data

Tousant, Kyle. 2018

Google Maps

Google Maps, Google, www.google.com.br/maps

20 Site Data

Tousant, Kyle. 2018

Aerial GIS Data

Tousant, Kyle. 2018

Tousant, Kyle. 2018

Topography map of Osnabruck

Interpretive Manual, Upper Canada Village, Internal Document

Topography map of Osnabruck

Interpretive Manual, Upper Canada Village, Internal Document

25 Site Diagram

Tousant, Kyle. 2018

27 Site Point Cloud Heightmap 58

Tousant, Kyle. 2018

28 Site Point Cloud

Tousant, Kyle. 2018

Mesh of Foundation

60

Tousant, Kyle. 2018

Textued Foundation

Tousant, Kyle. 2018

Resin Model

Tousant, Kyle. 2018

32 Plexiglass Model

Tousant, Kyle. 2018

33

Digital Model

Tousant, Kyle. 2018

Digital Re-Habilitation : Passive Experiences in a Mounted Tousant, Kyle. 2018 


\section{List of Illustrations}

Display

Tousant, Kyle. 2018

Digital Model in a Head Mounted Display

Tousant, Kyle. 2018

Digital Re-Habilitation : West Section of Site

Tousant, Kyle. 2018

Rob's VR Experience

Tousant, Kyle. 2018

UE 19.4 Screen Capture

Tousant, Kyle. 2018

Rob's VR Experience

Tousant, Kyle. 2018

The King's Highway

Tousant, Kyle. 2018

The Cottage

Tousant, Kyle. 2018

Moulinette

Tousant, Kyle. 2018

The Barn

Tousant, Kyle. 2018

Speculative Reconstruction of Lot 3317

Tousant, Kyle. 2018

Speculative Reconstruction of Lot 3317

Tousant, Kyle. 2018

Speculative Reconstruction of Lot 3317

Tousant, Kyle. 2018

Barn A-E

Tousant, Kyle. 2018

Cottage

Tousant, Kyle. 2018

Christ's Church

Tousant, Kyle. 2018

Blacksmith's Shed

Tousant, Kyle. 2018

Barn F

Tousant, Kyle. 2018

Barn G

Tousant, Kyle. 2018

Barn Interior

Tousant, Kyle. 2018

Submerged Barn

Tousant, Kyle. 2018

2009 Louis Helbig

helbig, luis. "the sunken villages story." sunken villages,

sunkenvillages.ca

Monument

Interpretive Manual, Upper Canada Village, Internal Document.

Christ's Church

Interpretive Manual, Upper Canada Village, Internal Document.

Cook's Tavern

Interpretive Manual, Upper Canada Village, Internal Document.

Chrysler's Battle Field

Interpretive Manual, Upper Canada Village, Internal Document.

Christ's Church Graveyard

Interpretive Manual, Upper Canada Village, Internal Document.

Interior of TheChrist's Church

Interpretive Manual, Upper Canada Village, Internal Document.

Christ's Church Graveyard

Interpretive Manual, Upper Canada Village, Internal Document.

Christ's Church, Osnabruck Book 2 Archive
70 Interpretive Manual, Upper Canada Village, Internal Document.

Christ's Church, Osnabruck Book 2 Archive 106

71 Interpretive Manual, Upper Canada Village, Internal Document.

The Cook's Tavern 108

73 Interpretive Manual, Upper Canada Village, Internal Document.

The Cook's Tavern 109

75 Interpretive Manual, Upper Canada Village, Internal Document.

The Cook's Tavern $\quad 110$

76 Interpretive Manual, Upper Canada Village, Internal Document.

Cook's Tavern, Osnabruck Archive

111

77 Interpretive Manual, Upper Canada Village, Internal Document.

Cook's Tavern, Osnabruck Archive

Cook's Tavern, National Air Photo Library (NAPL)

80 http://www.nrcan.gc.ca/earth-sciences/geomatics/

satellite-imagery-air-photos/9265

81 Cook's Tavern, National Air Photo Library (NAPL)

http://www.nrcan.gc.ca/earth-sciences/geomatics/

satellite-imagery-air-photos/9265

83 International Section

Google Maps, Google, www.google.com.br/maps.

84 Identifying Assets

116

Google Maps, Google, www.google.com.br/maps.

The Sky

Tousant, Kyle. 2018

$\begin{array}{ll}\text { Photogrammerty Diagram } & 118\end{array}$

91 Tousant, Kyle. 2018

Process Documentation 120

92 Tousant, Kyle. 2018

Process Documentation $\quad 121$

93 Tousant, Kyle. 2018

Lot Lot 3317

94 helbig, luis. "the sunken villages story." sunken villages,

sunkenvillages.ca

Park's Canada

https://www.canadiangeographic.ca/article/shipwreck-hunter

iPhone 7 plus

Tousant, Kyle. 2018

97

Tousant, Kyle. 2018

Non-Coded Targets

Tousant, Kyle. 2018

Coded Targets

Tousant, Kyle. 2018

Cattle Floor

Tousant, Kyle. 2018

Golbies on Coded Targets

Tousant, Kyle. 2018

Point Cloud

134

Tousant, Kyle. 2018

144

Preliminary Mesh

Tousant, Kyle. 2018

Textures

146

147

Tousant, Kyle. 2018

Photoscan Workflow

148 


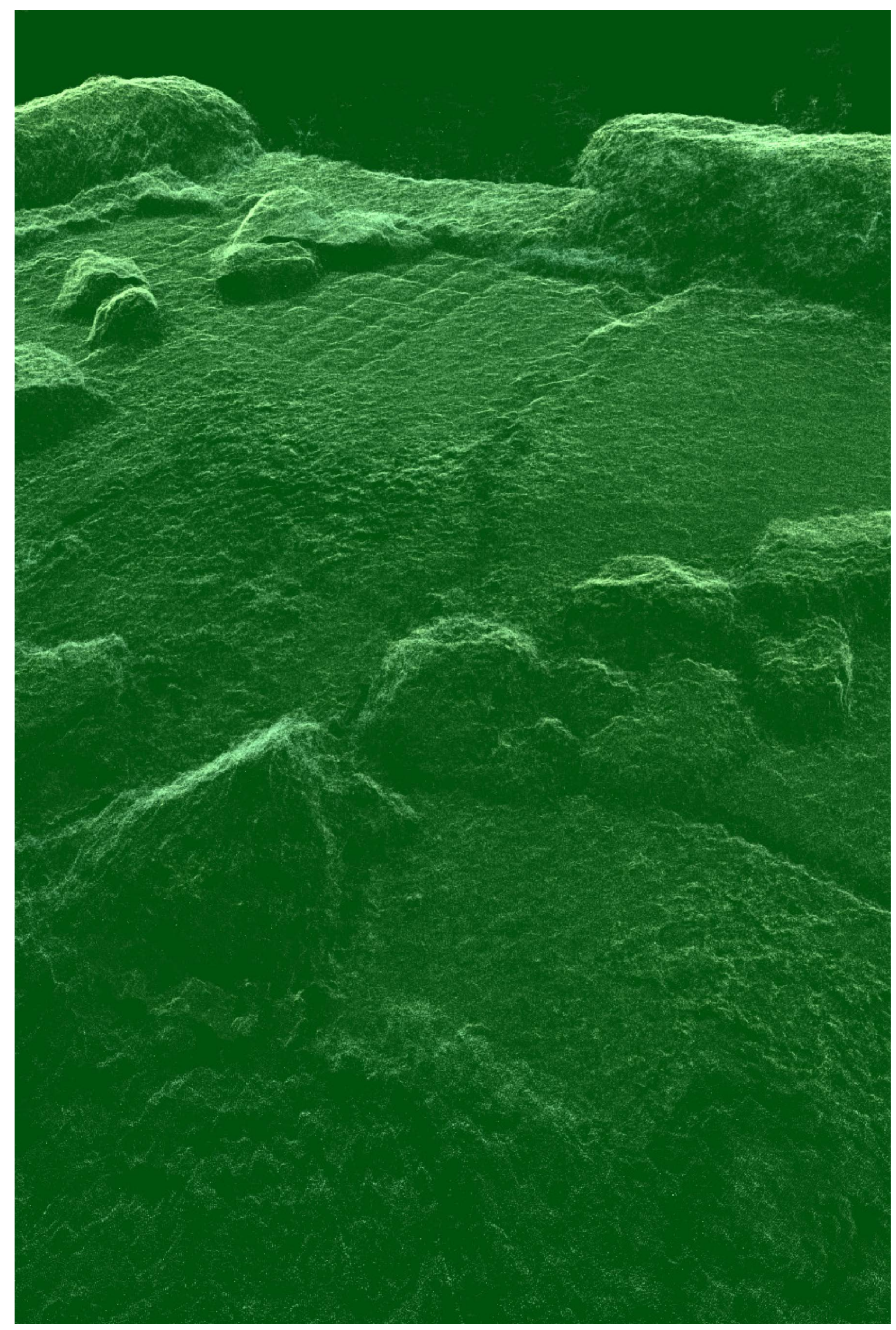




\section{Introduction}

The intent of this project is to promote heuristic explorations surrounding the history of the St. Lawrence Seaway, and the villages displaced during construction of passageways that was completed in 1958. As a general aspiration, I intended this project to encourage continuing research pertaining to The Lost Villages and enhance awareness of their heritage value as a cultural asset. More importantly, the content produced will demonstrate that there are benefits in maintaining a link between these forgotten assets and the historical lore of the community.

This study will begin with a review of the techniques involved in the digital restitution of submerged artefacts. It will be followed by a survey, which was created to select a site located within the flood zone of the St. Lawrence Seaway and Power Project. With this location identified, the acquisition of data on site will then be performed, as well as its digital replication.

As a proof of concept, the data will then be used as a model to explore methods in which heritage values can be generated and disseminated, while valourizing the site as a cultural resource for use in the future. As an installation, this investigation will enable individuals to explore an otherwise inaccessible site, and invite visitors to make judgments based off of their own first hand experiences. It will also enable a reflection on the political realities which greatly influenced the construction of the Seaway. Most importantly however, it will demonstrate the historical significance of the physical representations in a cultural context, specific to Canadian History, which were lost during the flood.

As a design paradigm, this concept will be carried out in 3 main forms:

1)The replication of a site, depicting current conditions

2)A speculative reconstruction of the building that existed on this site

3)The digital rehabilitation of a site, viewed from a head mounted display 


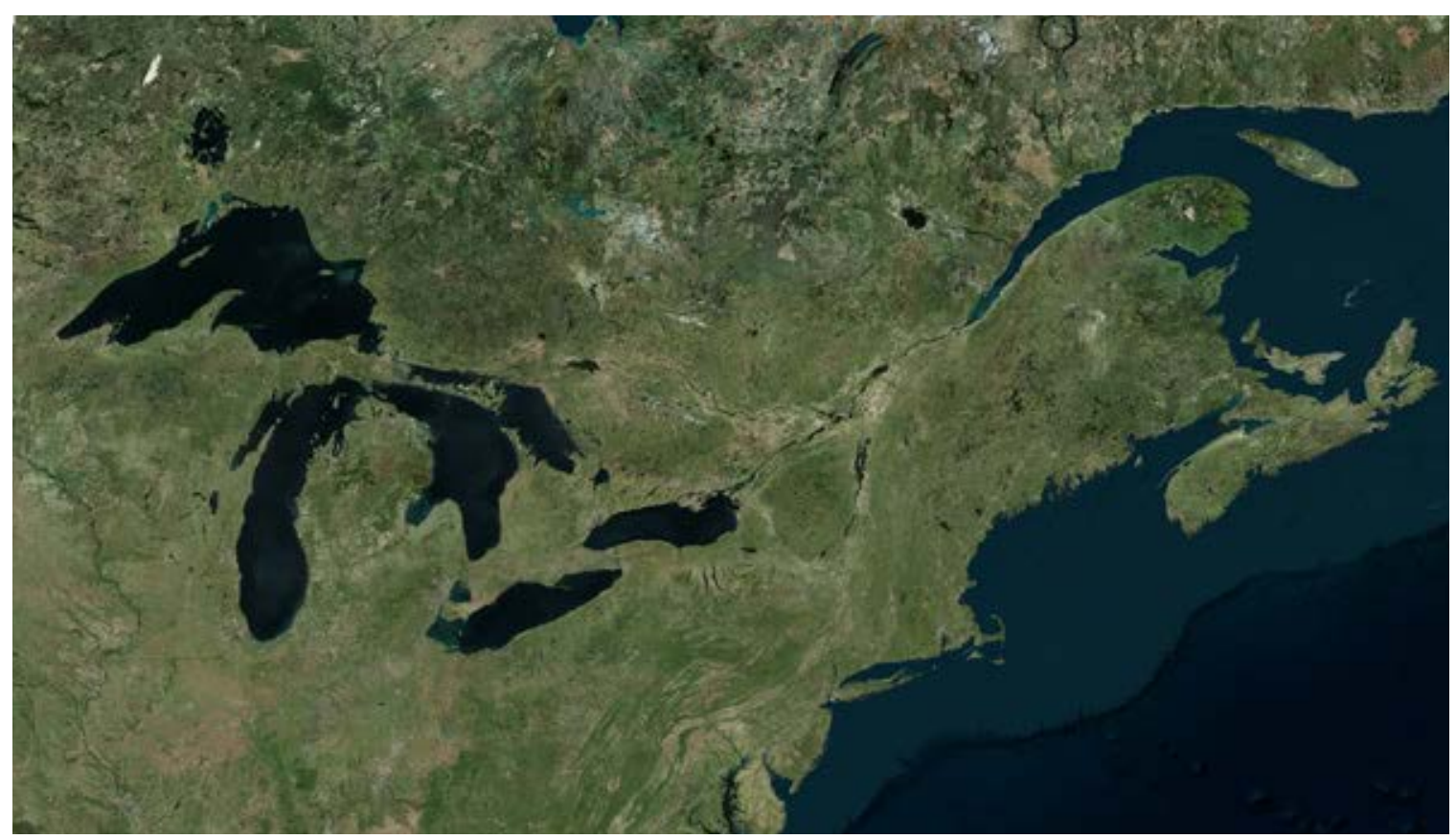

\subsection{Geographical Context}

Great Lakes-St. Lawrence Seaway

\subsection{Introduction to the Great Lakes-St. Lawrence Seaway}

The Great Lakes-St. Lawrence Seaway is located in Eastern Canada (formerly Upper Canada) and flows from The Great Lakes outward into the Atlantic Ocean. With all 5 of The Great Lakes and the St. Lawrence River, the entire waterway is about $3600 \mathrm{~km}$, from the east coast to the head of Lake Superior. ${ }^{2}$ The Great Lakes-St. Lawrence Seaway is also currently the largest navigable inland waterway in the world, bordering Canada and the US, it provides a vital artery into the "heart of Industrial North America". With 4 of the 6 largest ports in Canada located on the seaway, the great eastern river has defined much of Canada's early development and continues to do so. The Great Lakes-St. Lawrence Seaway now spans over 2 provinces, 9 states and serves an industrial area of with over 50 million inhabitants. ${ }^{3}$

\footnotetext{
2 Journault, Marc, et al. "High Precision Hydrography in Canada, the ST. Lawrence River Channel, HD Bathymetry, Production, Distribution and Updating.” Hydro12 - Taking Care of the Sea, 2012, doi:10.3990/2.221. Page. 17

3 Journault, Marc, et al. "High Precision Hydrography in Canada, the ST. Lawrence River Channel, HD Bathymetry, Production, Distribution and Updating." Hydro12 - Taking Care of the Sea, 2012, doi:10.3990/2.221. Page. 18
} 


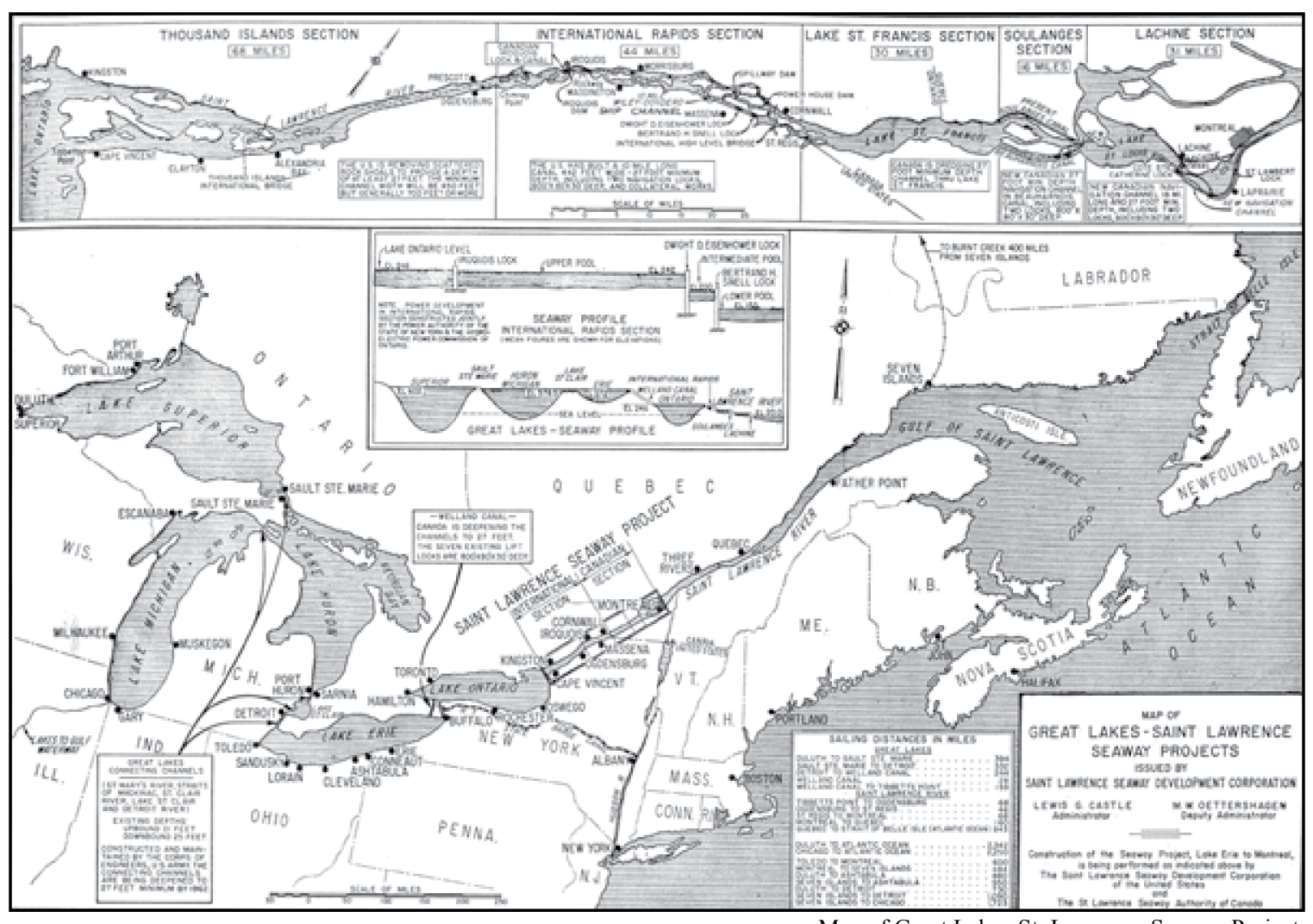

\subsection{Introduction to the St. Lawrence River}

The St. Lawrence River, the eastern-most portion of the seaway, is approximately $1800 \mathrm{~km}$ long starting at Lake Ontario and emptying into the Atlantic. ${ }^{4}$ Between Kingston and Montreal, the river's International Section, the St. Lawrence was formerly divided into 5 parts: The Thousand Islands section, The International Rapids section, Lake St. Francis, Soulanges and Lachine. ${ }^{5}$ For the interest of this study, the main focus will be on the formerly named, International Rapids Section, now referred to merely as the International section. This region spreads over $71 \mathrm{~km}$, from Iroquois to Cornwall and across two counties, Dundas and Stormont. ${ }^{6}$ It was formerly subdivided into 4 portions: 1) Galops Rapids, stretching from Iroquois to Cornwall, 2) Rapids Plat at Morrisburg, 3) The Farads Point Rapids and 4)The Long Sault Rapids.

\footnotetext{
4 Journault, Marc, et al. "High Precision Hydrography in Canada, the ST. Lawrence River Channel, HD Bathymetry, Production, Distribution and Updating." Hydro12 - Taking Care of the Sea, 2012, doi:10.3990/2.221. Page. 15

5 Wynn, Graeme. Canada and Arctic North America: an Environmental History. ABC-CLIO, 2007 . Page. 273-230 6 Wynn, Graeme. Canada and Arctic North America: an Environmental History. ABC-CLIO, 2007. Page. 273-230
} 


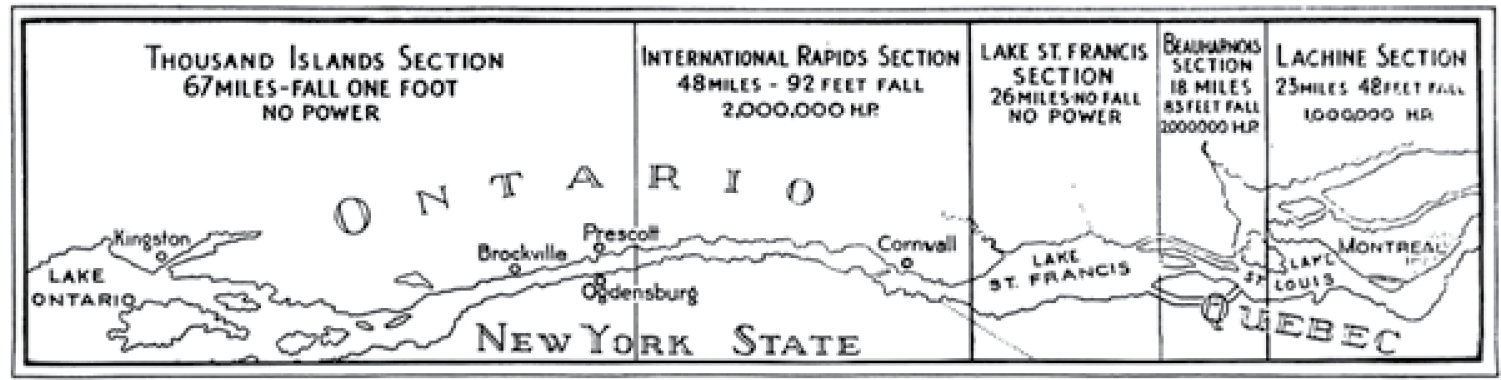

\subsection{The Power of the St. Lawrence}

St. Lawrence Seaway River

Unlike other rivers with high flow volumes, the St. Lawrence River is more or less consistent year round, producing 246,000 cubic feet/second $(6,982.4 \mathrm{cubic} \mathrm{m} / \mathrm{sec}){ }^{7} \mathrm{In}$ total the river begins $167.6 \mathrm{~m}$ above sea level and drops over a span of $1800 \mathrm{~km}$ before reaching the Atlantic Ocean. The water drains from Lake Erie to Lake Ontario dropping by $99.4 \mathrm{~m}$, from Lake Ontario to Montreal by $28 \mathrm{~m}$, another $15.2 \mathrm{~m}$ at SoulangesBeauharois and finally $15.2 \mathrm{~m}$ at Lachine. The International Rapids section spanned approximately $71 \mathrm{~km}$, with an overall average decent of $2.5 \mathrm{~m} / \mathrm{km}$, producing an estimated $2,000,000$ horse power.

\subsection{Historical Context}

\subsection{Early Canada - St. Lawrence}

Early Canadian economic and national development derived primarily from natural resources in the major metropolitan centres along the St. Lawrence River and Upper Canada. ${ }^{8}$ The River provided a means for the formation of transatlantic and transcontinental markets. ${ }^{9}$ Geographically, the International Rapids section proved to be one of the most difficult portions of the river to navigate. Canal construction contributed to the early development of the seaway, later joining forces with hydroelectric development. This initiative was brought on by both Canadian and

\footnotetext{
7 Wynn, Graeme. Canada and Arctic North America: an Environmental History. ABC-CLIO, 2007. Page. 273-230

8 Creighton, Donald, and Christopher Moore. The Empire of the St. Lawrence: a Study in Commerce and Politics. University of Toronto Press, 2017. Page. 47

9 Creighton, Donald Grant. The Commercial Empire of the St. Lawrence, 1760-1850. Ryerson Press, 1937. Page 18
} 
American nationalist associations, pushing for a more modern form of transportation and increased industrialization along the river. ${ }^{10}$ "The principal task of the St. Lawrence development was the improvement of the channels between Prescott and Montréal, allowing uninterrupted passage from the Atlantic Ocean to the Great Lakes". ${ }^{11}$ From the commencement of construction on the first canals in 1824, to the completion of the St. Lawrence Seaway and Power Project and official opening on June $26^{\text {th }} 1959,135$ years had elapsed. The end result was a new international waterway serving the world.

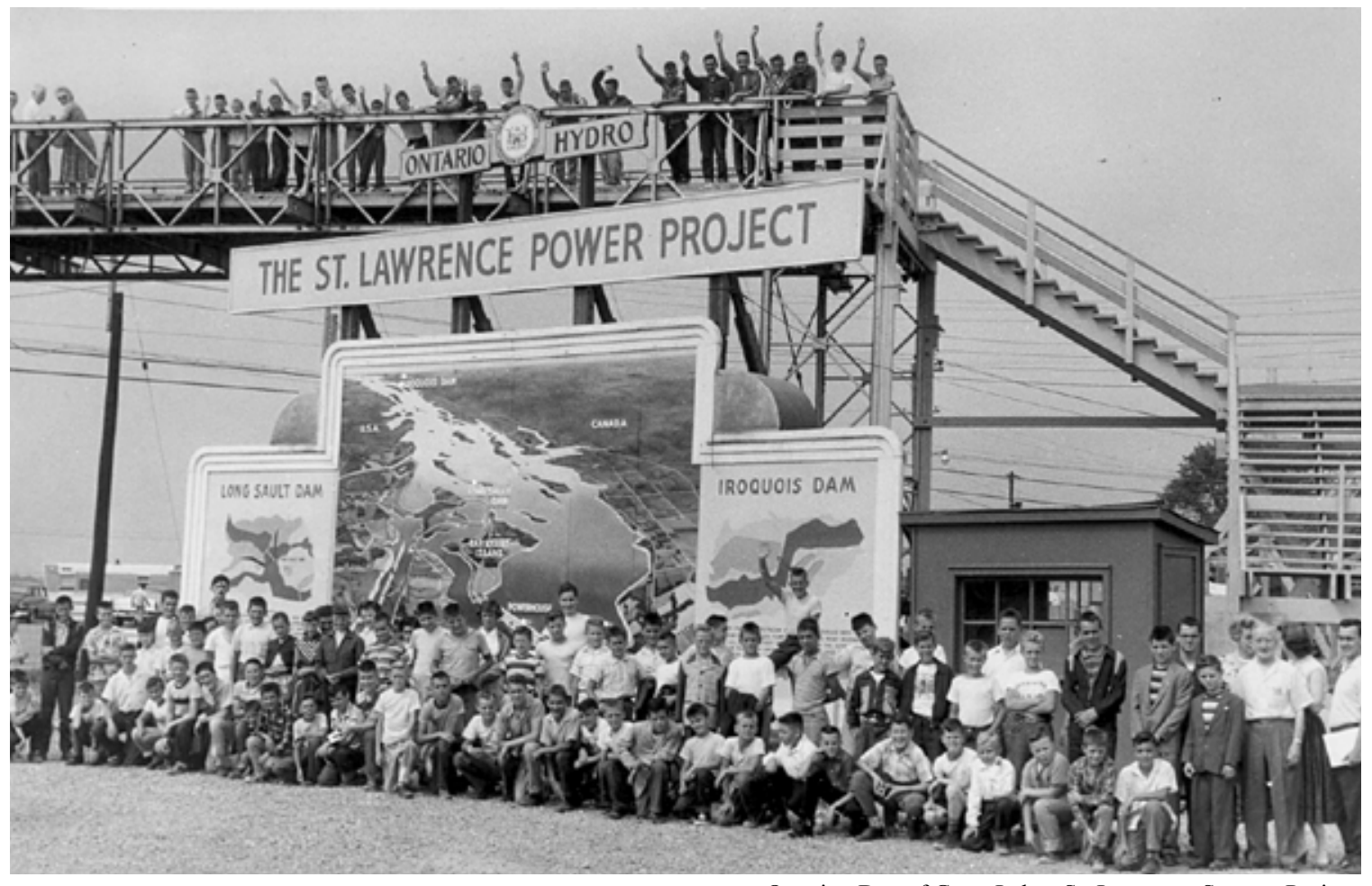

Opening Day of Great Lakes-St. Lawrence Seaway Project

\subsection{The St. Lawrence Seaway and Power Project}

Maintaining a minimum depth of 27 feet, The St. Lawrence Seaway and Power Project was one of the largest trans-border projects ever undertaken by two countries, and one of the greatest engineering achievements of the 20th Century. ${ }^{12}$ It consisted of 15 operable locks and four dams, two of which generated hydroelectricity. For the purposes of this

10 Macfarlane, Daniel. Negotiating a River: Canada, the US, and the Creation of the St. Lawrence Seaway. UBC Press, 2014. Page. 45

11 Macfarlane, Daniel. Negotiating a River: Canada, the US, and the Creation of the St. Lawrence Seaway. UBC Press, 2014. Page. 45 12 Macfarlane, Daniel. Negotiating a River:Canada, the US, and the Creation of the St. Lawrence Seaway. UBC Press, 2014. Page. 8 
study, the Moses-Saunders Power Dam is of interest. It is a $1005 \mathrm{~m}$ tall straight gravity fed dam from Barnhart Island to the Canadian shore near Cornwall. Outfitted with 32 generating units, the proposed dam was to be split between Canada and the US and was to produce approximately $1,880,000$ kilowatts of power needed to promote industrial growth in the immediate area. ${ }^{13}$ To produce enough pressure for the dam to run at full capacity, more than 35 thousand acres of land between Canada and The United States were flooded. Lake St. Lawrence was the resulting creation, a 100 square mile head-pond approximately 34 miles in length. ${ }^{14}$
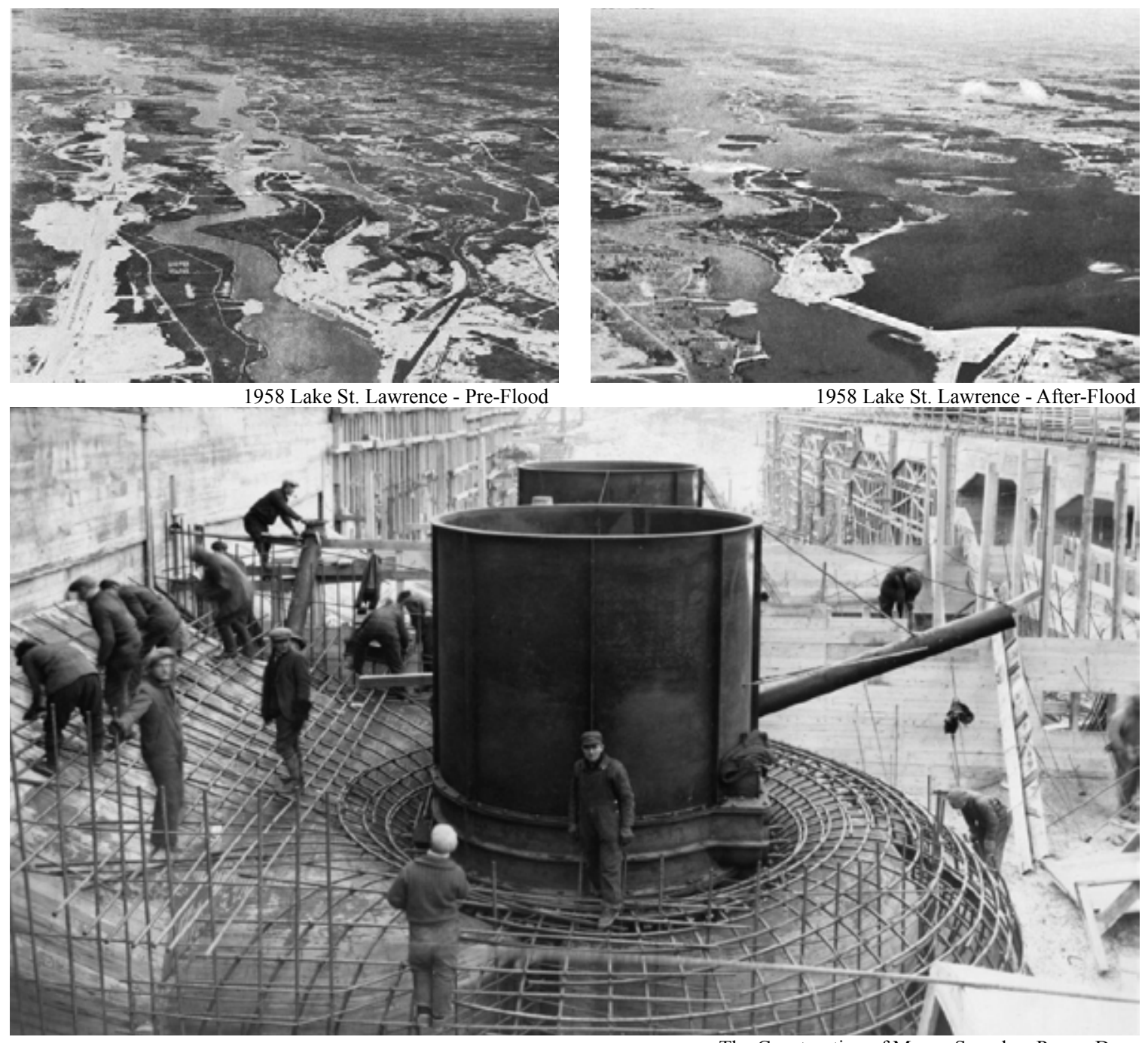

The Construction of Moses-Saunders Power Dam 13 Macfarlane, Daniel. Negotiating a River:Canada, the US, and the Creation of the St. Lawrence Seaway. UBC Press, 2014. Page. 54 14 Richardson, Ronald E. Developing Water Resources: the St. Lawrence Seaway and the Columbia - Peace Power Projects. Ryerson Press, 1969. Page. 22

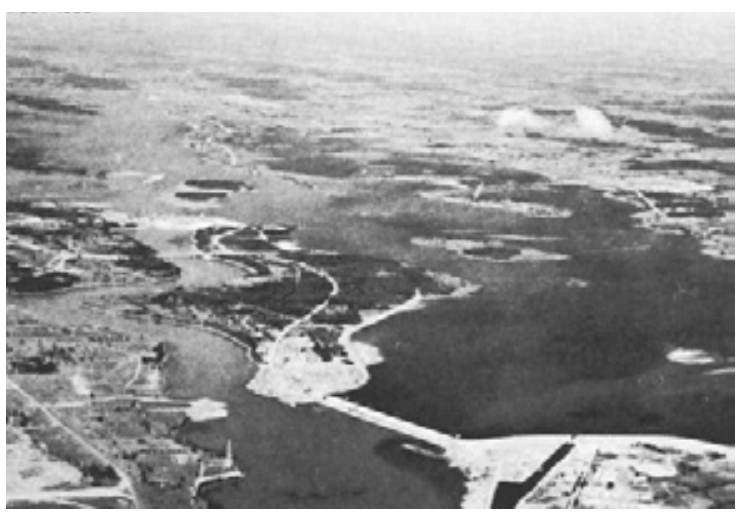

1958 Lake St. Lawrence - After-Flood

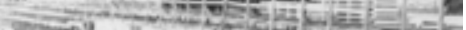




\subsection{Lake St. Lawrence}

The proposed floodplain of Lake St. Lawrence extended over 20,000 acres in Canada and 18,000 in the United States. To give an overview of the impact this project had with regards to human development and built infrastructure, the entire project displaced 40 miles of the 2 way Canadian National railway, 35 miles of the King's Highway [No.2, which at the time was the busiest highway in Canada $]^{15}$ and 225 farms. On a more personal level, the flood displaced 18 cemeteries, 1,000 cottages and entire communities, many that predate the 20 th century. In total the entire project relocated over 6,500 Canadian citizens and 1,100 American citizens. ${ }^{16}$

\subsection{The International Rapids Power Development Act}

In 1952, The Federal government passed The International Rapids Power Development Act in to law. The Act outlined "The transfer of the administration of lands or property to The Powers and capacities of Hydro-Electric Power Commission of Ontario (HEPCO) in addition to the application of The St. Lawrence Development Act, 1952 (No. 2)" (an act respecting the Construction of Works for the Generation of Electrical Power in the International Rapids Section of the St. Lawrence River). ${ }^{17}$ The provisions of The St. Lawrence Development Act, 1952 (No. 2) enabled "the expropriation or taking of lands or property for the purpose of constructing, operating and maintaining the works to be undertaken by Ontario, for the duration of the St. Lawrence Seaway Power Project."18

\footnotetext{
15 Richardson, Ronald E. Developing Water Resources: the St. Lawrence Seaway and the Columbia - Peace Power Projects. Ryerson Press, 1969. Page. 23

16 Macfarlane, Daniel. Negotiating a River:Canada, the US, and the Creation of the St. Lawrence Seaway. UBC Press, 2014.Page 140 17 Legislative Services Branch. “Consolidated Federal Laws of Canada, International Rapids Power Development Act.” Loi Sur Les Sports Nationaux Du Canada, 27 Apr. 2018, laws-lois.justice.gc.ca/eng/acts/I-19.8/page-1.html.

18 Legislative Services Branch. "Consolidated Federal Laws of Canada, International Rapids Power Development Act." Loi Sur Les Sports Nationaux Du Canada, 27 Apr. 2018, laws-lois.justice.gc.ca/eng/acts/I-19.8/page-1.html.
} 

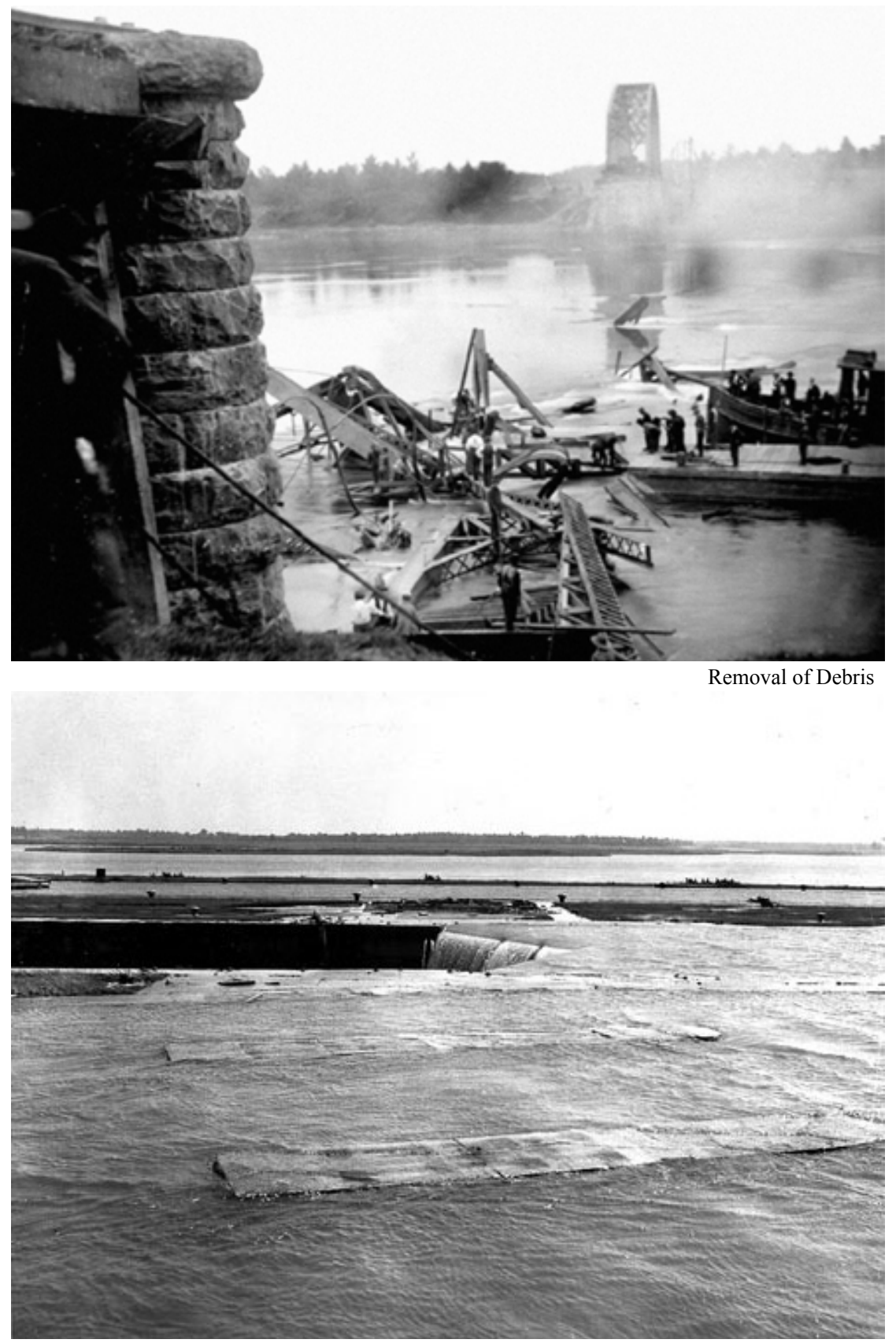

The Flood Running Over Former Lock No.22 

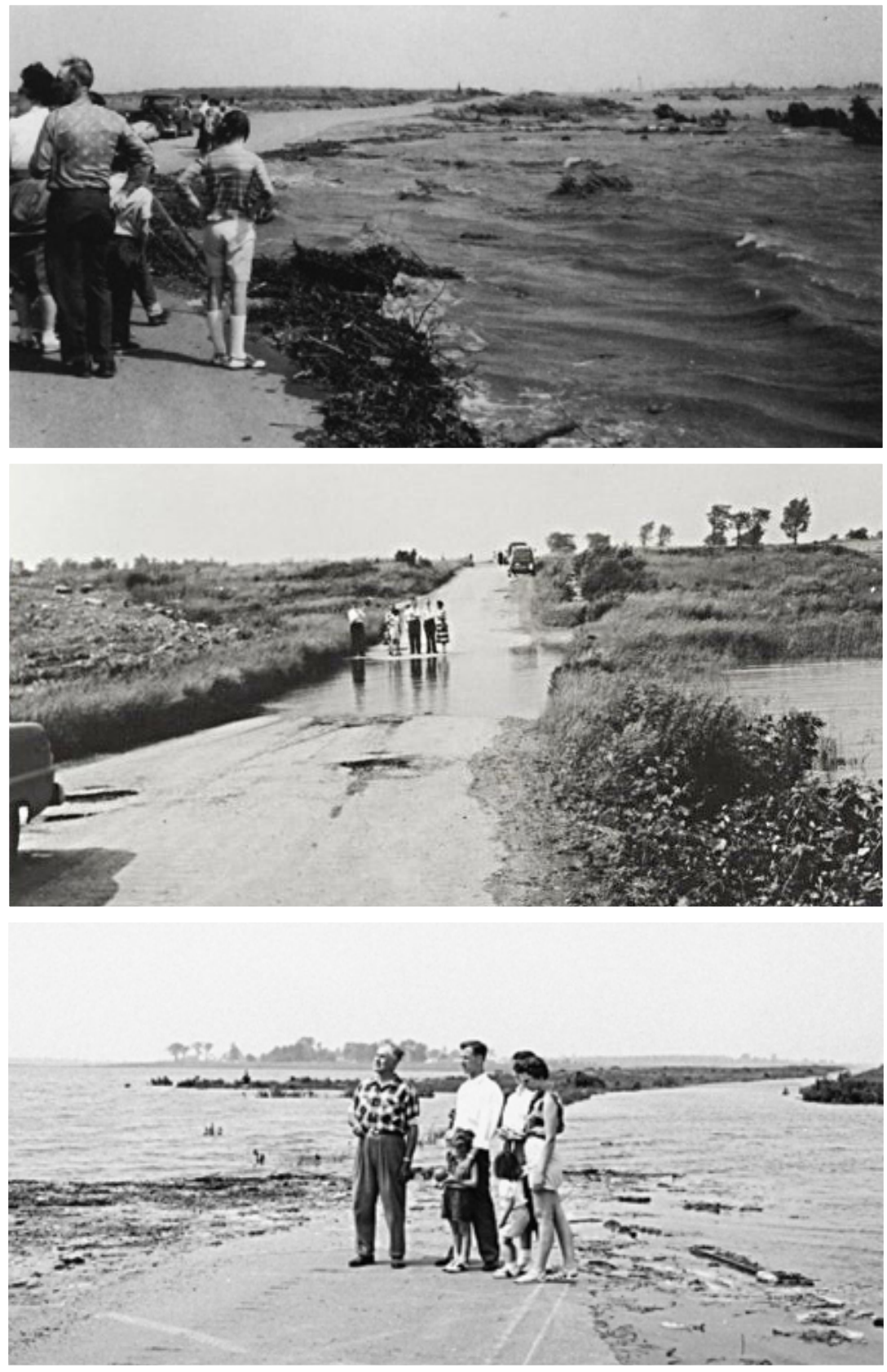

Water Running Over The King's Highway 

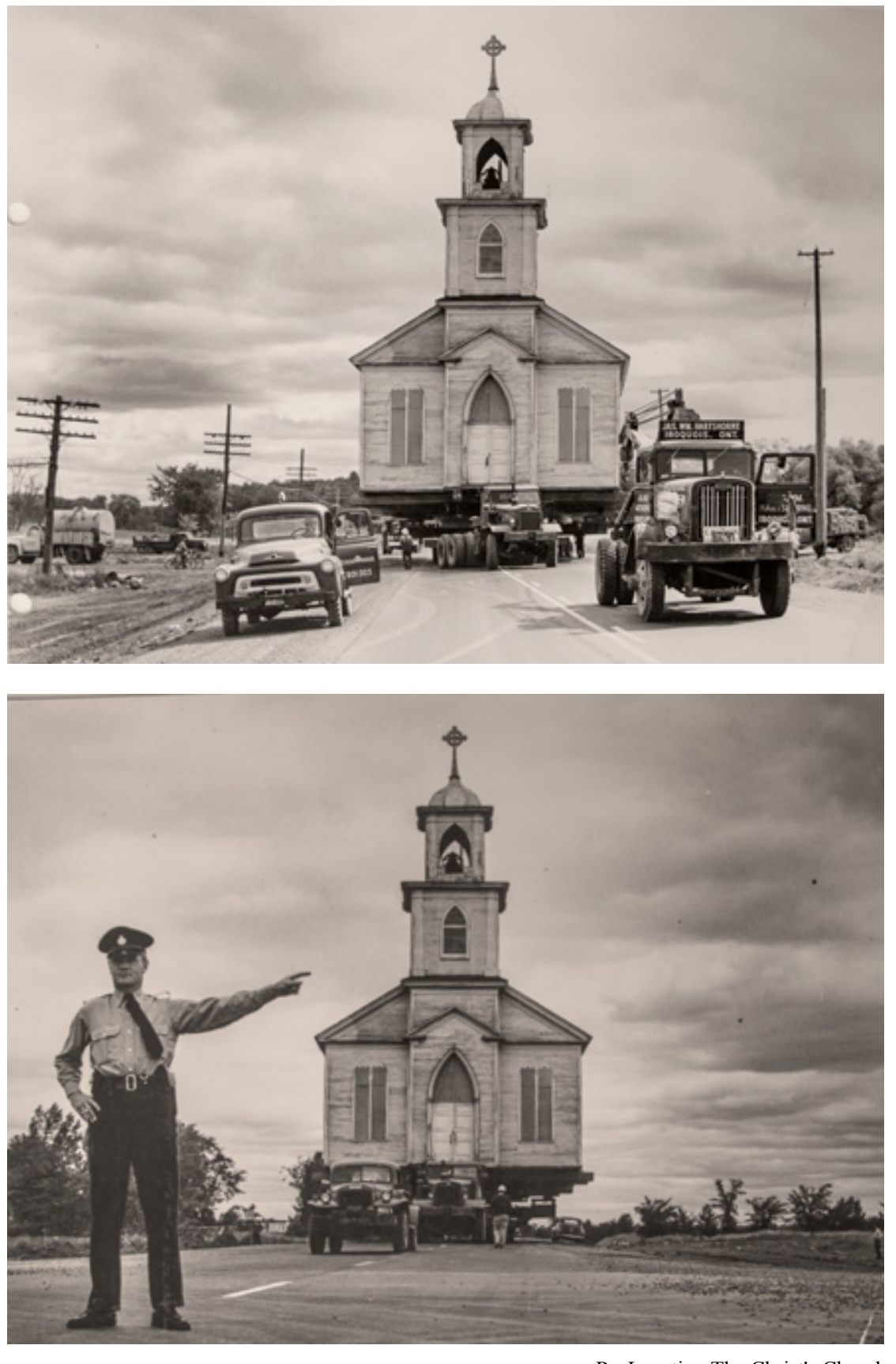

Re-Locating The Christ's Church 

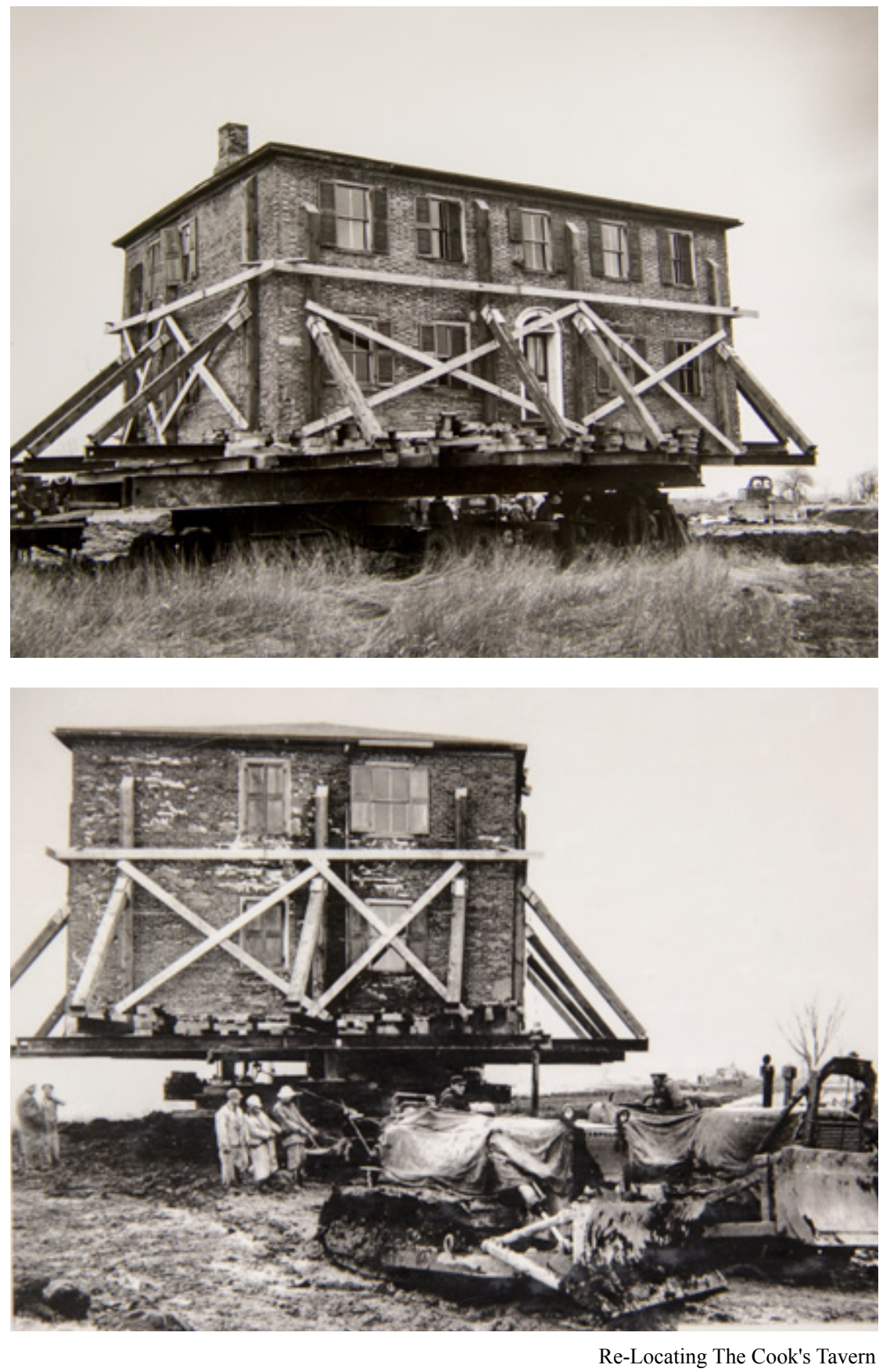


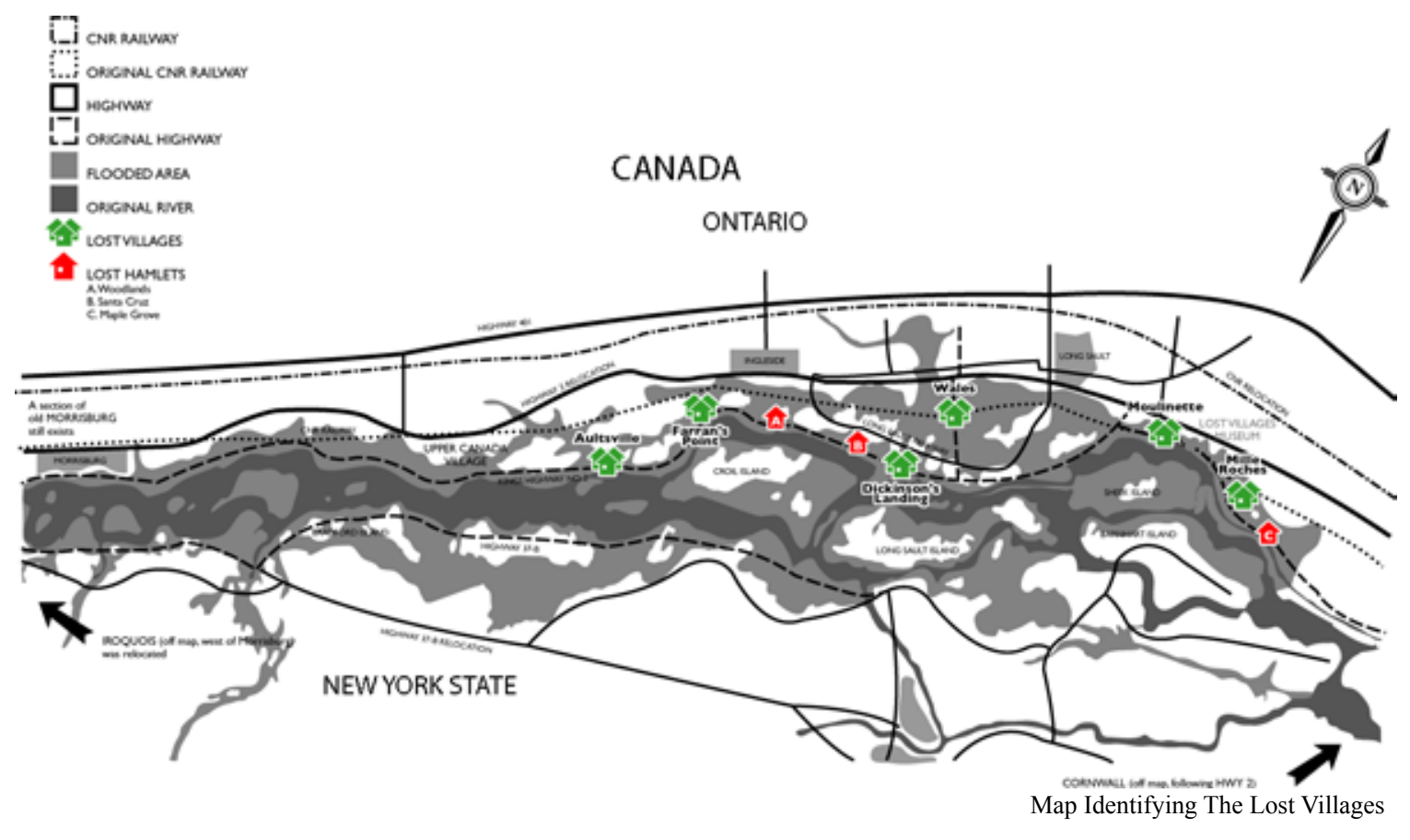

\subsection{The Displacement and Destruction}

The project required physically relocating the whole town of Iroquois and part of the town of Morrisburg. In addition to this, the villages of Aultsville, Farran's Point, Dickson's Landing, Wales, Moulinette, Mille Roches and the hamlets of Woodlands, Santa Cruz and MapleGrove were to be completely destroyed with their inhabitants relocated to new communities. According to the International Power Development Act, the provincial government was responsible for overseeing the operation, while HEPCO was responsible carrying out the process of relocation and construction. ${ }^{19}$ In July 1954, HEPCO began planning for the transfer of lands, generating a report estimating that 2,035 transactions were to take place, with an average settlement of $\$ 10,000-\$ 12,000$ per residence. ${ }^{20}$ Home owners were given the option of accepting the settlement, or having their home moved. ${ }^{21}$

19 Macfarlane, Daniel.Negotiating a River:Canada, the US, and the Creation of the St. Lawrence Seaway.UBC Press,2014.Page.141 20 HEPCO,SPP Series, Memorandum to Carrick: Property Transactions - St. Lawrence Seaway, July 121954 21 Macfarlane, Daniel. Negotiating a River: Canada, US, and the Creation of the St. Lawrence Seaway. UBC Press, 2014. Page.155 


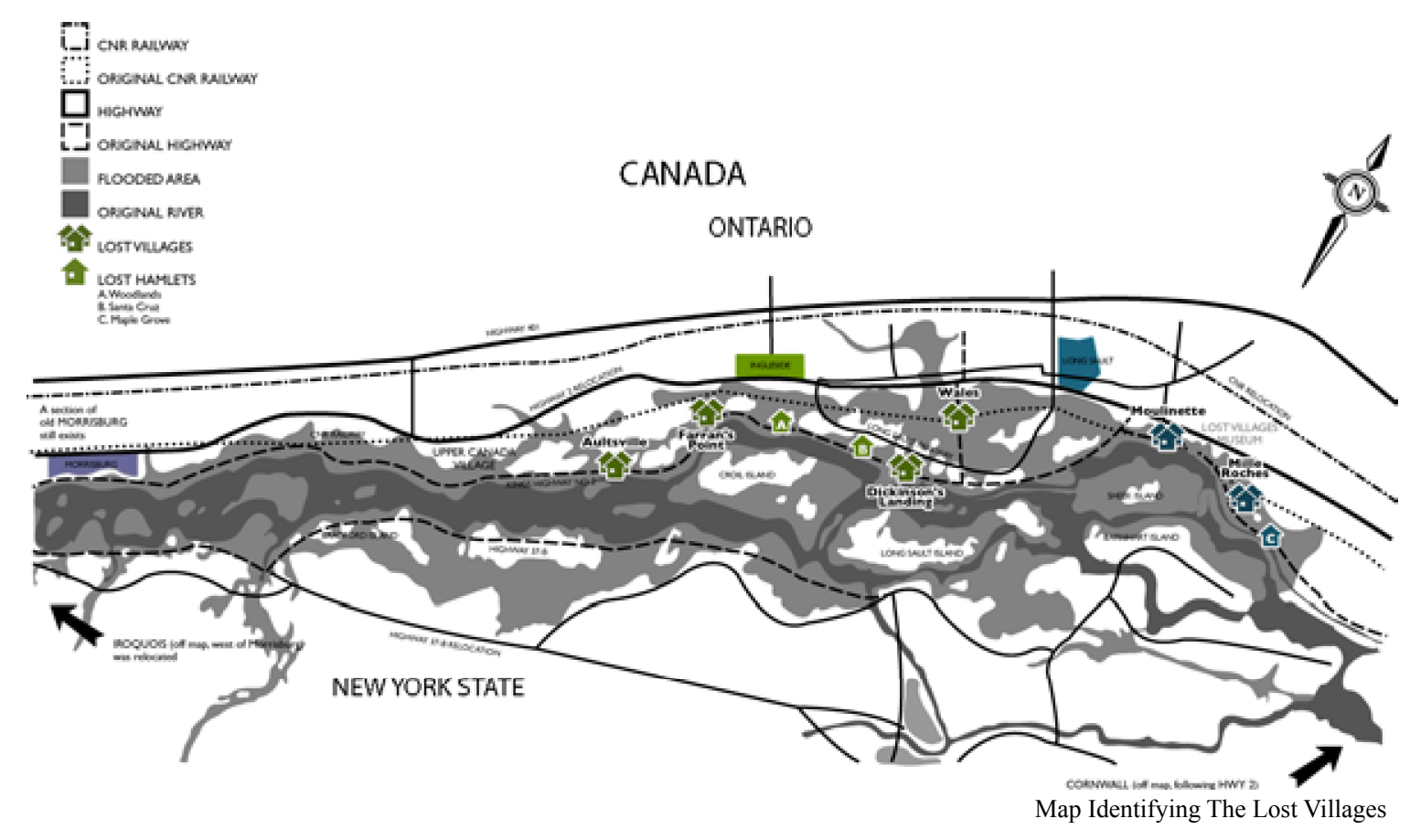

\subsection{New Homes}

Funded by the provincial government, HEPCO replaced the old communities with new ones. ${ }^{22}$ Long Sault replaced Mille Roches and Moulinette, Ingleside replaced Wales, Farran's Point, Dixon's Landing and Aultsville. Morrisburg, with the population of 2,100 relocated one third of it's entire town. Iroquois wasn't as fortunate as it moved north approximately $4 \mathrm{~km}$, a process that involved moving 152 homes and constructing 86 new buildings. Over the entire project, 525 dwellings were relocated. The new communities incorporated modern features for community living such as sewers, sidewalks, streets and civic buildings including schools and churches. ${ }^{23}$ They also incorporated wide curving streets, setback houses, parks and underground telephone and hydroelectric services. ${ }^{24}$ Additionally, many families were now able to experience the benefits of complete indoor plumbing for the first time. ${ }^{25}$ Overall, these changes were met by mixed emotions by the 22 Richardson, Ronald E. Developing Water Resources: the St. Lawrence Seaway and the Columbia - Peace Power Projects. Ryerson Press, 1969. Page. 23

23 Ibd. Page.26

24 Macfarlane, Daniel. Negotiating a River: Canada, US, and the Creation of the St. Lawrence Seaway. UBC Press, 2014. Page.100 25 Richardson, Ronald E. Developing Water Resources: the St. Lawrence Seaway and the Columbia - Peace Power Projects. Ryerson Press, 1969. Page. 23 
community at large.

\subsection{Socio-Environmental Context}

\subsection{Regional Changes}

The St. Lawrence Seaway and Power Project, being one of the largest trans-border projects ever undertaken by two countries, completely re-organized and re-colonized Eastern Ontario. "The perceived ability to master nature implicit in reconfiguring the river, extended to the planning model of 'modern' towns that absorbed the communities displaced by Lake St. Lawrence." ${ }^{26}$ It could be argued that HEPCO was focusing more on the management of natural resources as a commodity, rather than the organization of the territory and it's people. In many ways, this project facilitated a complete redefinition of regional space, and in doing so, shifted the focus from the people, their culture and it's heritage value, to the physical and geographical organization and mobilization of natural resources. ${ }^{27}$ This matter further strengthens MacFarlane's argument that "water is not only a natural element, but also a culturally constructed object capable of transforming a river into a power producing lake preceded by a system of canals and locks." 28

\subsection{The Community}

As a result of the regional changes, generations of social patterns were disrupted at the mercy of bilateral nationalist goals between Canada and the United States. These changes, mainly focusing on economic benefits, suggested that industrial progress was the only foreseeable future. ${ }^{29}$ MacFarlane later confirms this theory by stating that "the St. Lawrence Seaway Power Project was a modernistic initiative that brought Canadians and

26 Macfarlane, Daniel. Negotiating a River: Canada, the US, and the Creation of the St. Lawrence Seaway. UBC Press, 2014. Page. 45

27 Macfarlane, Daniel. "Watershed Decisions: the St. Lawrence Seaway and Sub-National Water Diplomacy." Canadian Foreign Policy Journal, vol. 21, no. 3, 2015, Page. 212-223

28 Macfarlane, Daniel. Negotiating a River: Canada, the US, and the Creation of the St. Lawrence Seaway. UBC Press, 2014. Page. 47

29 - Richardson, Ronald E. Developing Water Resources: the St. Lawrence Seaway and the Columbia - Peace Power Projects. Ryerson Press, 1969. Page. 22 
Americans together to further common economic and strategic goals as well as to create a stronger bond in Canada-US relations." ${ }^{30}$ This large scale technological project brought technology, politics and economics together to produce something extremely valuable to North America, however it was at the expense of many societal and environmental sacrifices. ${ }^{31}$ It needs to be discussed how "rising waters obliterated homes that have been in families for generations". ${ }^{32}$ Most of the individuals impacted by the construction confirmed that this was an extreme detriment to the community overall, and that multiple

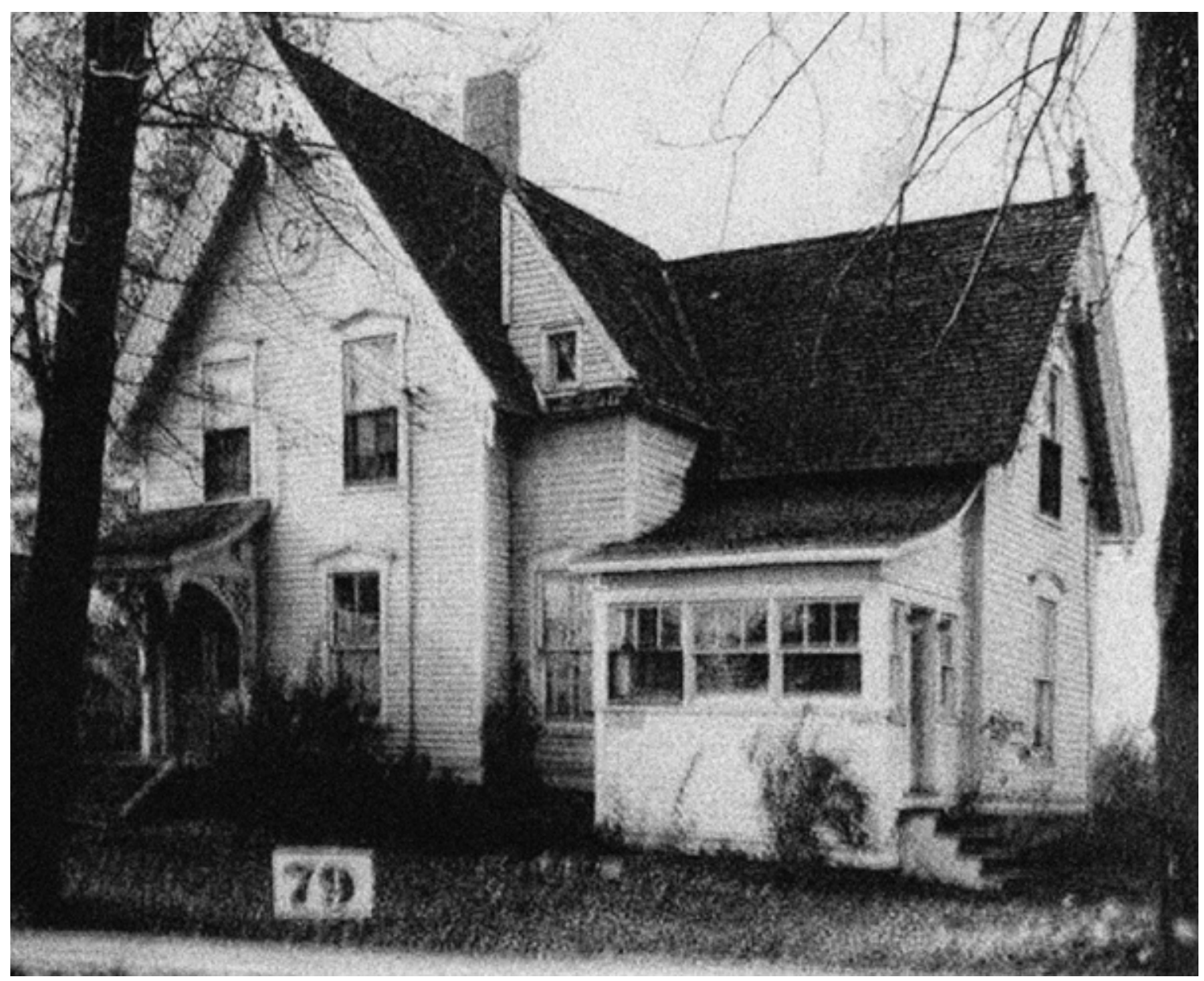

Moulinette Home 1920

30 Macfarlane, Daniel. Negotiating a River: Canada, the US, and the Creation of the St. Lawrence Seaway. UBC Press, 2014. Page. 50

31 Richardson, Ronald E. Developing Water Resources: the St. Lawrence Seaway and the Columbia - Peace Power Projects. Ryerson Press, 1969. Page. 28

32 Richardson, Ronald E. Developing Water Resources: the St. Lawrence Seaway and the Columbia - Peace Power Projects. Ryerson Press, 1969. Page. 30

33 Macfarlane, Daniel. Negotiating a River: Canada, the US, and the Creation of the St. Lawrence Seaway. UBC Press, 2014. Page. 125 


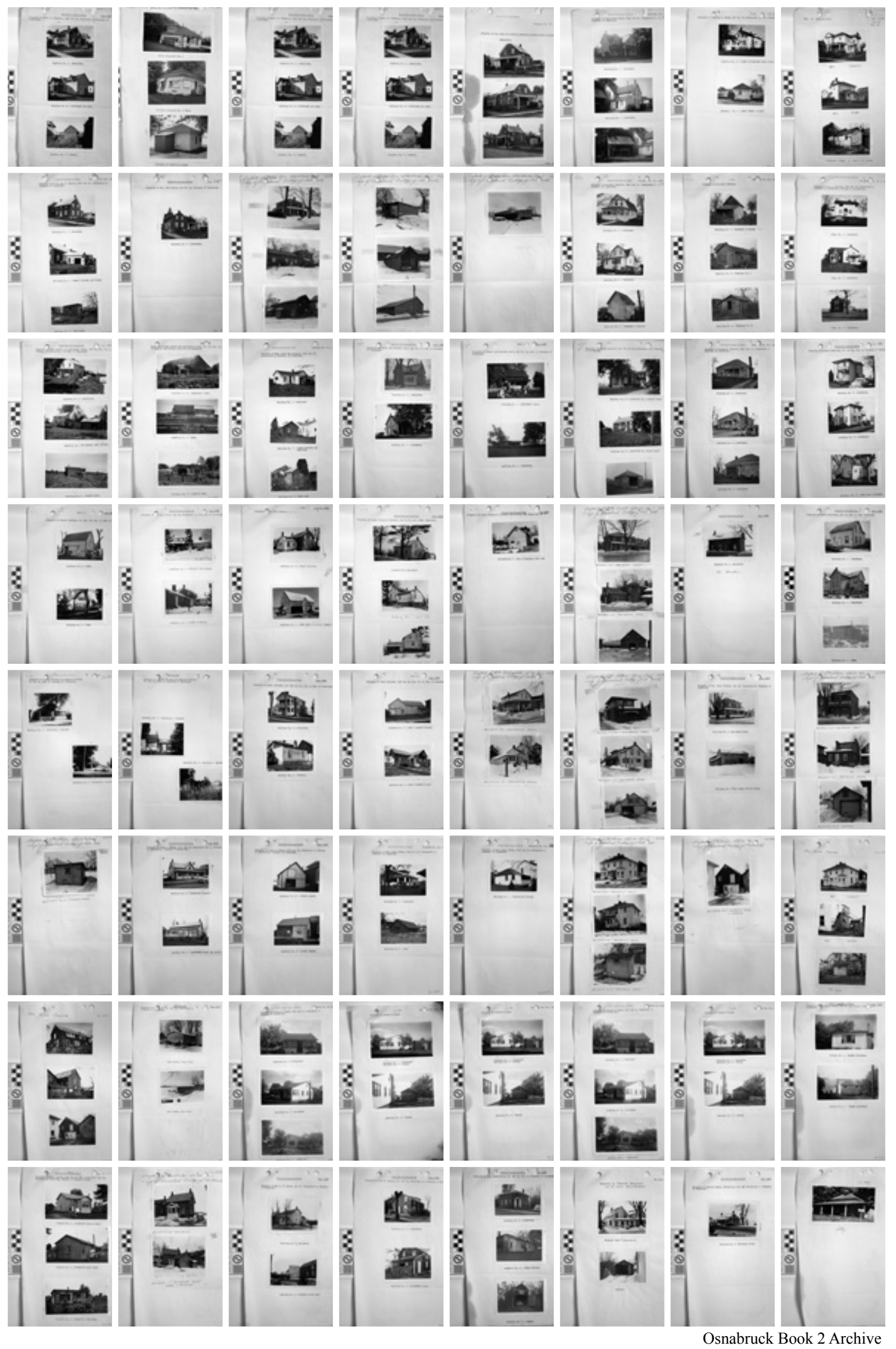




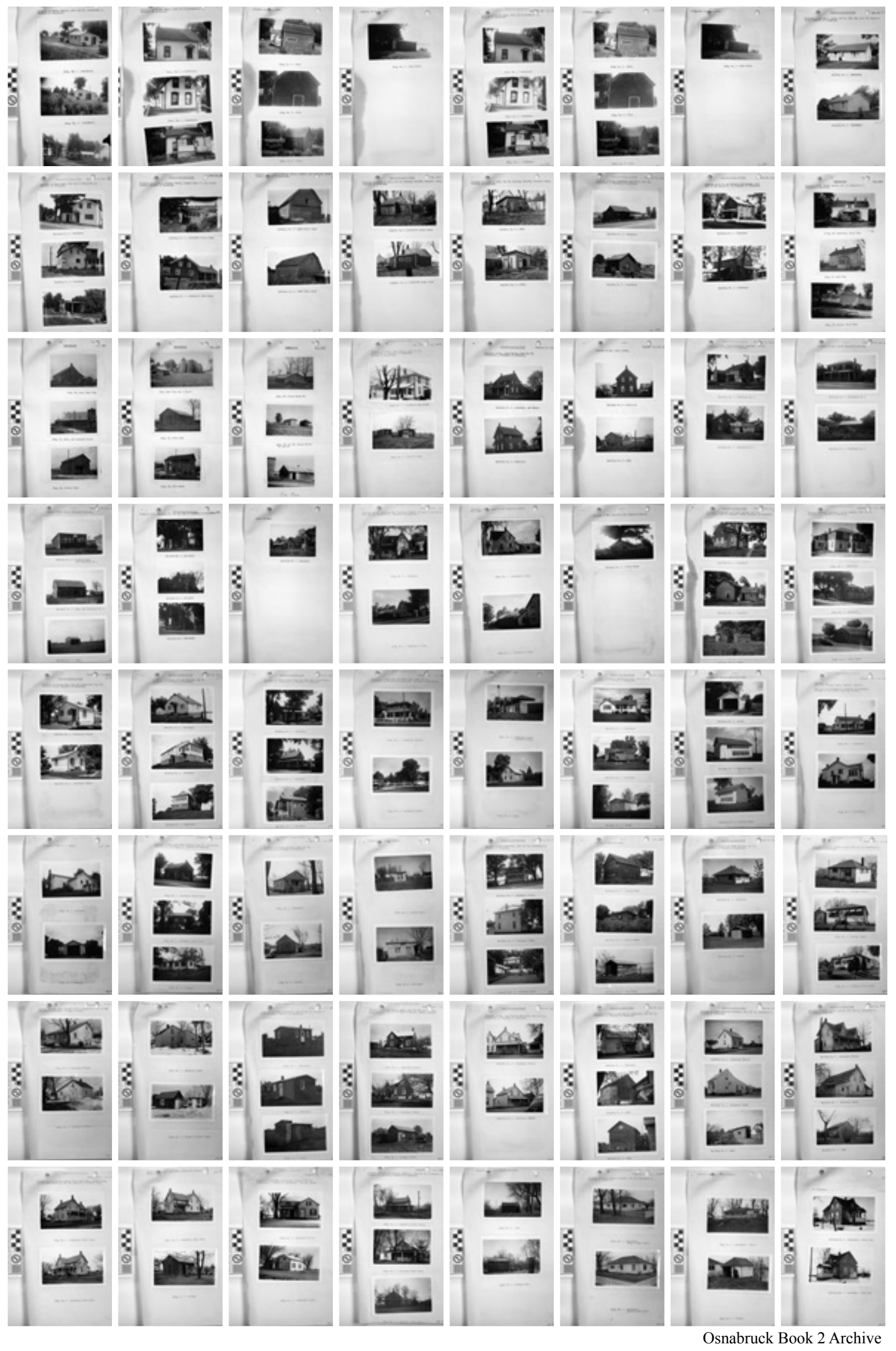




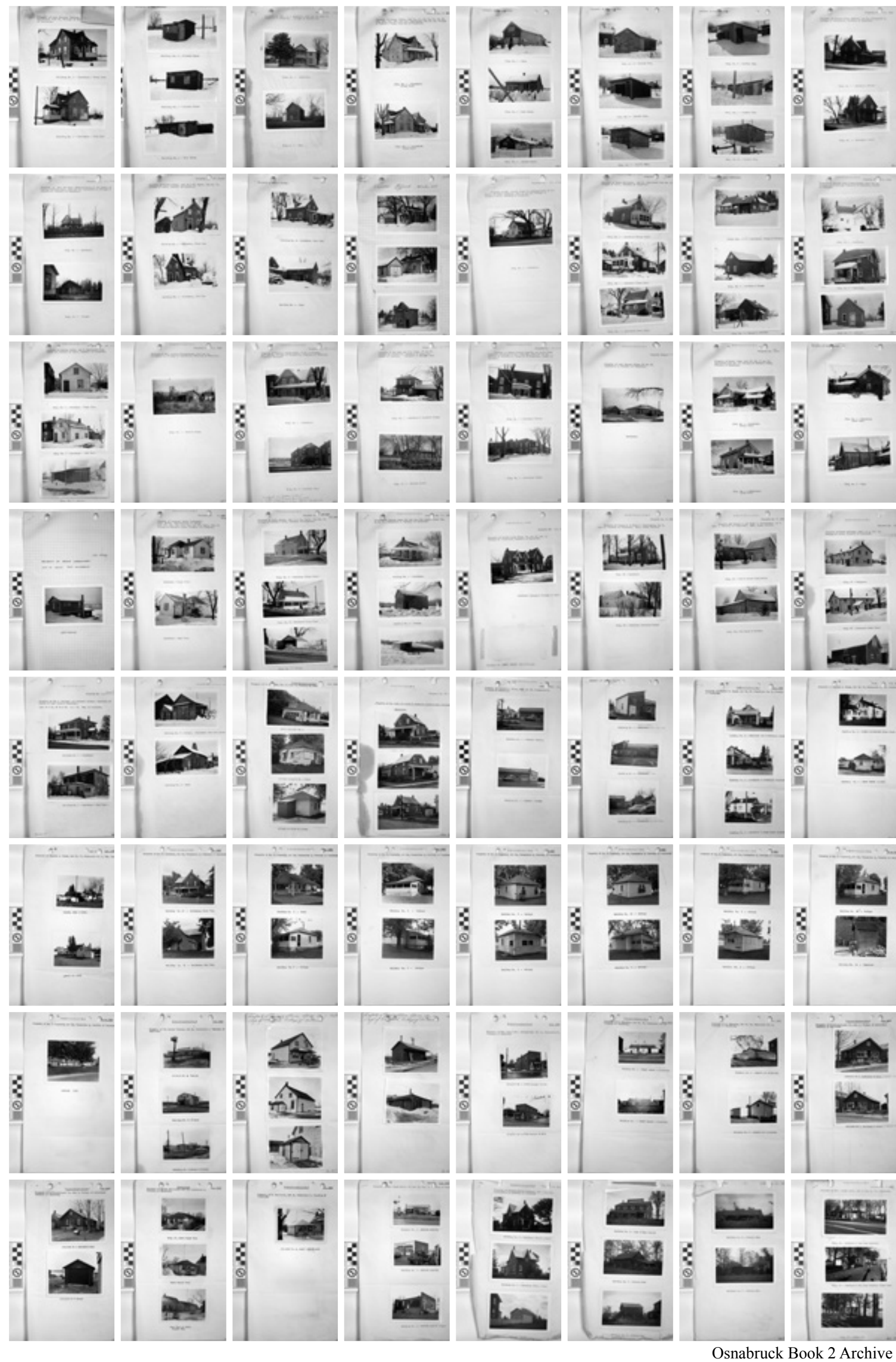




\subsection{Dysfunctional}

The emotional loss of identity as well as alienation was not only felt at a personal level but at an regional and inevitably national level. The St. Lawrence River, originally called the Great Eastern River, was seen as "the indelible link formed by nature between the Canada's and the source of the wealth, beauty and prosperity in our Country". ${ }^{44}$ The river played a large role in the social configuration and planning of communities, and how those communities identified themselves. "Our national identity and the riverine environments has a unique manifestation in the Canadian Context". ${ }^{35}$ For instance, before the construction of the Seaway, the streets and buildings of Morrisburg were situated on the water's edge. ${ }^{36}$ While today, there are still open views to the waterfront, the width of the parkland and golf courses separates the village from the water. ${ }^{37}$ In 2010 , the town of Morrisburg generated a report concluding that both Iroquois and Morrisburg were effectively turned 'inside out'. This was mostly due to the re-location of commercial plazas on Highway 2 instead of the main street in addition to large amounts of unused park land along the riverbank. ${ }^{38}$ The truth in this argument is that the large scale modernist developments of the St. Lawrence Seaway and Power Project fundamentally altered the ways in which the communities functioned. It is evident that each village suffered a degree of identity loss that was imposed on by Seaway ${ }^{39}$ Essentially, "the manipulation of the St. Lawrence basin re-shaped the culture, identity, region and environment. ${ }^{40}$ Many communities have since then have struggled to reassert their

34 Bouchette, Joseph. The British Dominions in North America. 1832. Page. 39-167 35 Macfarlane, Daniel. Negotiating a River: Canada, the US, and the Creation of the St. Lawrence Seaway. UBC Press, 2014. Page. 125 Page. 45

36 Township of South Dundas. Waterfront Final Report. 2010. Page 21

37Township of South Dundas. Waterfront Final Report. 2010. Page. 8

38 Township of South Dundas. Waterfront Final Report. 2010. Page. 5

39 Township of South Dundas. Waterfront Final Report. 2010. Page. 5

40 Macfarlane, Daniel. Negotiating a River: Canada, the US, and the Creation of the St. Lawrence Seaway. UBC Press, 2014. Page. 125 Page. 45 

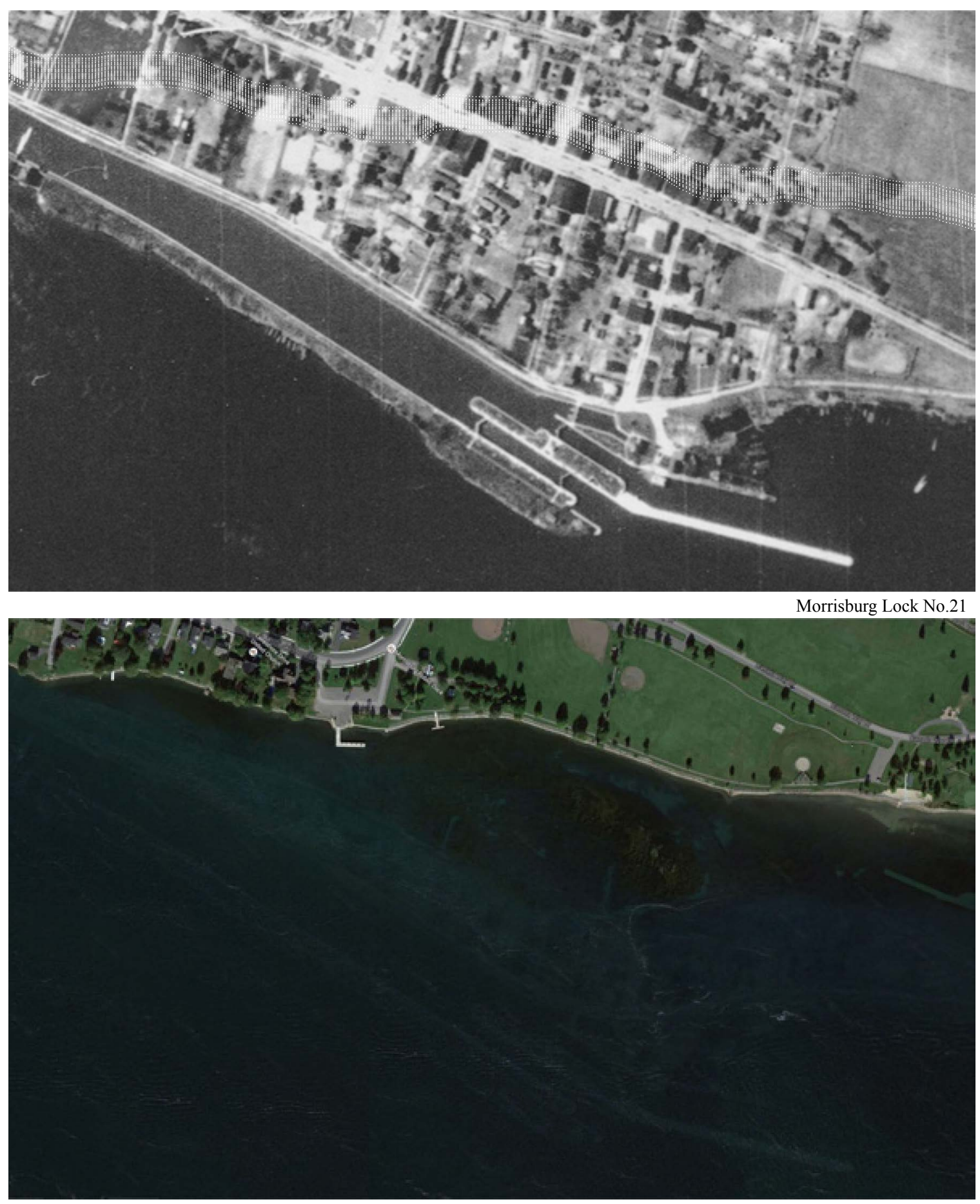

Morrisburg Lock No.21 


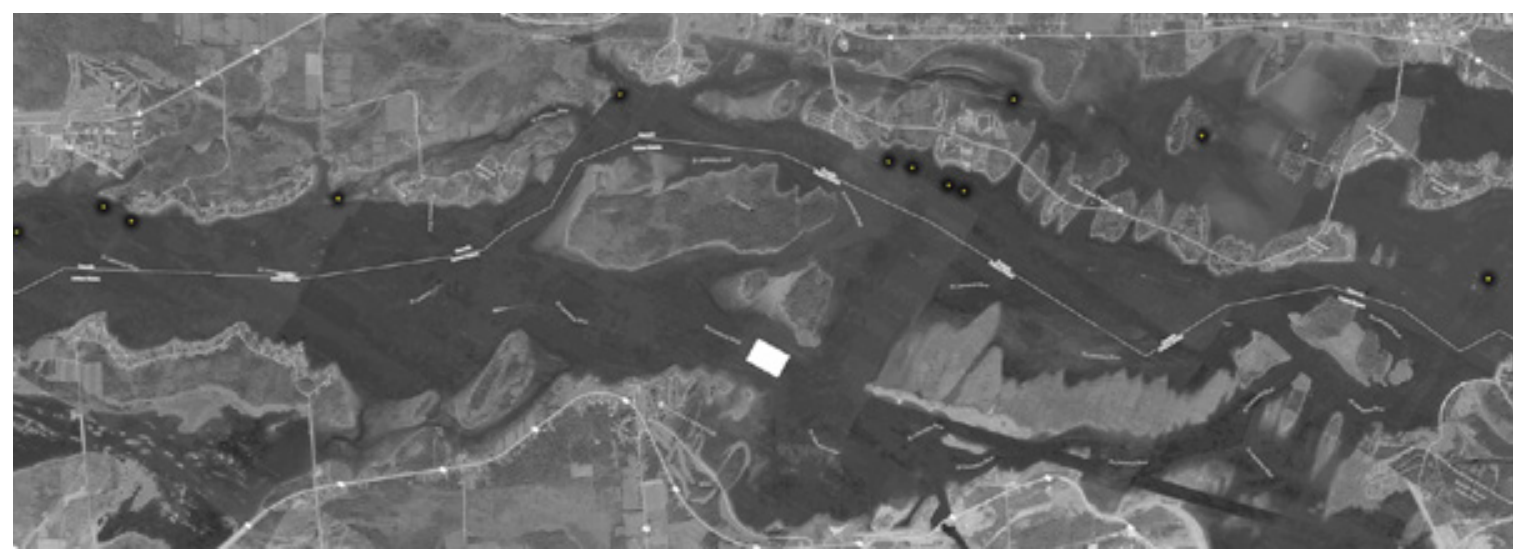

Potential Heritage Sites

connection to the river.

\subsection{Valourization - Heritage Conservation Districts}

The Designation of Heritage Conservation Districts (HCDs) gives the community an opportunity to recognize and commemorate cultural assets. This greatly contributes to a community's sense of place in a national context. ${ }^{41}$ Unfortunately, for the communities that were displaced, this was not a consideration at the time of the flood. Although a number of historically significant building's were relocated to The Lost Villages Museum and Upper Canada Village, the landscape that grounded them is no longer accessible. ${ }^{42}$ Perhaps if the community was able to contribute to the recognition of these sites, it could have decreased the tension.

Heritage district designation allows these resources and relationships to be identified and protected..$^{43}$ The Canadian Register of Historic Places (CRHP) was developed under the Historic Places Initiative, a federal-provincial-territorial partnership that created an online searchable registry of locally, provincially and federally recognized heritage sites across Canada. Unfortunately, not one of The Lost Villages are recognized as a HCD by the

\footnotetext{
41 Heritage Conservation Districts: a Guide to District Designation under the Ontario Heritage Act. Ministry of Culture, 2006. Page. 7

42 "About the Village - St. Lawrence Parks Commission." Eastern Ontario Morrisburg Historical Attractions Plan Your Visit - St. Lawrence Parks Commission, www.uppercanadavillage.com/about-the-village/

43 Heritage Conservation Districts: a Guide to District Designation under the Ontario Heritage Act. Ministry of Culture, 2006. Page. 7
} 


\section{CRHP.}

Individual heritage properties and HCDs designated under the Ontario Heritage Act are eligible for listing on the CRHP, together with properties protected by a heritage conservation easement and properties held in trust by the Ontario Heritage Trust. ${ }^{44}$ By listing The Lost Villages on the Canadian Register, it would provide the community with the opportunity to build awareness, understanding and support of their cultural heritage resources. ${ }^{45}$ It also creates an opportunity for visitors to develop an understanding and appreciation of the community's heritage resources and validate the relationships between patterns of activity, memory, and imagination. In addition to this, it promotes awareness of the more physically apparent damages such as the patterns of buildings, structures, streetscapes and land forms that have been expropriated.

\subsection{Under Water}

Although the designation of The lost Villages as a HCD and registering it on the CRHP would help promote their awareness, there is little documentation of their current condition. Survey results give the most recent picture of the St. Lawrence and its current bathymetric details. Using full bottom coverage, an acoustic system with multi-beam sonars and high definition gridded bathymetry (HDGB) created a system of hydrography with immense details. ${ }^{46}$ Most of this coverage only exists in areas of the St. Lawrence where intense commercial navigation occurs and the water depth and/or width is limited. Therefore, while the data collected is a powerful tool to enhance efficiency and safety of navigation, it unfortunately does not provide any insight into the hydrography of the areas

\footnotetext{
44 Heritage Conservation Districts: a Guide to District Designation under the Ontario Heritage Act. Ministry of Culture, 2006. Page. 15

45 Heritage Conservation Districts: a Guide to District Designation under the Ontario Heritage Act. Ministry of Culture, 2006. Page. 7

46 Journault, Marc, et al. "High Precision Hydrography in Canada, the ST. Lawrence River Channel, HD Bathymetry, Production, Distribution and Updating." Hydro12 - Taking Care of the Sea, 2012, doi:10.3990/2.221. Page 4
} 
lost during the creation of the seaway. ${ }^{47}$

\subsection{The Sunken Villages}

Up until recently, bathymetry and personal diving videos were the only form of documentation that could inform the public on the current condition of The Lost Villages. In 2009 Louis Helbig (an artist formerly located in Ottawa) captured a number of largeformat aerial photographs documenting the submerged villages. ${ }^{48}$ Helbig then exhibited this work in 2010, at Toronto's Canvas Gallery in an exhibition titled "Sunken Villages". 49 After the first show, people began approaching Helbig, and a collaborative audio project soon accompanied his display. ${ }^{50}$ Later, Helbig held a show in Brockville, Ontario, and again in Cornwall. ${ }^{51}$ The audio track was composed of 20 personal interviews, hosting people that were either displaced from their farms and homes or somehow involved in the Seaway's development and construction, or both. ${ }^{52}$ An article describing the show states that some viewers found the experience somewhat cathartic as it provided a space for processing the events that surrounded the flood. ${ }^{53}$

"The Sunken Villages images themselves are subtly beautiful abstract compositions when viewed from afar and without a backstory. But look closer - at the remains of a churchyard, the foundations of downtown Aultsville, a barn and silo - and the human footprint emerges. The story of lives lived is told in footpaths worn through the woods to the fairgrounds, or in cottage lots that once had an enviable view of the river that now covers them."

47 Journault, Marc, et al. "High Precision Hydrography in Canada, the ST. Lawrence River Channel, HD Bathymetry, Production, Distribution and Updating." Hydro12 - Taking Care of the Sea, 2012, doi:10.3990/2.221. Page 4 48 Helbig, Luis. Sunken Villages St Lawrence River, www.louishelbig.com/sunkenvillagesst.html. 49 Helbig, Luis. Sunken Villages St Lawrence River, www.louishelbig.com/sunkenvillagesst.html. 50 Helbig, Luis. "The Sunken Villages Story." SUNKEN VILLAGES, sunkenvillages.ca/story/. 51 Helbig, Luis. Sunken Villages St Lawrence River, www.louishelbig.com/sunkenvillagesst.html. 52 Helbig, Luis. “The Sunken Villages Story.” SUNKEN VILLAGES, sunkenvillages.ca/future-plans/ 53 "Louis Helbig: Sunken Villages." AlJ - Canada's Environmental Voice, 8 Sept. 2013, www.alternativesjournal.ca/ community/reviews/louis-helbig-sunken-villages. 


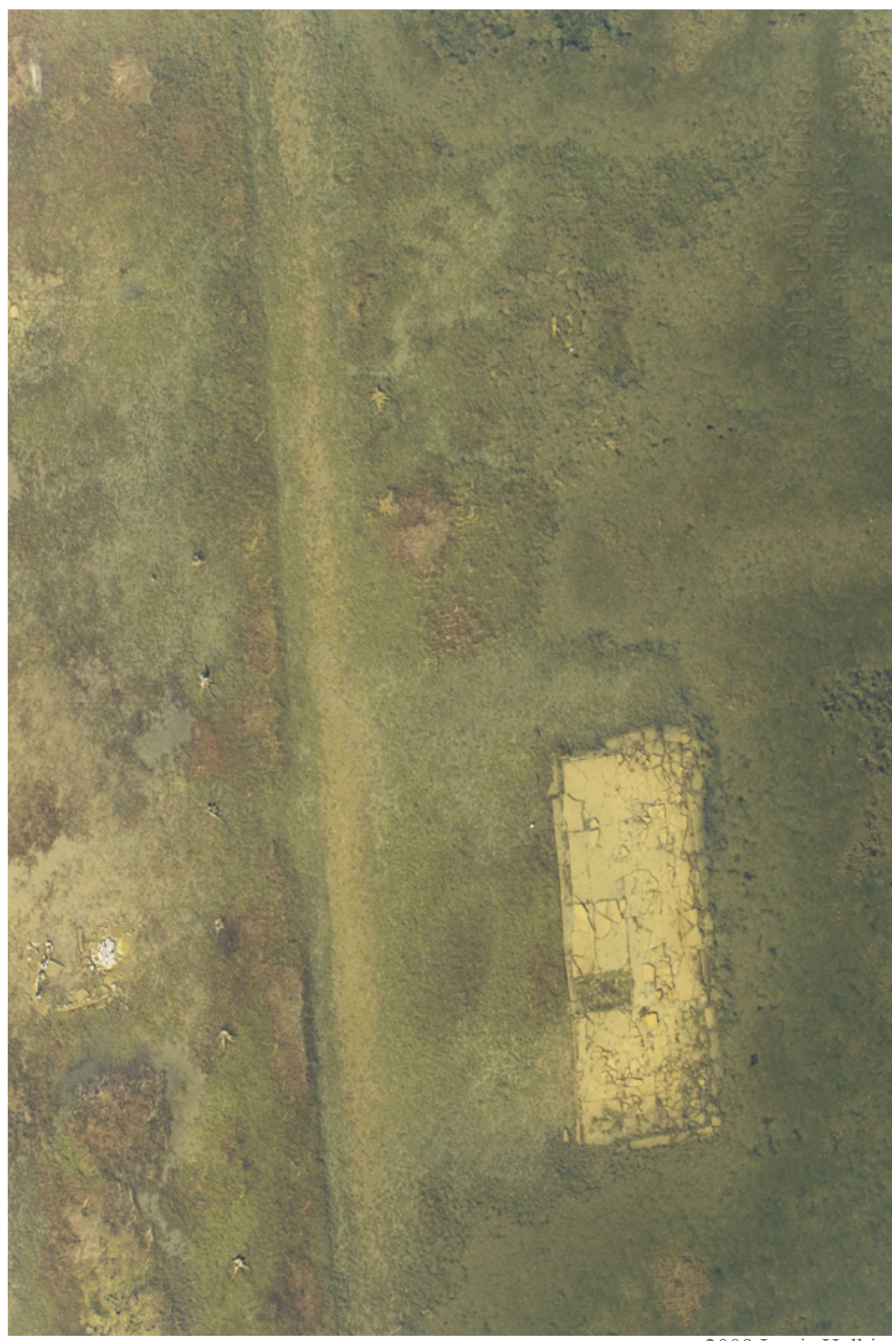




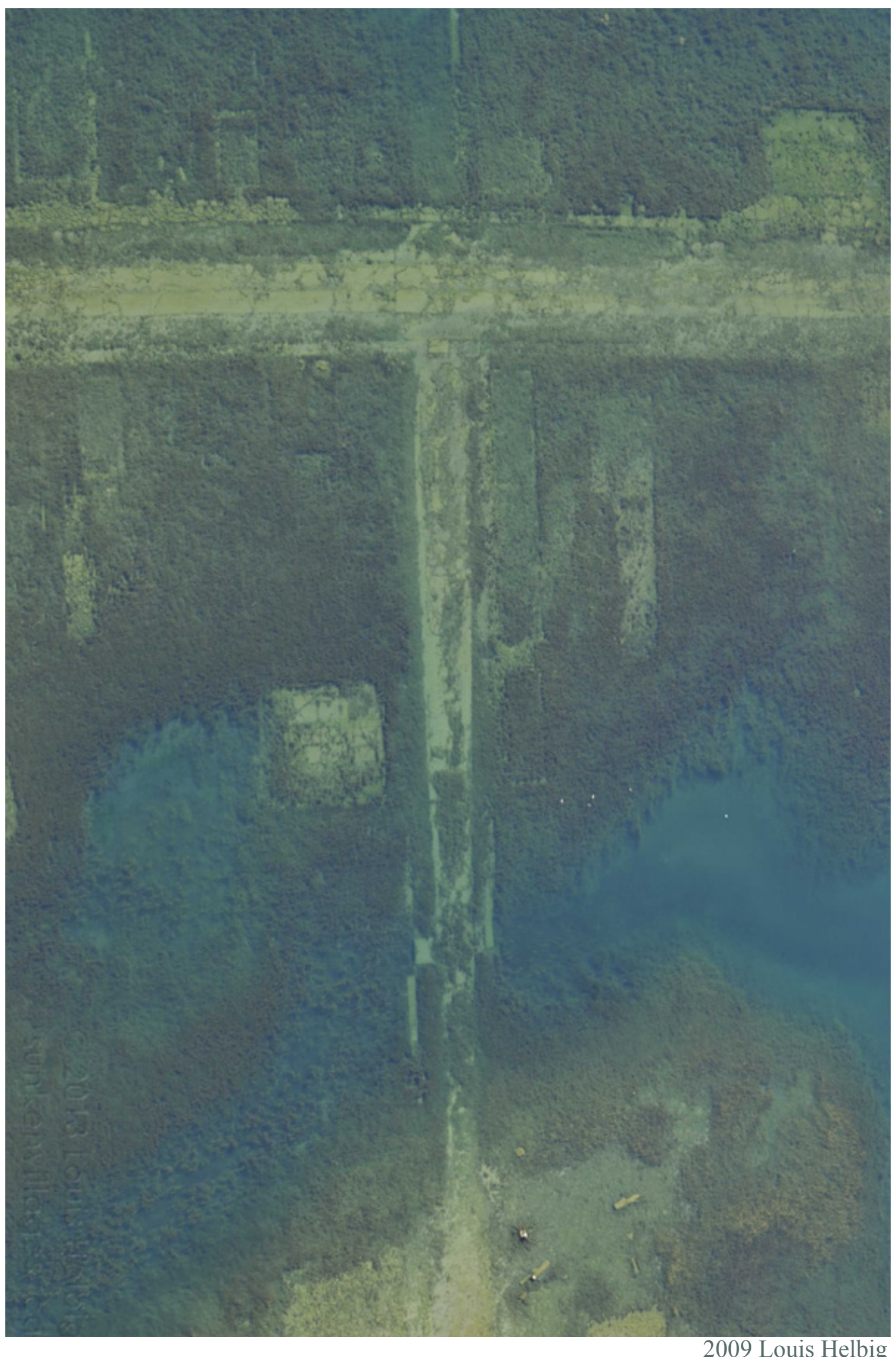




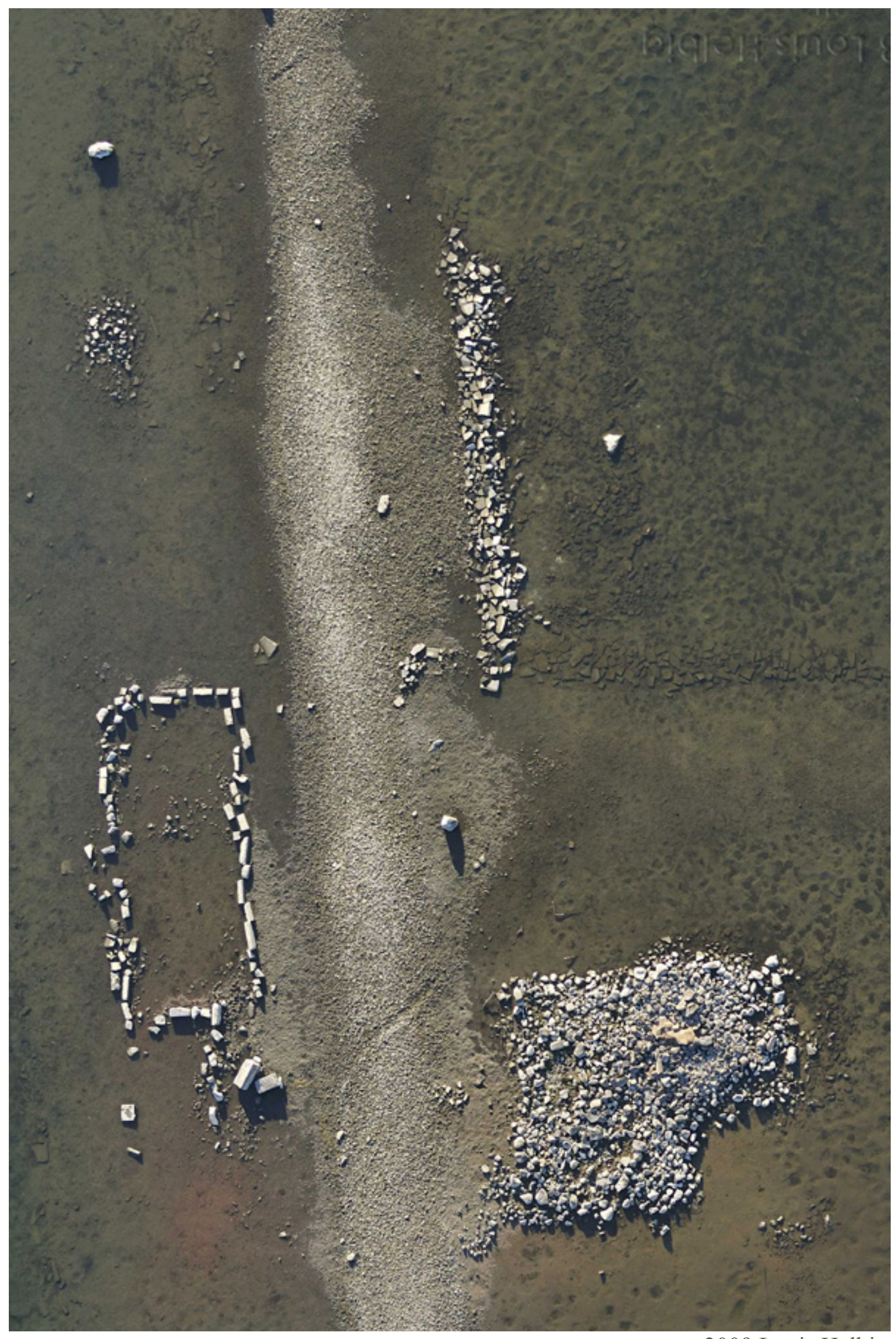




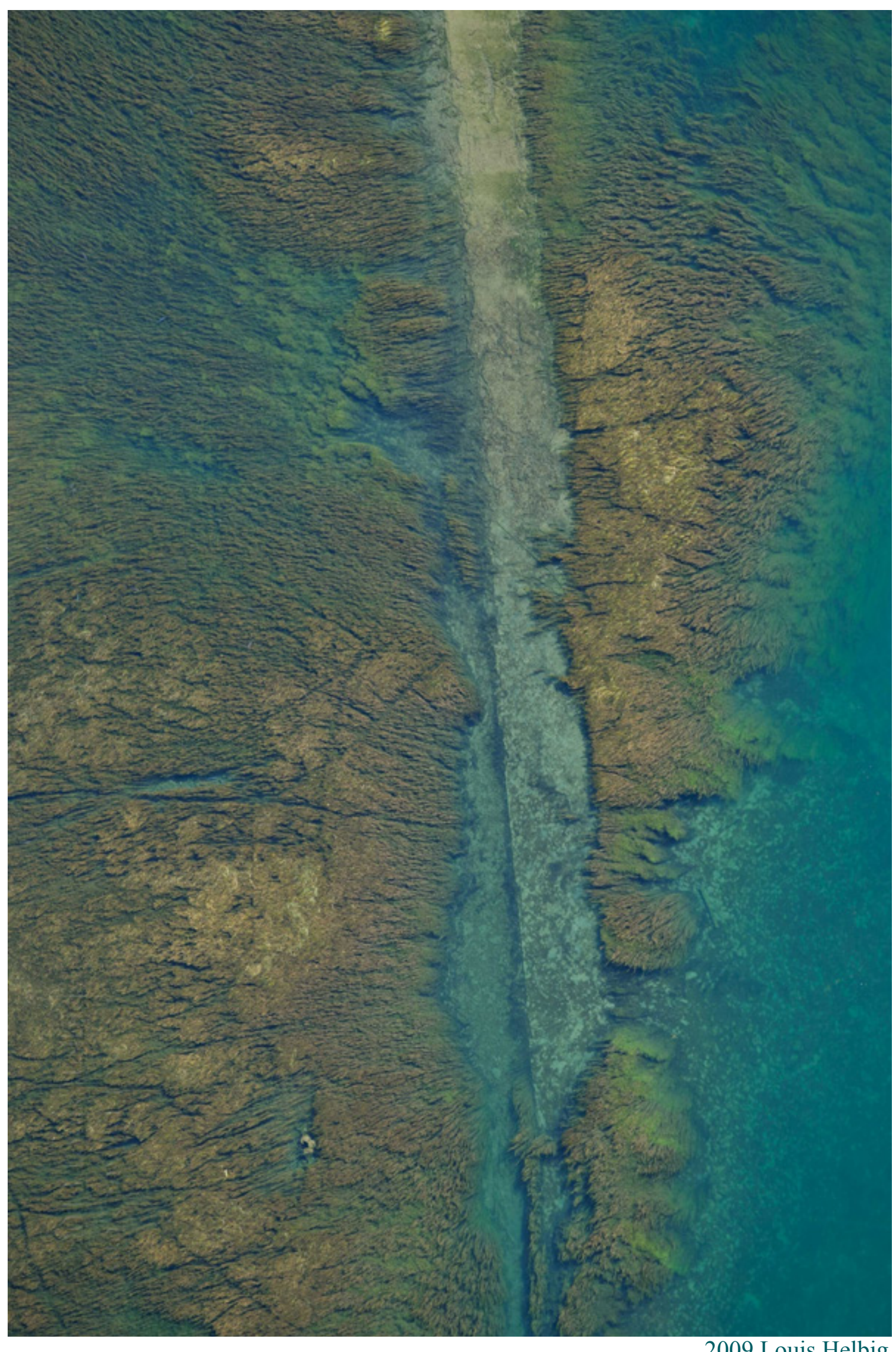




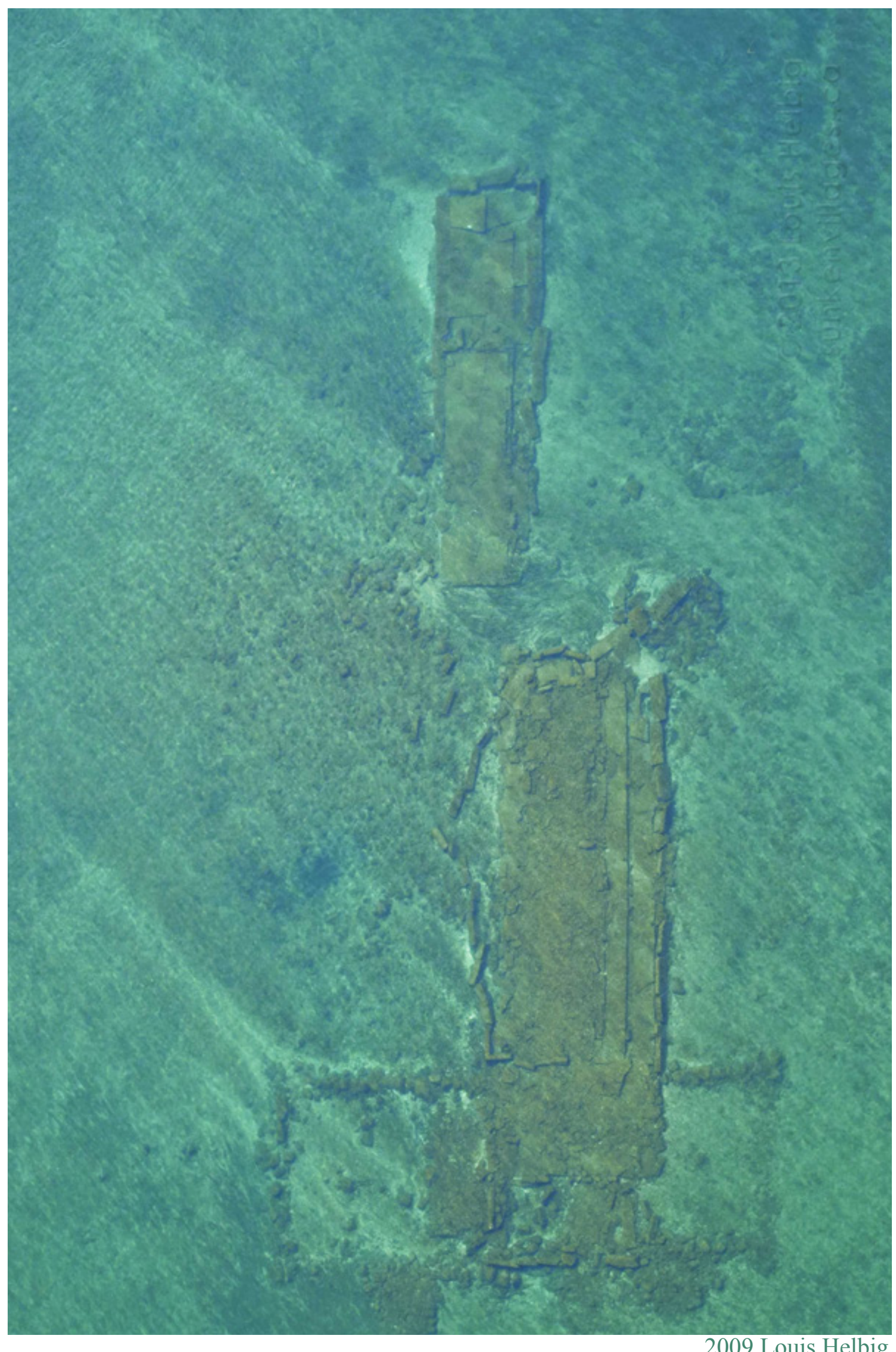




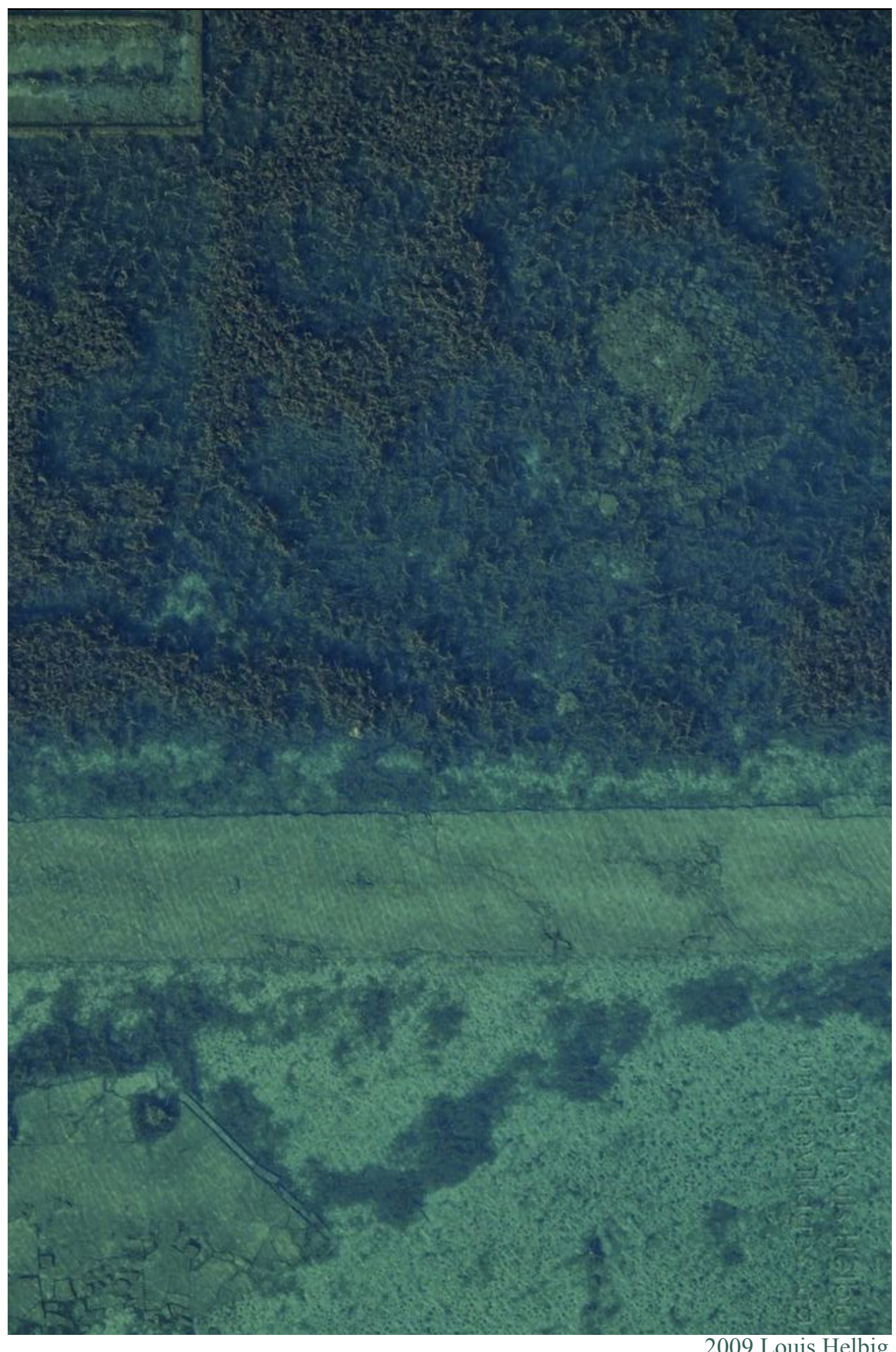


Helbig states "With the villages' reappearance, it becomes clear just how much the story of the villages and their inhabitants has also been filtered". ${ }^{54}$ Another statement indicated "it's harder to ignore something you can actually see". ${ }^{55}$ These assumptions proved to be true, and the curated images inspired many people to come forward to confirm Helbig's assumptions. Helbig later stated in an interview that he hopes the imagery allows people "to think, imagine and reflect." ${ }^{\text {6 }}$ In addition to this, his work is meant to encourage both local and national discussions about how we undertake industrial development and address conservation. ${ }^{57}$ Above all, Helbig hopes to inspire people to consider how the past can inform the future.$^{58}$ Due to the response in Helbig's show, it is evident that his artwork was meant to reconnect the community with the areas affected by the flood. By creating a visual connection, Helbig conceptually connects the viewer with the site. He confirms this by proposing a semi-permanent outdoor display, spread out along the

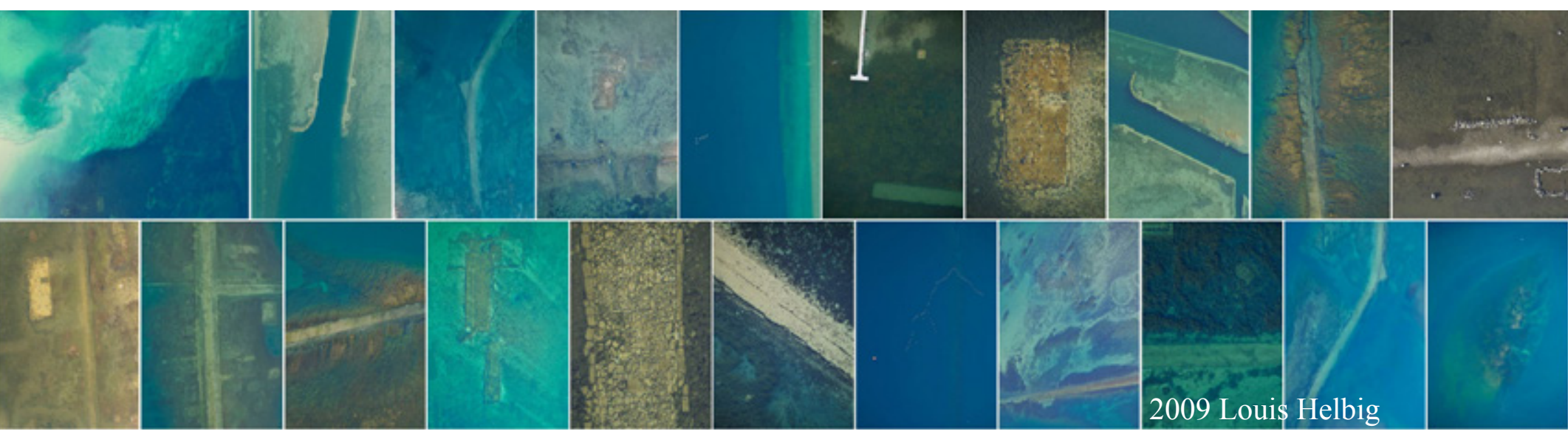

54 "Louis Helbig: Sunken Villages." AlJ - Canada's Environmental Voice, 8 Sept. 2013, www.alternativesjournal.ca/ community/reviews/louis-helbig-sunken-villages.

55 "Louis Helbig: Sunken Villages." AlJ - Canada's Environmental Voice, 8 Sept. 2013, www.alternativesjournal.ca/ community/reviews/louis-helbig-sunken-villages.

56 Hickman, Angela. "Photographer Explores the St. Lawrence's Sunken Villages." National Post, 26 May 2011, nationalpost.com/canada/photographer-explores-the-st-lawrences-sunken-villages.

57 Helbig, Luis. "The Sunken Villages Story." SUNKEN VILLAGES, sunkenvillages.ca/future-plans/ 58 Helbig, Luis. "The Sunken Villages Story." SUNKEN VILLAGES, sunkenvillages.ca/future-plans/ 59 Helbig, Luis. "The Sunken Villages Story." SUNKEN VILLAGES, sunkenvillages.ca/future-plans/ 


\subsection{Accessibility}

Many of the sites documented in Helbig's work are extremely close to popular tourist destinations. Some of which include The Long Sault Parkway, The McLaren Campground, Milles Roches Campground, Woodlands Campground, Farran Park Campground, Upper Canada Camp Ground, Riverside-Cedar Campground as well as The Upper Canada Village and The Lost Villages Museum. In addition to these tourist venues, there are also recreational destinations such as The Chrysler Park Marina, The Upper Canada Migratory Bird Sanctuary in addition to a cemetery that holds the headstones of the many grave sites forcefully abandoned by the receding shoreline. ${ }^{60}$ The unfortunate reality is that even with many destinations relatively close, these sites go unnoticed. This is due to the fact that each site is not publicly recognized and they are only accessible by boat, making them extremely difficult to find. Even with information relative to the pre-existing topographic conditions, the reflections from the water make the riverbed almost impossible to see. Even then, depending on the weather conditions, the depth of the water and the amount of vegetation, most sites can't be identified without entering

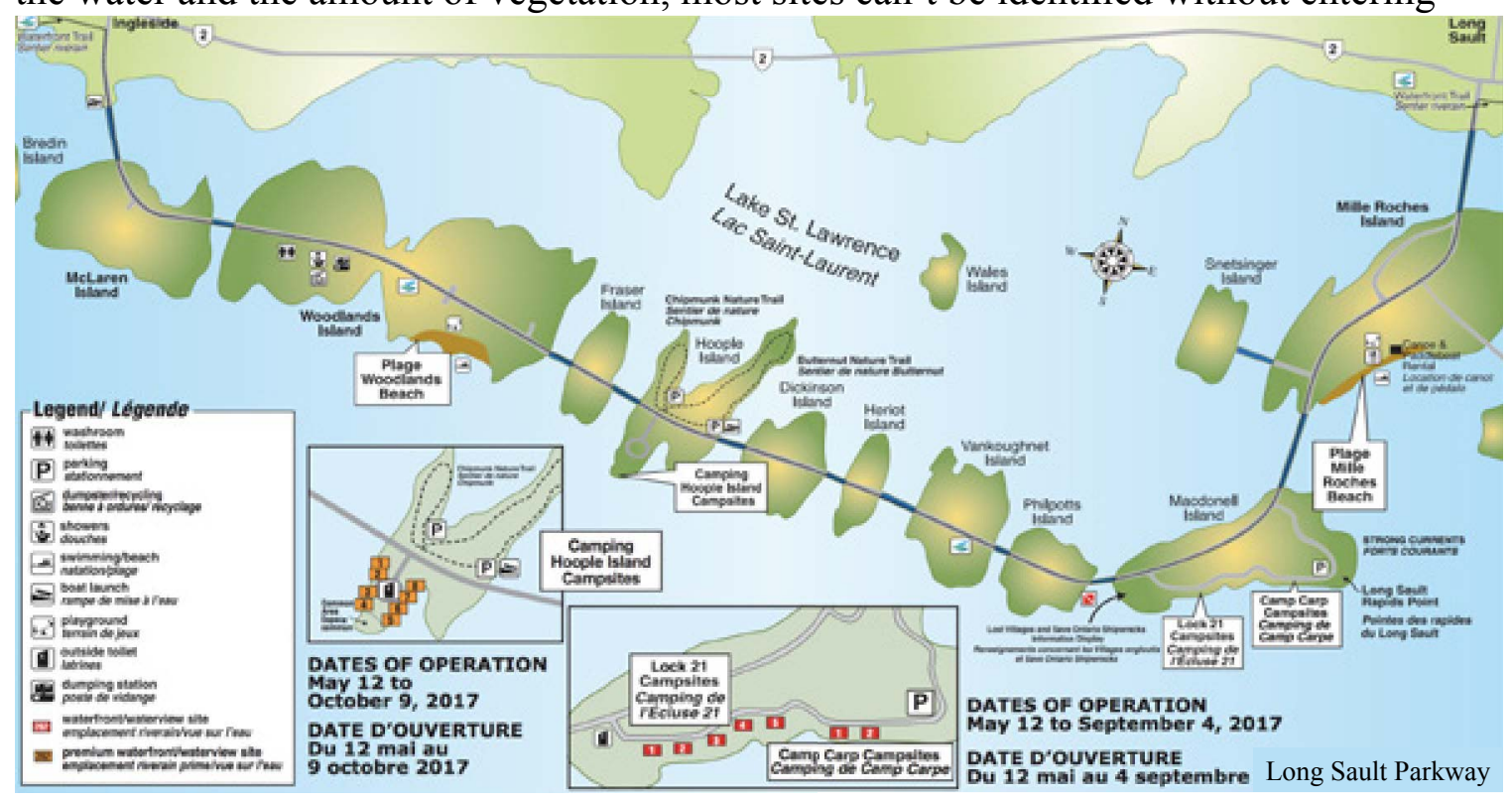

60 Helbig, Luis. "The Sunken Villages Story." SUNKEN VILLAGES, sunkenvillages.ca 

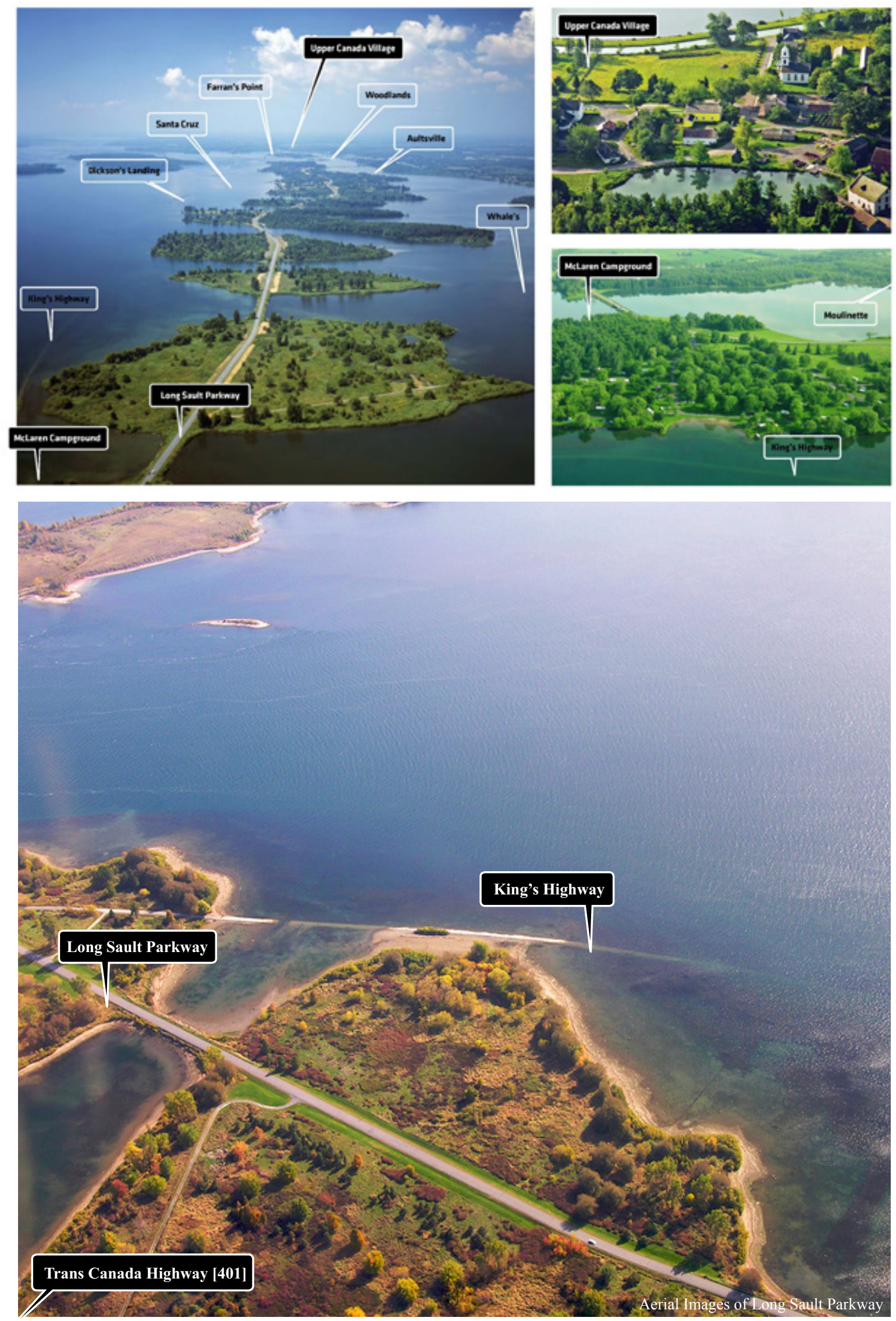


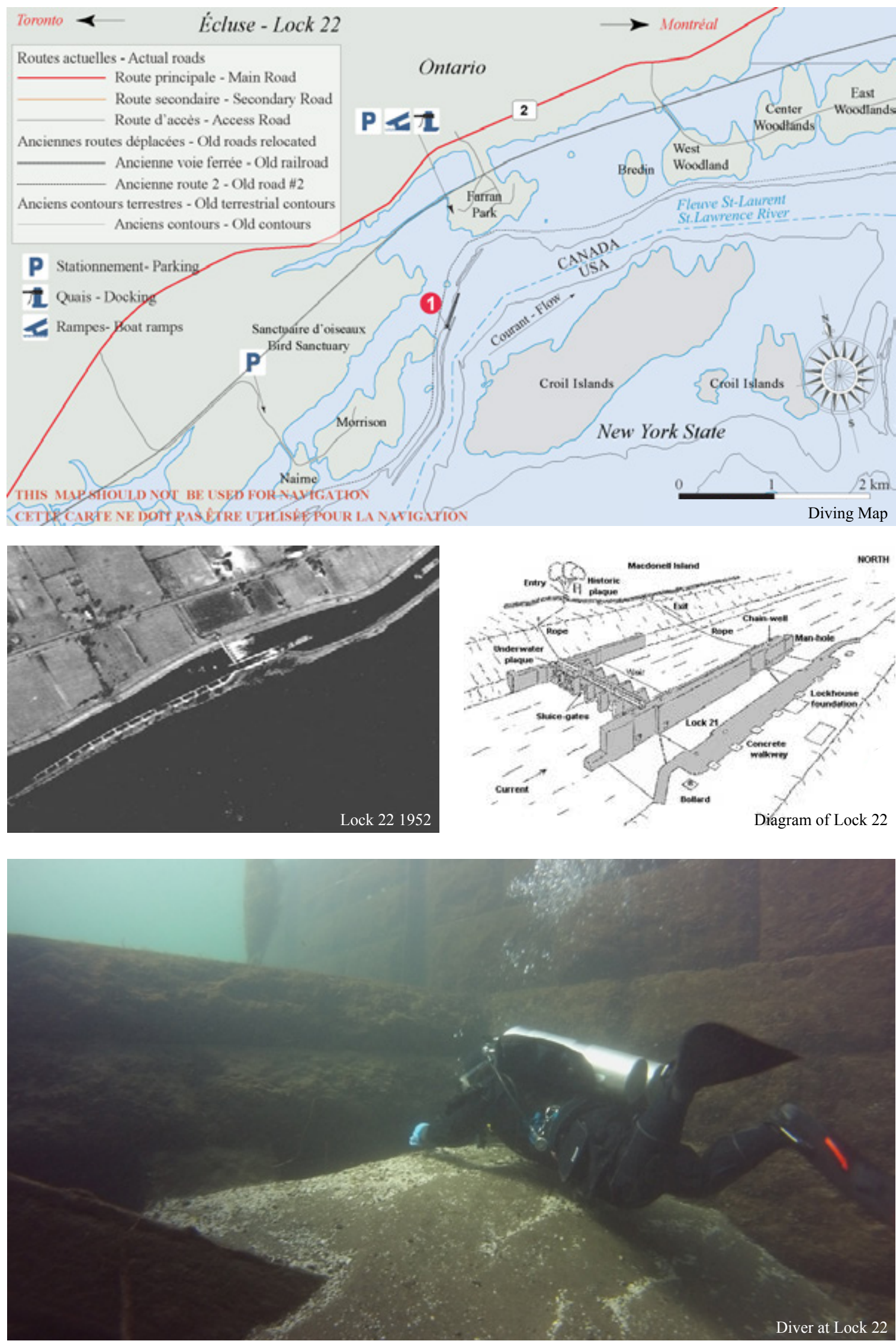


It is economically beneficial for Canada when travellers visit historic places. It allows Canadians to showcase their rich history while benefitting from tourist's aspirations for experiencing things first hand. The current trend towards more experiential holidays is an opportunity for Canadians to encourage local and international travellers to visit historic places. ${ }^{l}$

international travellers to visit historic places. ${ }^{61}$

This is a direct quote from The Canadian Registry of Historical Places, and it highlights the growing need for first person involvement in heritage sites, especially if they wish to be successful tourist destinations. After analyzing this statement, it appears that heritage tourism is concerned with the people visiting sites where objects are venerated for their cultural, aesthetic and/or historic value. ${ }^{62}$ Objects of interest are 'consumed' by the visitor as part of the tourism experience.$^{63}$ If this is true, then it can also be said that in heritage tourism, the value of both physical objects and intangible heritage is directly related to the tourist's need for a stimulating experience.

\subsection{Re-Habilitation}

Unfortunately, as these areas are underwater, the preservation and/or implementation of traditional procedures in retrofitting archaeological sites with the intent of generating tourism is not possible. To facilitate or stimulate any level of interaction, a hybridization 61 Parks Canada Agency, and Government of Canada. "Canadian Register of Historic Places (CRHP)." Parcs Canada | Parks Canada, 8 June 2017, www.pc.gc.ca/en/culture/rclp-crhp.

62 David Fisher \& Becky Smiley (2015) Adapting Rubbish Theory for heritage tourism, Journal of Heritage Tourism, 11:2, 143-154, DOI: 10.1080/1743873X.2015.1080711

63 David Fisher \& Becky Smiley (2015) Adapting Rubbish Theory for heritage tourism, Journal of Heritage Tourism, 11:2, 143-154, DOI: 10.1080/1743873X.2015.1080711 
of current dissemination techniques must be considered. As per the suggestions in the Canadian Registry of Historic Places, the medium in which the participant experiences the site would benefit from being a first-hand experience. ${ }^{64}$ On an additional note, it must not only satisfy the need for tourist consumption, but must also promote awareness of the site and contribute to its veneration. With current technologies, the visual exploration of a digitally augmentd asset could maintain these goals, while creating an interface that bridges the gap between the site and the potential visitor. ${ }^{65}$

\subsection{Data Acquisition}

As defined by the International Society for Photogrammetry and Remote Sensing (ISPRS), Photogrammetry is the science and technology of extracting reliable three dimensional geometric and thematic information of objects and scenes from image and range data. ${ }^{66}$ The importance of photogrammetry as a tool, is that it provides a practice in which relatively accurate metric data can be captured, processed and packaged ${ }^{67}$ This process falls under the realm of spatial information science, a technique concerned with the modelling, processing, retrieval and application of information with a spatial reference. ${ }^{68}$ Employing techniques and concepts used in spatial information science is an essential step in the process of replicating culturally significant objects. ${ }^{69}$ This transcription of data serves as a mechanism to promulgate content and experiential qualities that are otherwise inaccessible. The resulting data can be used for the development of graphical visualizations and spacial information systems, specific to the creation of valuable cultural installations.

64 Parks Canada Agency, and Government of Canada. "Canadian Register of Historic Places (CRHP)." Parcs Canada | Parks Canada, 8 June 2017, www.pc.gc.ca/en/culture/rclp-crhp.

65 ISPRS Journal of Photogrammetry and Remote Sensing. Elsevier. 2008. Page. 10-40

66ISPRS Journal of Photogrammetry and Remote Sensing. Elsevier. 2008. Page. 10-40

67 ISPRS Journal of Photogrammetry and Remote Sensing. Elsevier. 2008. Page. 10-40

68 ISPRS Journal of Photogrammetry and Remote Sensing. Elsevier. 2008. Page. 10-40

69 ISPRS Journal of Photogrammetry and Remote Sensing. Elsevier. 2008. Page. 10-40 


\subsection{Visualizations}

Mediums and methods in visualization have always been an important aspect of disseminating spatial information and heritage data. As an installation, this investigation will enable individuals to explore an otherwise inaccessible site, and invite visitors to make judgments based off of their own experiences. It will also enable a reflection on the political realities which greatly influenced the construction of the Seaway. Most importantly however, it will demonstrate the historical significance of the cultural assets lost during the flood and allow for physical representations in a cultural context, specific to Canadian History.

\section{As a design paradigm, this concept will be carried out in 3 main forms:}

1) The generation of a physical model, which provides a tangible solution, depicting current site conditions

2) A speculative reconstruction of the building that may have existed on this site, to provide contextual information and make the archeological site more perceivable

3) The digital re-habilitation of a submerged foundation, experienced from within a head mounted display 


\subsection{Developing Assets}

\subsection{Canadian Inventory of Historic Buildings}

In the 1960s, Canadian conservationists were concerned with the preservation of early Canadian architectural heritage. As a result, The National Survey of Early Structures was created by The Canadian Inventory of Historic Buildings (CIHB $)^{70}$. This project began in the Rideau Corridor, later progressing into a nationwide initiative. Between 1970 and 1976, external characteristics, such as building components, construction methods, building functions and interior spaces of 169,000 buildings were digitally archived ${ }^{71}$.

This study concluded that little was known about the patterns and extent of early Canadian building construction ${ }^{72}$. It was evident that "The Canadian archives must radically increase their acquisition of other material, if the future needs of architectural research are to be met". ${ }^{73}$ The CIHB now prepares about 25 papers, per year, on buildings under consideration for national commemoration by The Historical Sites and Monuments Board of Canada ${ }^{74}$. This suggests that further documentation on early Canadian construction technologies, architectural styles and specific building typologies is still needed.

\footnotetext{
70 The Canadian Inventory of Historic Buildings. National and Historic Parks Branch, Dept of Indian Affairs and Northern Development, 1971. Page. 140

71 The Canadian Inventory of Historic Buildings. National and Historic Parks Branch, Dept of Indian Affairs and Northern Development, 1971. Page. 147

72 The Canadian Inventory of Historic Buildings. National and Historic Parks Branch, Dept of Indian Affairs and Northern Development, 1971. Page.160

73 The Canadian Inventory of Historic Buildings. National and Historic Parks Branch, Dept of Indian Affairs and Northern Development, 1971. Page. 160.

74 The Canadian Inventory of Historic Buildings. National and Historic Parks Branch, Dept of Indian Affairs and Northern Development, 1971. Page.157
} 


\subsection{Identifying Lot 3317}

With the development of canals in the St. Lawrence River, European immigrants came directly up the river in as early as $1812 .{ }^{75}$ As a result, the shoreline of the St. Lawrence was spotted with early loyalist settlements, farms, hamlets and villages. Considering this, Upper Canada's building stock would have created a significant contribution to the studies conducted by the CIHB. Unfortunately, due to the development of the Seaway, many structures, such as barns, outhouses and other non-residential type buildings were completely destroyed or permanently altered. ${ }^{76}$

In an attempt to recover valuable data, a survey of the submerged sites along the river could be conducted. By capturing existing site conditions, a speculative review identifying building typologies could then be generated, providing insight into the buildings that populated the area. From this document, building construction methods in the area could be further speculated, contributing to the research of early Canadian building construction. As an example, the remains of buildings on either side of the Kings Highway No. 2 were surveyed in the area formerly known as Santa Cruz, Ontario. Aerial photographs visualize part of a submerged foundation on the south side of the road, and a concrete floor on the north side. After careful research in collaboration with the Interpretive Training Programs \& Historical Research Officers at Upper Canada Village, the foundation was speculated to be a barn, once owned by The Campbells (lot 3317).

75 Leacock, Stephen. CANADA. The Foundations Of Its Future. Montreal: Privately Printed, 1941. 65 76 Macfarlane, Daniel. Negotiating a River: Canada, the US, and the Creation of the St. Lawrence Seaway. UBC Press, 2014. Page. 58-72 


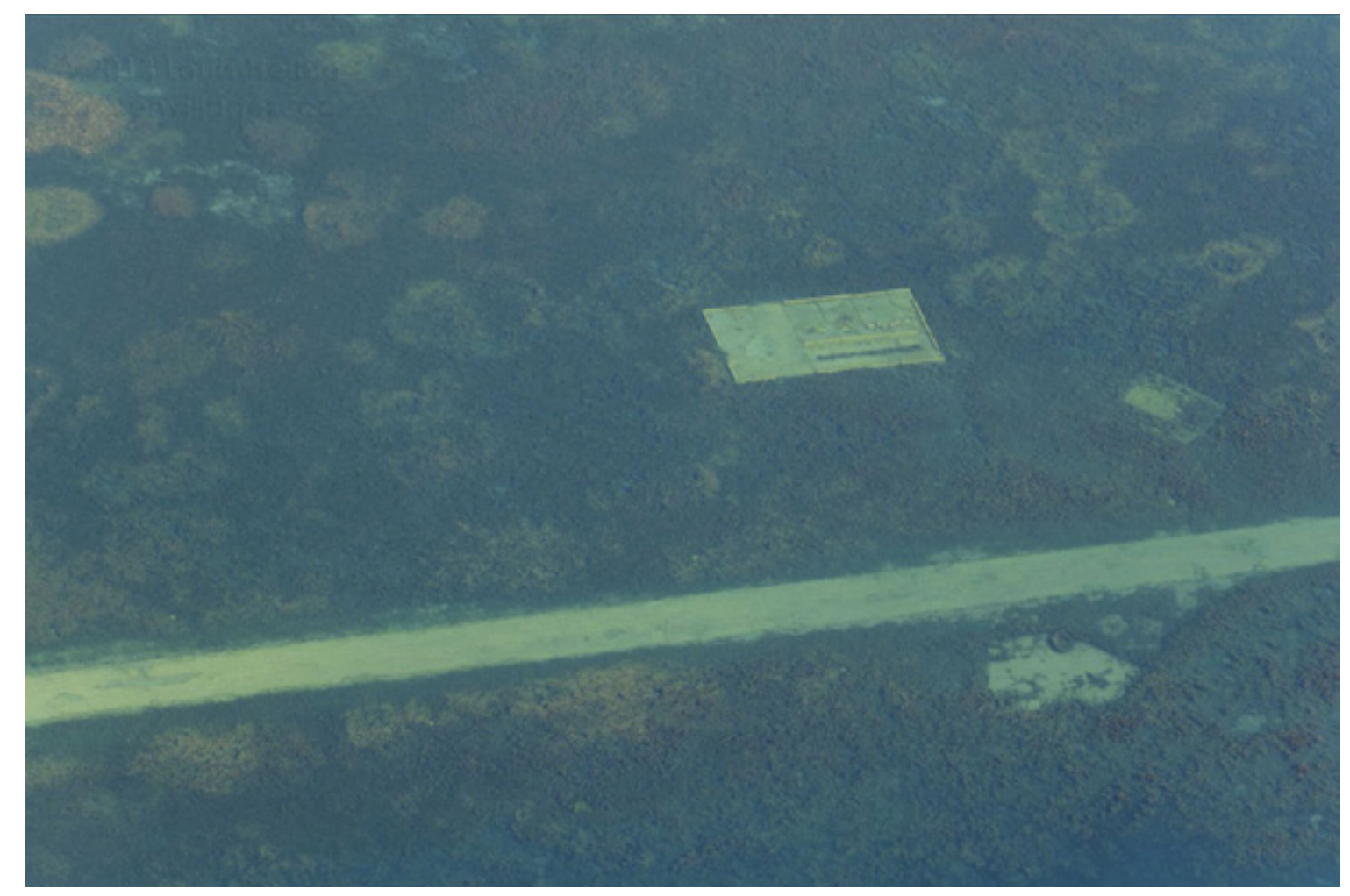

E. Cambell property adjacent to the Kings Highway No.2 in Santa Cruz, Ontario.

\subsection{The Canadian National Air Photo Library}

Aerial photographs were collected from online resources, in addition to the National Earth Observation Data Framework (NEODF) Catalogue at Canada's National Air Photo Library. Each aerial photo depicts a theoretical "footprint" based on a number of variables such as altitude and ground elevation. Photos from the years 1950, 1958 and 1960 were collected respectively. Selected photographs were used to create an orthophoto by stitching the overlapping photos together in Adobe Photoshop. The resulting image depicts the development of the area throughout the duration of the St. Lawrence Seaway and Power Project. As noted in the orthophoto, the remnants of the building in question are clearly visible prior to the demolition phase. During the demolition phase, the building of interest unfortunately was not preserved or relocated. This may be due to the fact that the condition of the building did not permit retrieval, or was not proven to be 

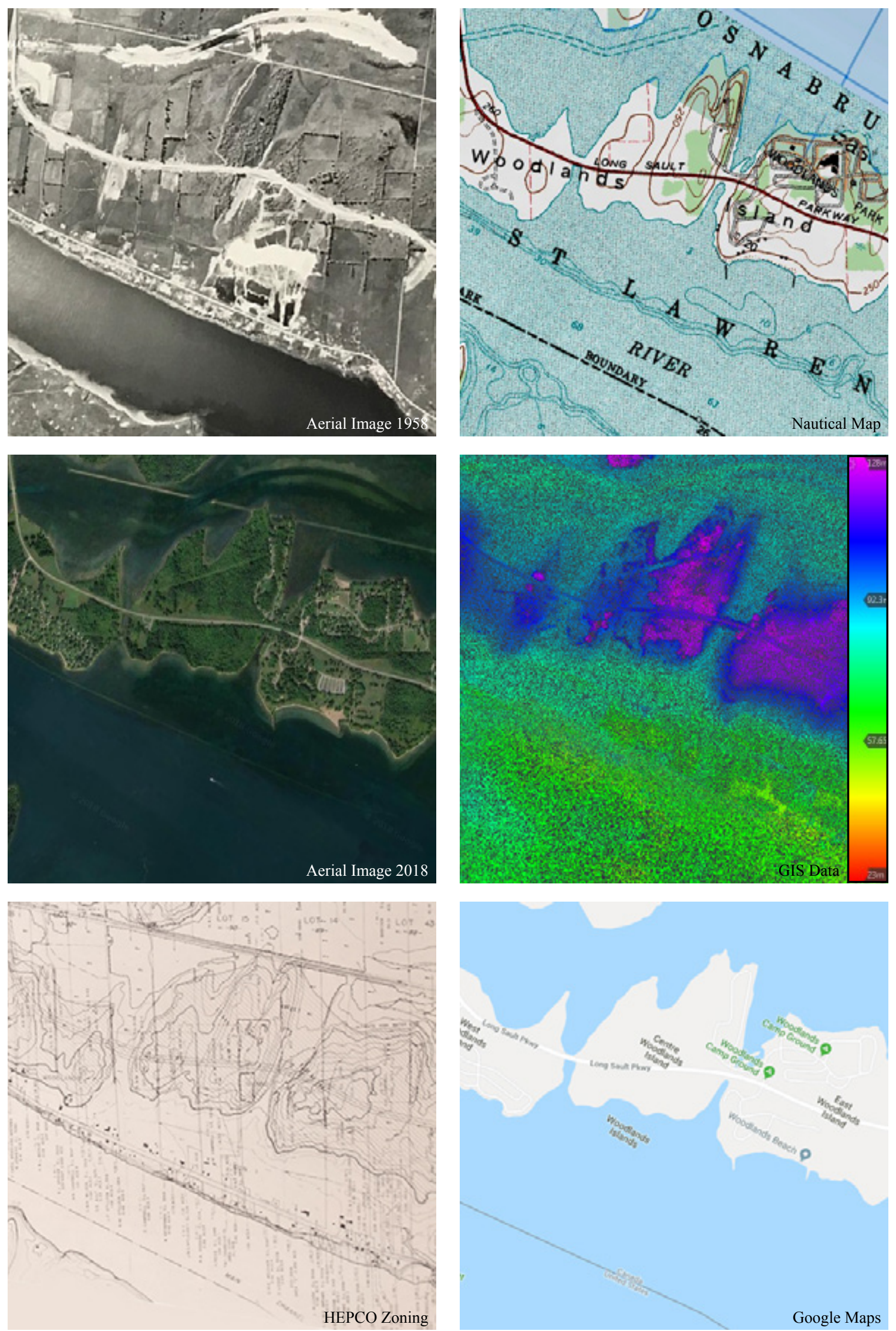

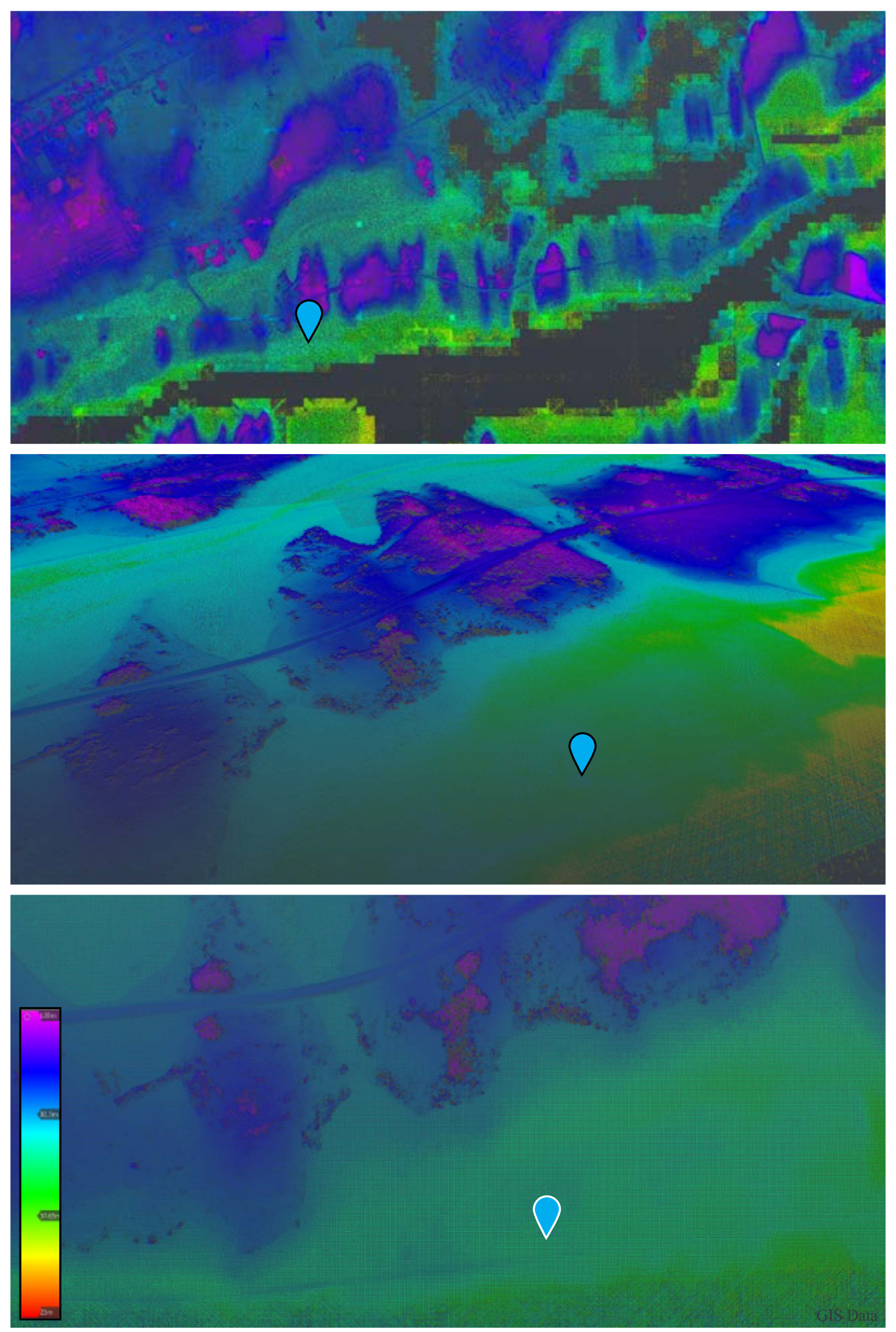

Aerial GIS Data 


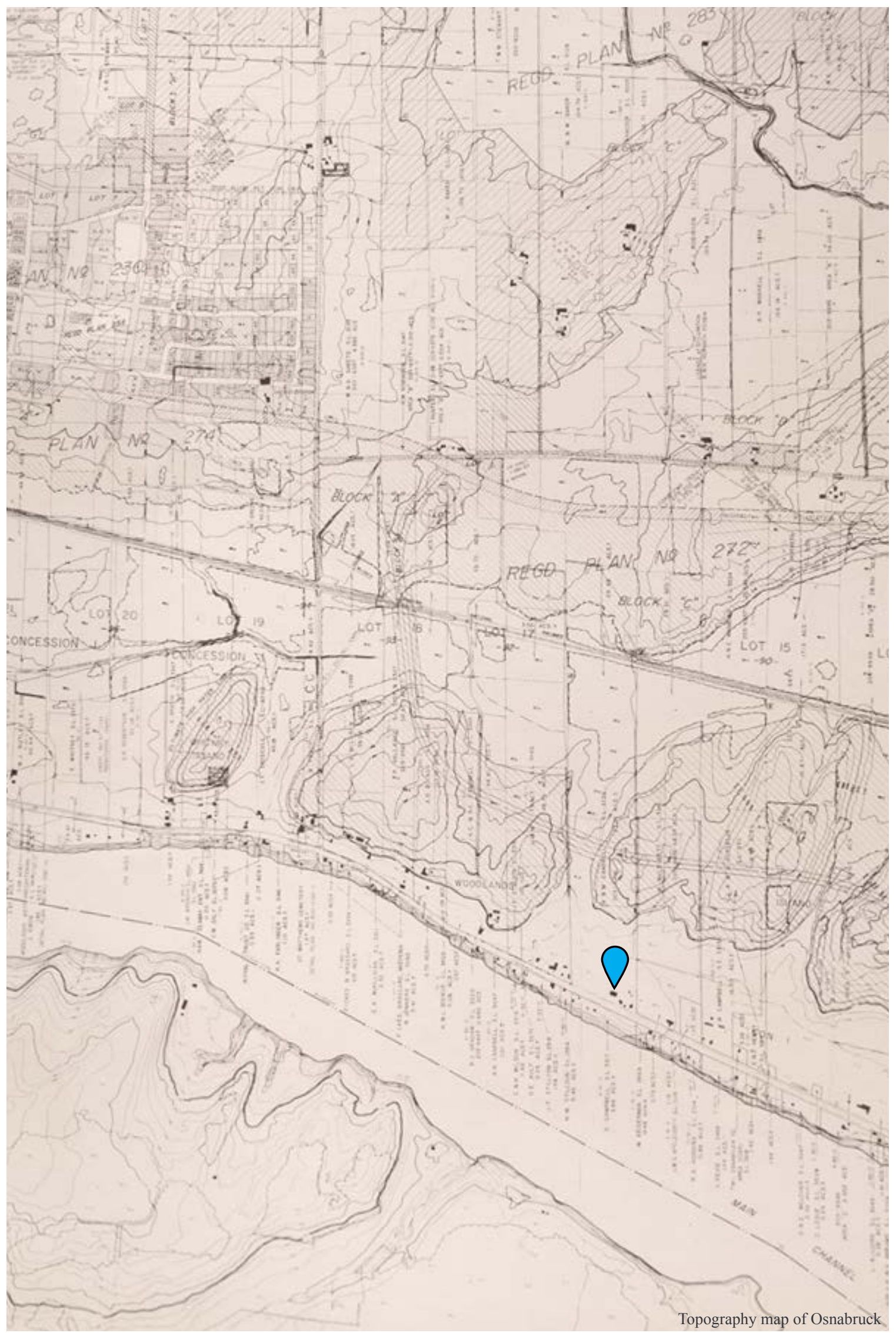




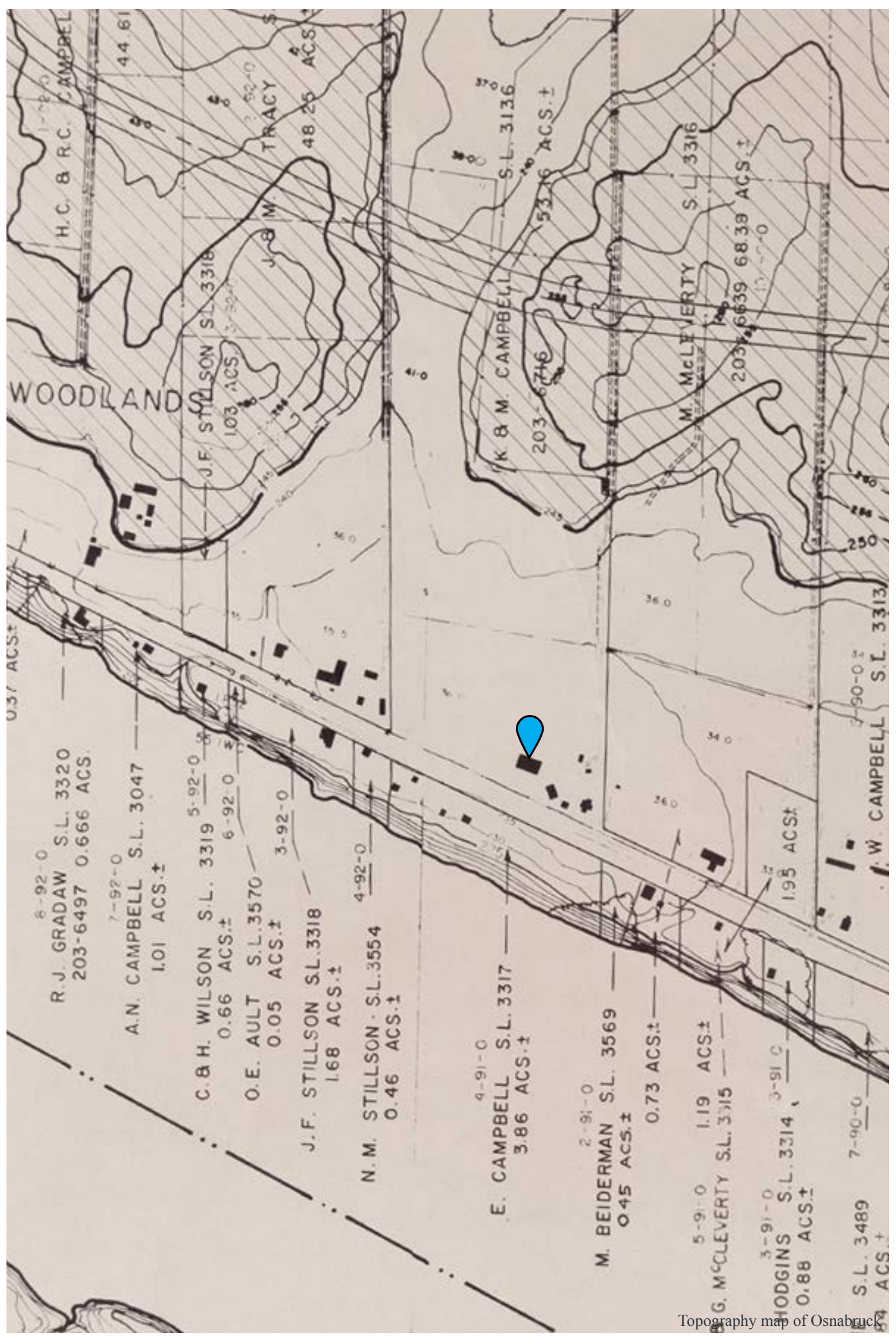



worthy of relocation.

\subsection{Site Access by Boat}

To access the site, a 15 foot fibre-glass boat, affectionately named Bertha, was used. The vessel was equipped with a 15HP 2-stroke outboard motor. Over the duration of the project, the boat was launched from a number of sites along the Seaway. Two of these launches took place where the old No.2 Highway surfaces along the new Long Sault Parkway. For the duration of this project, the main boat launch was located at the McLaren Campground, an approximate 10 minute boat ride from the primary dive site. Three survey trips were completed in order to asses and identify any possible assets, while twelve dives were required to capture the data.

\subsection{Digital Restitution through Photogrammetry}

The digital restitution of submerged assets was completed using photogrammetry, that is, the production of $3 \mathrm{D}$ geometry reconstructed from a series of overlapping photographs. ${ }^{77}$ Currently, photogrammetry is the most reliable form of capturing and reconstructing underwater data in the field of marine archaeology. ${ }^{78}$ This method also proved to provide the best results when camera calibration was not a prerequisite. It also mitigated environmental influences and allowed for the capture of data in conditions where strong currents and wave motion were present. ${ }^{79}$ The acquisition of data is comprised of five main stages: Capturing Data, Camera Alignment, Building Dense Point Clouds, Building Mesh Topologies and the Texturing of Mesh Topologies. This procedure can be read in more detail as a summary in the Documentation and Digital Restitution of Lot 3317, in the Appendix.

77 ISPRS Journal of Photogrammetry and Remote Sensing. Elsevier. 2008. Page. 4

78 The International Archives of the Photogrammetry, Remote Sensing and Spatial Information Sciences, Volume XL-5/ W5, Underwater 3D Recording and Modeling, 16-17 April 2015, Piano di Sorrento, Italy p.6

79 T Van Damme. The International Archives of Photogrammetry, Remote Sensing and Spatial Information Sciences, suppl. W5; Gottingen Vol. XL, Iss. 5, : 231-238. Gottingen: Copernicus GmbH. (2015) 


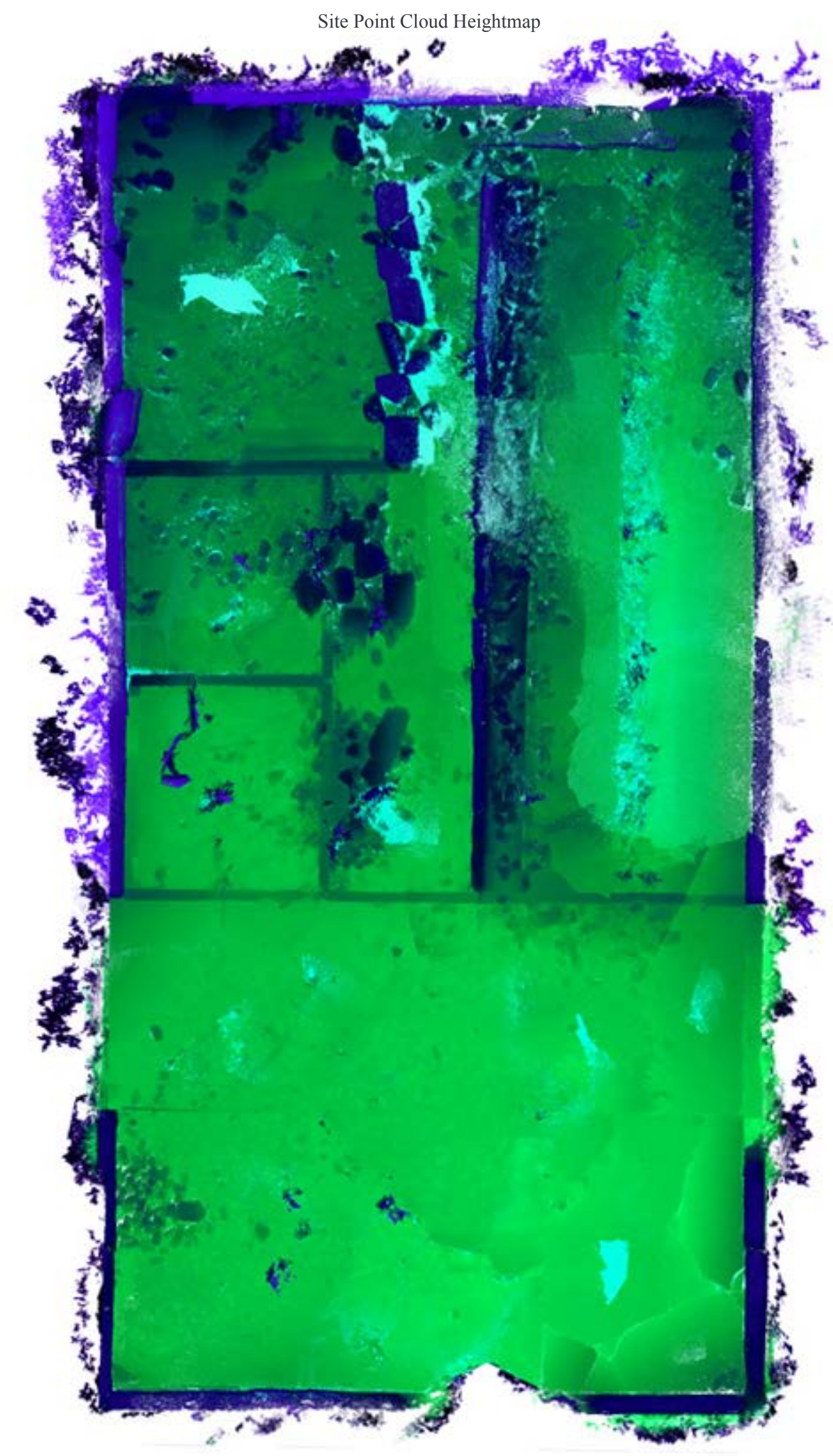




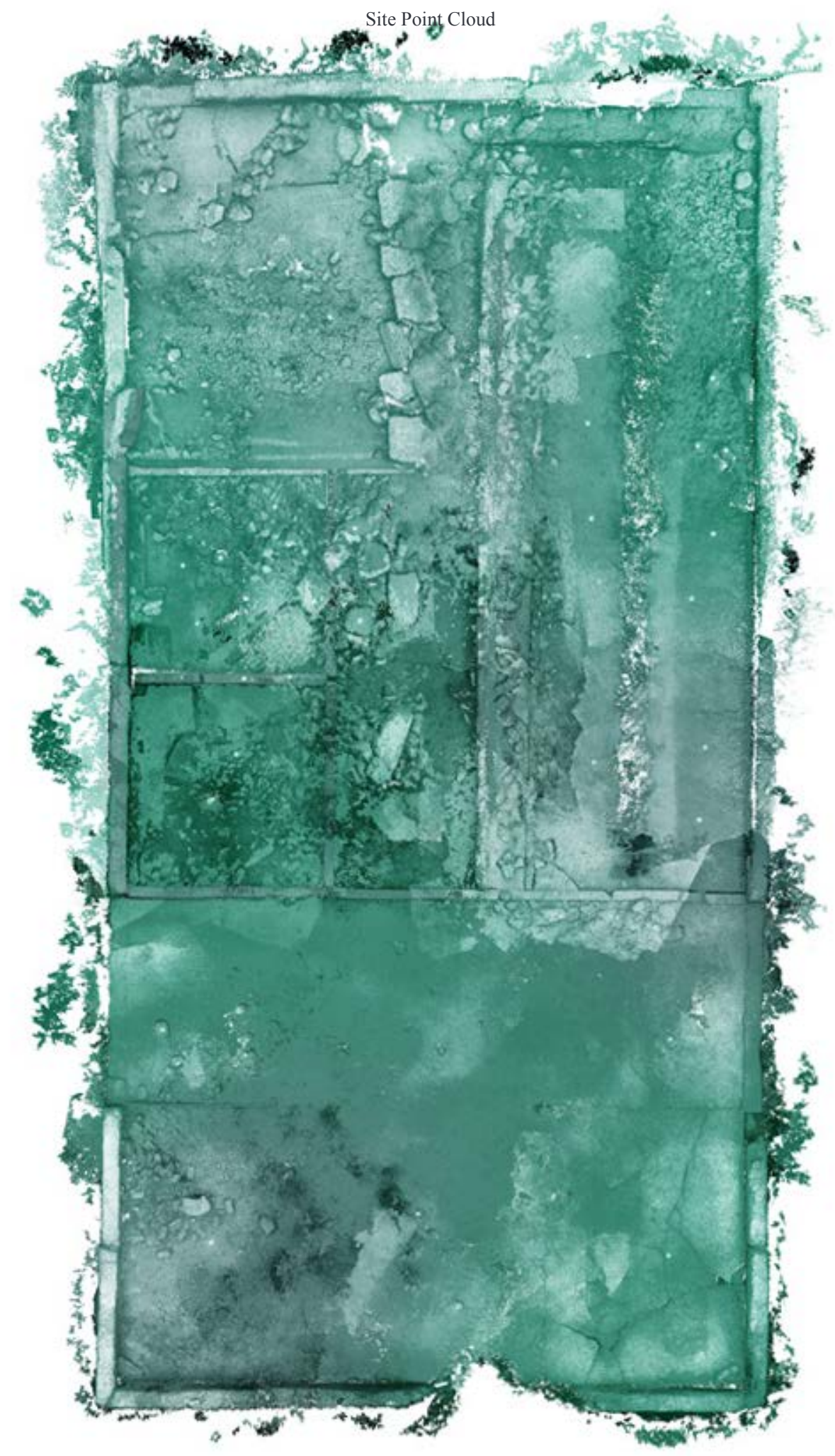


Mesh of Foundation

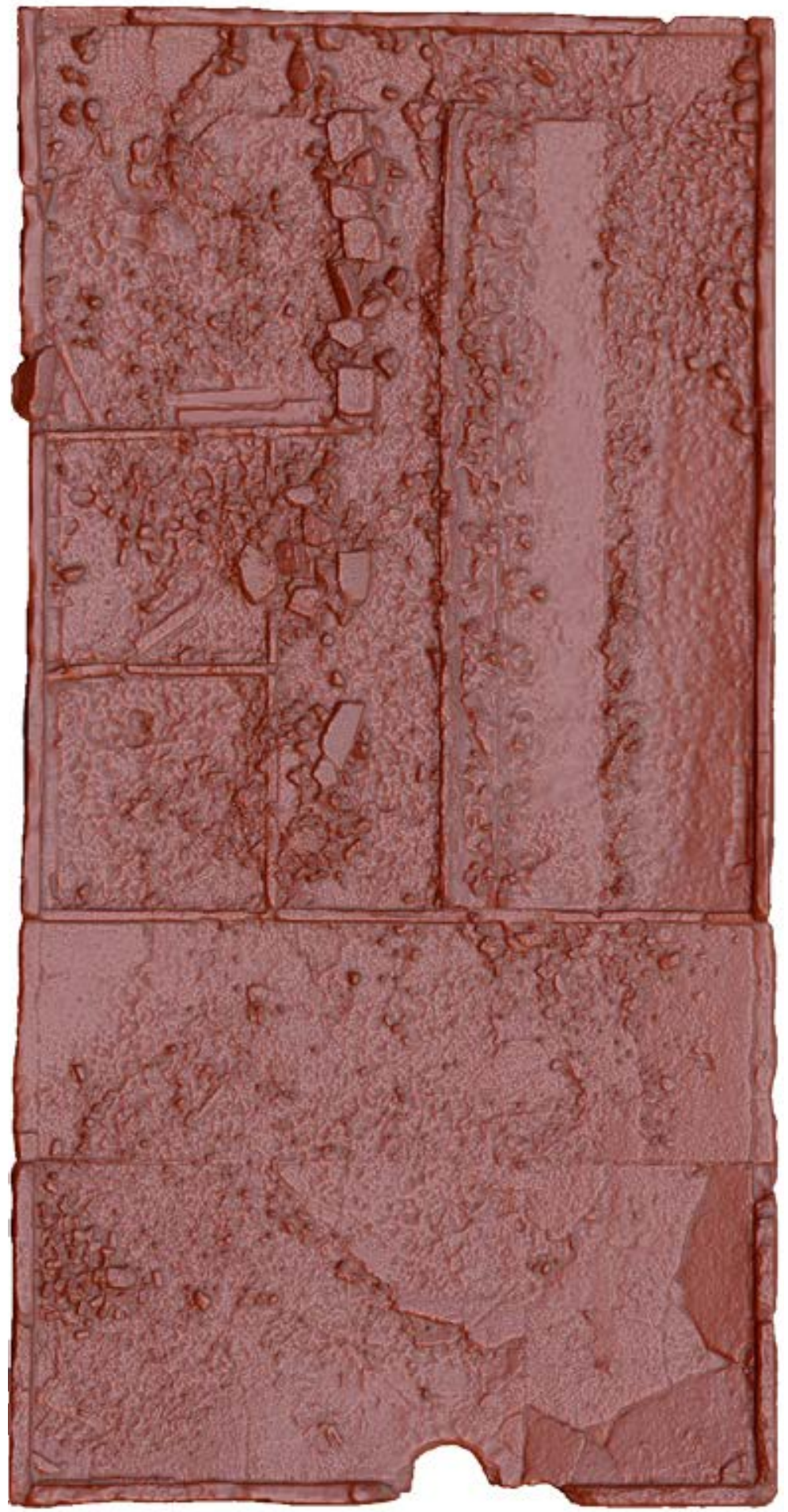


Textued Foundation

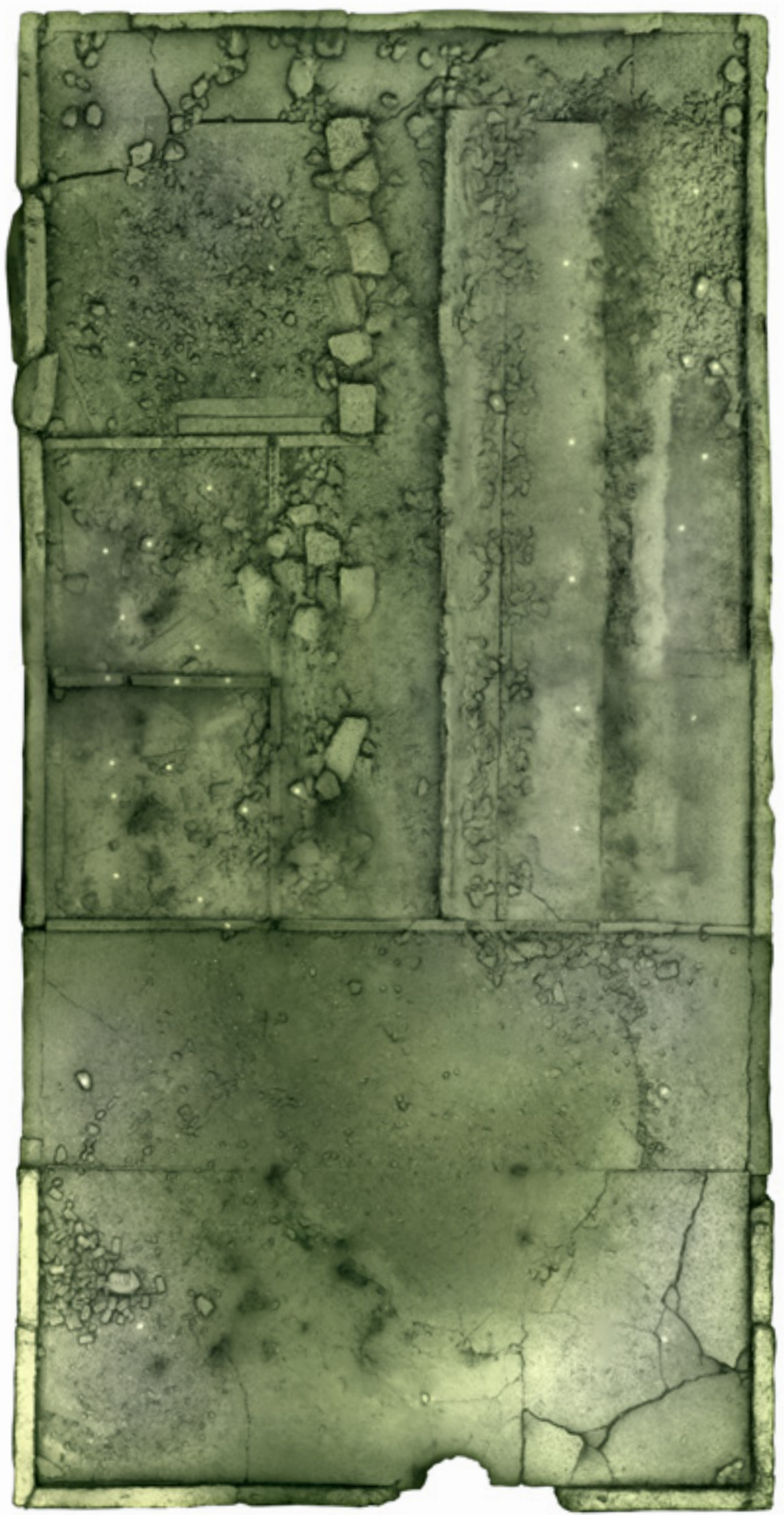


Resin Model

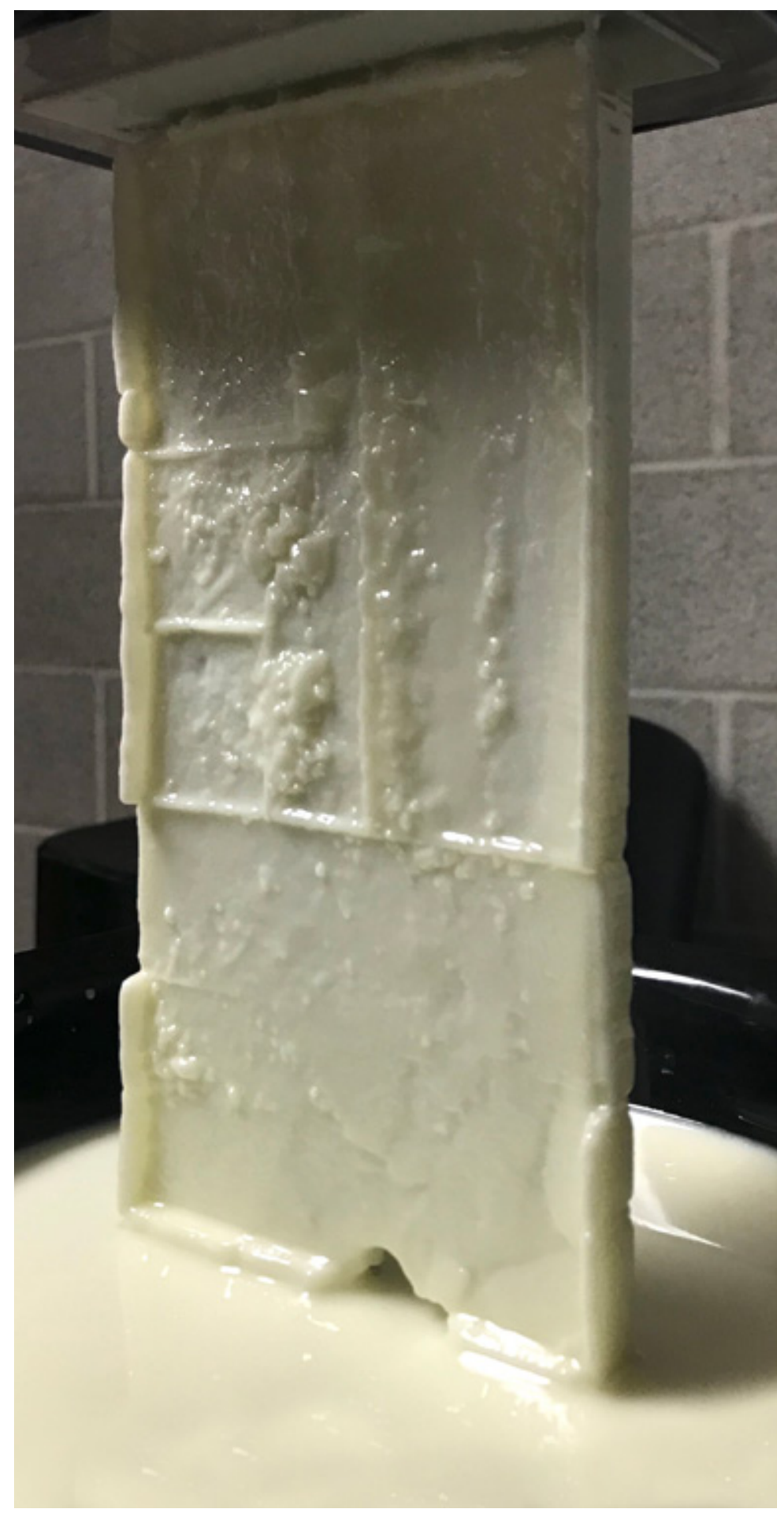




\subsection{Speculative Reconstruction}

\subsection{The Barn}

Prior to $1958,85 \%$ of the population lived in a rural setting, most likely on a farm. At this time, farmer's often placed more value on their barn than their houses. As a result, the farmhouse was considered to be a secondary structure to the main barn. ${ }^{80}$ Although this was generally true for most farmers, there is a lack of literature on the North American barn, and little research has been done with regards to their documentation. ${ }^{81}$ This demonstrates there was a lack of public concern for the preservation or documentation of these structures, and unfortunately very few barns still remain as case studies. ${ }^{82}$ Although this site was chosen because it was more pragmatic, its restitution will contribute to the research of early barn construction in Upper Canada.

Barns in Eastern Canada were primarily erected to provide shelter for livestock; therefore the proportions of each barn were a direct response to the farmer's needs and the variety of livestock they farmed. ${ }^{83}$ In the early construction of North American barns, bay width (the spacing of bents), was determined by the desirable width for standing livestock. ${ }^{84}$ The term "bent" describes the basic structural unit of post and beam in barns. The bent is typically composed of structural timbers, forming a cross section through the building. Determined by the width of each bay, the bents are most often connected together with joists and purlins in order to give the barn it's rigid shape. ${ }^{85}$

\footnotetext{
80 Klamkin, Charles. Barns: Their History, Preservation, and Restoration. Bonanza, 1979. Page. 5

81 Schoenherr, John. The Barn. Little, Brown, 1968. Page 18

82 Schoenherr, John. The Barn. Little, Brown, 1968. Page 18

83 Klamkin, Charles. Barns: Their History, Preservation, and Restoration. Bonanza, 1979. Page. 43

84 Schoenherr, John. The Barn. Little, Brown, 1968. Page. 68

85 Schoenherr, John. The Barn. Little, Brown, 1968. Page. 68
} 
The distance between post holes located on site was approximately $4 \mathrm{~m}$. This would allow for about 4 head of cattle to stand comfortably in each bay. There were 13 stalls over the entire cattle floor. Prior to 1850 , most farmers had only enough cows to supply milk for their own consumption. The number of stalls in this structure suggests that it was built after 1850 , as it would have more cattle than needed for a single household. ${ }^{86}$ When surveying the area, no remnants of a silo were found, therefore this barn may have been serviced by a wooden silo. This indicates that the barn was probably built closer to the last quarter of the 19th century, as more permanent silo materials such as concrete would have been used in the 1900's. ${ }^{87}$ In addition to this, the use of concrete in the foundation and floor instead of stone or dirt, further suggests that the structure was built closer to the end of the 19th century. This study concludes that the barn most likely housed cattle, and was probably a dairy farm, built between 1850 and the early 1900 's.

\subsection{The English Barn}

The building stock in Upper Canada was influenced by English, French and GermanPennsylvanian wood frame construction techniques ${ }^{88}$ Despite the differences between these barn typologies, many barns built during this time period shared design strategies such as program division, structural proportions, materials and building construction methods ${ }^{89}$ Along the International Rapids section of the St. Lawrence River, two main typologies existed: the German-Pennsylvanian style barn and the English style barn.

Loyalist settlers were among the most predominant in the area, and as a result, most wood frame structures, including barns, had English characteristics..$^{90}$

\footnotetext{
86 Klamkin, Charles. Barns: Their History, Preservation, and Restoration. Bonanza, 1979. Page. 56

87 Klamkin, Charles. Barns: Their History, Preservation, and Restoration. Bonanza, 1979. Page. 57

88 Schoenherr, John. The Barn. Little, Brown, 1968. Page. 68

89Klamkin, Charles. Barns: Their History, Preservation, and Restoration. Bonanza, 1979. Page. 3

90 Rempel, John I. Building with Wood: and Other Aspects of Nineteenth-Century Building in Central Canada. University of Toronto Press, 1986. Page. 143
} 
English style Barns built in the late 1800's and early 1900's were an adaption of the three bay barn. ${ }^{91}$ This typology was known to be the most popular in Upper Canada and Northern United States. The primary character defining element that distinguishes the German-Pennsylvanian style from the English style was the forebay, an overhang on the second floor that cantilevered past the foundation wall. ${ }^{92}$ In addition to this, barns of a German-Pennsylvanian influence traditionally had openings for livestock along the length of the barn, beneath a forebay. ${ }^{93}$. Due to the height of the foundation walls and the lack of openings perpendicular to the longitudinal section of the building, this barn was most likely a barn built with English style characteristics.

English style barns are typically designed with two central doors, providing a throughway into the barn. The barn itself consists of two levels, the first level contained a threshing floor, a double height mow and an extended area for the housing of livestock. Over the extended cattle floor is a loft for the storage of fodder, which is usually supported by a large swing beam. ${ }^{94}$ The swing beam was a North American element in the English style barn, enabling the area below the beam to be extended and uninterrupted. Typically the swing beam was used to maximize floor space and extend the threshing floor by one bay into the mow.

\footnotetext{
91 Schoenherr, John. The Barn. Little, Brown, 1968. Page.18 92 Rempel, John I. Building with Wood: and Other Aspects of Nineteenth-Century Building in Central Canada. University of Toronto Press, 1986. Page. 146

93 Rempel, John I. Building with Wood: and Other Aspects of Nineteenth-Century Building in Central Canada. University of Toronto Press, 1986. Page. 146 94 Schoenherr, John. The Barn. Little, Brown, 1968. Page. 65
} 


\subsection{The Speculative Construction}

Speculative reconstructions are an invaluable tool for the interpretation of archeological sites..$^{95}$ Analytical reconstructions of buildings provide perceptive visualizations that help participants contextualize the archaeological fragments on site. The resulting, hypothetical reproductions are a powerful and influential tool when disseminating augmentd products of previously captured data. ${ }^{96}$ To contextualize the foundation and add perceivable functions to its narrative, a speculative reconstruction based off an existing barn was implemented.

After analyzing the results from the captured data, it was confirmed that the foundation shared similar characteristics of the English style barn. On the west end of the foundation, large openings suggest that there were two doors providing a throughway from the south facade to the north facade. This large unobstructed bay could have been used for threshing grain and providing access to the mow, located immediately to the west. In addition to serving the mow, the threshing floor was also used to access the loft, located above the extended cattle floor found in the larger eastern portion of the building.

The extended cattle floor consisted of a granary, one central feed alley that serviced 13 milking stanchions, two box stalls and a cattle loafing area. The raised trough that runs down the centre of the foundation was most likely a manger used for feeding cattle. In addition to this, the long trench found along the southern side of the cattle floor was most likely a gutter servicing the 13 stanchions. Behind this gutter was a litter alley, providing circulation along the southern facade.

95 Stone, Peter G., and Philippe G. Planel. The Constructed Past: Experimental Archaeology, Education and the Public. Routledge, 2012. Page. 12

96 Stone, Peter G., and Philippe G. Planel. The Constructed Past: Experimental Archaeology, Education and the Public. Routledge, 2012. Page. 12 


\subsection{Asset No.2 A Speculative Reconstruction}

Traditionally, speculative reconstructions are performed on site, and serve as a method of experimental research for communicating ideas between archeologists/heritage conservationists. The popularity of this method across Europe and North America can be accredited to their versatility beyond pure archaeological research and their use as a cultural asset. As many sites are funded by tourism, it is important for experimental research to be accessible as an educational device, providing that its value is transferable to public institutions, tourists and fellow researchers. ${ }^{97}$

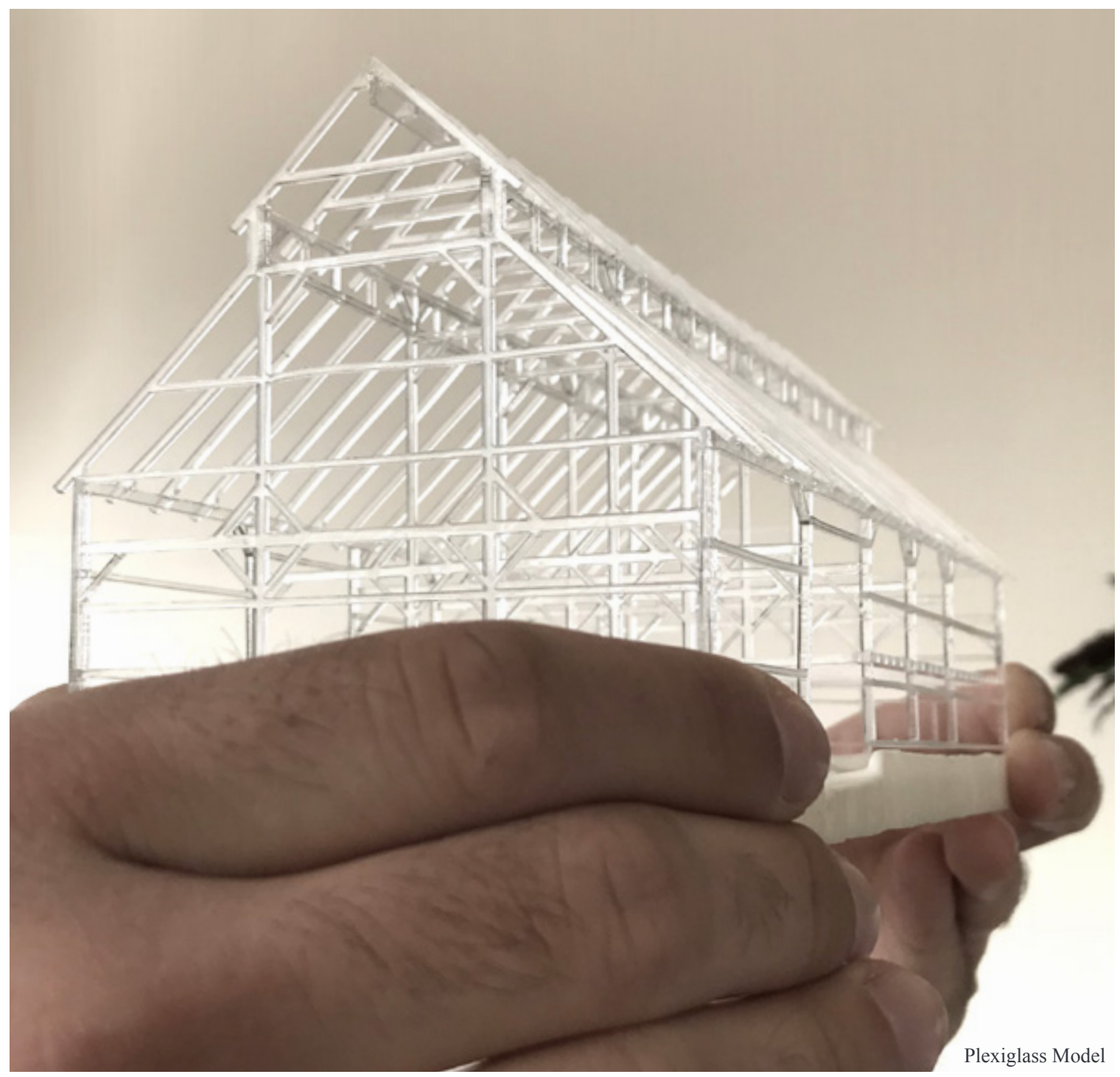

97 Stone, Peter G., and Philippe G. Planel. The Constructed Past: Experimental Archaeology, Education and the Public. Routledge, 2012. Page. 12 


\subsection{First Person Experience in a Head Mounted Display}

\subsection{The Experience}

Pine and Gilmore argue that "an experiential economy is developing, where value is added by the experience that is associated with consumption". ${ }^{2}$ Meaning, for tourists, it is possible for some things to transition from being valueless (when they do not facilitate a tourist experience), to having high value when they are the primary facilitator of that experience. ${ }^{3}$

This is especially true when you consider The Lost Villages. Divers from many locations often visit the abandoned sites flooded by the St. Lawrence Power Project, as they provide interesting locations to dive. This generates interest and heritage value, however it is shared within a close knit community of divers. To fully tap into these cultural resources, it is necessary to create a system that facilitates similar experiences for the general public, rather than a select demographic.

In turn, this procedure could be used to bolster interest and kickstart future research or project activity in relation to The Lost Villages. Accessing content on the internet does provide insight into the current condition of many sites, but a first person experience that allows any individual to actively participate in viewing the flooded locks, hamlets and farm lands may prove to be more valuable in the veneration of these assets. It may also allow participants to address the broad array of processes, operating at multiple spatial scales, pertaining to the socio-environmental transformations that took place in a locational context.

2 Pine, B. Joseph., and James H. Gilmore. Welcome to the Experience Economy. Harvard Business Review Press, 1998. Page. 34 3 David Fisher \& Becky Smiley (2015) Adapting Rubbish Theory for heritage tourism, Journal of Heritage Tourism. 


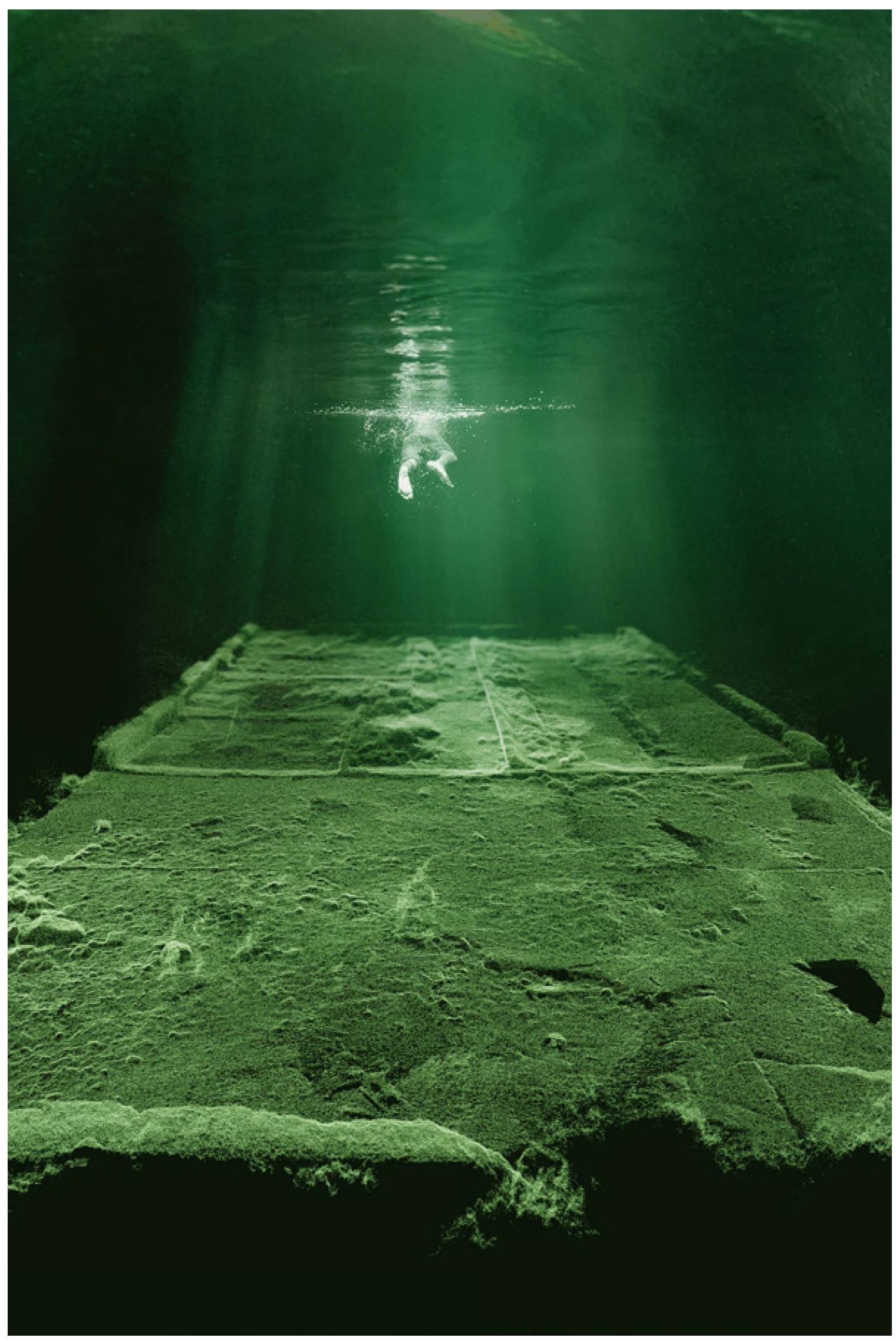




\subsection{First Person Interpretation}

Freeman \& Tilden define interpretation as "an educational activity, which aims to reveal meanings and relationships through the use of original objects, first-hand experiences and by illustrative media, rather than factual information". ${ }^{4}$ This statement suggests that in order to facilitate a healthy interpretation, a medium that is immersive, interactive, and viewer-centred must be considered.

As digital representations of real spaces, virtual environments provide the illusion of presence. ${ }^{5}$ In doing so, they offer participants the chance to digitally visit places normally inaccessible, either due of their location or because they no longer exist. ${ }^{6}$ As an interactive and immersive experience, these synthetic environments provide a surrogate to reality, but in a medium that is simulated and autonomous. ${ }^{7}$ The benefits of such experiences can be defined in their ability to create meaningful connections between the real world and virtual visitors, while also enabling participants to interpret objects and environmental qualities on their own accord.

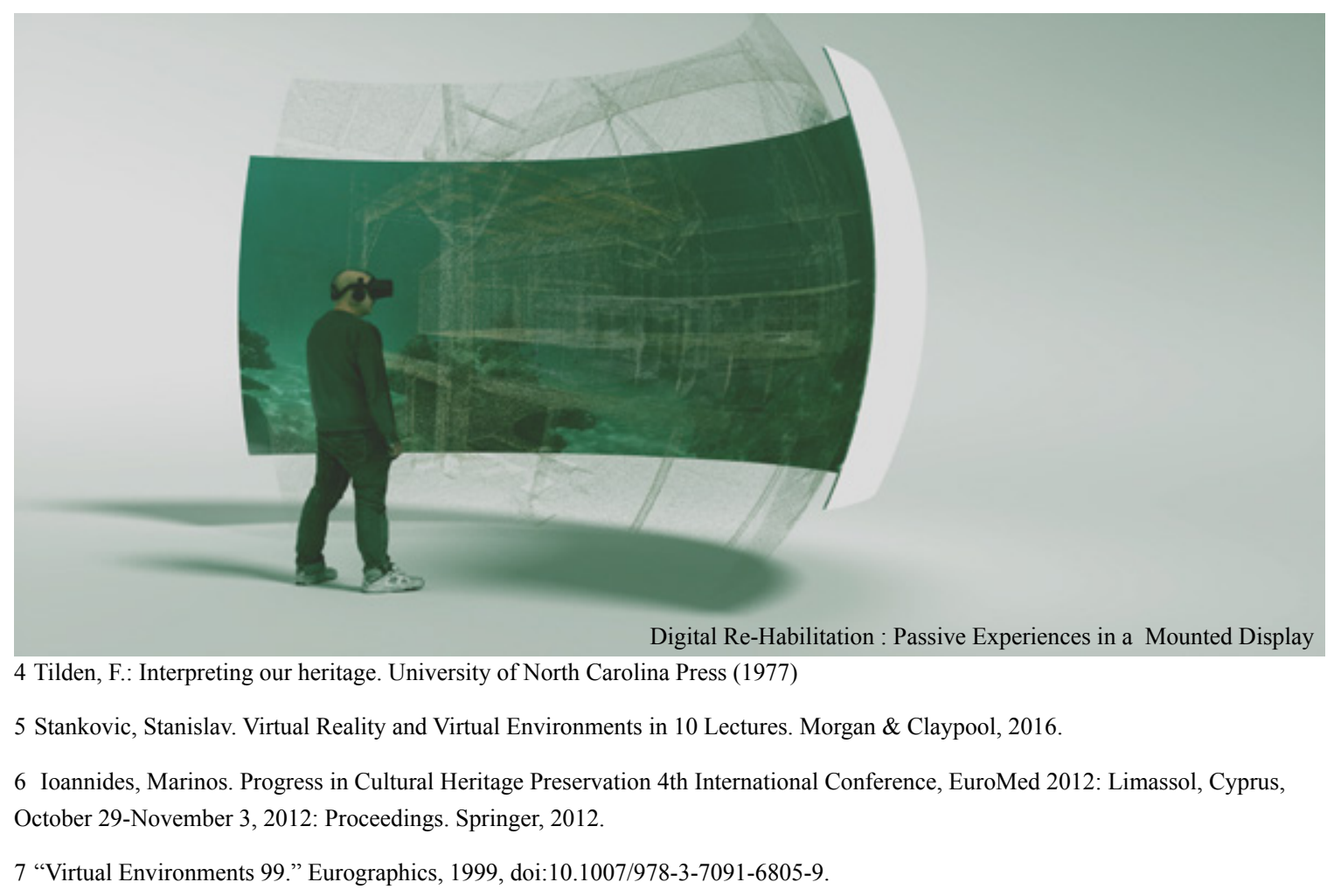




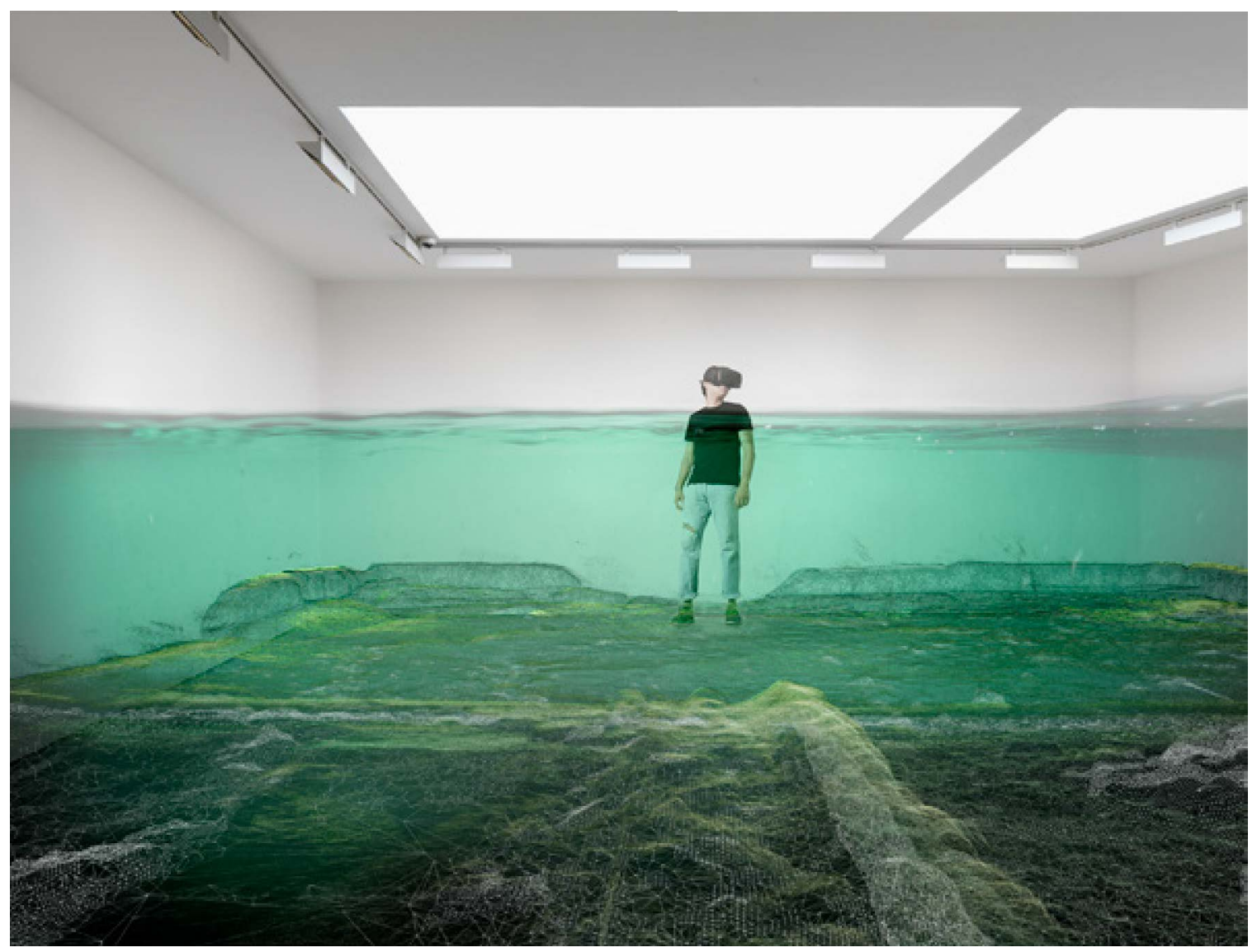

\subsection{Virtual Heritage}

Digital Model in a Head Mounted Display

The term 'Virtual Heritage' $(\mathrm{VH})$ can be used to describe the digital products that use virtual-reality (VR) to disseminate cultural-heritage.8 For the purpose of this paper, cultural heritage refers to "objects, properties and sites with archaeological, aesthetic or historical value" and 'virtual heritage' refers to instances of these objects, properties and sites represented within a digital context.9 In this definition, Virtual Heritage provides heritage conservationists with an alternative medium of disseminating heritage values, opposed to the traditional techniques such as pre-formulated external observations.

8 Ioannides, Marinos. Progress in Cultural Heritage Preservation: Proceedings. Springer, 2012. P.241

9 Ioannides, Marinos. Progress in Cultural Heritage Preservation: Proceedings. Springer, 2012. P.241 


\subsection{VH Experiences of Lot 3317}

For the purposes of this study, a series of real-time, interactive representations of lot 3317 were expressed through interactive $\mathrm{VH}$ experiences. The digital assets identified in the previous chapters were utilized to provide virtual visitors with real-time interactive graphic representations, viewed within a Head Mounted Display (HMD). This allows for the participant to become fully immersed within the re-constructed environment, and the augmented geometry within it.

In order to minimize heritage dissonance and enhance the understanding of inherent significance in cultural heritage, an interpretive visualization method was adopted to ensure each experience was proven to be provocative, yet educational. Photo realistic representations were avoided to prevent visitors from assuming the representations were not true, but speculative. It was important to limit the conceptual content to three main elements, being the water, the speculative reconstruction of the barn and the foundation itself. This is in turn allowed for a more focused experience. Overall, a series of seven passive panoramic visualizations were created. In addition to this, a smaller, more interactive model was generated to allow participants to actively explore the west end of the foundation. 


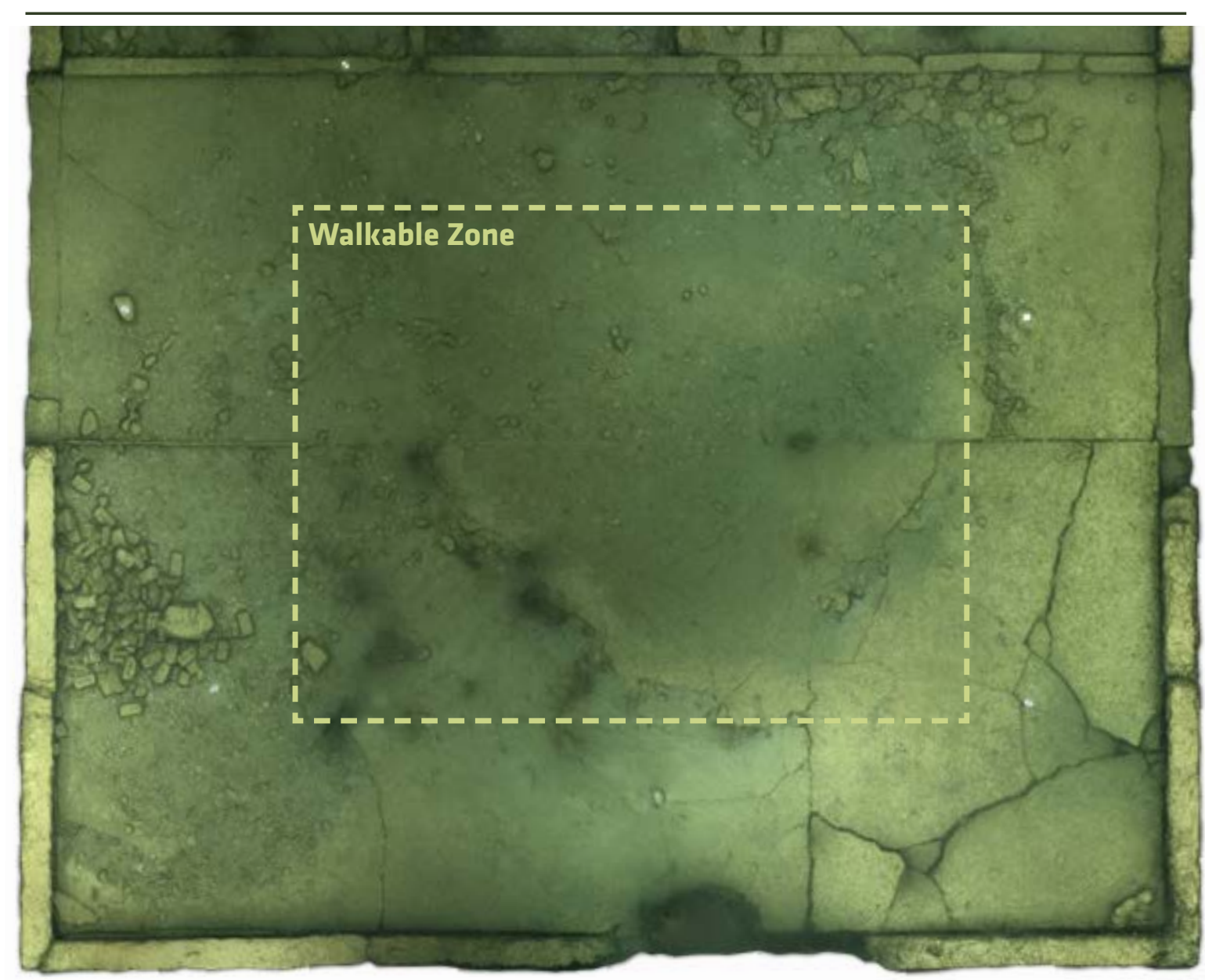

Digital Re-Habilitation : West Section of Site

\subsection{Concluding Remarks}

As an installation, the digital restitution of the submerged archaeology found on lot 3317 will enable participants to partake in a synthetic re-appropriation of space. In this action, each person is given the opportunity to understand, observe and explore the site. While at the same time, challenging the current spatial dynamics by conceptually reducing the distance between the viewer and the flooded landscape. By improving the understanding of how the political, economic and geographical changes challenged previous members of the community, it allows for the development of a new a discourse, further enhancing the value of the $\mathrm{VH}$ experience. 
"The history of Canada is the sum total of the biographies of all its citizens. In its unfolding, all have a share; from its narrative, all derived that pride which comes of participation. Written in national terms, it is yet, in so far as every Canadian is concerned, a deeply personal record; for here, fashioned into a composite picture are the activities, in peace and war, Of industry and commerce, Of labor and capital, of the great and the humble.. Other departments of letters may perhaps have a special appeal; history belongs to us all. “98

As Canadian Citizens, we need to acknowledge that there is not just one past acceptable to everyone, but many interpretations of it. ${ }^{99}$ The key to understanding this concept lies just as much in the realm of sociology, anthropology and psychology as it does within the architectural forensic study of lot.1337. The combined narratives of those who were displaced by the Seaway, as well as the cultural assets they left behind, are tremendous educational tools. ${ }^{100}$ They allows us to draw attention to the physical, representational and political conflicts surrounds the construction of The St. Lawrence Seaway and Power Project, while enabling us to understand, observe and explore its consequences.

As a design paradigm, this project serves as a mechanism enabling the community to heuristically explore the history of the St. Lawrence Seaway and to re-habilitate The Lost Villages in a dialectic manner. In doing so, it generates accessible cultural assets that enable us to reflect on contemporary concerns with the modern environment and start a discourse of our own.

\footnotetext{
98 Leacock, Stephen. CANADA. The Foundations Of Its Future. Montreal: Privately Printed, 1941. Page. 10 99 Stone, Peter G., and Philippe G. Planel. The Constructed Past: Experimental Archaeology, Education and the Public. Routledge, 2012. Page. 34 100 Corsane, Gerard. Heritage, Museums and Galleries: an Introductory Reader. Routledge. 1994. Page 10-82
} 


\subsection{Digital Re-Habilitation Appendix:}

\subsection{West Section of Site}

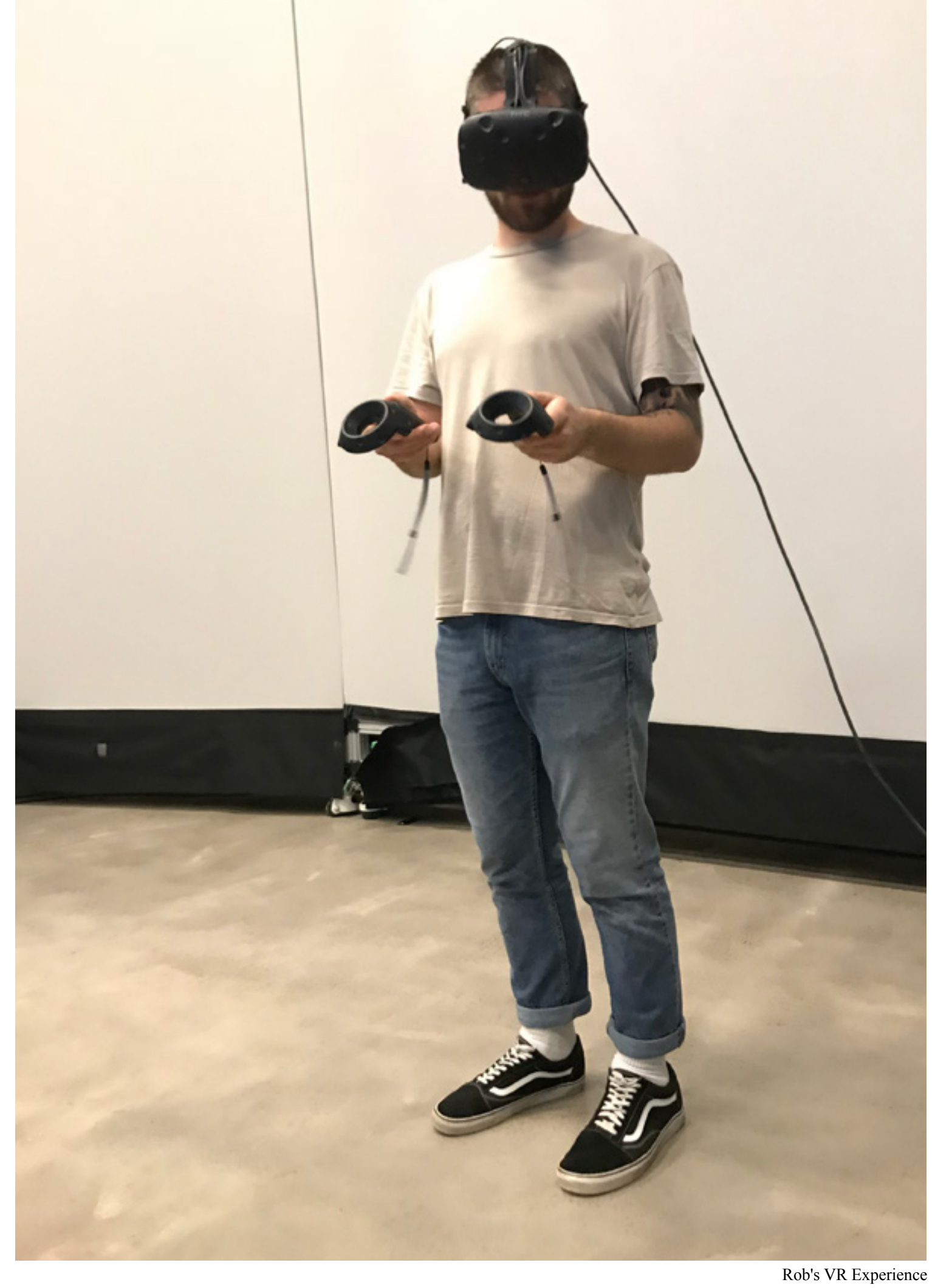



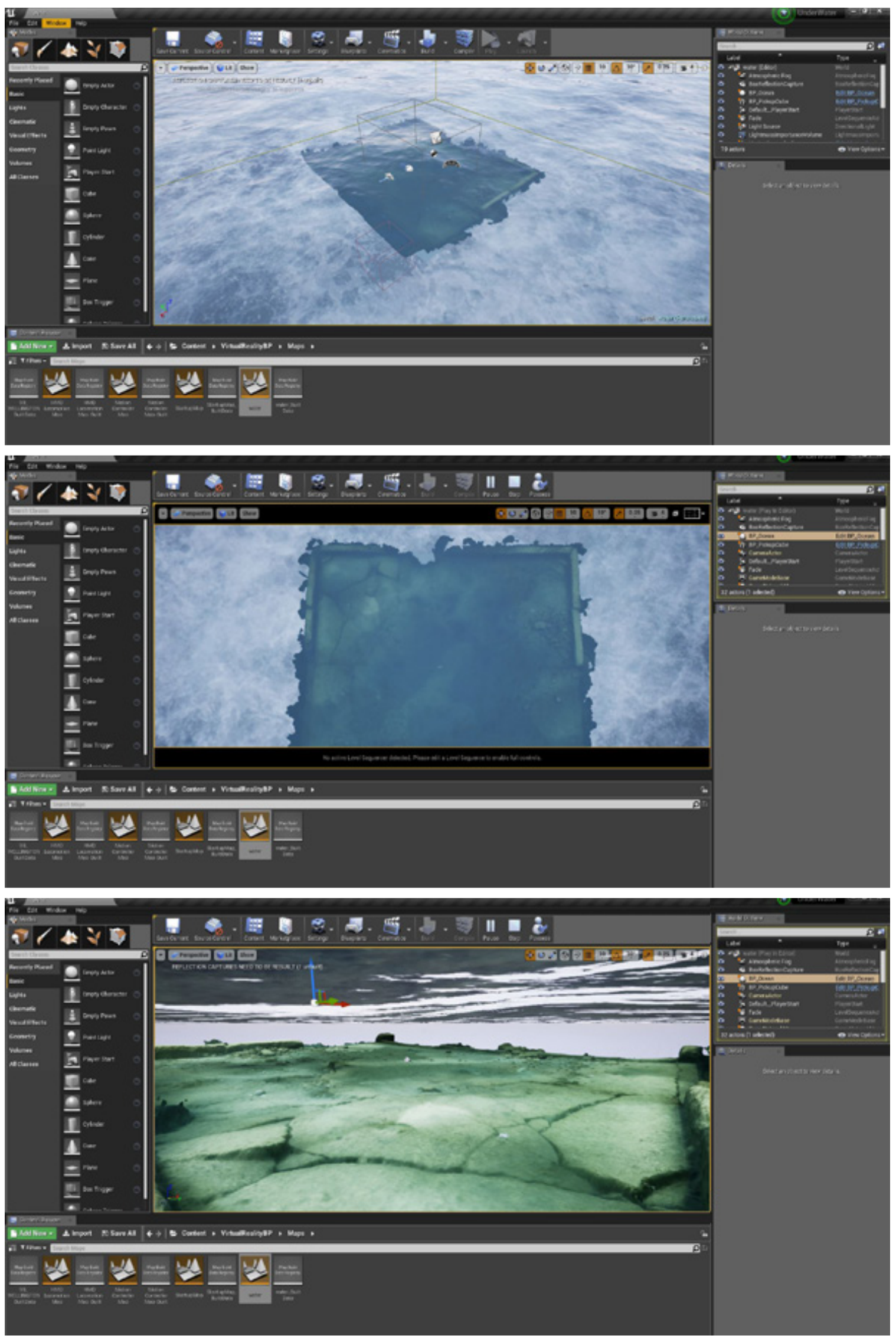

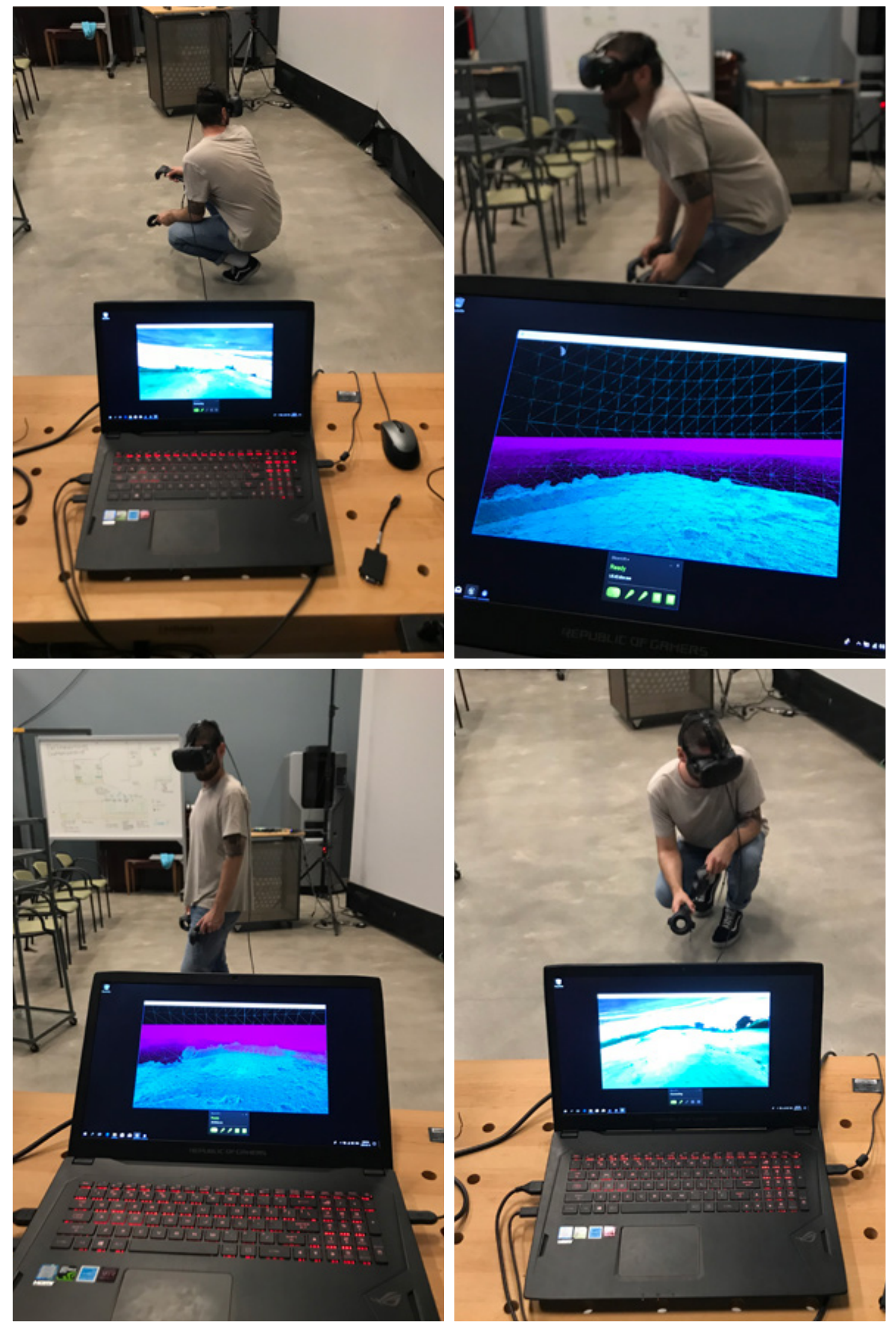


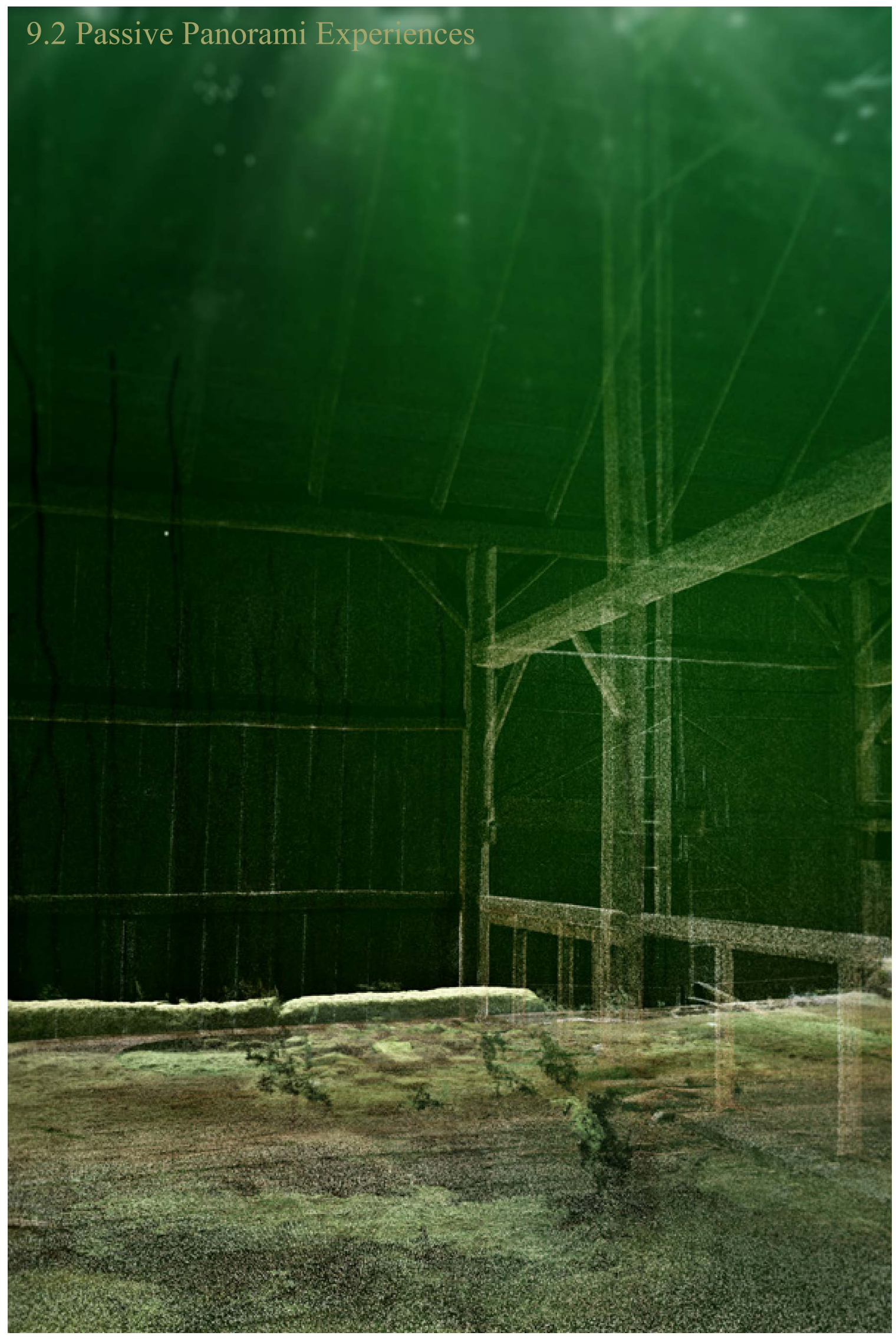




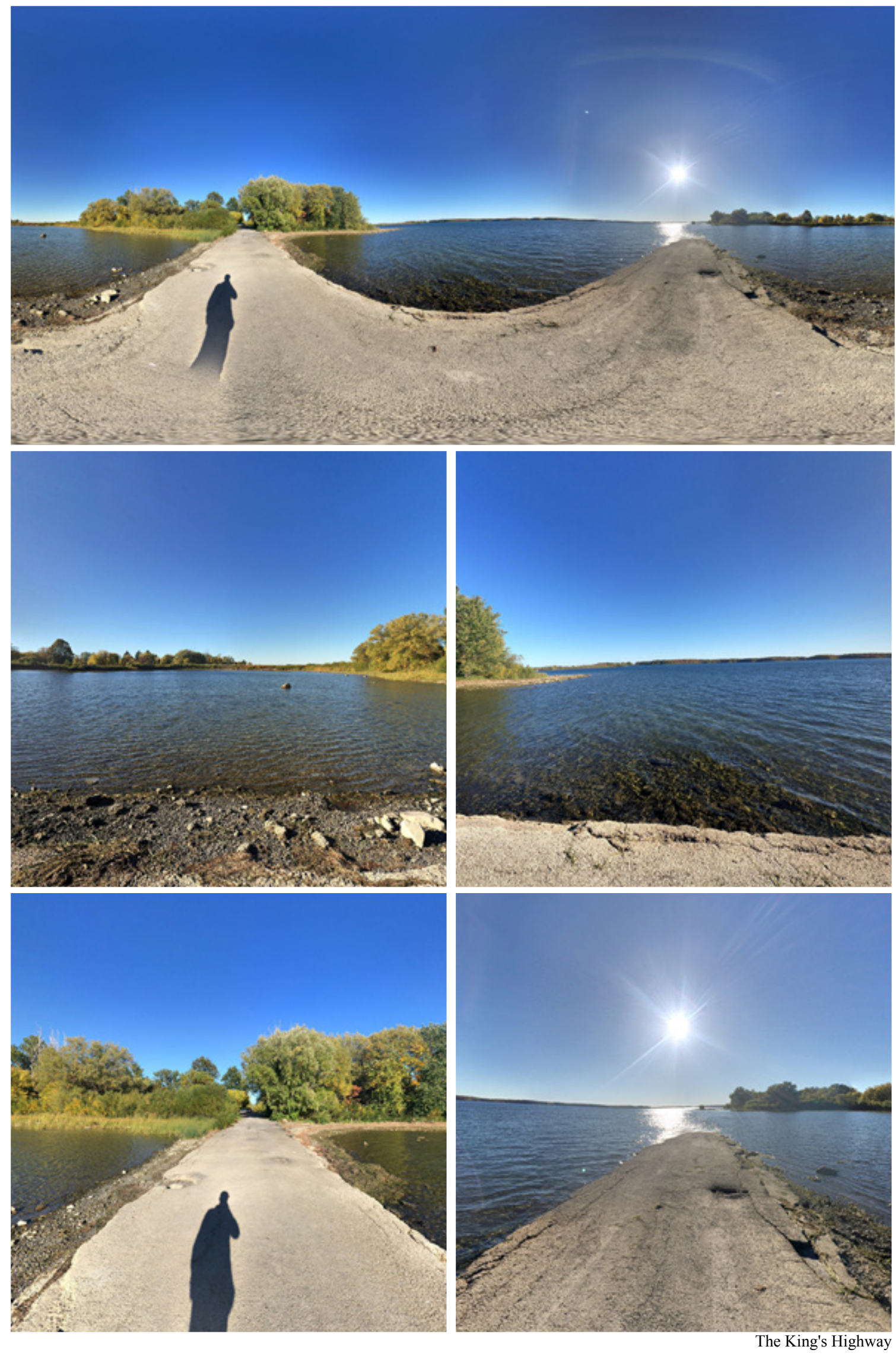



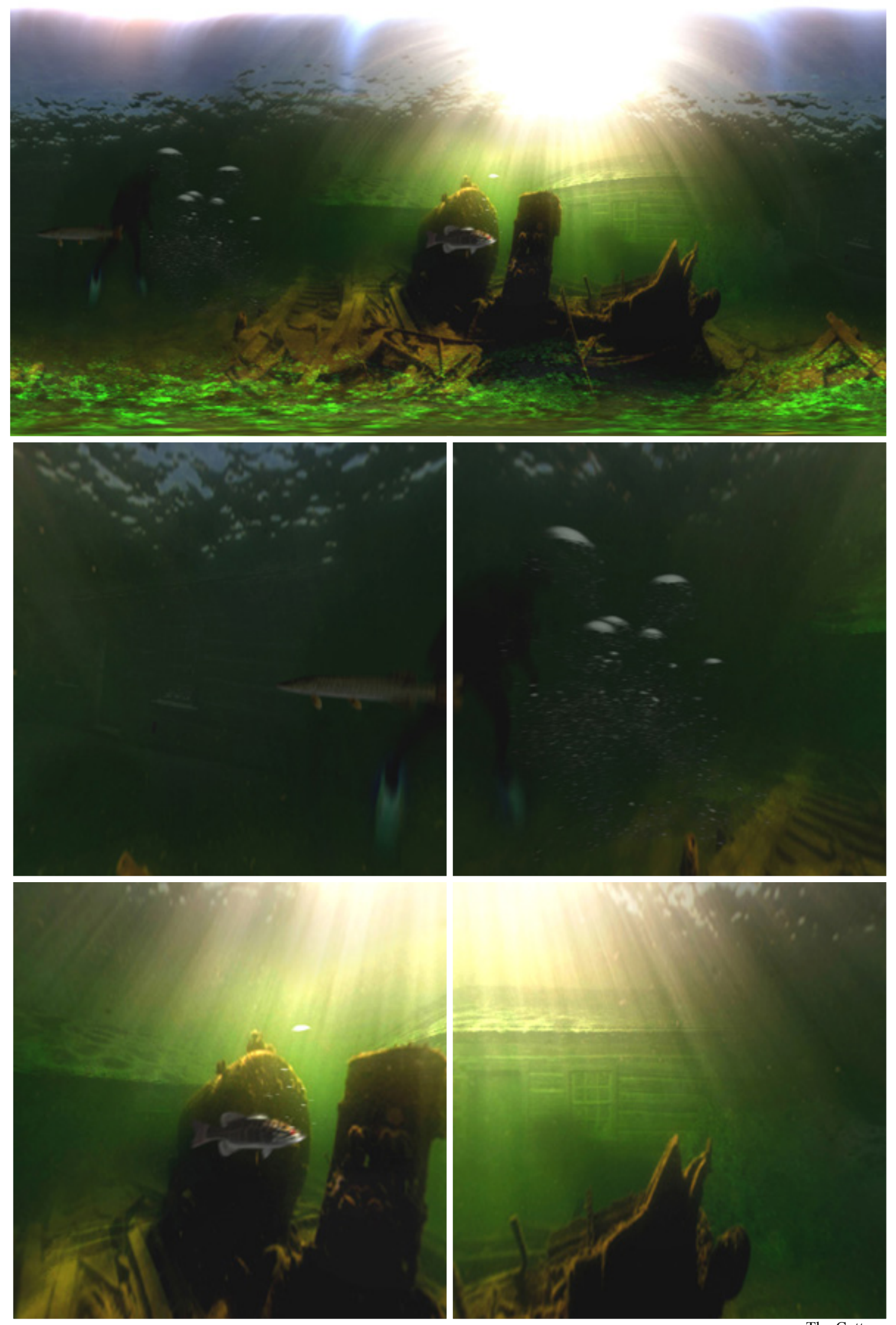

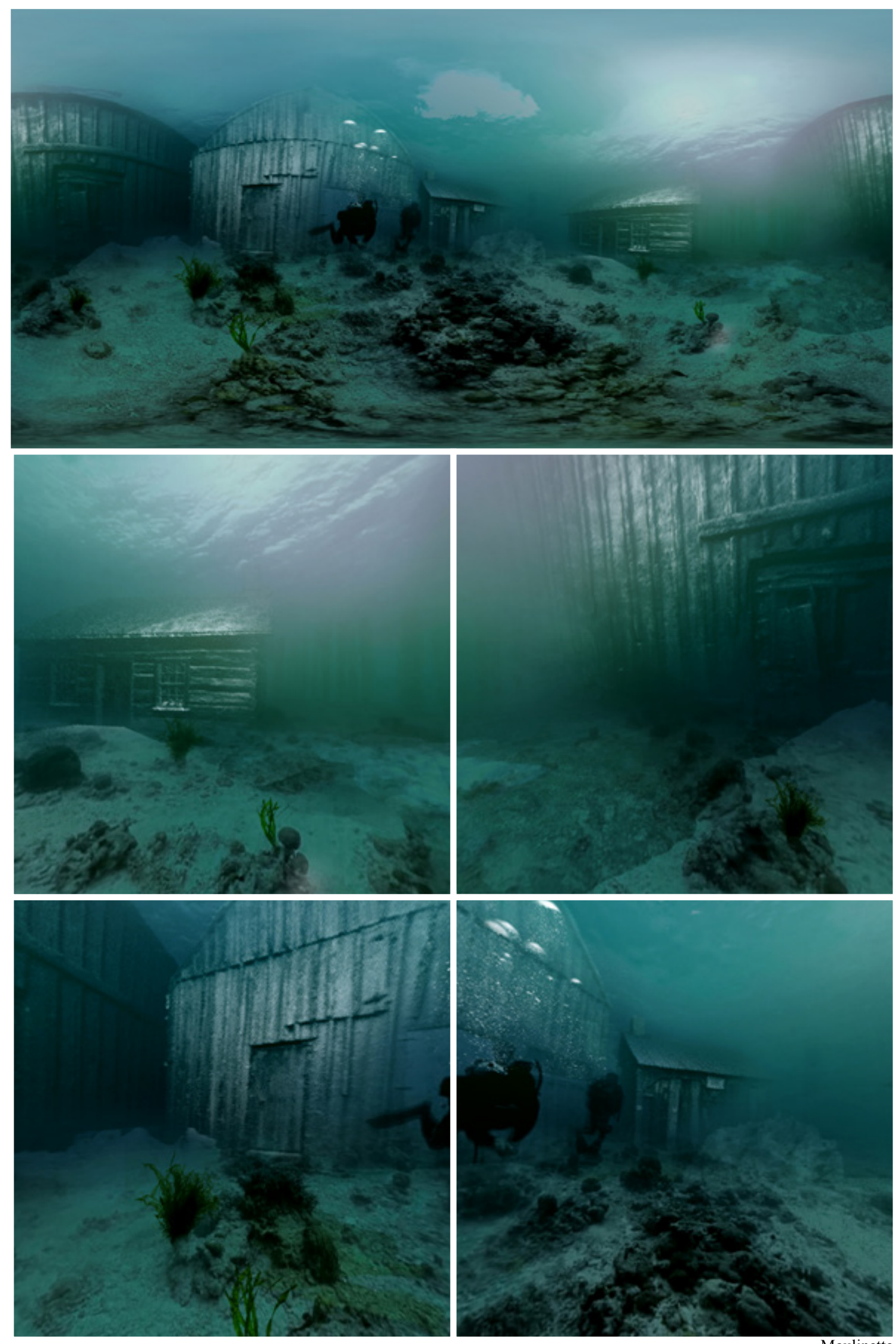

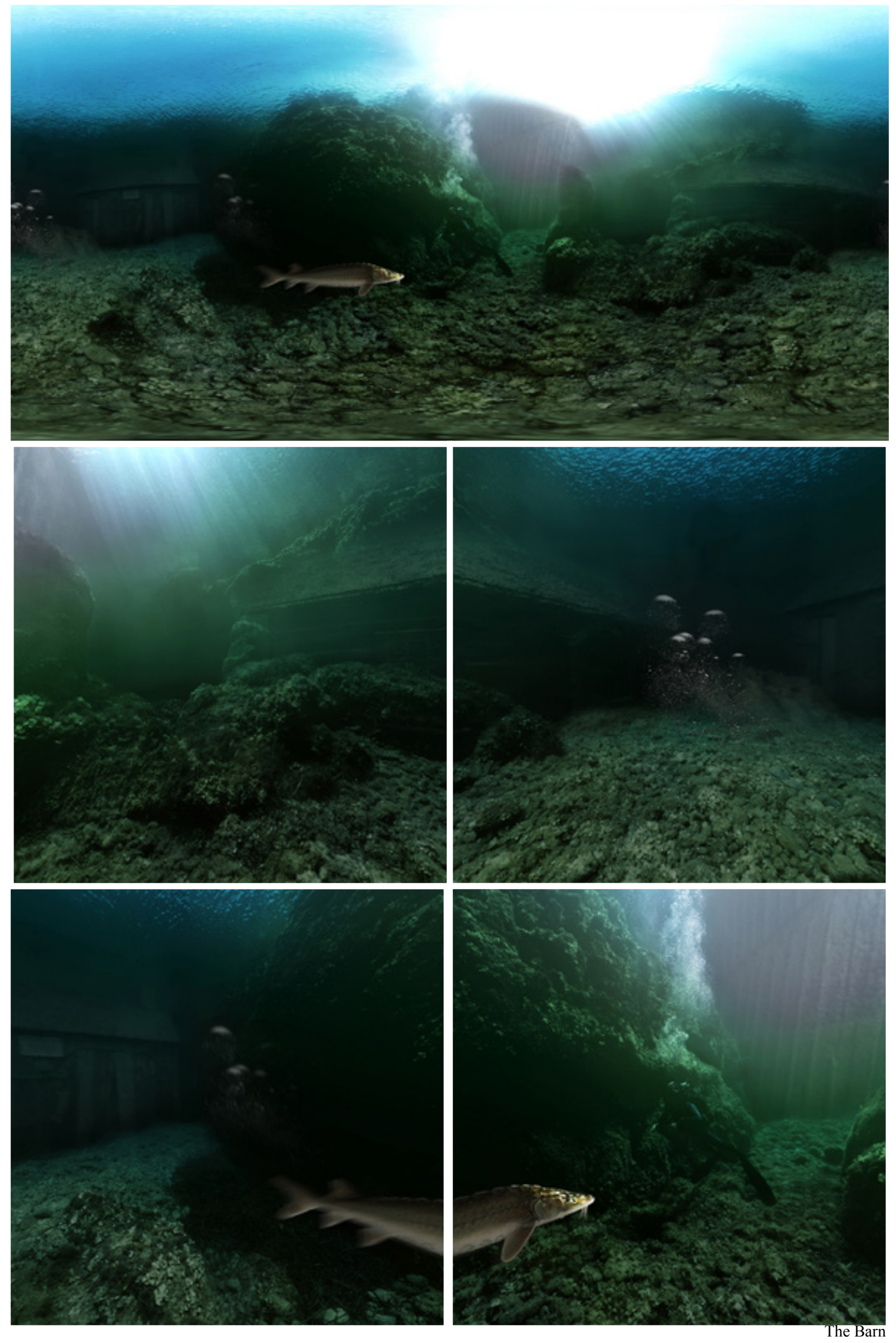

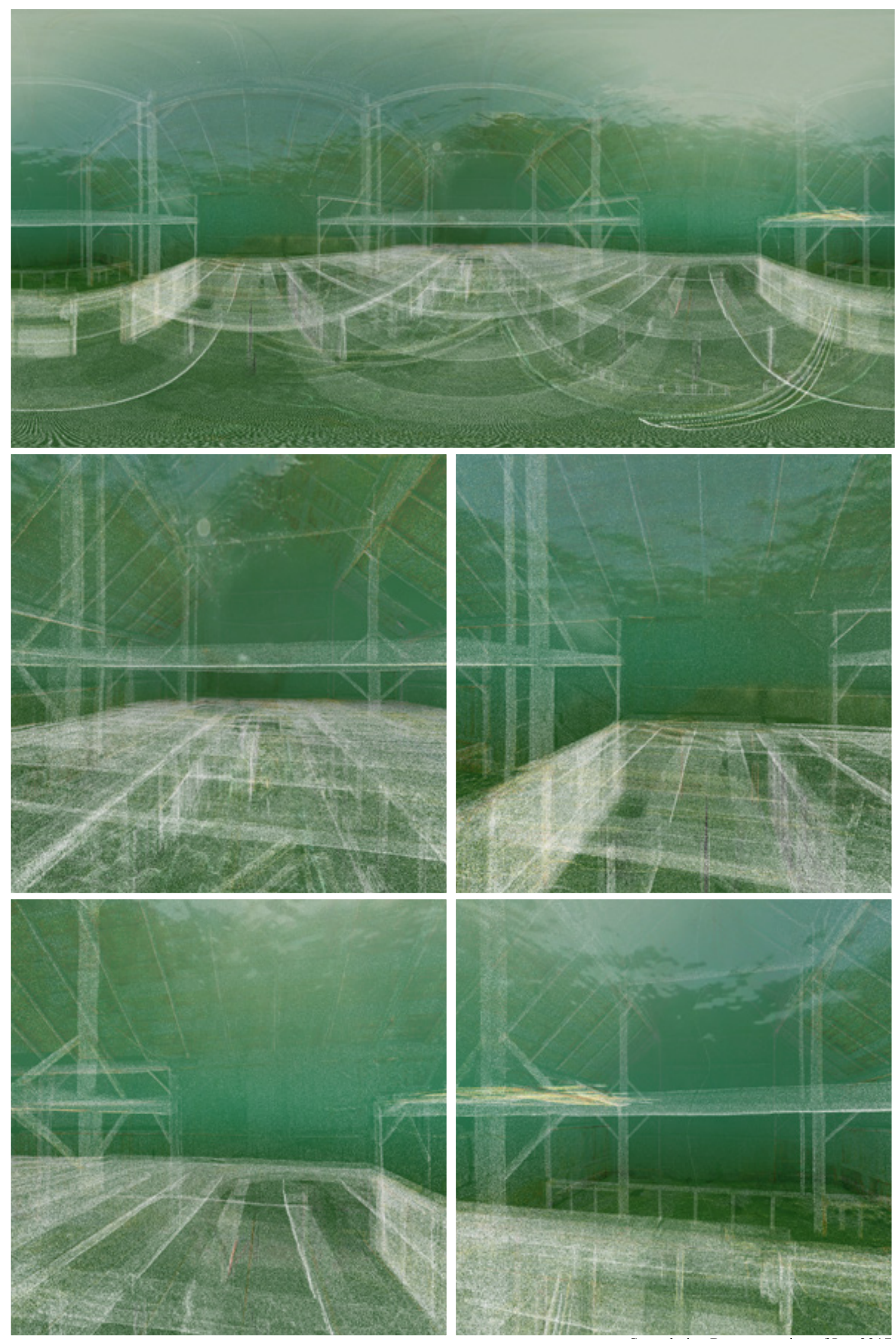

Speculative Reconstruction of Lot 3317 

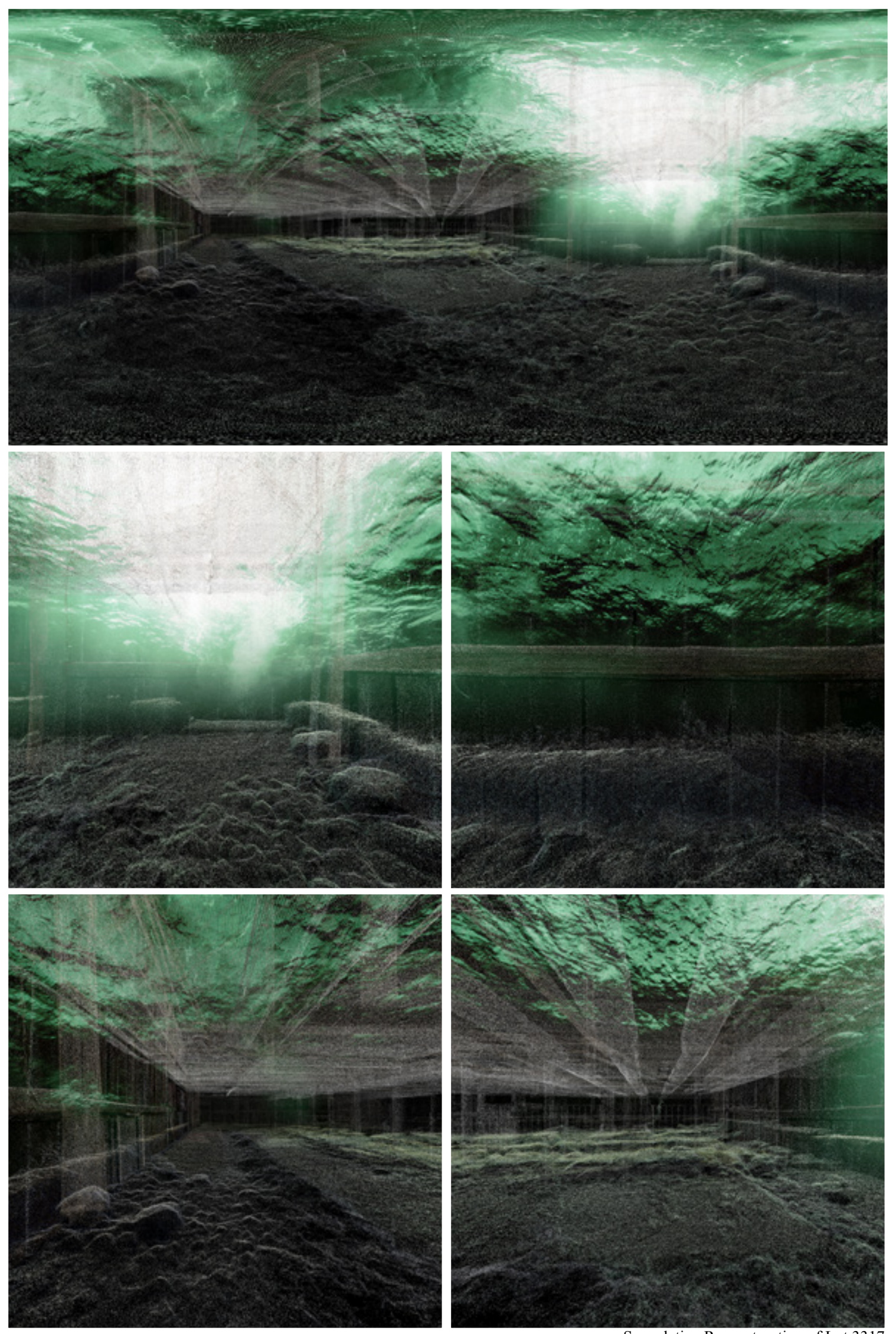

Speculative Reconstruction of Lot 3317 

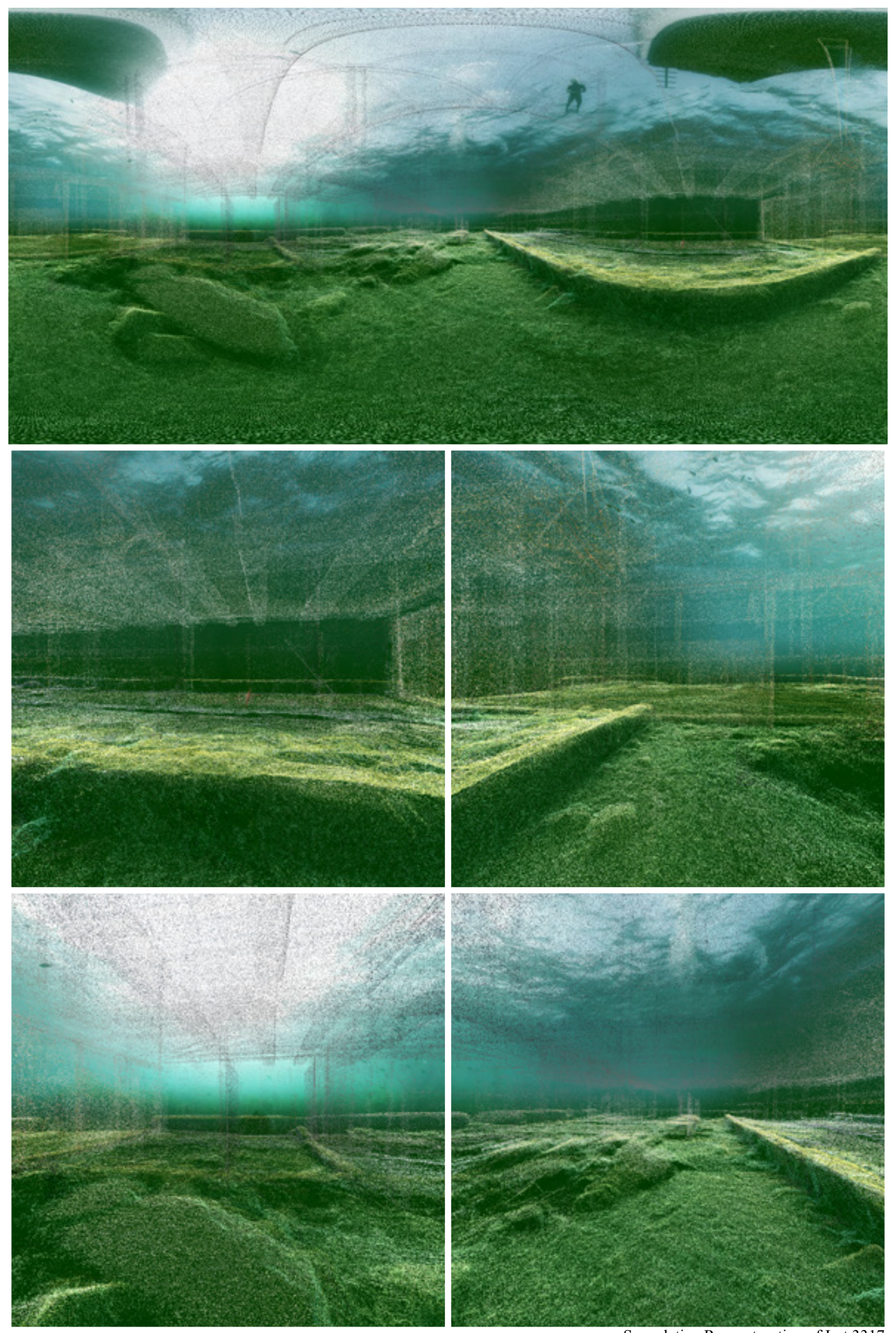

Speculative Reconstruction of Lot 3317 


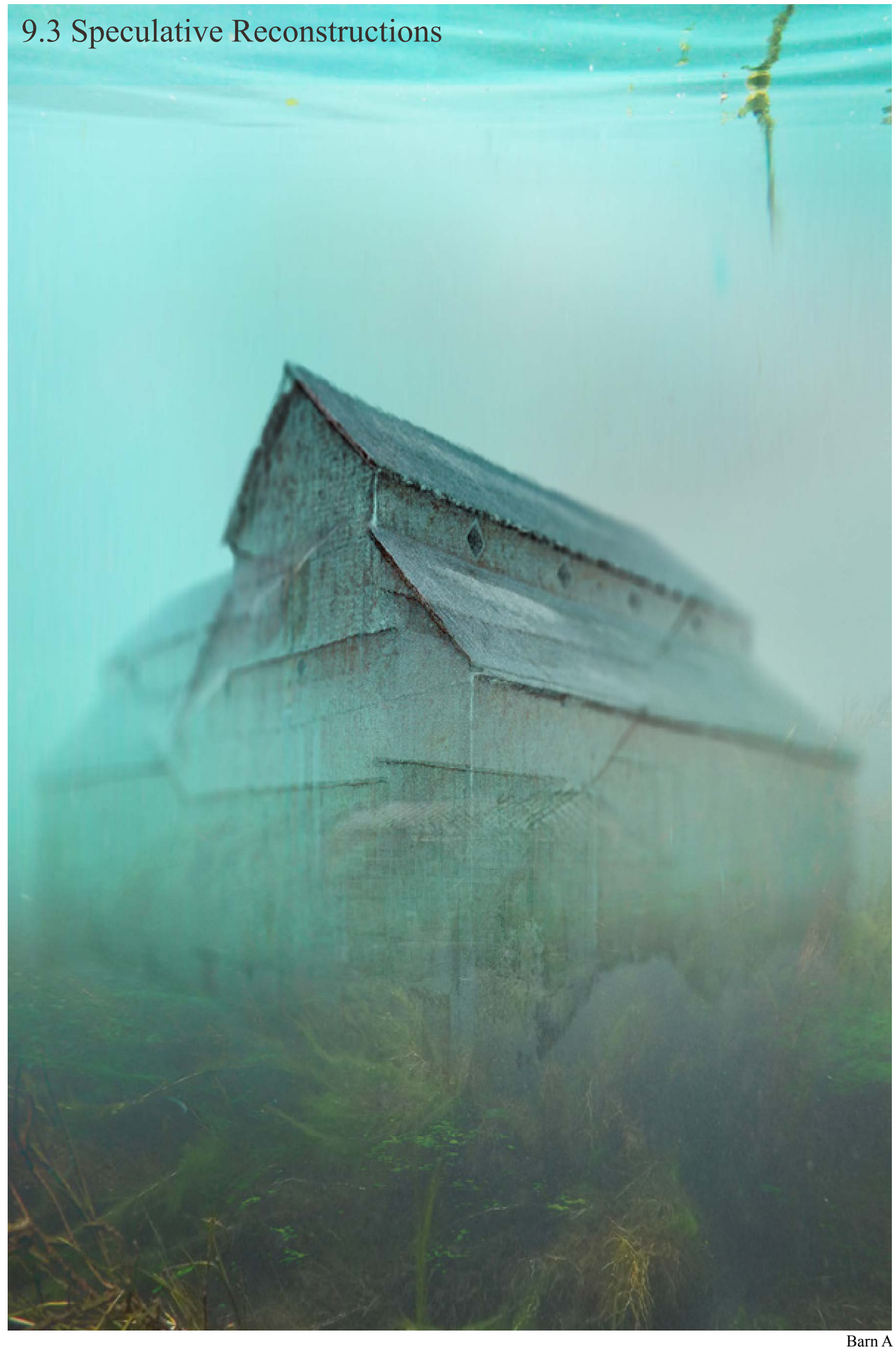




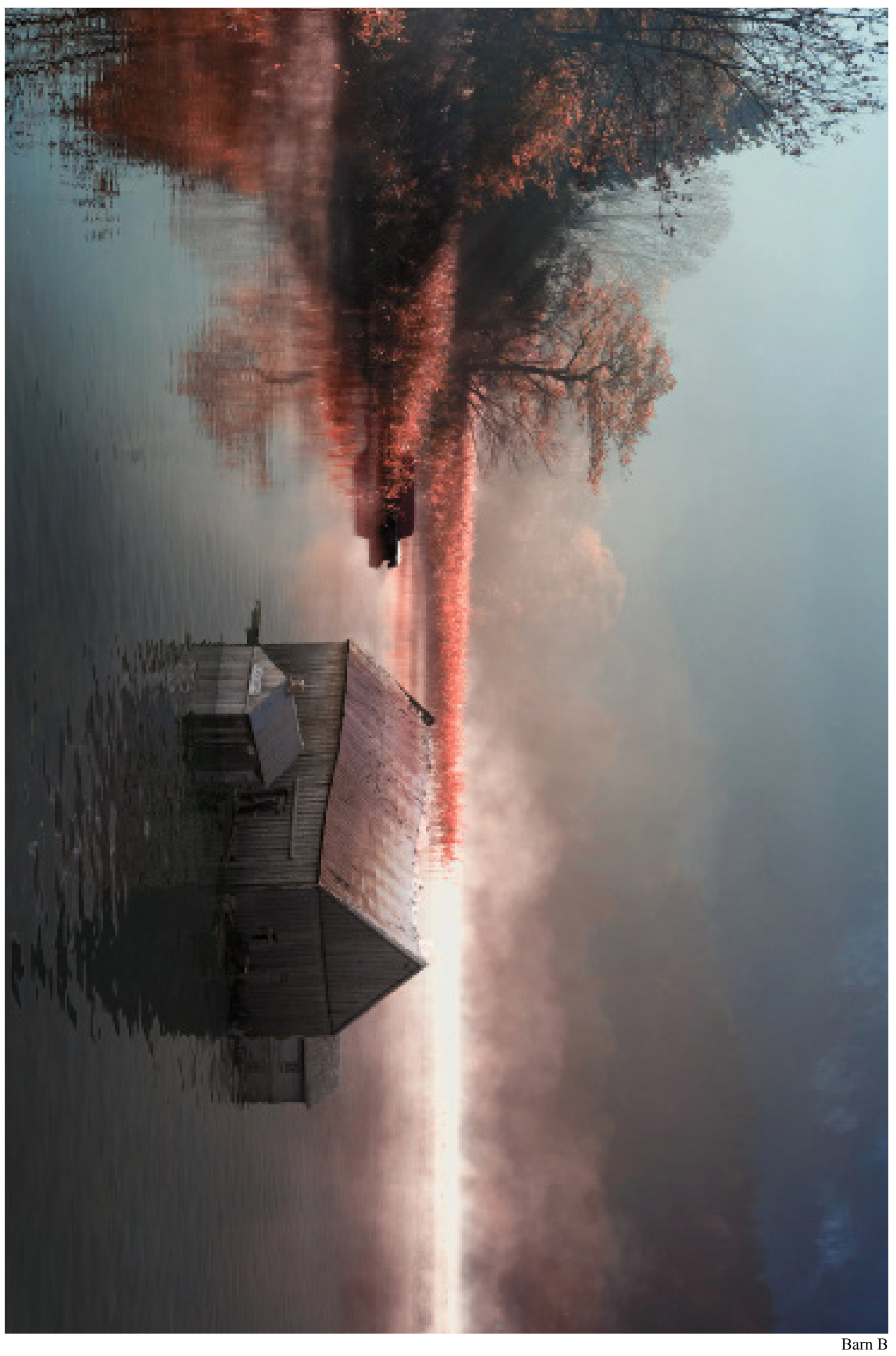




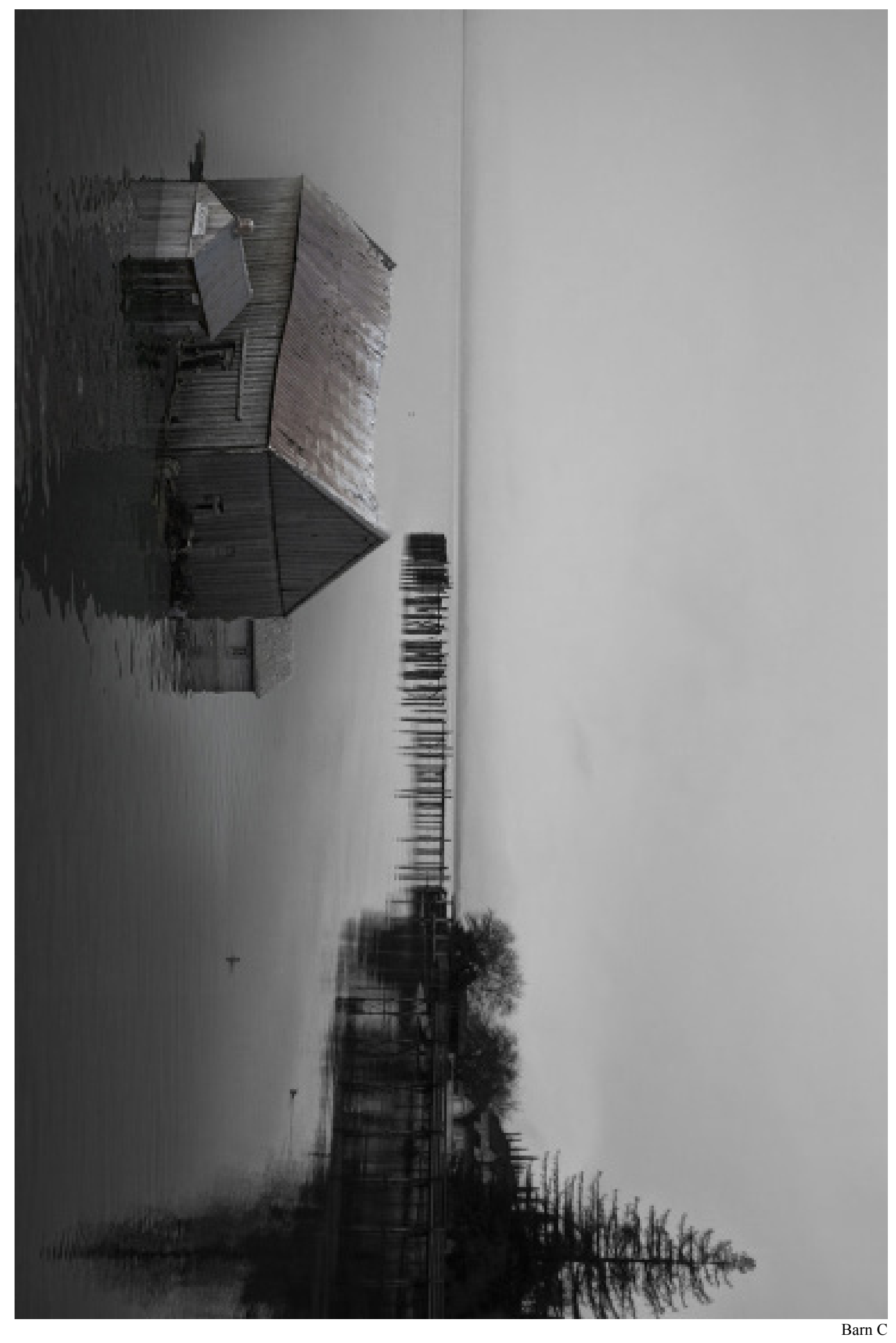




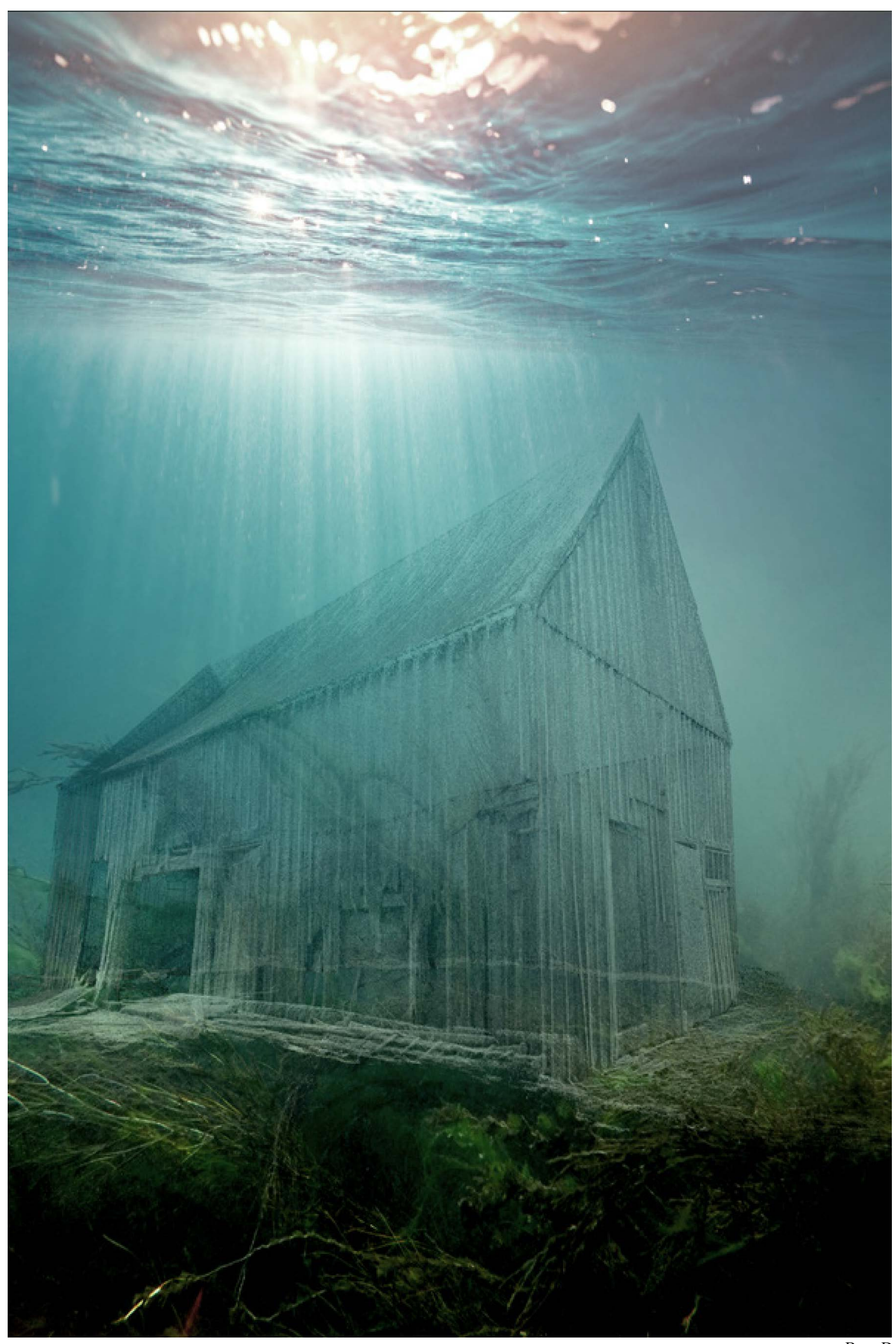




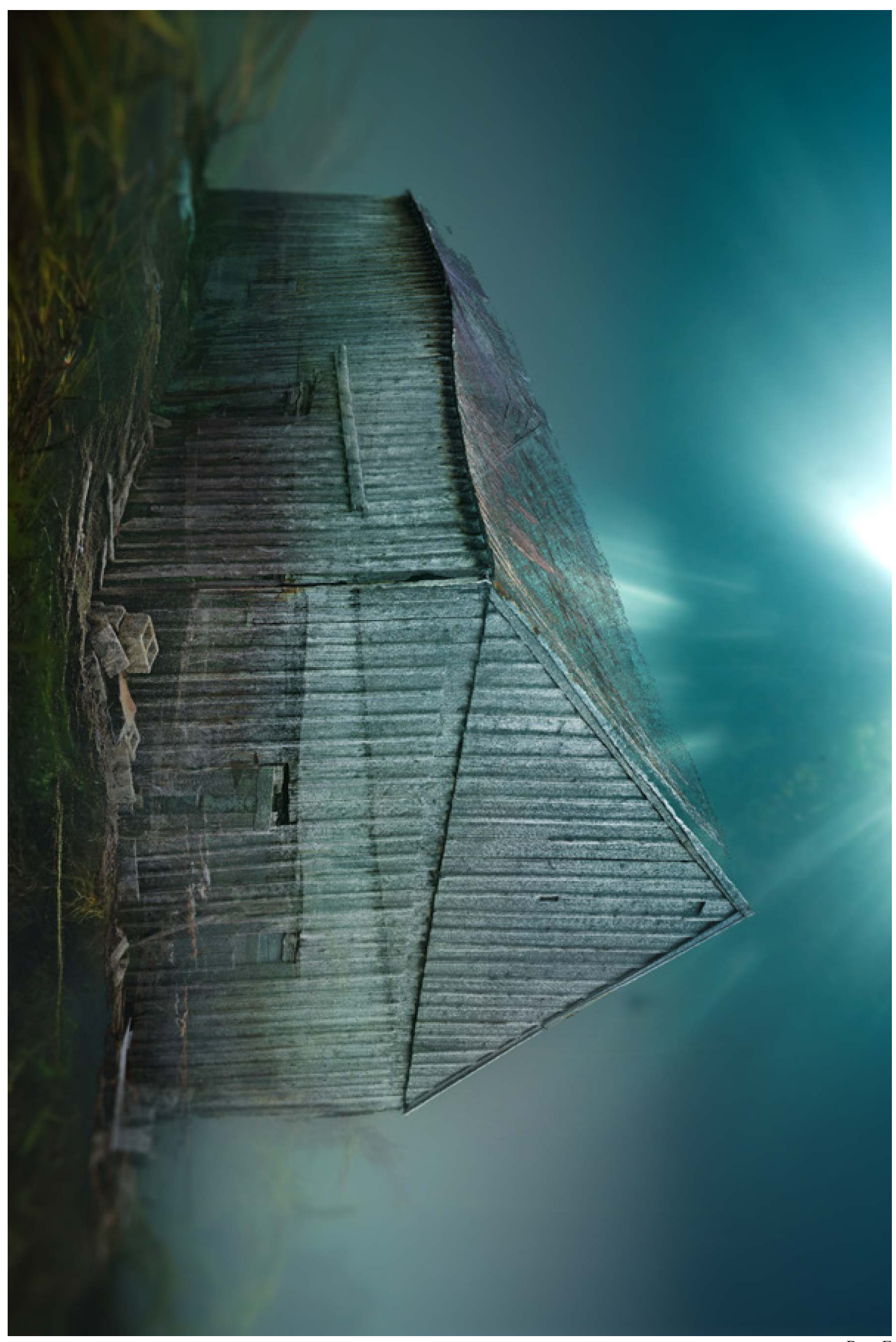




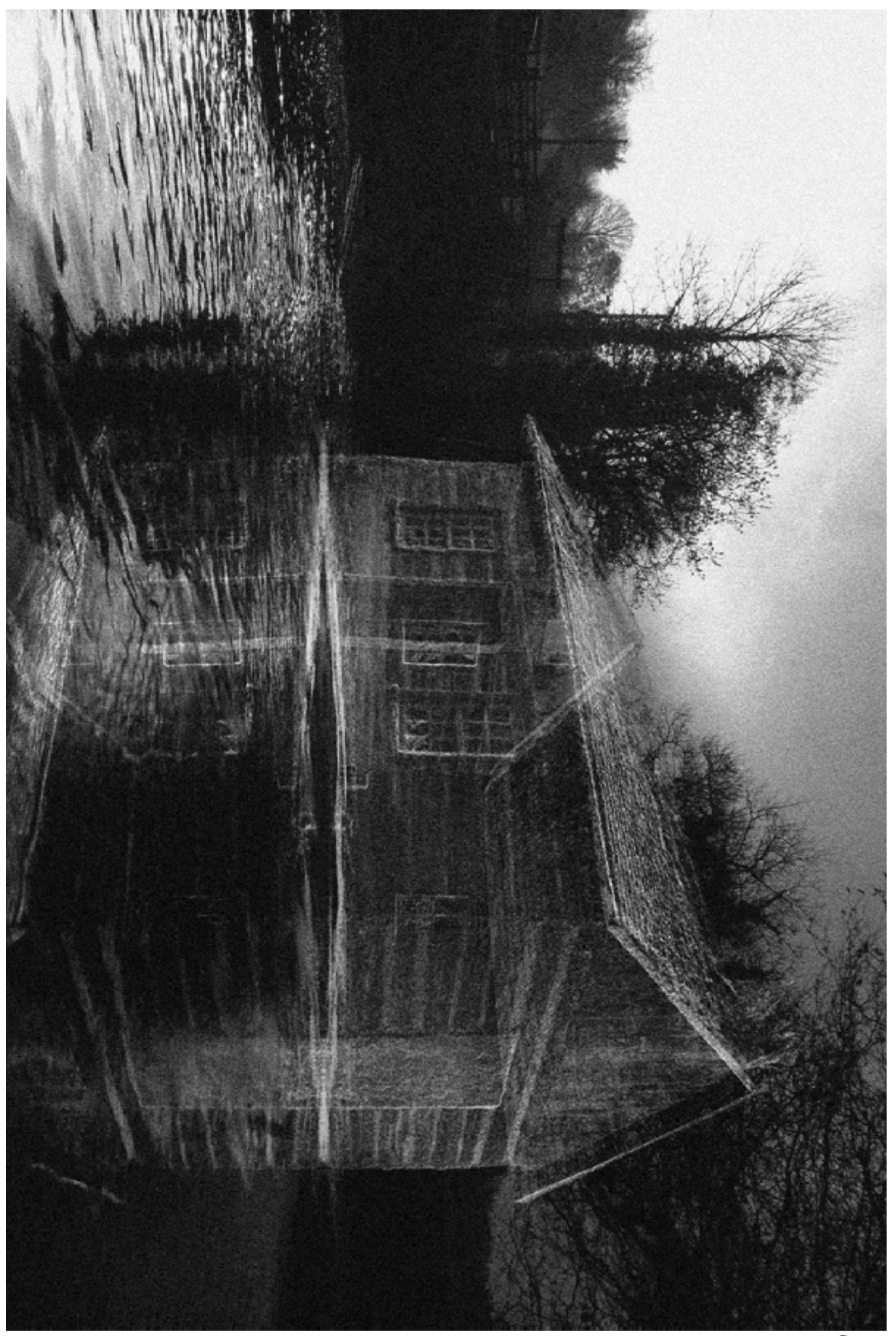




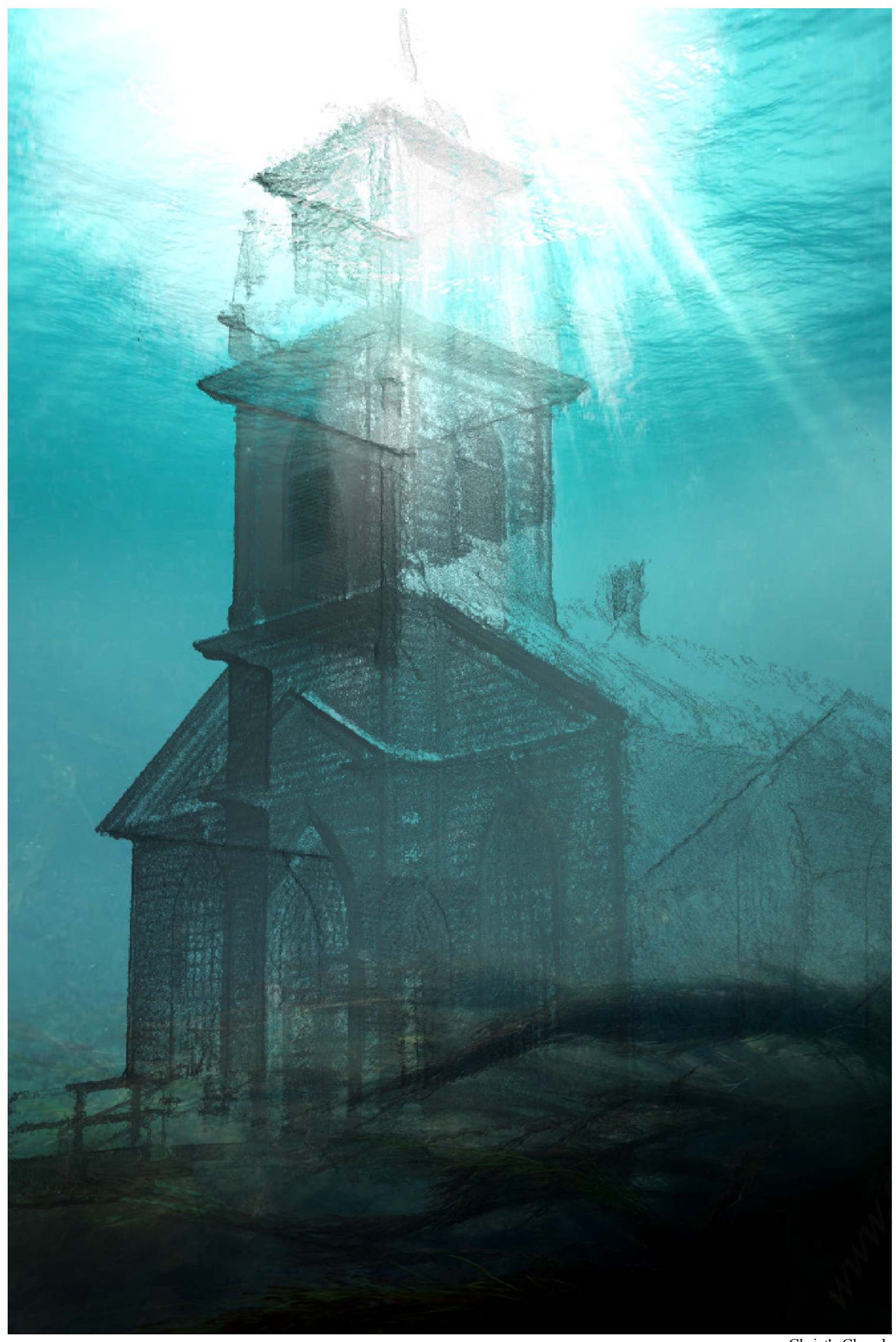




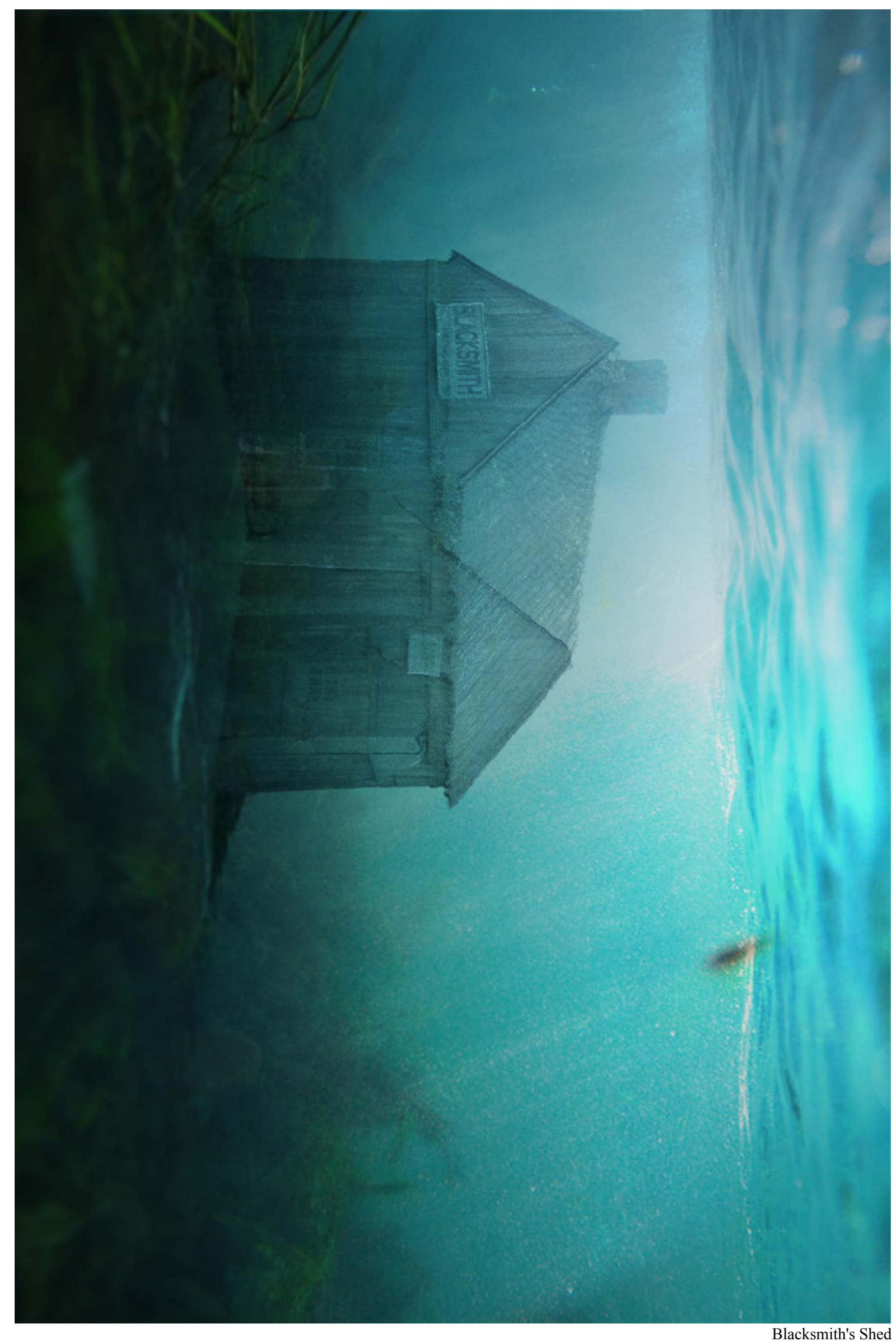




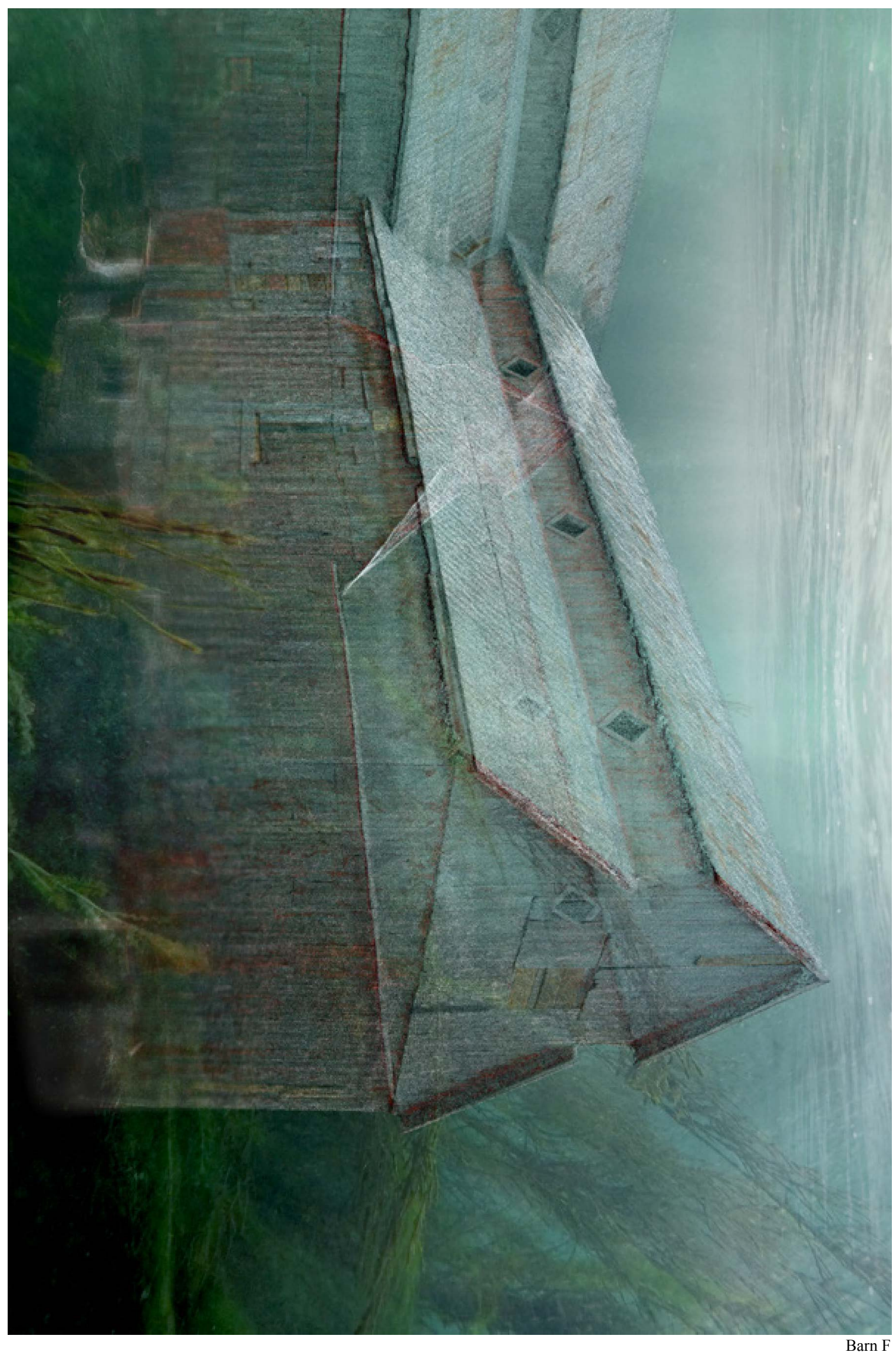




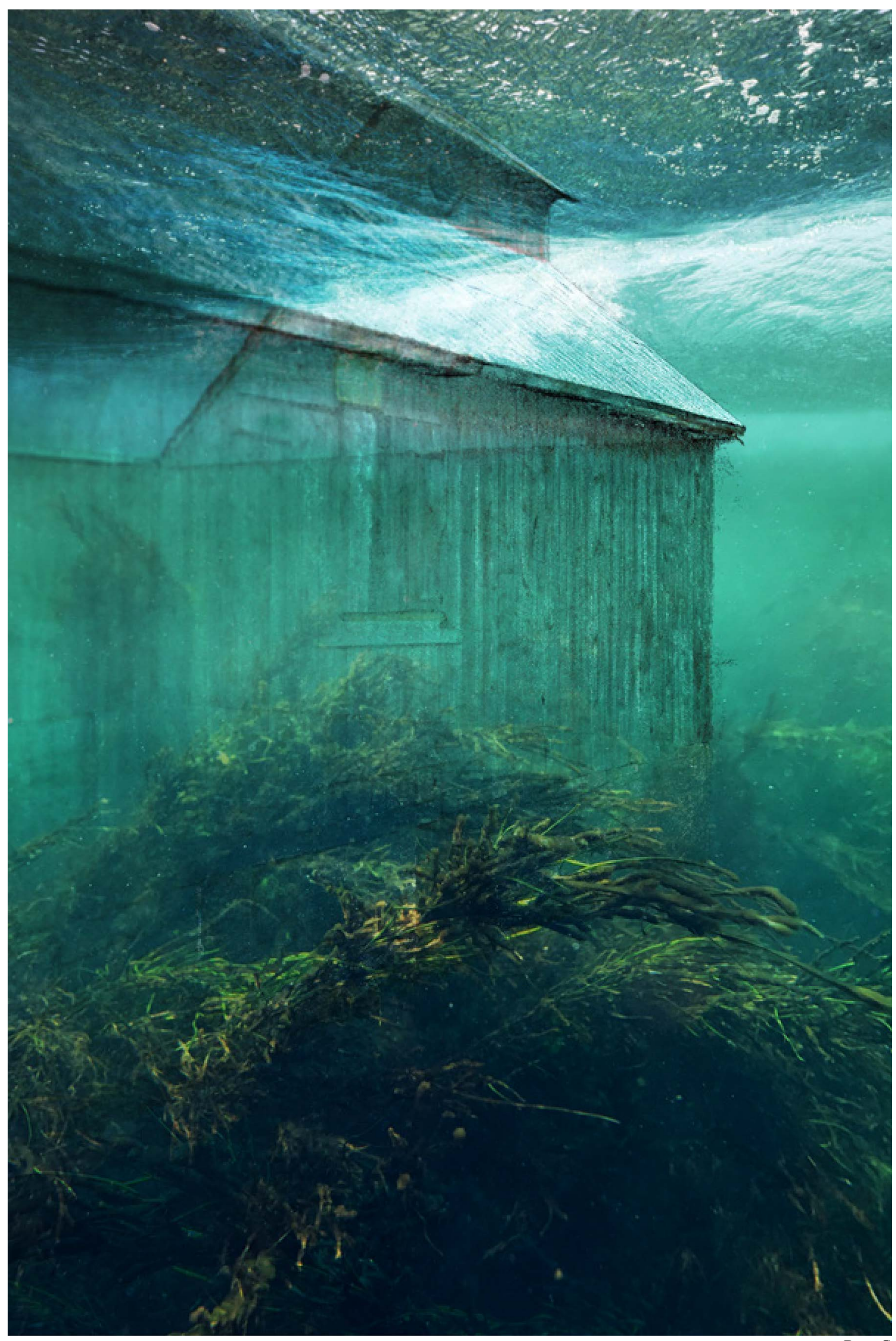




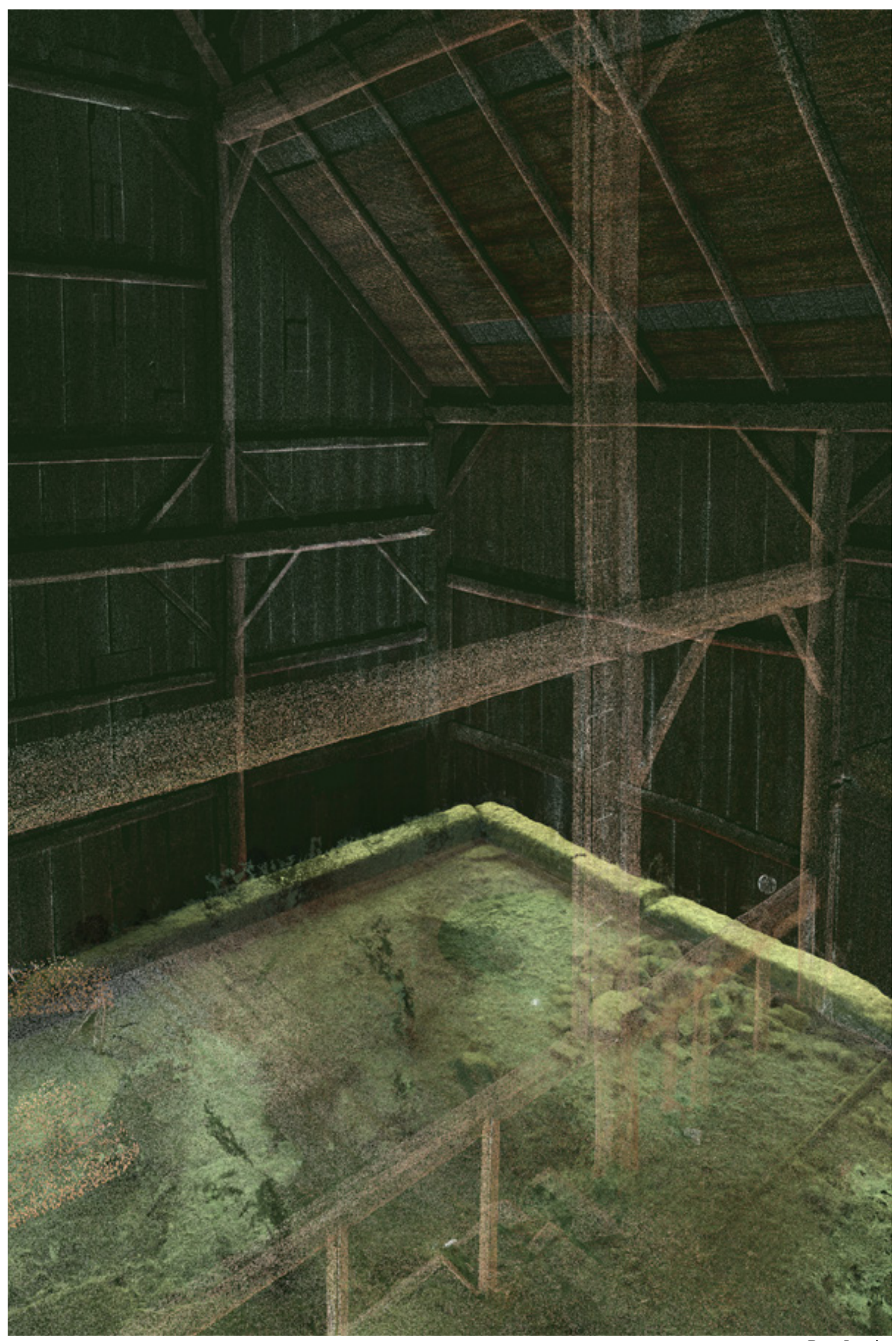




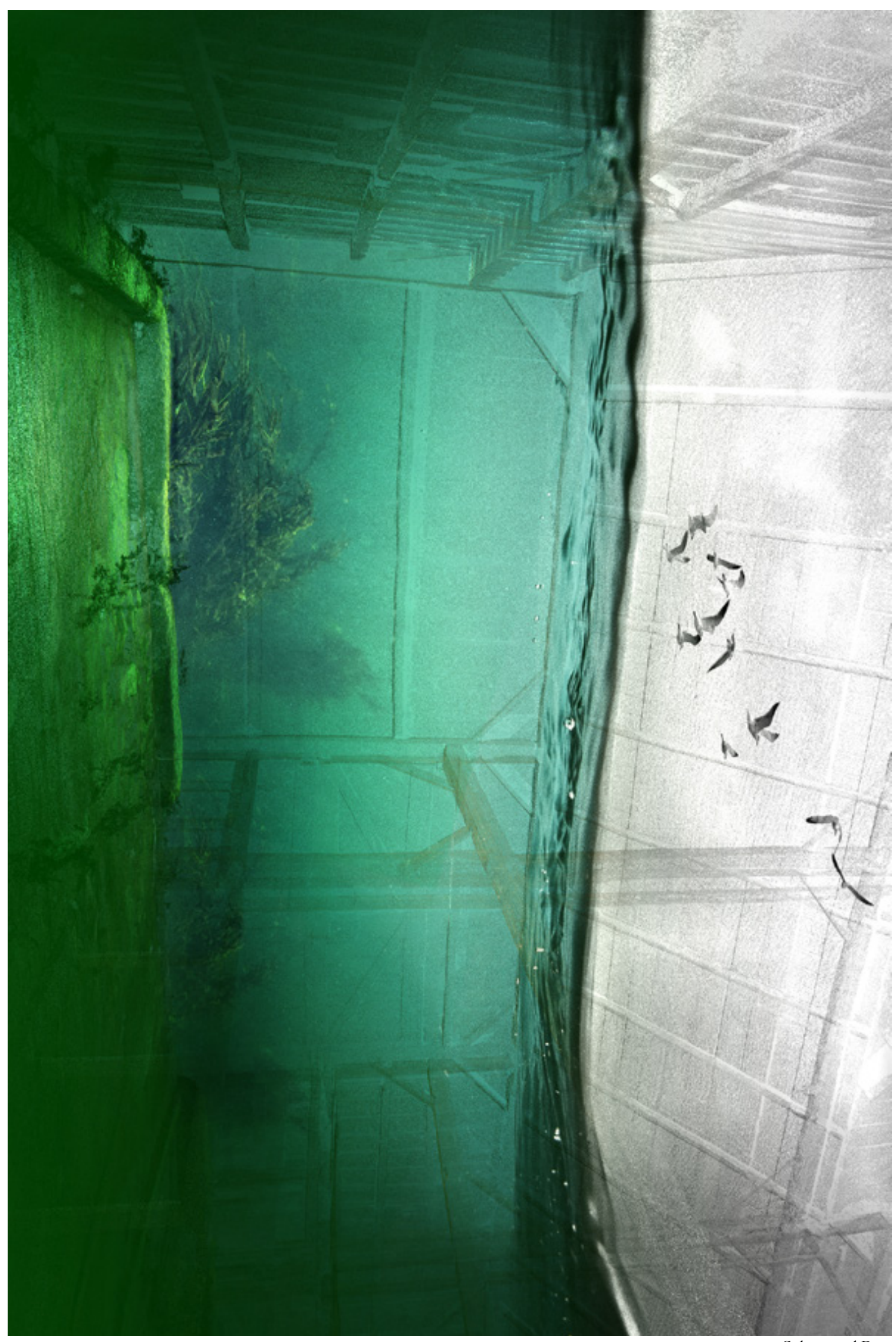




\subsection{Identifying Assets}




\subsection{Identifying Assets: Introduction}

Founded in 1961, Upper Canada Village (UCV) is one of the largest living-history sites in Canada. Over forty historical buildings are featured there; many moved prior to flood during the St. Lawrence Seaway and Power Project. ${ }^{2}$ In addition to UCV, The Lost Villages Museum consists of an additional ten heritage buildings. ${ }^{3}$ As per the Canadian Inventory of Historic Buildings, the heritage values of each building have been specified primarily by the building's program, in addition to its construction and architectural features. ${ }^{4}$ Of these collections, many building typologies have been restored into staged homes, functioning mills, taverns, churches and trades workshops.

Of the typologies mentioned, a study was conducted on 2 buildings located at Upper Canada Village, and a monument adjacent to the park was chosen as a case. Public resources such as Canada's National Air Photo Library, Google Maps and GIS data were accessed to identify the sites, as well as pair these subjects to their previous locations. Much of this research was conducted in collaboration with the Interpretive Training Program \& Historical Research Officers at Upper Canada Village, who later confirmed their origins to be correct. From this research, the sites were geo-located and 6 dive attempts were made to discover the foundations under water, all of which returned unsuccessful. The following Chapter outlines the research that was conducted prior to the site survey, followed by the research of the site that was alternatively selected.

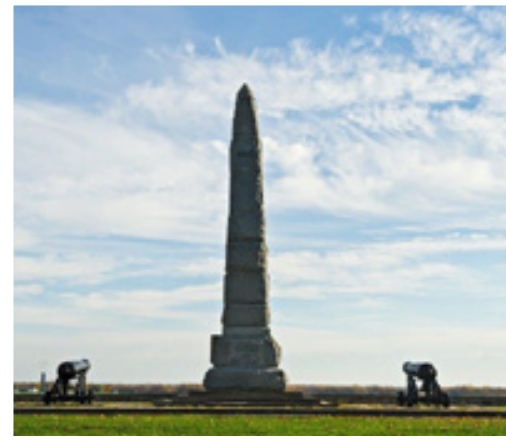

Monument

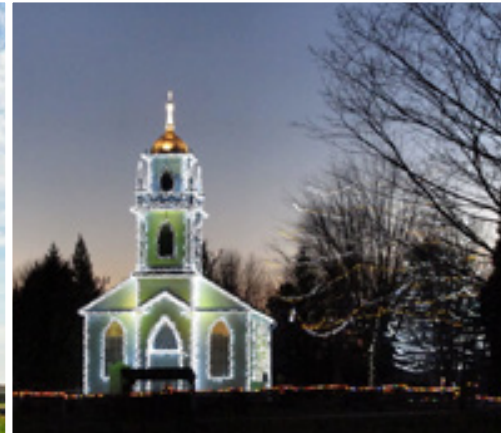

Christ's Church

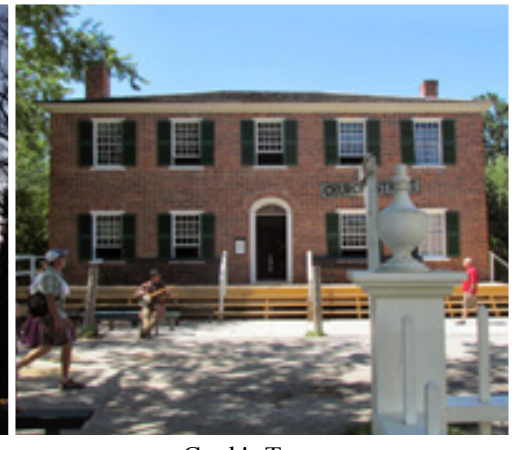

Cook's Tavern

2 https://www.uppercanadavillage.com/about-the-village

3 http://lostvillages.ca

4 Canadian Inventorv of Historic Buildinas 


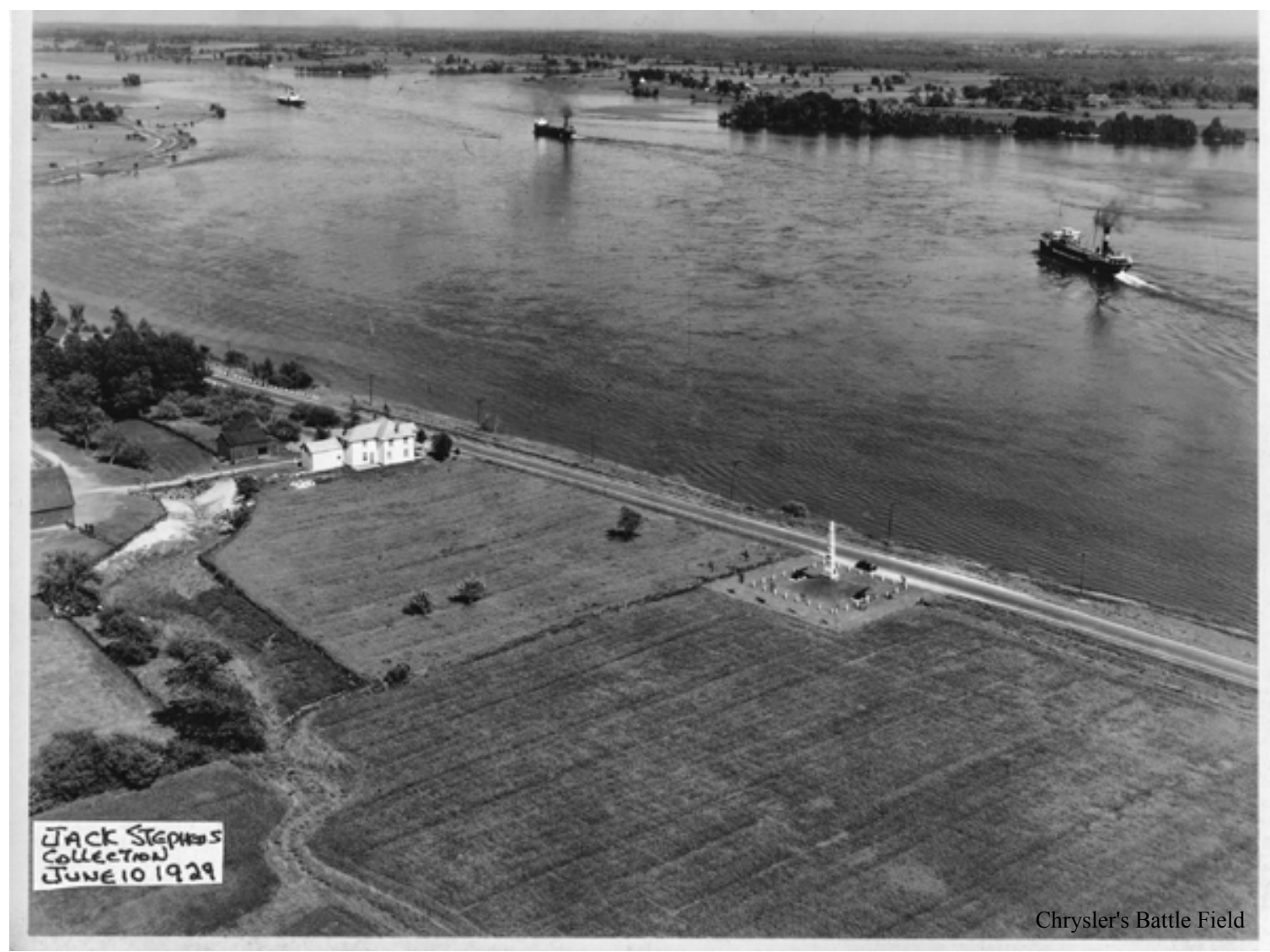

\subsection{Identifying Assets Part 1:}

\section{The Monument of Chryslers Battle Field}

The Canadian registry of historic places recognizes the Battle of Crysler's Farm National Historic Site of Canada. It is located in Crysler's Farm Battlefield Park, near Upper Canada Village, east of Morrisburg, Ontario. The battle, which took place on November 11, 1813 on farmland belonging to John Crysler, ended the American campaign for Montréal. While the original battlefield is now underwater, a grassy knoll made from earth removed from the original site and a commemorative monument consisting of an obelisk surrounded by a rectangle of flagstones and two flanking guns on garrison carriages together comprise the historic site. Unfortunately, due to the scale of this site and the lack of identifiable features, it was not chosen as a case study. 


\subsection{Identifying Assets Part 1: The Christ's Church}

The Christ Church was built in 1837 in a picturesque style. The main character defining elements of the building are the pointed Gothic window arches and decorative trim, the tower is also to be noted, as it reflects the sense of order, symmetry and balance known to 18th century classicism. ${ }^{5}$ In addition to the architectural heritage, the Church's Narrative may also prove to be of cultural value. The land for the church and the financial support for its construction were donated to The Church of England, congregation of Moulinette, by Adam Dixson (a wealthy, local miller).

The first service conducted in the church (before it was completed) was for his wife's funeral, and within a year, his own funeral service had also taken place. In addition to this, the church ground also housed a cemetery that contained 46 graves. Many grave sites were not relocated during the flood, as per the wishes of the family members. Fortunately, church was proven to be of historic value and successfully relocated at Upper Canada Village. It is now re-purposed as a venue to facilitate events.

Unfortunately, the original location of The Christ's Church was inaccessible without additional training and more advanced diving equipment. The site is located in a depth of over $15 \mathrm{~m}$ and the area is overgrown with large beds of vegetation. With this in mind, even if the foundation and grave sites were identified, the low level of light and the movement of the sea weed would prove to be problematic for capturing good quality images with the available equipment. In addition to this, the current in this area was quite strong which would make the process of capturing data extremely difficult.

5 https://www.uppercanadavillage.com/about-the-village 


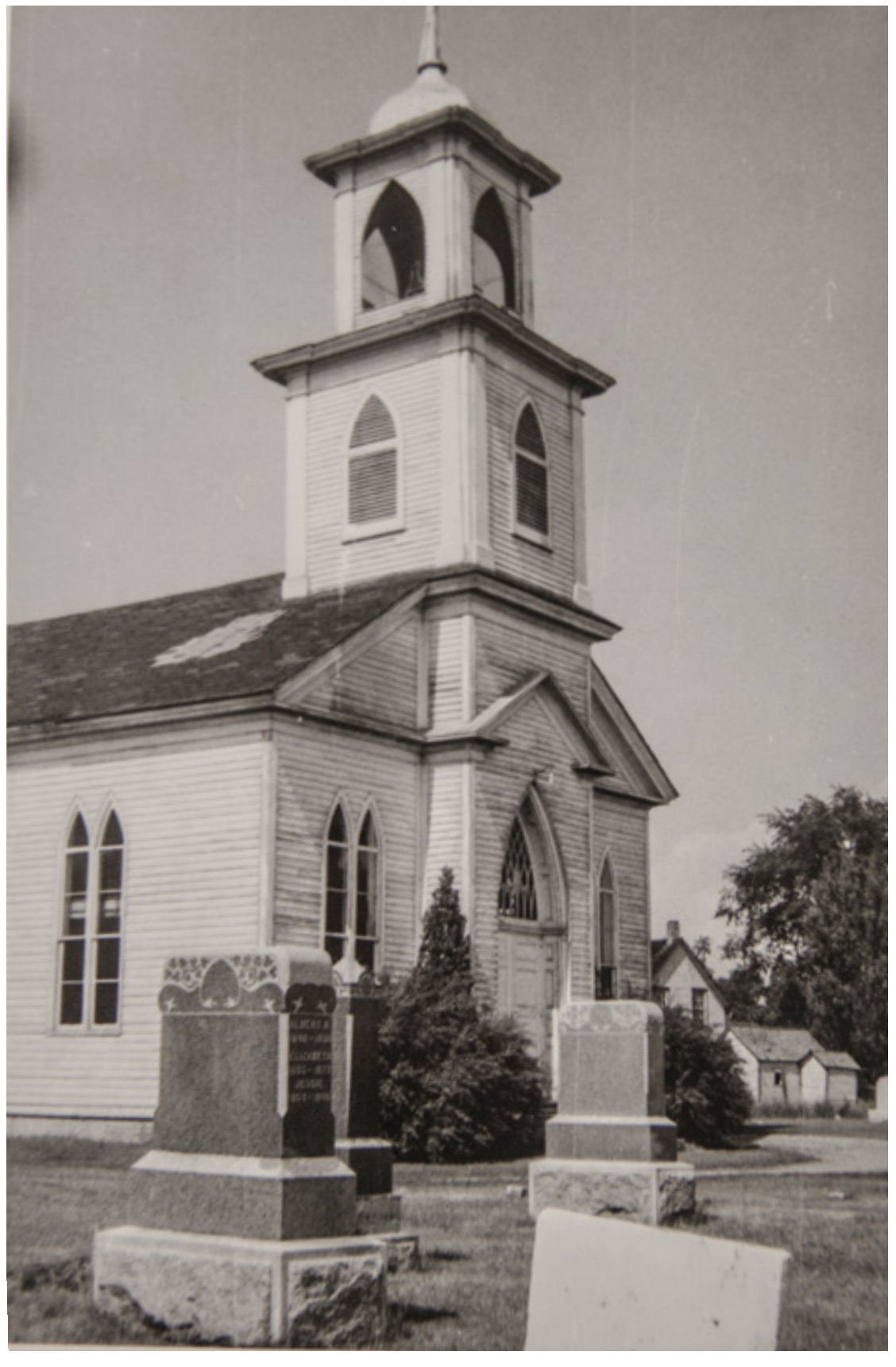

Christ's Church Graveyard 

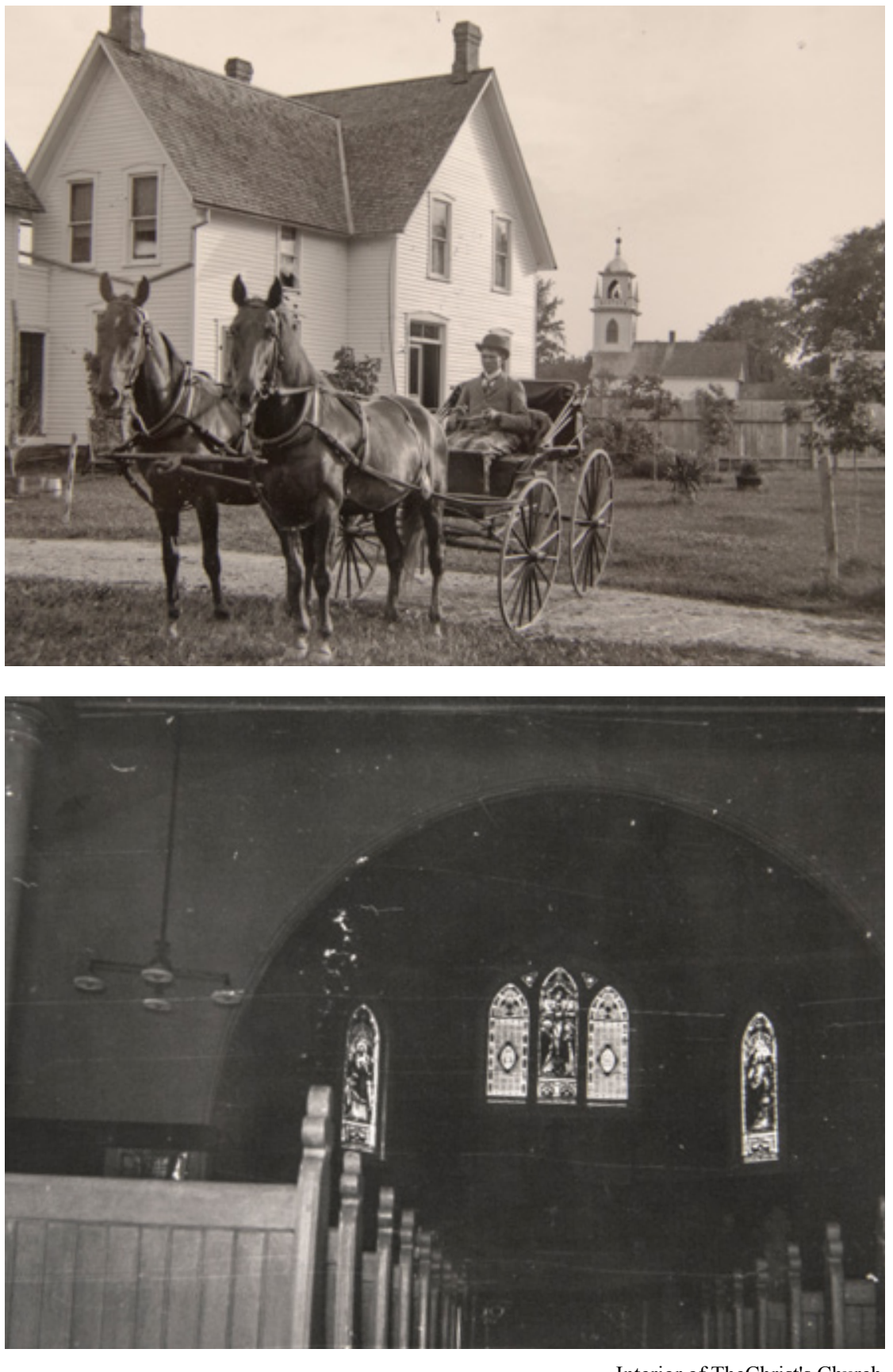

Interior of TheChrist's Church 

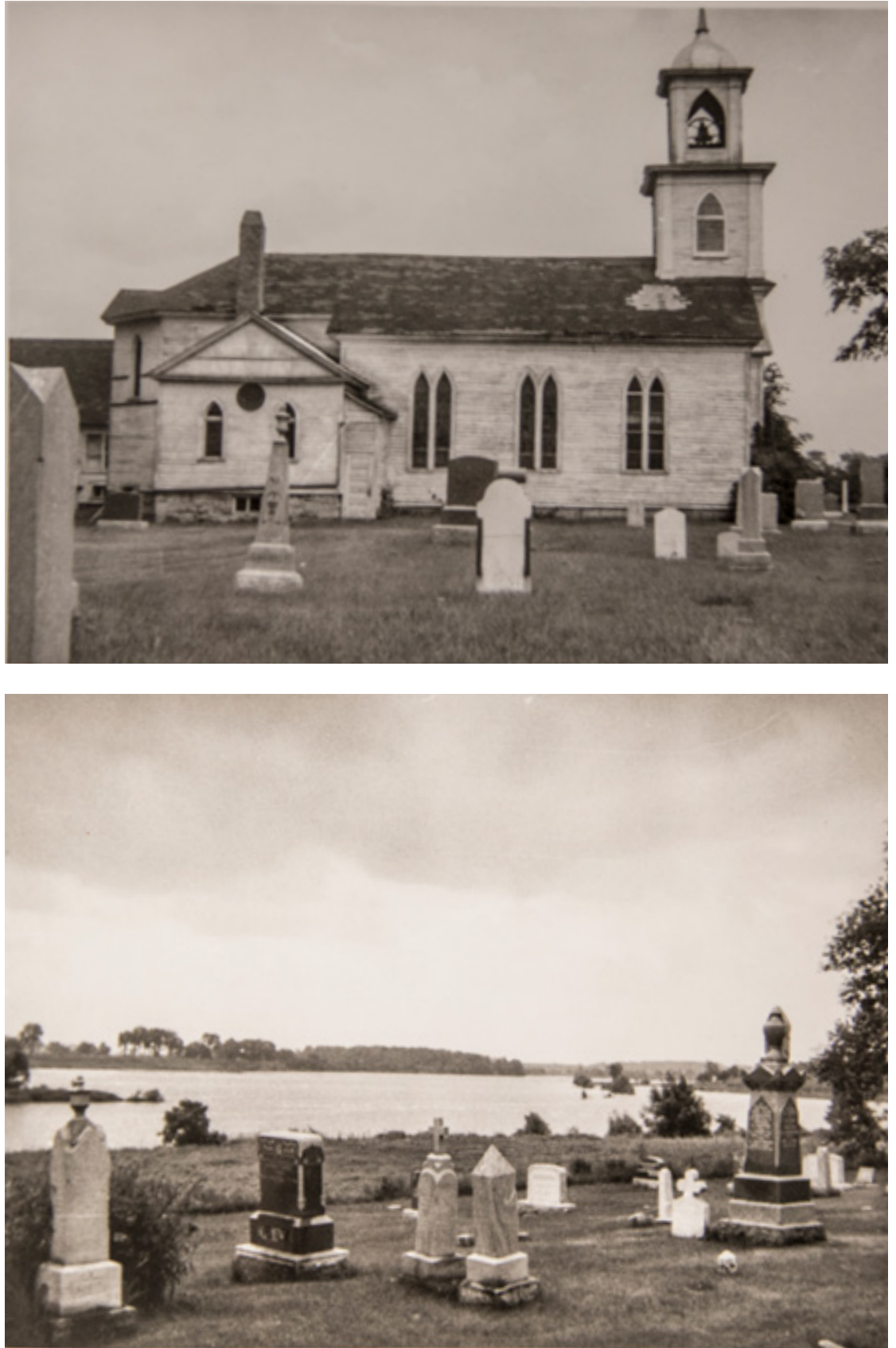

Christ's Church Graveyard 


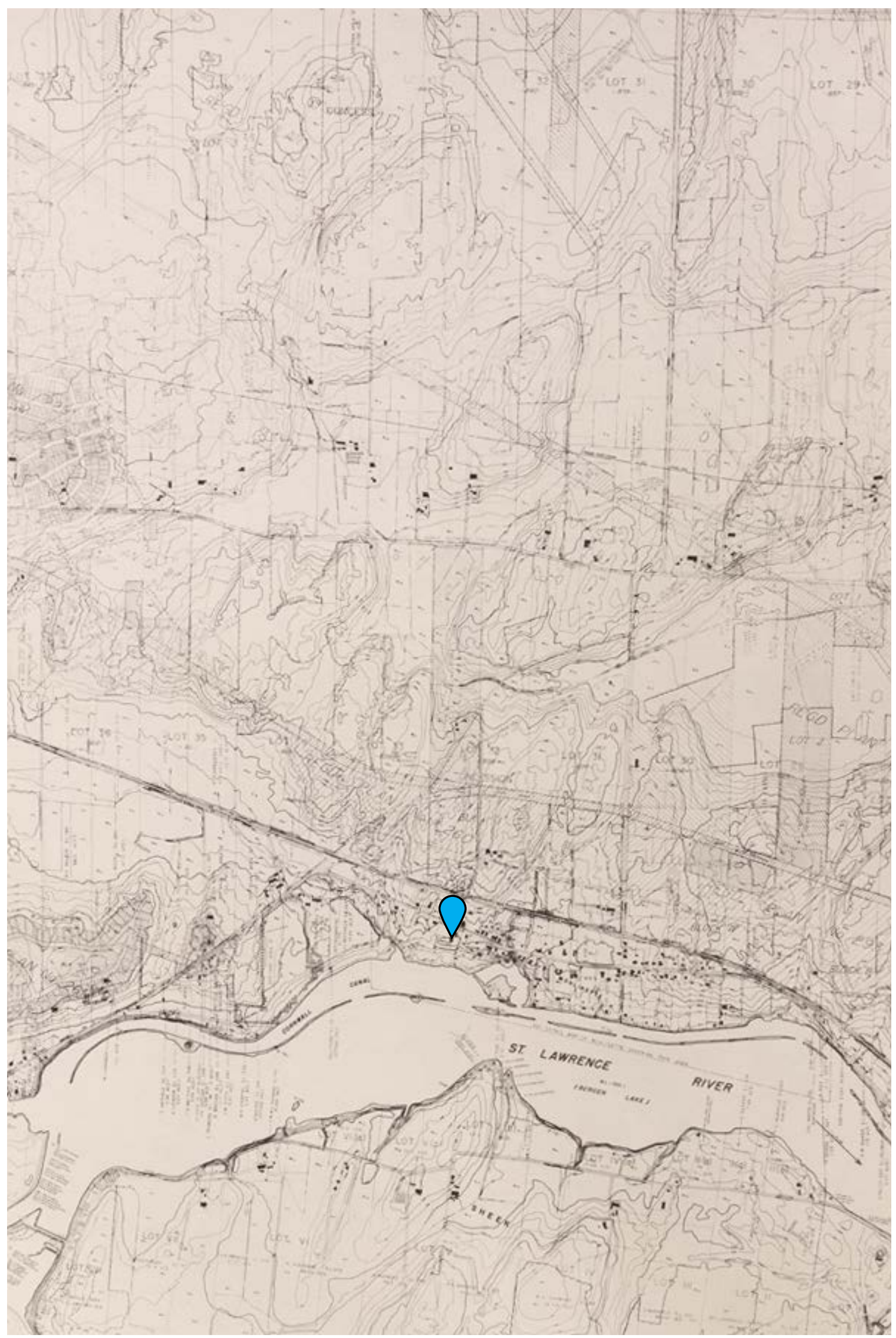




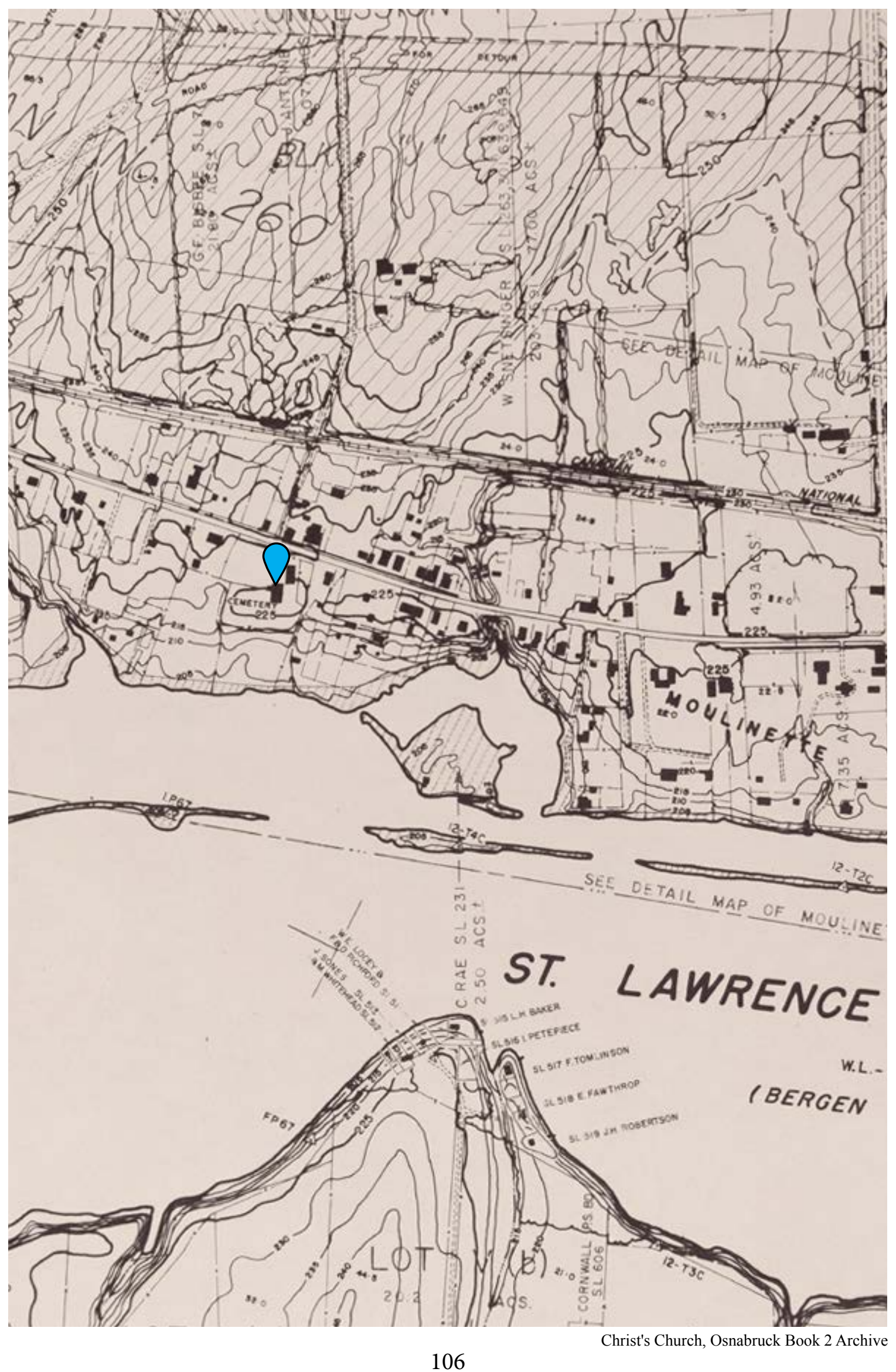




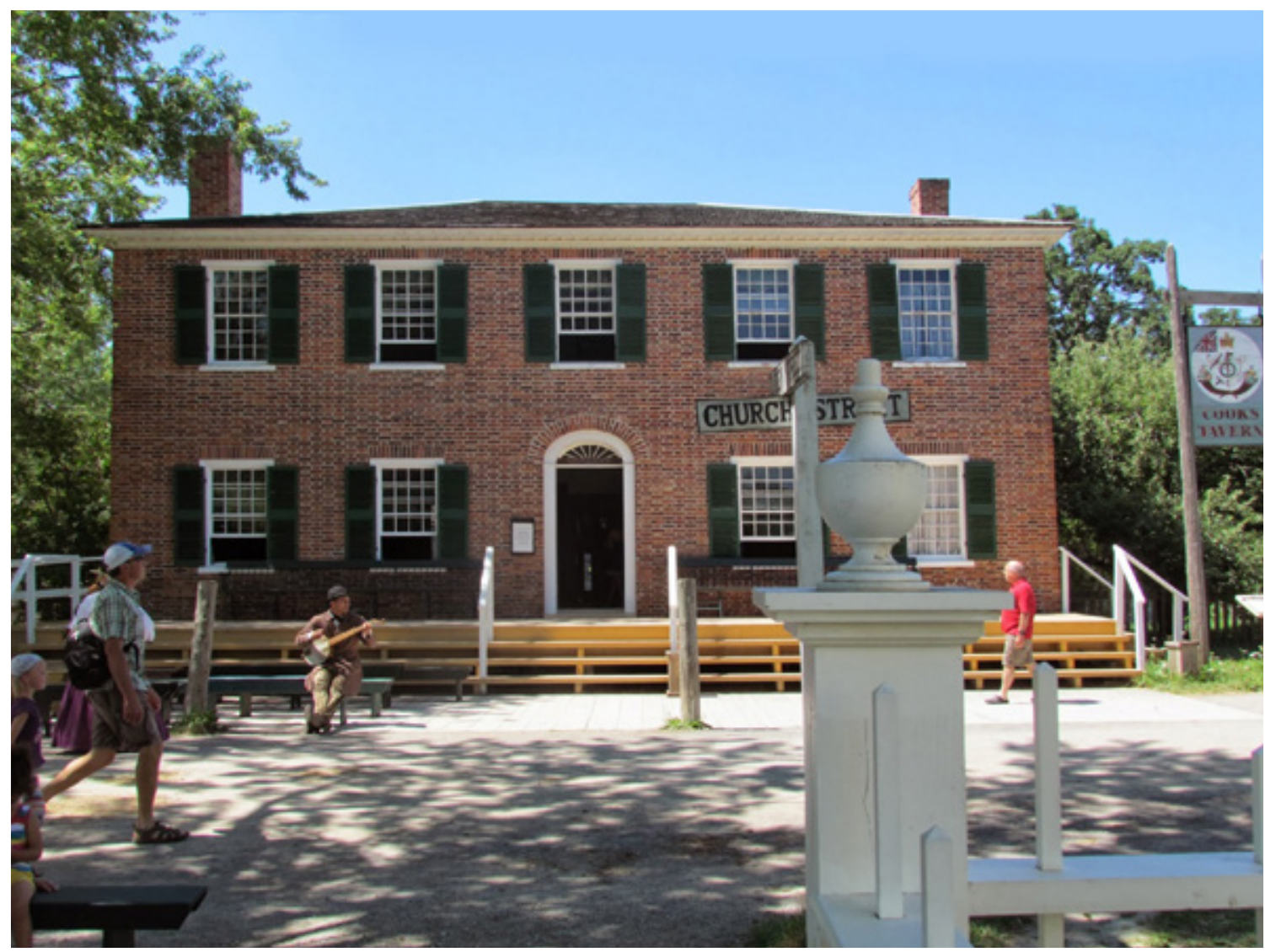

\subsection{Identifying Assets Part 1: Cook’s Tavern}

Cook's Tavern

The Cook's Tavern was relocated to at Upper Canada Village and its current resting place in 1956. Research conducted in collaboration with the archival staff suggested that it was originally built sometime between 1820 and 1822 . Research also suggested that this tavern replaced an earlier tavern that was destroyed during the Battle of Crysler's Farm in 1813.The building's replacement was partly paid for by the government, in compensation for damages incurred during the war.

Similarly to The Christ Church, The Cook's tavern was located close to the old shoreline of the river, and as a result it is located quite deep. Given the constraints of this project it was determined that the digital restitution of this site would be unsafe, as it is close to the international shipping route of the seaway. 

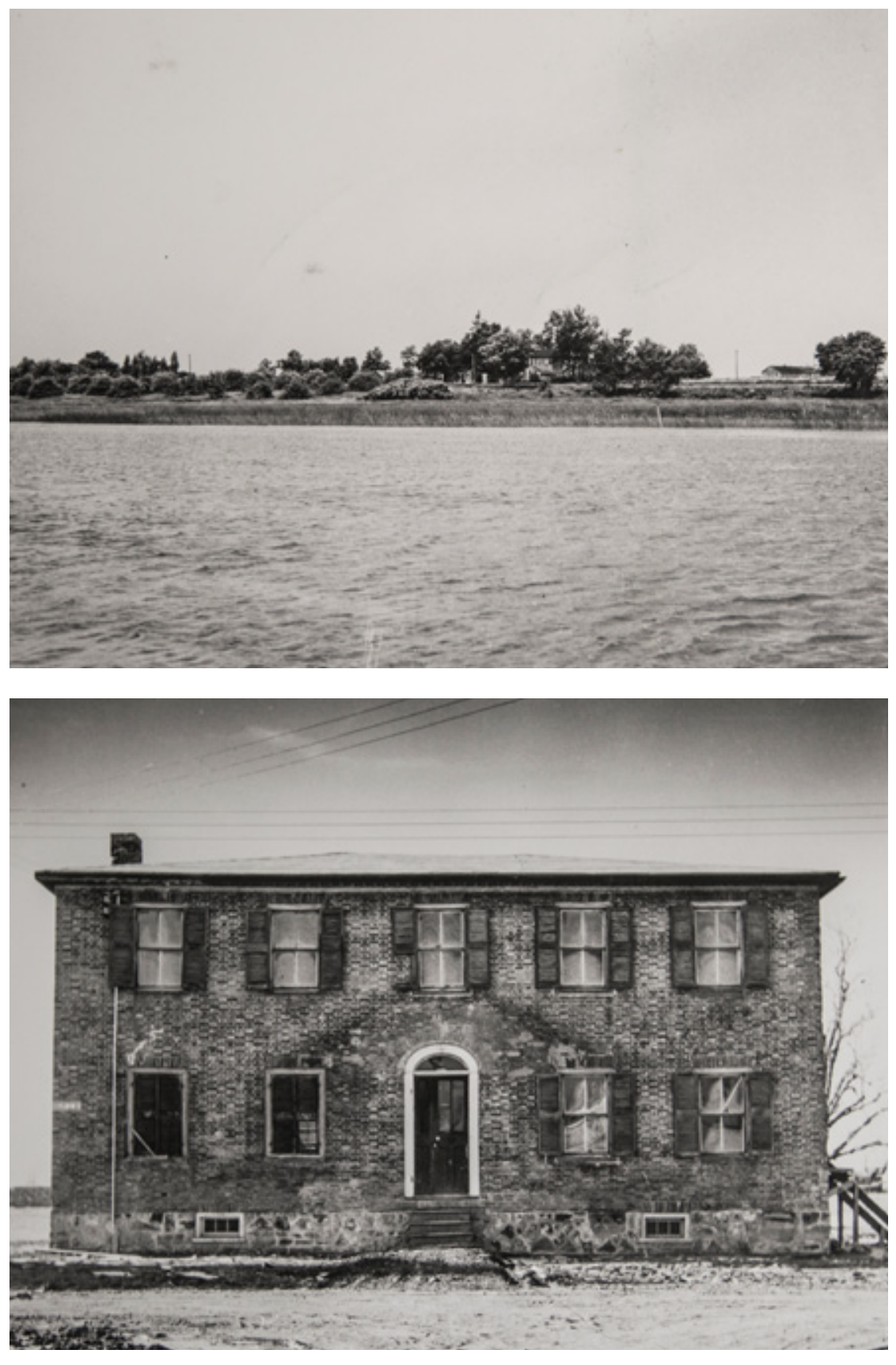

The Cook's Tavern 

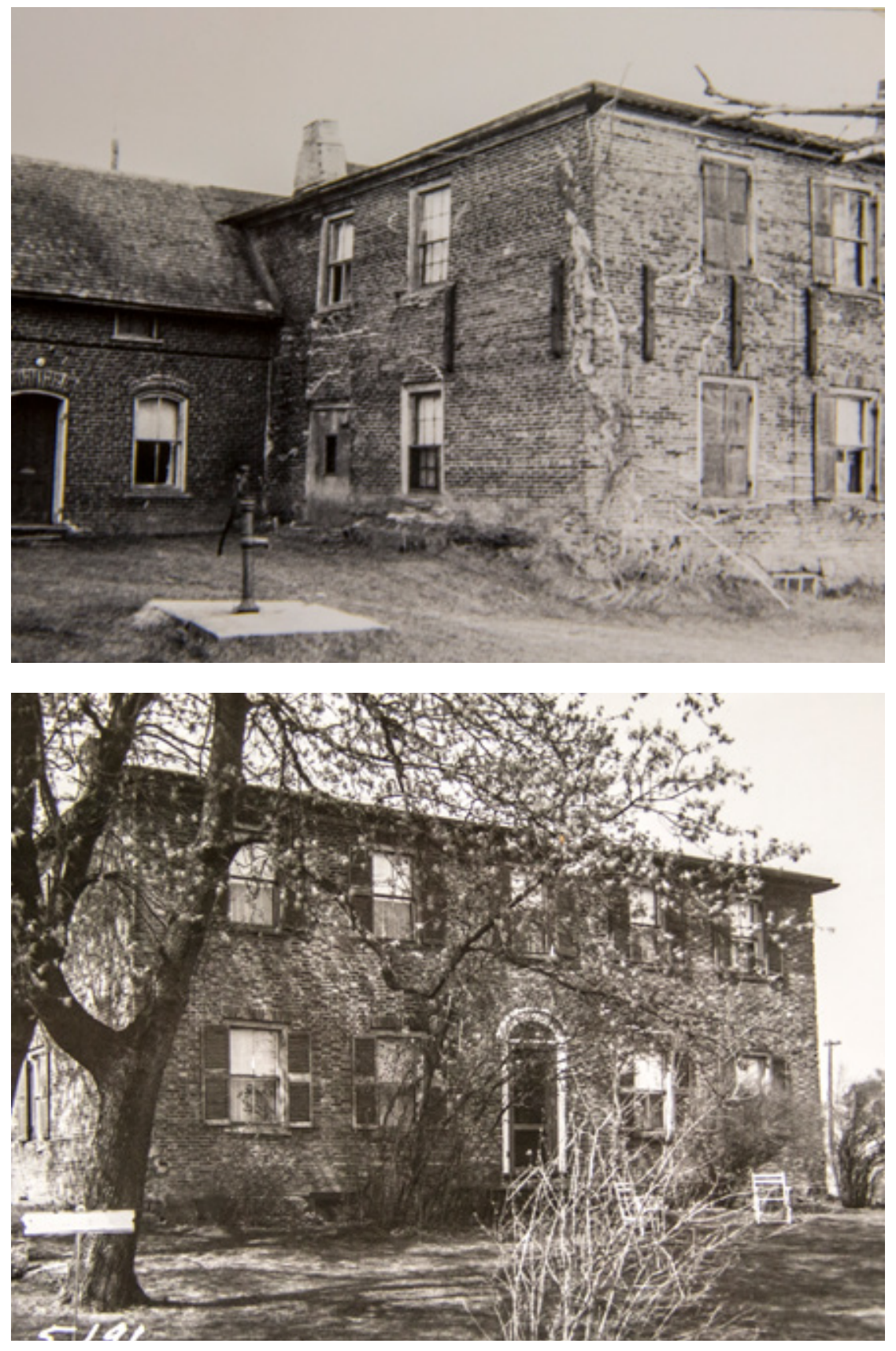

The Cook's Tavern 

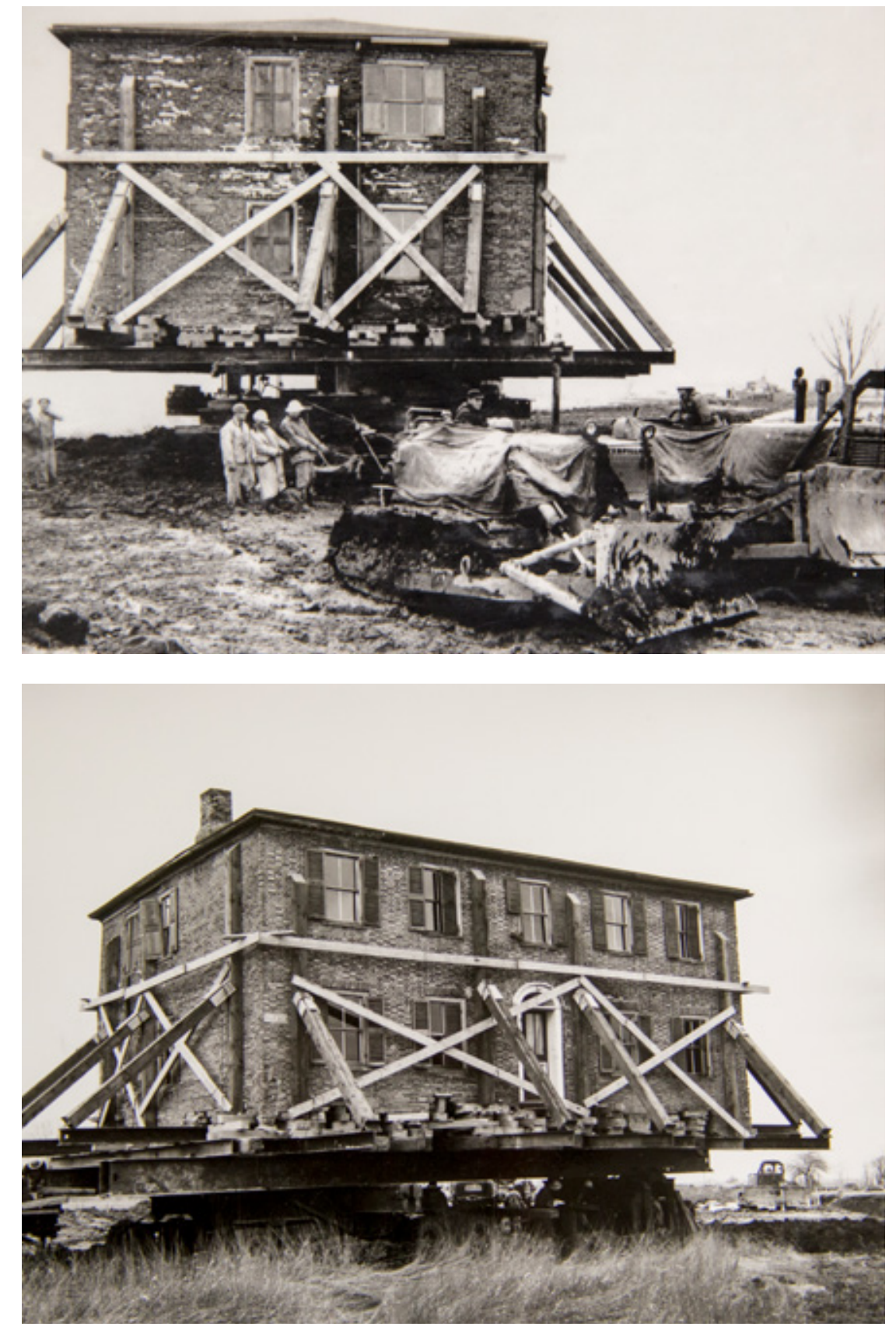

The Cook's Tavern 


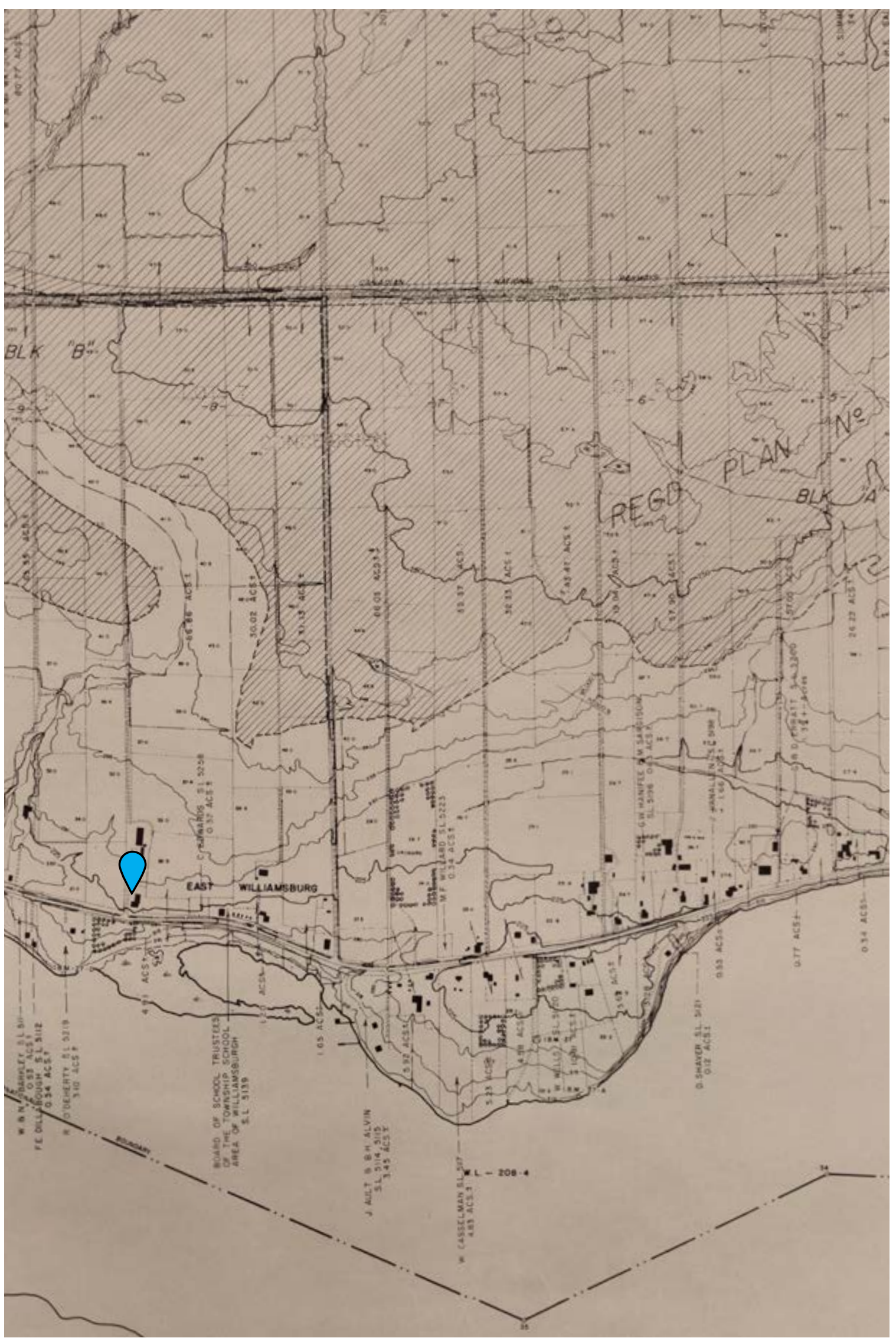




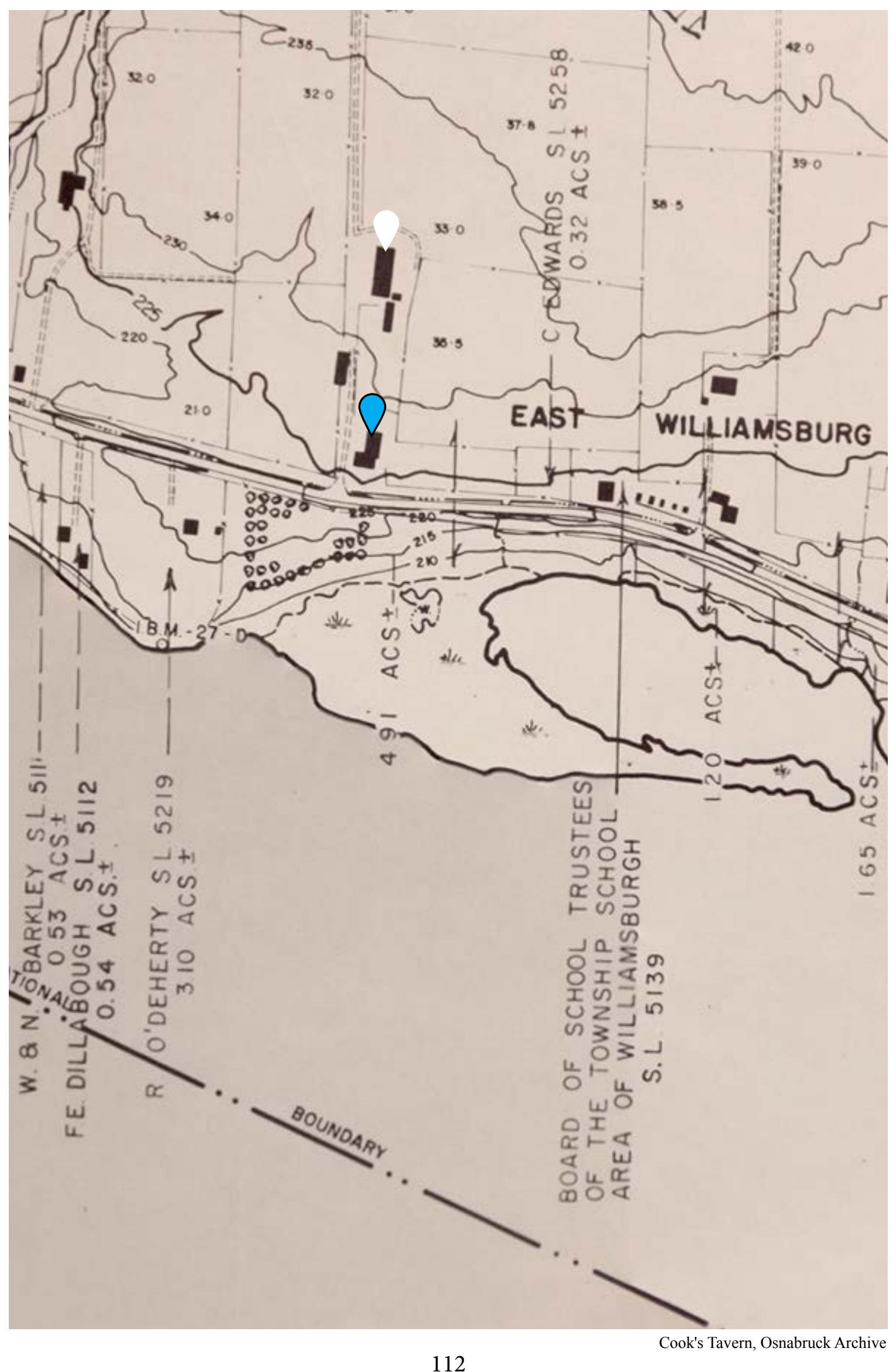




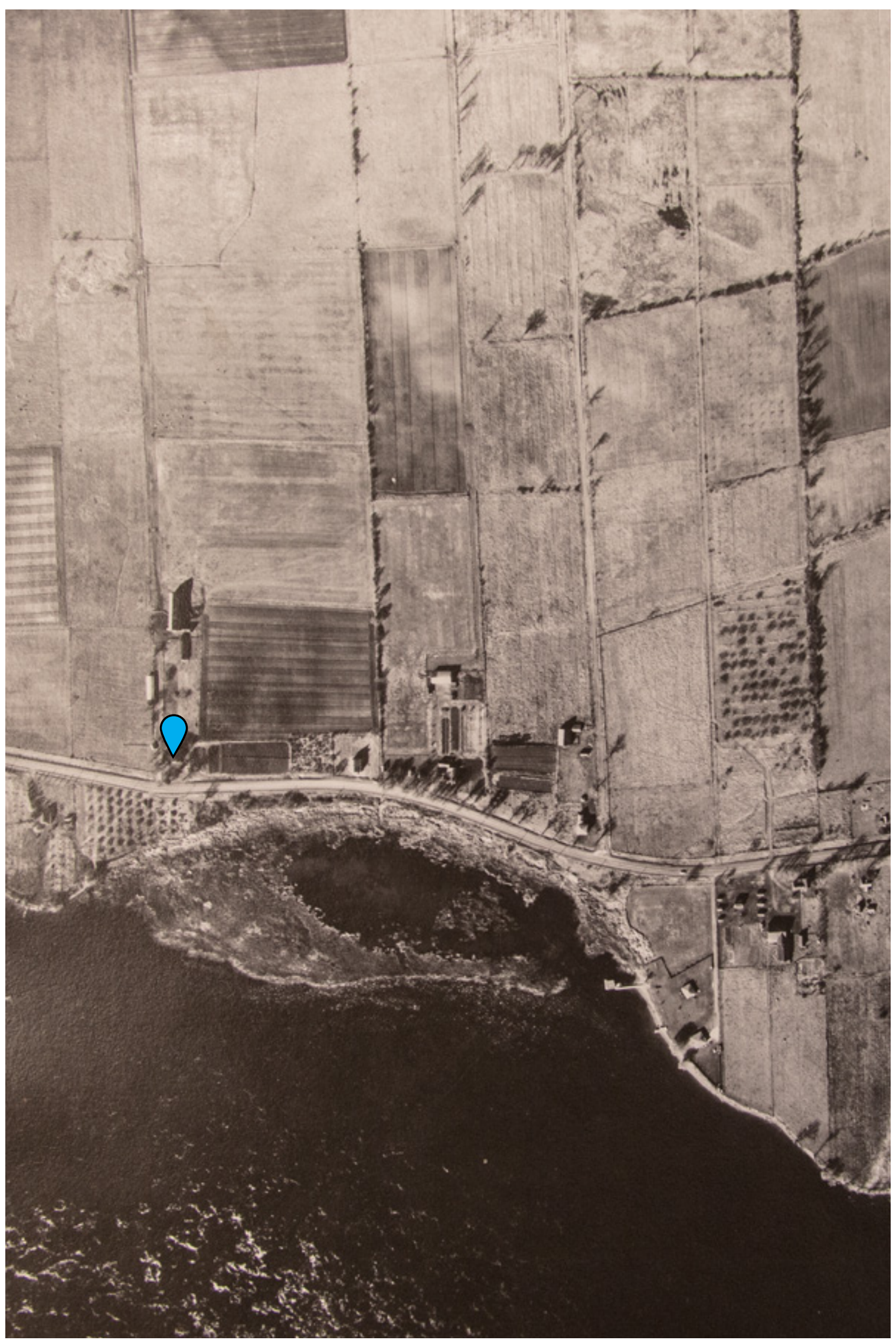




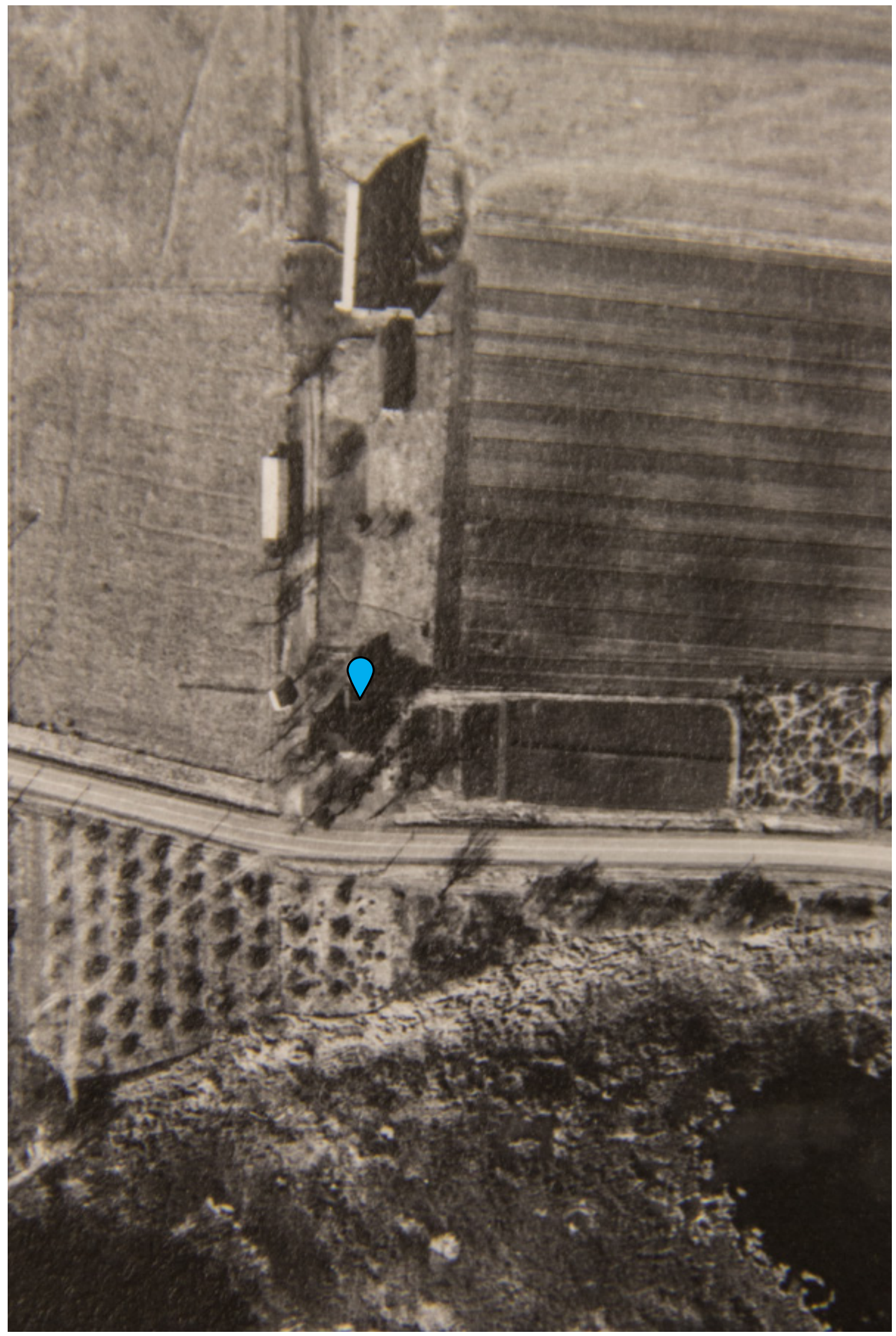




\subsection{Identifying Assets Part 2}

Due to the inability to accurately find or capture data from the Cooks Tavern, The Christ's Church or the Monument of the Chrysler battle field, a new methodology was developed: find a site in good condition that is easily accessible and ideal for data acquisition. To determine the location of each site, aerial photographs and various diving resources were used. A considerable amount of time was spent analyzing aerial photographs taken by local artist, Louis Hielbig and by contacting locals that may have knowledge of the area. Once a list of possible locations were generated, an expedition took place in an attempt to locate a site in of restitution. The following images visualize and document the process of identifying potential assets during the second phase.

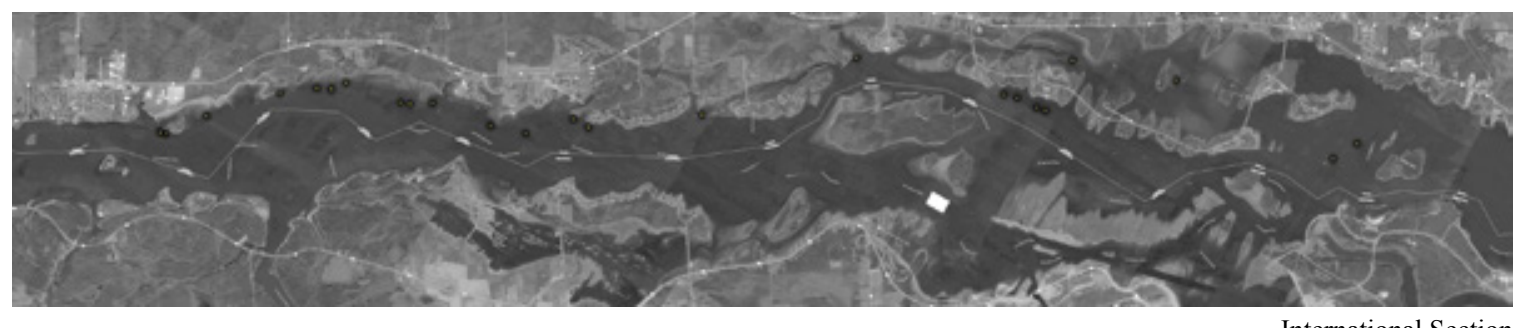

International Section

After conducting another 4 site survey expeditions, one foundation proved to be ideal. In an attempt to recover valuable data, a survey of the submerged sites along the river could be conducted. By capturing existing site conditions, a speculative review identifying building typologies could then be generated, providing insight into the buildings that populated the area. From this document, building construction methods in the area could be further speculated, contributing to the research of early Canadian building construction. As an example, the remains of buildings on either side of the Kings Highway No.2 were surveyed in the area formerly known as Santa Cruz, Ontario. Aerial photographs visualize part of a submerged foundation on the south side of the road, and a concrete floor on the north side. After careful research in collaboration with the Interpretive Training Programs \& Historical Research Officers at Upper Canada Village, the foundation was speculated to be a barn, once owned by The Campbells (lot 3317). 

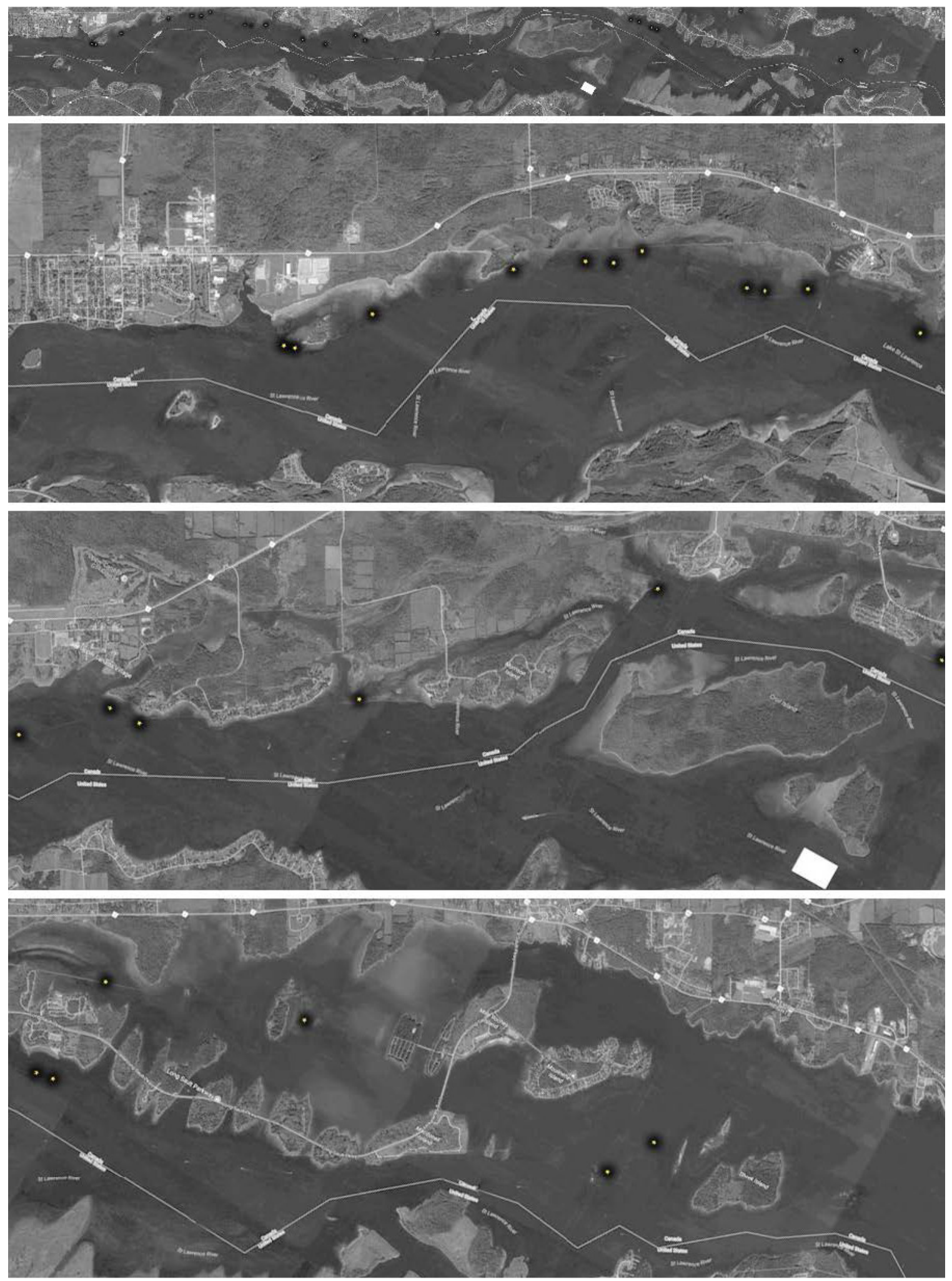


\subsection{Generatig The Asset}

The Sky

\subsection{Introduction}

\subsection{Introduction to Diving + Data Acquisition}

Attempting to collect high resolution images and precise data while working underwater poses significant challenges. The most significant of which is a lack of control over the environment. This section outlines the methodologies used to mitigate these challenges. 


\subsection{Introduction to Photogrammetry Process}

The digital restitution of submerged assets was completed using photogrammetry, that is, the production of $3 \mathrm{D}$ geometry reconstructed from a series of overlapping photographs. ${ }^{2}$ Currently, photogrammetry is the most reliable form of capturing and reconstructing underwater data in the field of marine archaeology. ${ }^{3}$ This method also proved to provide the best results when camera calibration was not a prerequisite. It was also successful in mitigating environmental influences and allowing for data to be captured in conditions where strong currents and wave motion were present. ${ }^{4}$ The procedures carried out during the acquisition are comprised of five main stages: Capturing Data, Camera Alignment, Building Dense Point Clouds, Building Mesh Topologies and the Texturing of Mesh Topologies.

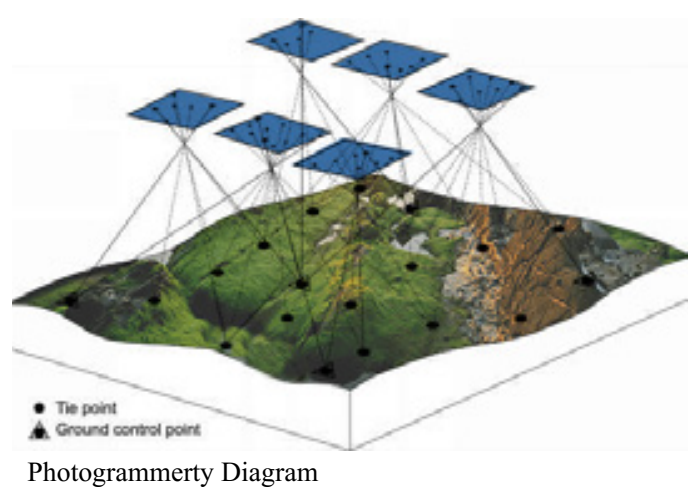

\subsection{Underwater Survey Safety Considerations}

Open water diving is an activity that requires a number of safety considerations, many being outlined in the courses provided by the Professional Association of Diving Instructors (P.A.D.I.). For the purpose of this project, a short introductory course on underwater surveying was reviewed, insuring that each dive was conducted safely. From this review, a rough protocol was adapted for capturing and mapping underwater

\footnotetext{
2 Weilberg, Matt. Photogrammetry and Remote Sensing. Syrawood Publishing House, 2016. Page. 4

3 Damelio, S., et al. "3D Modeling For Underwater Archaeological Documentation: Metric Verifications." ISPRS International Archives of the Photogrammetry, Remote Sensing and Spatial Information Sciences, XL-5/W5, 2015, Page, 73-77

4 Damme, T. Van. "Computer Vision Photogrammetry For Underwater Archaeological Site Recording In A Low-Visibility Environment." ISPRS - International Archives of the Photogrammetry, Remote Sensing and Spatial Information Sciences, XL-5/W5, 2015, Page. 231-238
} 
features, along with the acquisition of data for the purpose of 3D modelling. This review highlighted several key aspects of planning a successful dive, such as: 1) planning for the safety of each diver 2) gauging what each diver is capable of doing, 3) identifying under what conditions each diver should be able to dive and 4) preparing the equipment required for each dive. ${ }^{5}$ The pre-planning and subsequent delegation of tasks prior to each dive ensured the appropriate and safe use of specialized equipment. The following section outlines the list of equipment prepared for a dive, geared towards the surveying and capturing data with the intent of 3D-modelling. ${ }^{6}$

Standard diving equipment: mask, snorkel, fins, depth and time gauge, marker buoy (supplementary to this was a visible marker buoy with a diving flag [PADI, 2015]), and exposure protection suit (in the spring and fall the diving temperatures where often below 60 degrees $)^{7}$

In addition to the standard diving equipment, site survey specific equipment included: a nautical map of the area, metallic poles, hammer, coded + non-coded targets, digital underwater cameras (GoPro Hero 5, iPhone 7 plus), plastic measuring tapes, underwater carrying net, a plummet tied with a $300 \mathrm{~mm}$ line and a number of small floaters. ${ }^{8}$

It must be noted, as per my grandmother's recommendation, that a minimum of 2 people were required for each dive. This coincided with the protocols developed in reviewing the P.A.D.I. course outline. It also provided a great opportunity to include family and friends in the process.

\footnotetext{
5 PADI Open Water Diver Manual. BPADI, 1990.

6 Troisi, S., et al. "3D Models Comparison Of Complex Shell In Underwater And Dry Environments." ISPRS - International Archives of the Photogrammetry, Remote Sensing and Spatial Information Sciences, XL-5/W5, 2015, Page. $215-222$.

7 PADI Open Water Diver Manual. BPADI, 1990.

8 Damelio, S., et al. "3D Modeling For Underwater Archaeological Documentation: Metric Verifications." ISPRS International Archives of the Photogrammetry, Remote Sensing and Spatial Information Sciences, XL-5/W5, 2015, Page, 73-77
} 

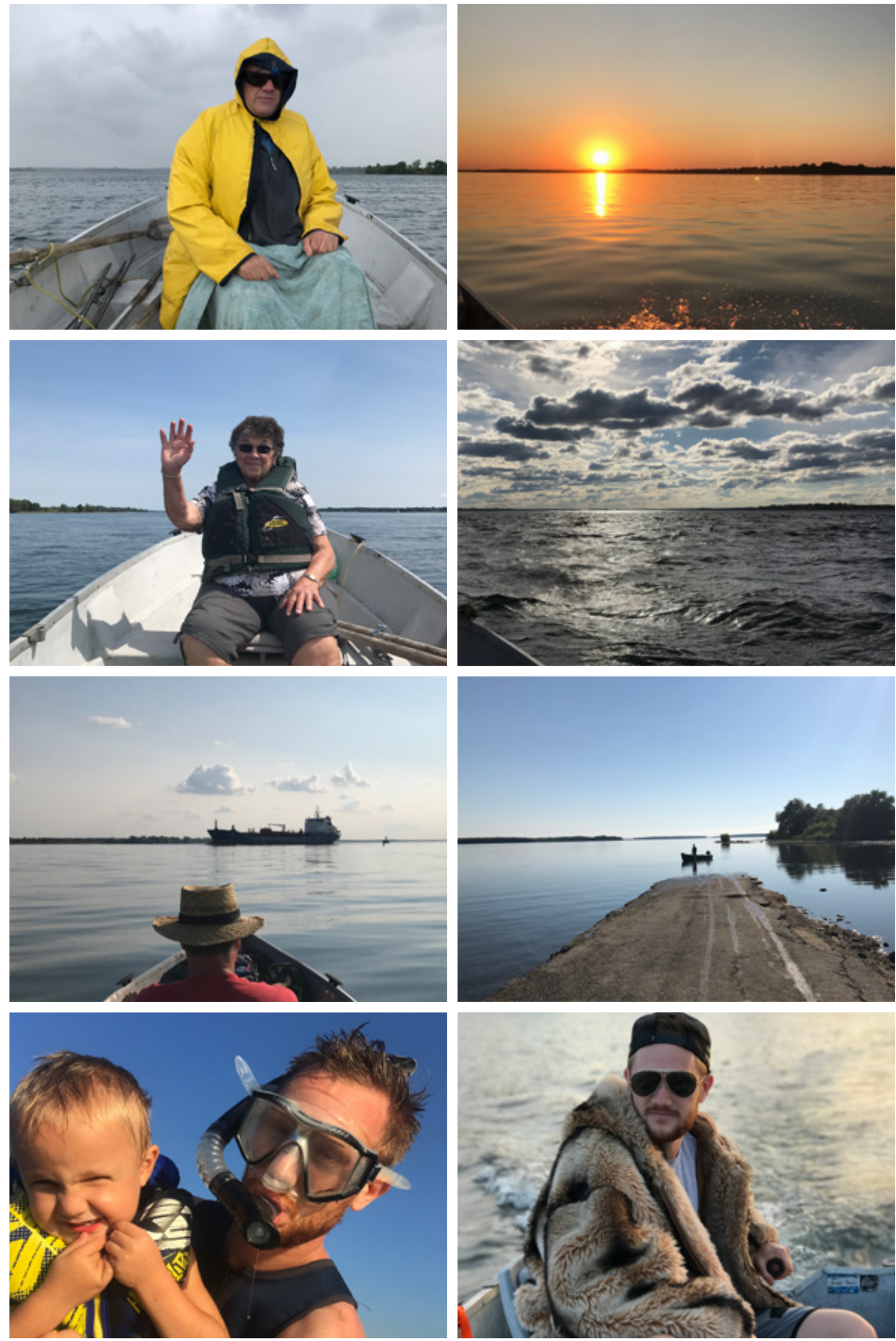

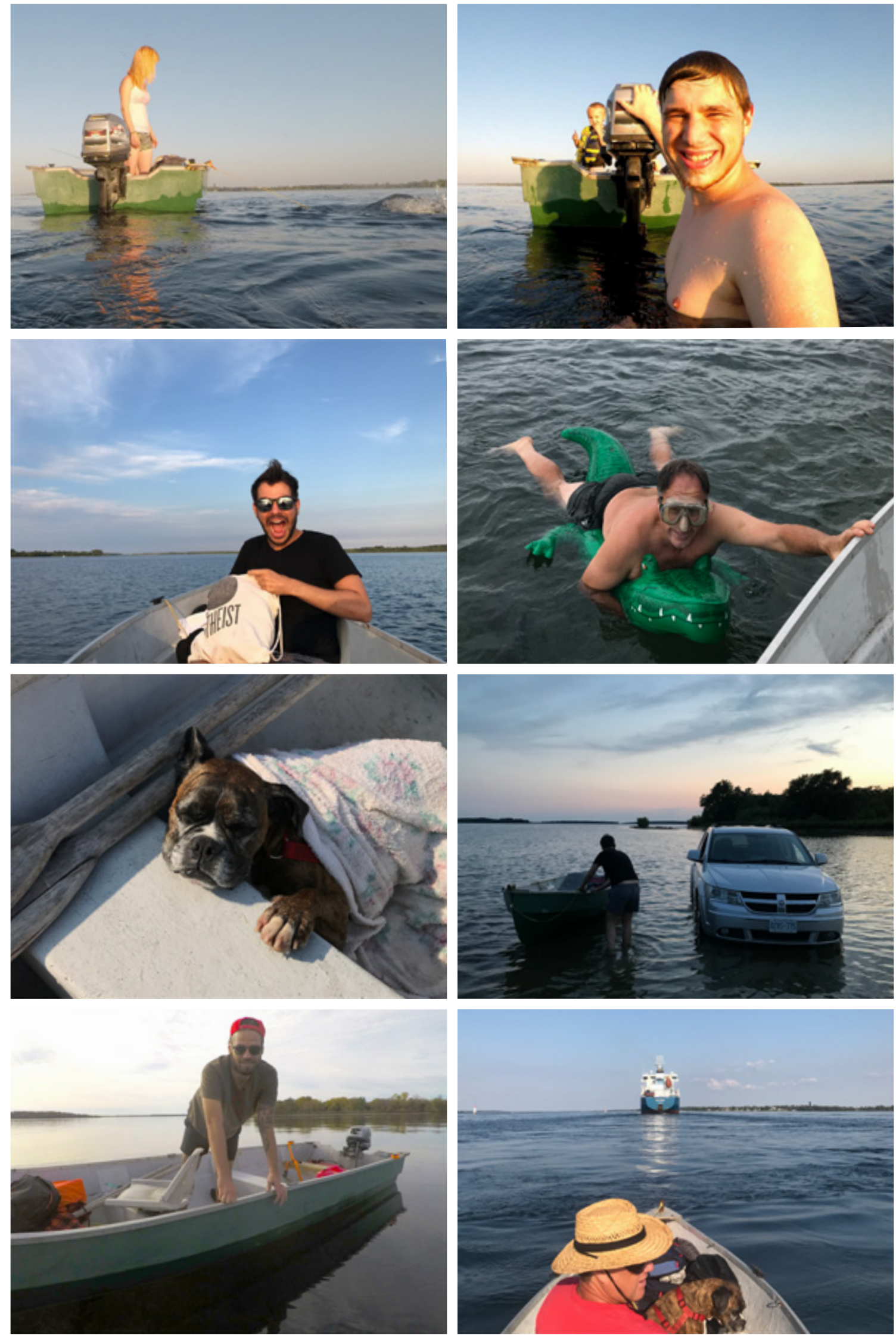


\subsection{Site Acquisition}

\subsection{Site Access by Boat}

To access the site, a 15' fibre-glass boat, affectionately named Bertha, was used. The vessel was equipped with a 15HP 2-stroke outboard motor. During the average launch and site visit, the engine used approximately $8.5 \mathrm{~L}$ of fuel. Over the duration of the project, the boat was launched from a number of sites along the Seaway. Two of these launches took place where the old No.2 Highway surfaces along the new St. Lawrence parkway. For the duration of this project, the primary boat launch was located at the McLaren Campground, an approximate 10 minute boat ride from the primary dive site. For transportation to and from the campground, my grandfather's Dodge $4 \times 4$ was used. In total, the trip took approximately 2.5 hours (one way) for each visit. This includes the time it took to load and unload the boat, ensuring it was safely secured. For the duration of the project, approximately 3 survey trips occurred in order to asses and identify any possible assets, as well as 12 dives to capture the data from the sites chosen.

\subsection{Capturing Data}

For the best results in photogrammetry, an even light source with little to no shadow is optimum. In many cases, the photographer will create scenes with diffused lighting systems and avoid using flashes. ${ }^{9}$ This is done as highly contrasting shadows will create unwanted variations in the surface textures. ${ }^{10}$ When capturing data in an uncontrolled environment, such as the outdoors and underwater, the surface conditions are more accurately captured on cloudy days. Capturing the data at similar times of the day ensures the position and influence of the sun is relatively consistent. ${ }^{11}$

\footnotetext{
9 “1 Introduction." Close-Range Photogrammetry and 3D Imaging, Page. 1-27

10 Verhoeven, G. J. "Computer Graphics Meets Image Fusion:The Power Of Texture Baking To Simultaneously Visualize 3DSurface Features And Colour." ISPRS Annals of Photogrammetry, Remote Sensing and Spatial Information Sciences, IV-2/W2, 2017, Page 295-302

11 Agisoft PhotoScan User Manual, Professional Edition, Version 1.2,“Downloads User Manuals.” Agisoft PhotoScan, www.agisoft.com/downloads/user-manuals
} 
Still, working in consistent lighting conditions proved to be a challenge. Variables including weather conditions and the availability of volunteers/transportation were problematic. Even partly cloudy days proved to be an issue, as high levels of light would refract through the surface of the water creating irregular distortions on the features of the site. Overcoming this problem was key as it prevented the software from creating tie point matches during the alignment phase. Although the availability of the boat was not consistent, the photographs were generally captured between $10 \mathrm{am}$ and $3 \mathrm{pm}$ in an attempt to ensure the angle of light received on the foundation slab was consistent. Given this consideration, the data acquisition took place only on days when the weather was overcast, sometimes even raining.

\subsection{Capturing Data}

\subsection{Multimedia Photogrammetry}

The underwater documentation of this archaeological site was carried out to capture a complete understanding of it's current condition, while also providing an opportunity to digitally augment it's features for the purposes of dissemination as a cultural resource. In practice, each portion of the foundation was identified, documented and digitally recreated. Since this can only be done within the water, a number of optical considerations were weighed prior to capturing the data. 
Photogrammetry conducted through multiple mediums, with different refractive indices is referred to as 'multimedia photogrammetry'. Underwater photogrammetry is considered a form of 'multimedia photogrammetry' as it is characterized by the refraction of optical rays that transition between both water and air. ${ }^{12}$ As a result, the captured data is subject to an image invariant interface causing inaccuracies in measurements. ${ }^{13}$ In addition, when a camera is underwater, the effective focal length is multiplied by the refractive index of water. This, in tandem with the density of water, decreases the clarity of objects and shortens the field of view. Therefore to achieve the clearest photographs, the object must be close to the camera. ${ }^{14}$ This may cause to be problematic, as it will increase the number of photos required to properly document the site.

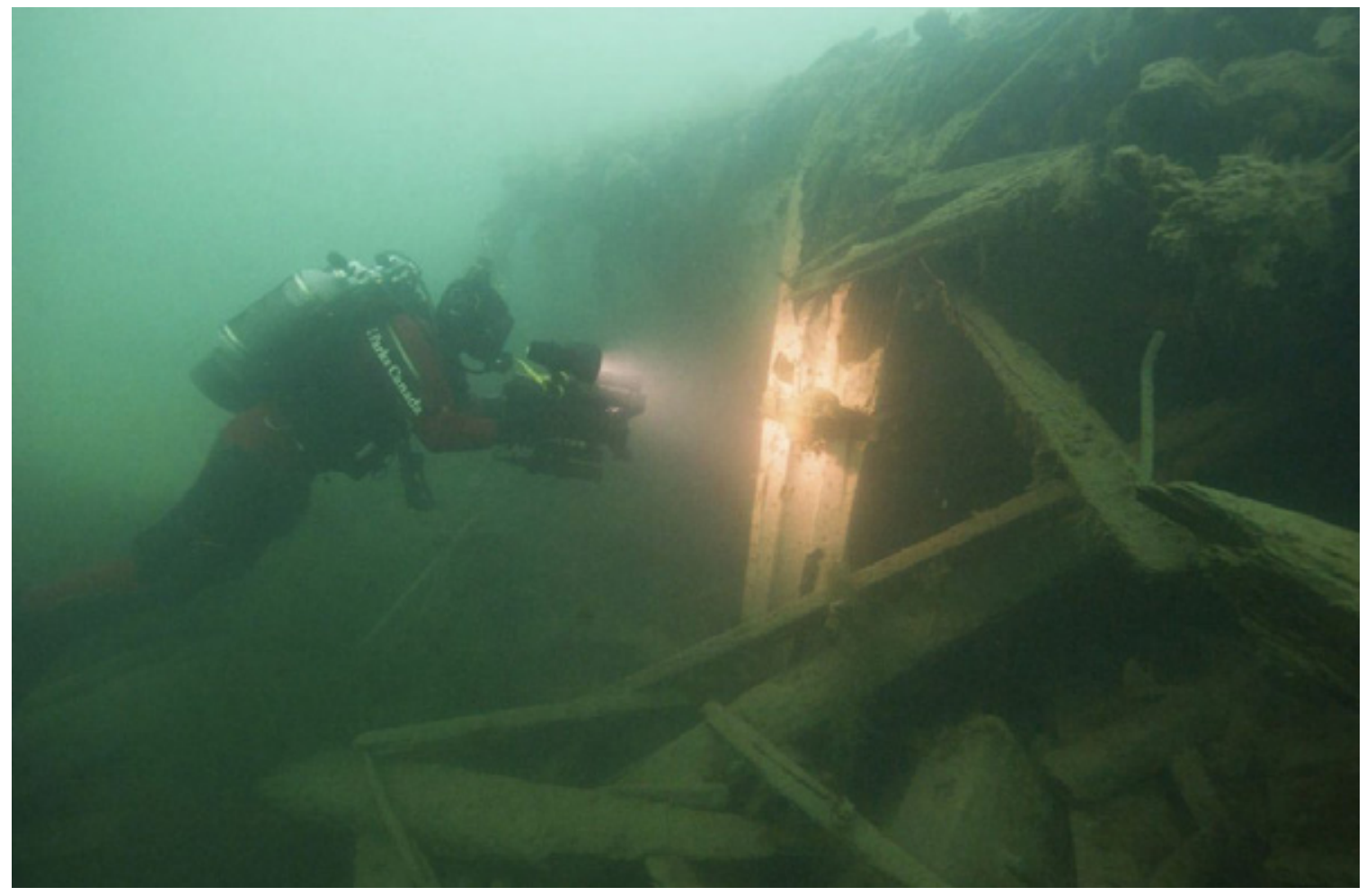

Park's Canada

12 Menna, Fabio, et al. "Optical Aberrations in Underwater Photogrammetry with Flat and Hemispherical Dome Ports." Videometrics, Range Imaging, and Applications XIV, 2017

13 Maas, H.-G. "A Modular Geometric Model For Underwater Photogrammetry." ISPRS - International Archives of the Photogrammetry, Remote Sensing and Spatial Information Sciences, XL-5/W5, 2015, Page. 139-141

14 Agrafiotis, P., and A. Georgopoulos. "Camera Constant In The Case Of Two Media Photogrammetry." ISPRS International Archives of the Photogrammetry, Remote Sensing and Spatial Information Sciences, XL-5/W5, 2015, Page. $1-6$. , 
Specialized equipment can be used to reduce the impact of these measurement inaccuracies. For example: the use of a lens concealed within dome port housings would correct the diminished angle of vision from water's refraction index. ${ }^{15}$ Unfortunately, as this project was not funded, the most economically viable cameras were considered. Of the 2 available underwater cameras, an exercise to evaluate performance in capturing data for the purposes of metric applications, such as photogrammetry, was performed.

\subsection{Camera Comparison}

Recently, the development of digital sensors in action grade cameras and cell phones have greatly improved. With the advancement of sensor technologies and improved hardware, faster image acquisition rates are easily attainable for producing geospatial data. ${ }^{1617}$ Most photogrammetry software will support the calibration of four major types of cameras: frame cameras, fisheye cameras, spherical cameras and cylindrical cameras. ${ }^{18}$

For this comparison, several images were acquired with a GoPro Hero 5 and an iPhone 7 plus. For successful estimation of camera orientation parameters, the information on approximate focal length (pix) is required. This data is extracted automatically from the EXIF metadata and estimated during camera calibration. To calculate this, the focal length (in $\mathrm{mm}$ ) and the sensor pixel size (also in millimetres) is used. During photo alignment, the software will then estimate nonlinear radial distortions, tangential distortions, skewing and/or shear distortions. ${ }^{19}$

\footnotetext{
15 Menna, Fabio, et al. "Optical Aberrations in Underwater Photogrammetry with Flat and Hemispherical Dome Ports." Videometrics, Range Imaging, and Applications XIV, 2017

16 ISPRS Journal of Photogrammetry and Remote Sensing. Elsevier. 2008. Page. 10-40

17 ISPRS Journal of Photogrammetry and Remote Sensing. Elsevier. 2008. Page. 7

18 "1 Introduction." Close-Range Photogrammetry and 3D Imaging, Page. 1-27

19 Agisoft PhotoScan User Manual, Professional Edition, Version 1.2,“Downloads User Manuals.” Agisoft PhotoScan, www.agisoft.com/downloads/user-manuals
} 


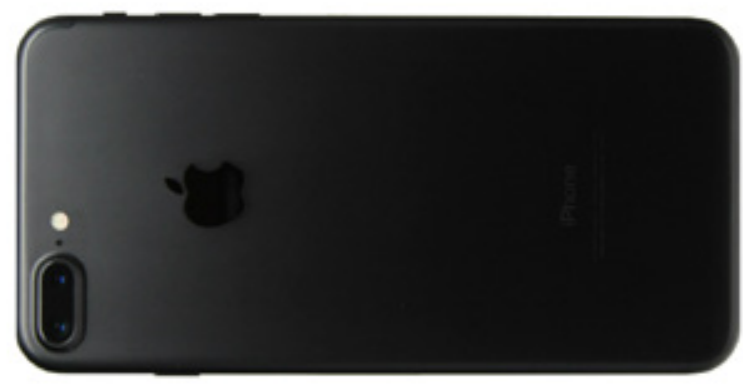

iPhone 7 plus

A: iPhone 7 plus [telephoto optical zoom] [https://9to5mac.com/2016/09/12/iphone-7-plussensor-size/]

SENSOR SIZE :6.6x 8.6

IMAGE SIZE : $3024 \times 4032$

F $3.99 \mathrm{~mm}$ (f1.8) or $6.6 \mathrm{~mm}$ (f2.8)

$56.8 \mathrm{~mm}$ lens effect equivalent to $56 \mathrm{~mm}$

crop factor 8.6

\section{B: iPhone 7plus ${ }^{2}$}

SENSOR SIZE :3.99 x 7.21 [Sony Exmor RS (1.22 $\left.\left.\mu \mathrm{m}, 1 / 3^{\prime \prime}\right)\right]$

IMAGE SIZE :3024 x 4032

Focal lenth $3.99 \mathrm{~mm}$ (f1.8)

$28.7679 \mathrm{~mm}$ lens effect equivalent to $28 \mathrm{~mm}$

The IOS was controlled with an app to determine the depth of field.

\begin{tabular}{|c|c|c|}
\hline Propety & value & - \\
\hline \multicolumn{3}{|l|}{ Camera } \\
\hline Comere maker & Goplo & \\
\hline Comere model & HER05 Dlock & \\
\hline Fatcop & $1 / 28$ & \\
\hline Eecosure time & $1 / 672 \mathrm{sec}$. & \\
\hline 190 speed & $150-100$ & \\
\hline Eepouve bias & Ostep & \\
\hline Focal length & $3 \mathrm{~mm}$ & \\
\hline Max aperture & 297 & \\
\hline Netering mode & Unknown & \\
\hline Subject datance & $0 \mathrm{~mm}$ & \\
\hline Pash mode & No flash function & \\
\hline \multicolumn{3}{|l|}{ Aash energy } \\
\hline $\begin{array}{l}35 \mathrm{~mm} \text { focal length } \\
\text { Image }\end{array}$ & 15 & \\
\hline \multicolumn{3}{|l|}{ mape ID } \\
\hline Dmeneions & $4000 \times 3000$ & \\
\hline Wath & 4000 posts & $=$ \\
\hline Height & 3000 posuls & \\
\hline Hotzortal ressition & 72 dol & \\
\hline Ventical retoluton & 72 dsi & \\
\hline De septh & 24 & \\
\hline \multicolumn{3}{|l|}{ Comprestion } \\
\hline Peaclioson unt & 2 & \\
\hline Colst represertation & $\triangle A G O$ & \\
\hline Compresued bes/petel & 1466116597979790 & \\
\hline
\end{tabular}

2 [main] [https://9to5mac.com/2016/09/12/iphone7-plus-sensor-size/]

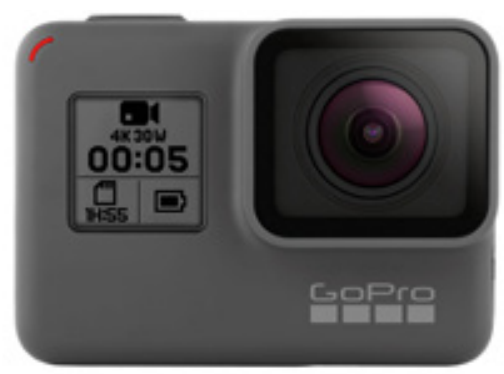

Hero 5

\section{A: GoPro Hero $5^{2}$}

SENSOR SIZE : $1 / 2.3$ " actual dimensions are

$6.17 \mathrm{~mm} \times 4.63 \mathrm{~mm}$

IMAGE SIZE :

4096 × 3072

Focal length multiplier [crop factor] $=5.64$

Focal length 3.97 [stock fish eye lens]

Focal length 3.37 [IDEAL non fish eye lens not used in this project]

***Alternatively, a $3.37 \mathrm{~mm} \mathrm{f} / 2.887 \mathrm{~d}$ HFOV 16MP (No Distortion)[HERO 6/5] lens could have replaced the fish eye lens. This is a $4 \mathrm{~K}$ lens designed for the GoPro Hero $6 \& 5$. With an 87 degree FOV 16MP sharp 7 glass $(4 \mathrm{G}+3 \mathrm{MO})$ non-fisheye optics this lens would have captured the entire image sensor without distortion.

\begin{tabular}{|c|c|}
\hline Prosenty & Volve \\
\hline Camera - & \\
\hline Comers maver & Apoph \\
\hline Camera model & iphene 7 Pus \\
\hline Fetsos & $f / 1.8$ \\
\hline Eposure time & $1 / 30 \mathrm{sec}$. \\
\hline ISO speed & $150-40$ \\
\hline Exposure bias & $0=0$ \\
\hline Focal length & $4 m$ \\
\hline \multicolumn{2}{|l|}{ Max aventure } \\
\hline Meterng mode & Pattem \\
\hline \multicolumn{2}{|l|}{ Subiect distance } \\
\hline Rash mode & Nafosh, ats \\
\hline \multicolumn{2}{|l|}{ Pash energy } \\
\hline $35 \mathrm{~mm}$ focd length & $z$ \\
\hline \multicolumn{2}{|l|}{ Image - } \\
\hline \multicolumn{2}{|l|}{ mage ID } \\
\hline Dmencions & $4032 \times 3024$ \\
\hline Whth & 4032 pouels \\
\hline Height & 3024 poucls \\
\hline Henzortal resolution & 72 di \\
\hline Vefical resolution & $72 d x$ \\
\hline Bt depth & 24 \\
\hline \multicolumn{2}{|l|}{ Comonetivion } \\
\hline Reschlition unt & 2 \\
\hline Color represertation & Uncalbrated \\
\hline
\end{tabular}

2 [https://9to5mac.com/2016/09/12/GoProHero5sensor-size/] 
iPhone 7 Plus

iPhone 7 Plus : Camera Parameters

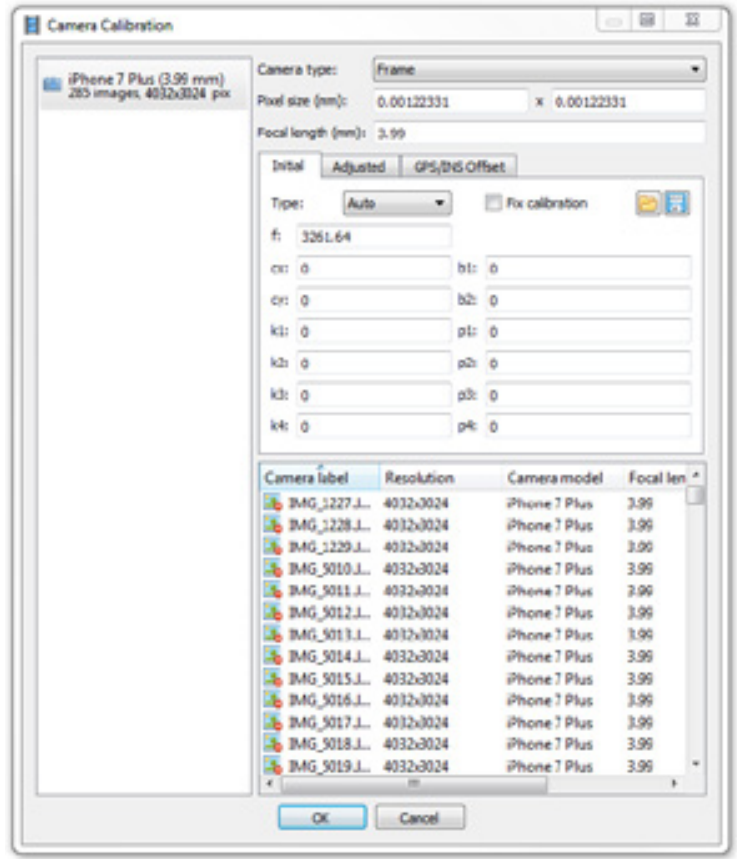

iPhone 7 Plus : Tie Point Matches

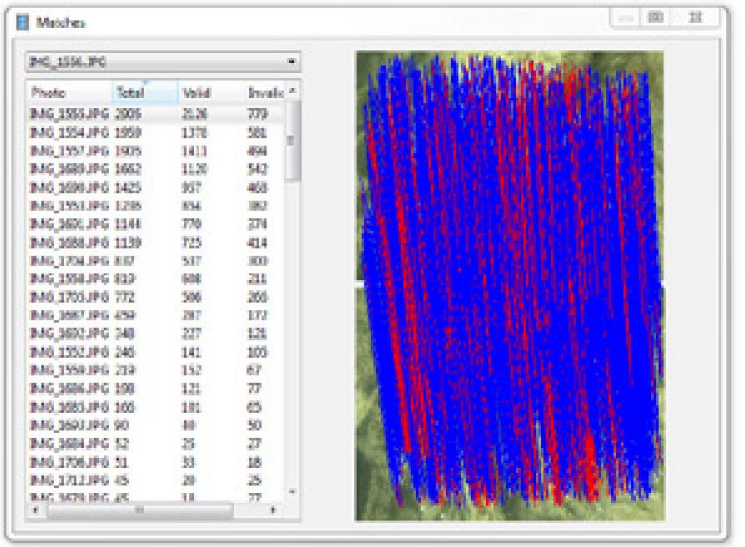

iPhone 7 Plus : Distortion Plot

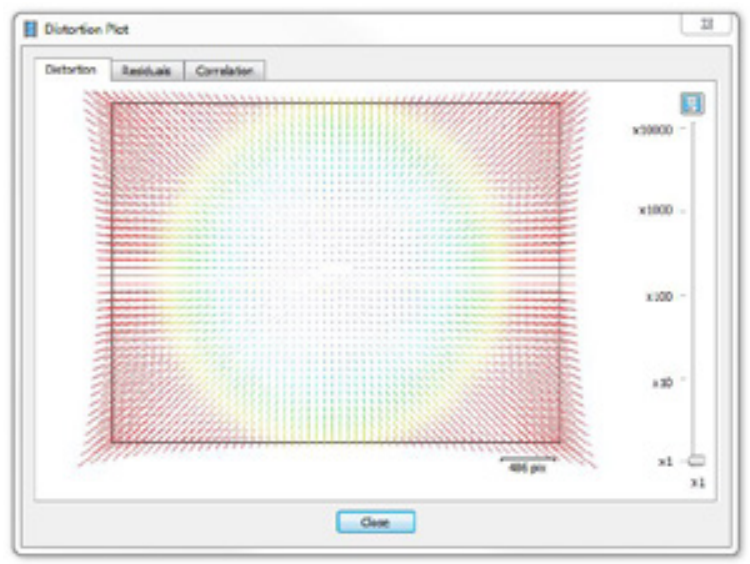

Hero 5

Hero 5: Camera Parameters

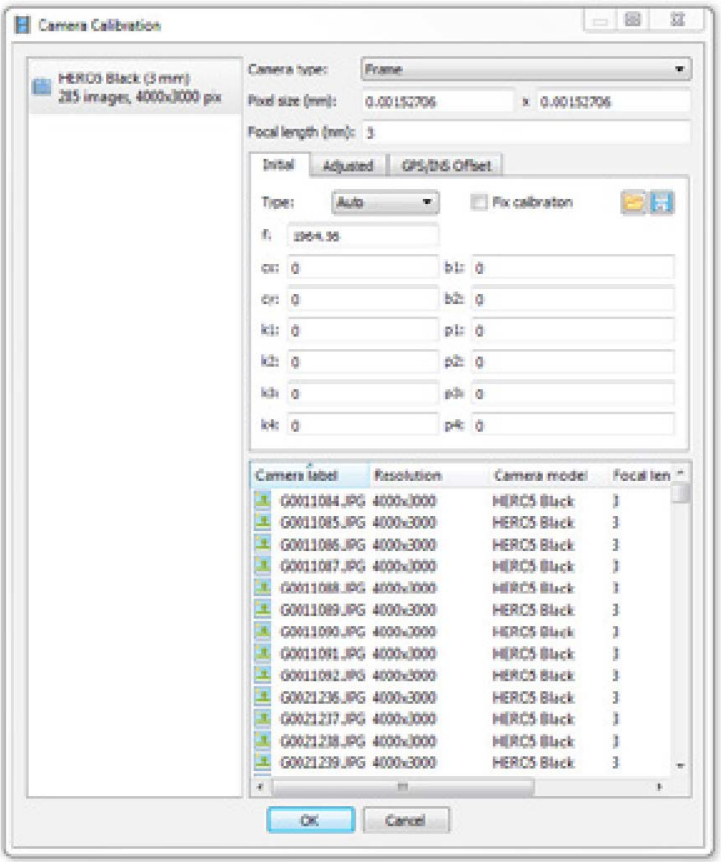

Hero 5: Tie Point Matches

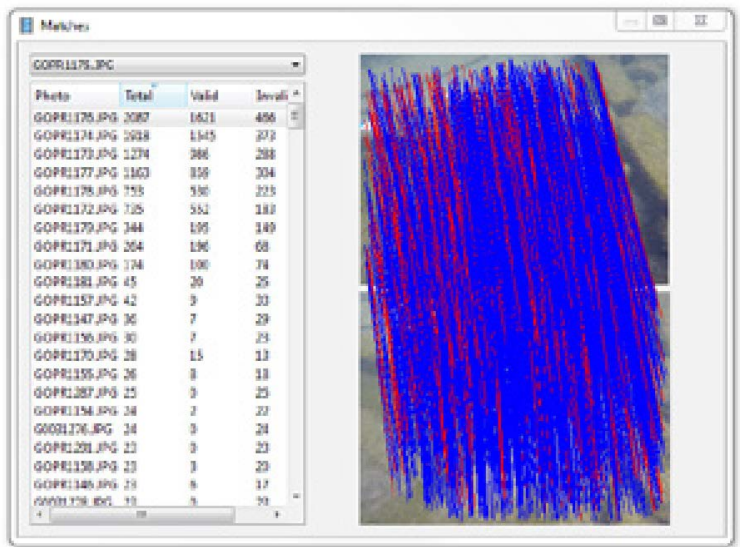

Hero 5: Distortion Plot

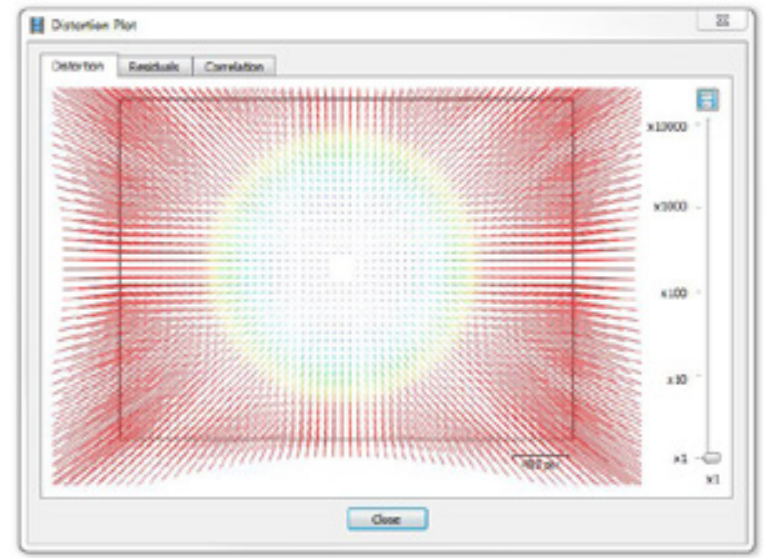




\section{Primary Alignment}

iPhone 7 Plus

iPhone 7 Plus : Residuals Diagram

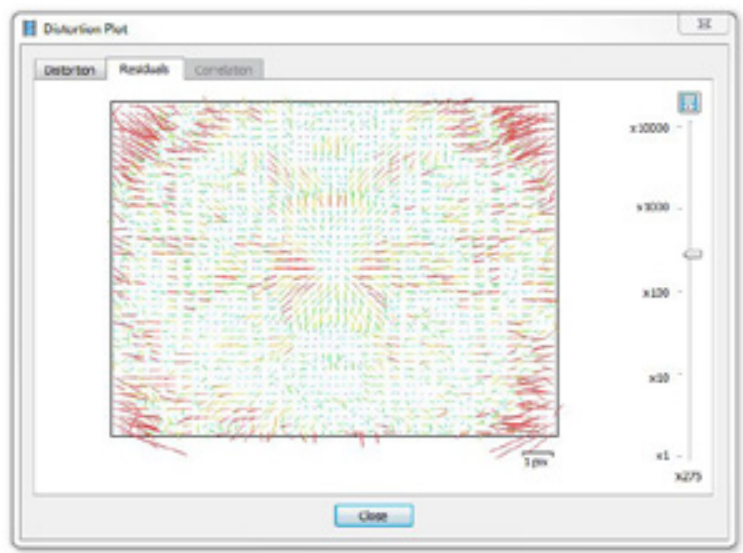

Hero 5

Hero 5: Residuals Diagram

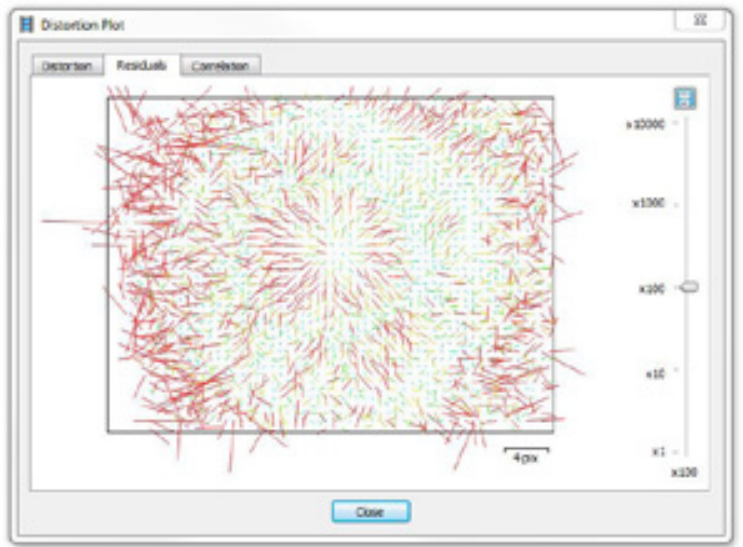

\section{Secondary Alignment}

iPhone 7 Plus : Distortion Plot

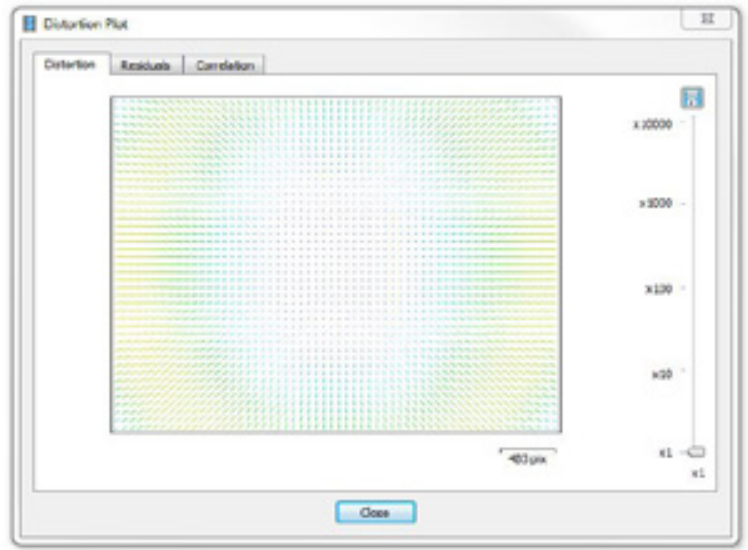

iPhone 7 Plus : Residuals Diagram

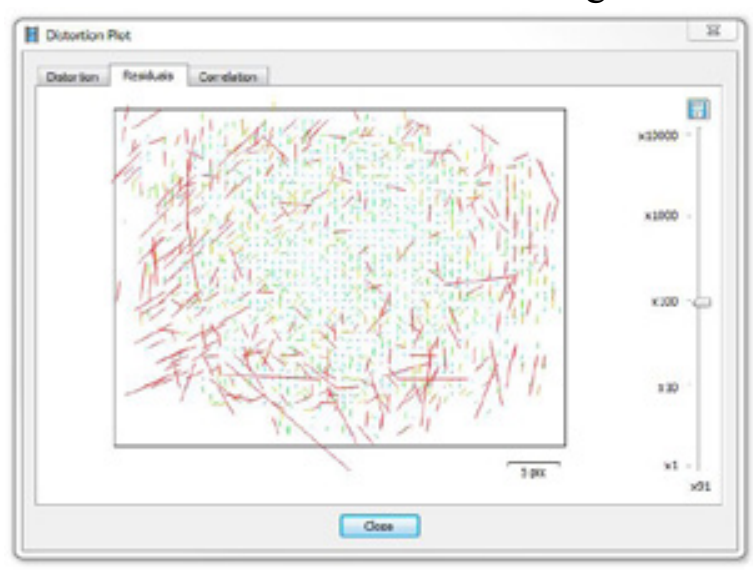

Hero 5: Distortion Plot

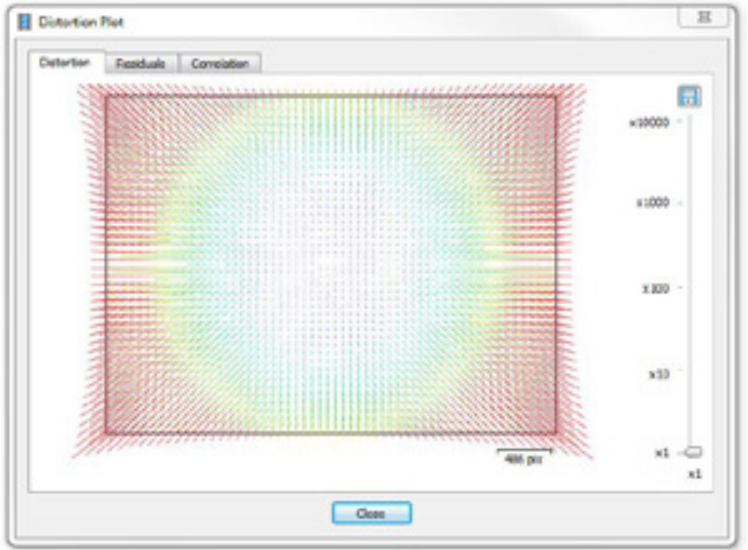

Hero 5: Residuals Diagram

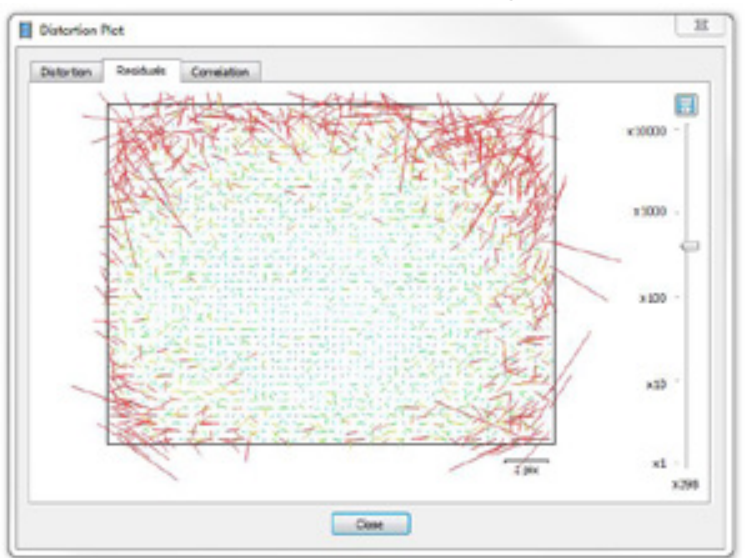




\subsection{Camera Results}

As the GoPro is retrofitted with a wide-angle lens, the standard photogrammetry software camera model will not estimate the camera's parameters successfully. Wide-Angle (Fisheye) camera type settings will initialize implementation of a different camera model, designed to fit lens distortions. On the basis of the preliminary tests, the GoPro Hero 5 exhibited unfavourable characteristics for underwater metric purposes. This is likely due to the strong distortion caused by lenses with very small focal length. ${ }^{20}$ However, due to water depth, the iPhone's field of view was not large enough to capture large portions of the site. As a result, the iPhone produced better quality images, but more images were required to capture the data. This increased processing time during alignment significantly. In addition to this, the iPhone failed to maintain its water "resistant" specs and it's ability to function underwater after 12 hours of use.

\subsection{Working Distance}

The primary purpose of capturing the riverbed is purely for visualizations and not for metrics, therefore there is a larger tolerance for invariance. The target Ground Sample Distance (GSD) for the asset was approximately $50 \mathrm{~mm}$. This value determines that the resolution of the captured data will only define features up to $50 \mathrm{~mm}$ and larger. In order to maintain the desired GSD, the maximum distance between the object and the camera must be defined as a set parameter. ${ }^{21}$

As the St.Lawrence is an active waterway, the water levels are subject to change without notice. Specifically, the operation of the locks changed the depth of the water between site visits making it difficult to maintain a constant working distance between the object and the camera. However, because the average depth of the water was less than the

20 Menna, Fabio, et al. "Optical Aberrations in Underwater Photogrammetry with Flat and Hemispherical Dome Ports." Videometrics, Range Imaging, and Applications XIV, 2017

21 Luhmann, Thomas, et al. Close Range Photogrammetry: Principles, Techniques and Applications. Whittles Publishing, 2014. 
targeted working distance, the working distance was defined by the space available between the water surface and the object. With this in mind, an approximate target distance of $1370 \mathrm{~mm}-1600 \mathrm{~mm}$ was maintained throughout the entire workflow. To avoid having the camera break the surface of the water while capturing data, it was submerged approximately $200 \mathrm{~mm}$ (depending on the water level). This was done to prevent reflections and unnecessary distortions. For this reason, there were many sites that did not allow for the proper acquisition of underwater features.

\subsection{Network Design}

In most cases of aerial photography captured for metric purposes, the suggested overlap requirement is $60 \%$ of side overlap $+80 \%$ of forward overlap. ${ }^{22}$ To capture the required data, a network design similar to the flight paths of unmanned aerial vehicles (UAVs) was adopted. ${ }^{23}$ In addition to this, close range photogrammetry techniques were also utilized to capture the more vertical elements of the submerged foundation in its environment.

As per the Agisoft PhotoScan user manual, with large primarily planar subjects such as this, a linear sequence is suggested. ${ }^{24}$ To adhere to this method, the images were captured in one linear sequence divided in half and defined by two capturing strategies. The 1 st overlapping "s" pattern began at the most north-eastern portion of the foundation and moved westward covering the entire slab. Once at the end, a secondary path moved from the south-west corner back to the north-eastern origin with a similar motion. The first pass consisted of a series of perpendicular images, each shot as vertical as possible

\footnotetext{
22 Murtiyoso, A., et al. "Acquisition And Processing Protocols For Uav Images:3D Modeling Of Historical Buildings Using Photogrammetry." ISPRS Annals of Photogrammetry, Remote Sensing and Spatial Information Sciences, IV-2/W2, 2017, Page. 163-170.

23 Murtiyoso, A., et al. "Acquisition And Processing Protocols For Uav Images:3D Modeling Of Historical Buildings Using Photogrammetry." ISPRS Annals of Photogrammetry, Remote Sensing and Spatial Information Sciences, IV-2/W2, 2017, Page. 163-170

24 Agisoft PhotoScan User Manual, Professional Edition, Version 1.2,"Downloads User Manuals." Agisoft PhotoScan, www.agisoft.com/downloads/user-manuals
} 
to capture orthographic projections. ${ }^{25}$ While the second pass was used to obtain oblique photographs to strengthen the image network geometry and cover areas with overhanging features. ${ }^{26}$ Overall, the goal for each photo was to effectively capture all character defining elements, while maintaining a sufficient overlap.

\subsection{Targets}

Targets were used on site to establish a network of local coordinate systems known as GCPs (ground control points). ${ }^{27}$ By distributing targets on site, the computer vision software can later identify GCPs through projections of source images. To define a GCP location within a scene, it must be visible on a minimum of 2 photos. ${ }^{28}$ However, higher accuracy in marker position is relative to the number of source images that can be used to identify it's placement. This is important, as the markers are used during camera calibration to confirm matches between images during the photo alignment, measure distances within the scene and perform marker based chunk alignments. ${ }^{29}$

The photogrammetry software used for this project supports two approaches to marker placement, manual and guided. ${ }^{30}$ For this project, 30 vectorized non-coded cross targets with the dimensions of $100 \mathrm{~mm} \times 100 \mathrm{~mm}$ were created for manual placement and 24 , 12 bit coded targets where generated for guided placement. All targets were processed as PDF documents and each individual target was positioned in Adobe InDesign to achieve 25 Agisoft PhotoScan User Manual, Professional Edition, Version 1.2,“Downloads User Manuals.” Agisoft PhotoScan, www.agisoft.com/downloads/user-manuals

26 Barazzetti, L. "Network Design In Close-Range Photogrammetry With Short Baseline Images." ISPRS Annals of Photogrammetry, Remote Sensing and Spatial Information Sciences, IV-2/W2, 2017, Page. 17-23

27 Agisoft PhotoScan User Manual, Professional Edition, Version 1.2,“Downloads User Manuals.” Agisoft PhotoScan, www.agisoft.com/downloads/user-manuals

28 Agisoft PhotoScan User Manual, Professional Edition, Version 1.2,"Downloads User Manuals." Agisoft PhotoScan, www.agisoft.com/downloads/user-manuals

29 Agisoft PhotoScan User Manual, Professional Edition, Version 1.2,“Downloads User Manuals.” Agisoft PhotoScan, www.agisoft.com/downloads/user-manuals

30 Agisoft PhotoScan User Manual, Professional Edition, Version 1.2,“Downloads User Manuals.” Agisoft PhotoScan, www.agisoft.com/downloads/user-manuals 
optimal spacing in preparation for printing. The target sheet was then printed onto a matte vinyl material with an adhesive backing. Reflective surfaces prove to be difficult to process making it hard to locate and register the markers, it proved to be easier to print the targets on a matte vinyl with a low level specularity. To further ensure the targets had a matte finish, a final ultraviolet (UV) repellant adhesive film was applied over the entire surface.
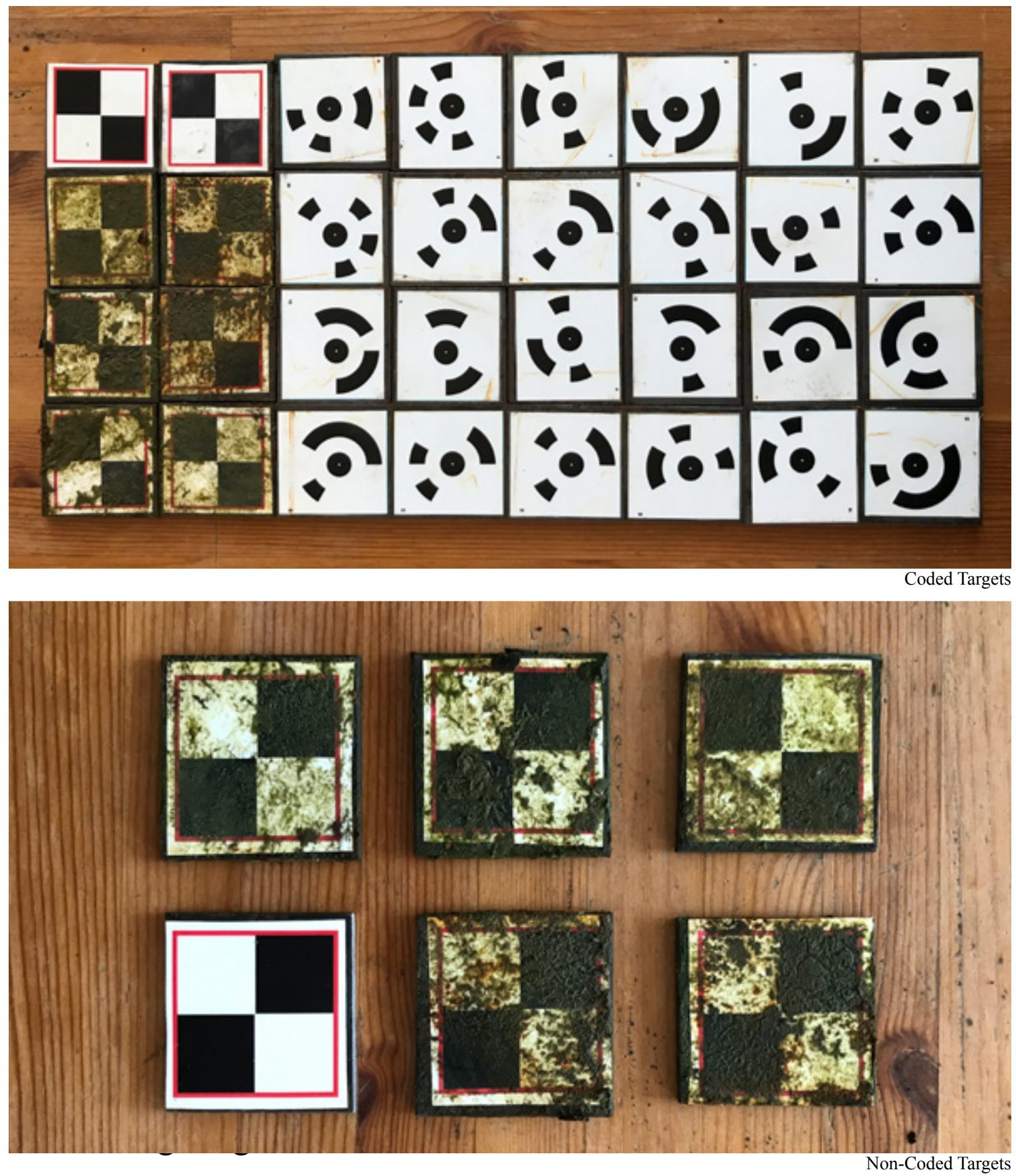


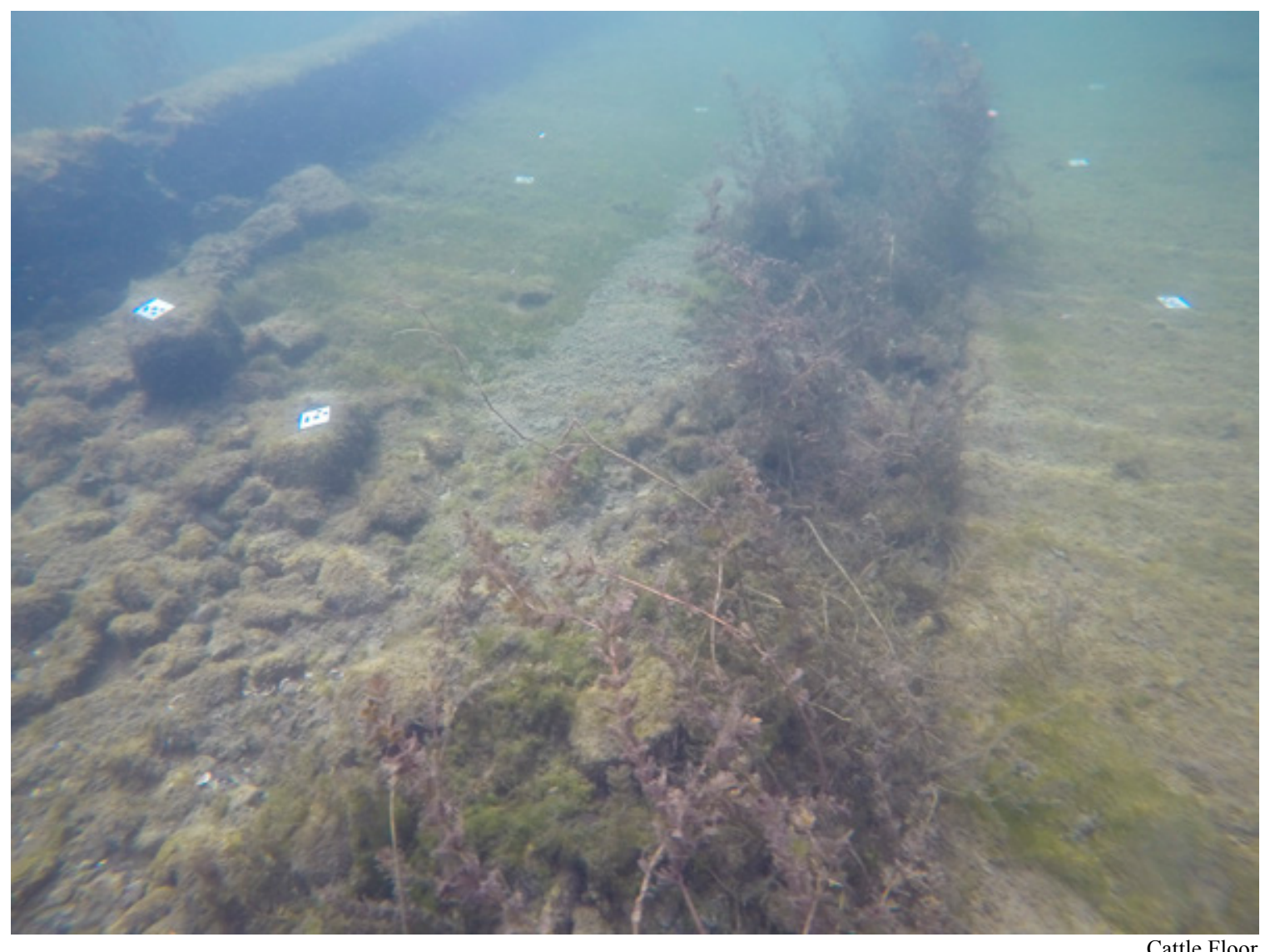

On site, the water current is quite strong, requiring weighting of the targets to prevent them from moving during the acquisition phase. As a precaution, the targets were mounted onto cold rolled steel plates to prevent movement when positioned under water. In total, 54 metal plates were cut from 1/4" sheet at $105 \mathrm{~mm}$ x $105 \mathrm{~mm}$. Once on site, the markers were evenly distributed along the foundation slab. This created a network of reference coordinates that would allow for the optimized visibility and the highest quality in geometrical precision. To ensure accuracy the targets were placed in areas that lacked surface variation or could be easily viewed from multiple camera angles. The distance between a minimum of 3 targets was also measured, per dive, to be later implemented as a measurement of scale. ${ }^{31}$ 

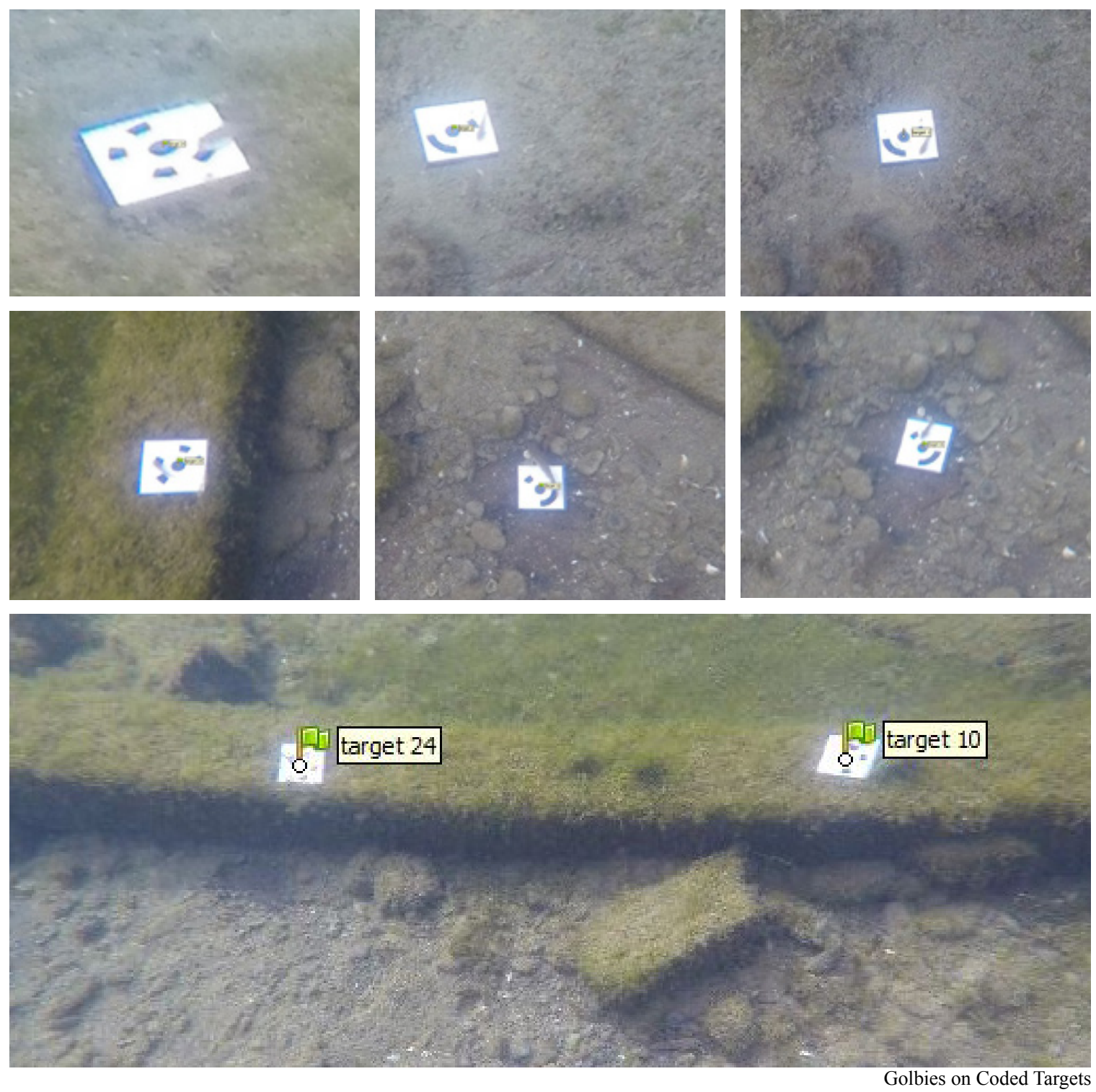

Many of the coded targets neeeded to be added manually because round golbies were attracted to the metal plates. Unfortunately, this prevented Agisoft Photoscan from identifying coded targets. Round Golbies are an invasive species, native to The Black and Caspian Sea. Researchers believe they habve been brought to The St. Lawrence in the ballasts of large ships.

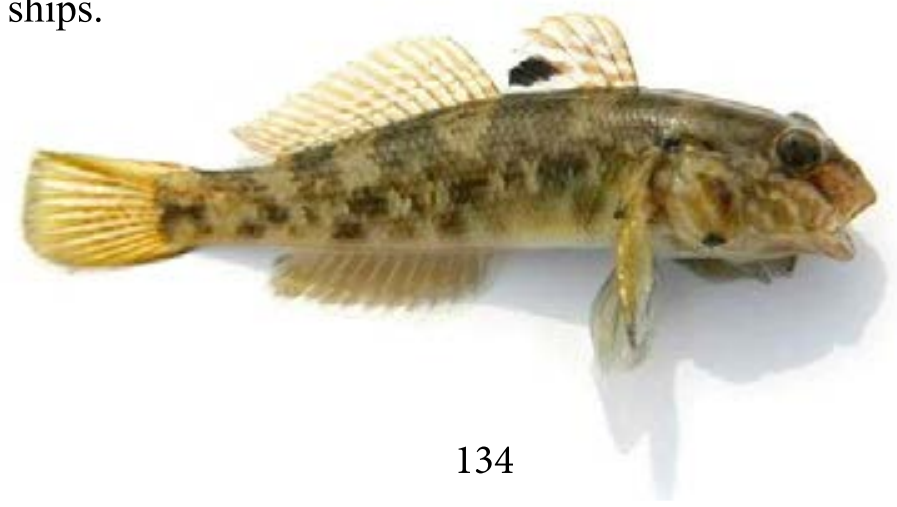




\subsection{Digital Restitution}

\subsection{Alignment \& Camera Calibration}

Prior to the photo alignment, the parameters of the camera must be modelled in the photogrammetry software. For the purposes of this project, the self-calibration method was used. With the increasing number of readily available consumer grade cameras and their various lenses, the self-calibration method has proven to be the most common technique used in most structure from motion applications. ${ }^{32}$ This is because it proves to be the least complicated and most versatile, catering to any type of digital camera. ${ }^{33}$

In Agisoft PhotoScan, the self-calibration tool estimates both the internal and external camera orientation parameters by extracting information from the images .EXIF metadata. Parameters such as the focal length and sensor size are used to solve the unknown parameters such as interior and exterior orientation and establish object coordinates during the bundle adjustment. During photo alignment, the software will then estimate nonlinear radial distortions, tangential distortions, skewing and/or shear distortions. ${ }^{34}$ In many cases, with the use of properly placed markers, the software can identify how these parameters deviate from collinearity through projections of the captured source images. This allows for automatic correction of the invariance in camera projections. ${ }^{35}$

It must also be noted that for the best calculations, it is crucial to apply the calibration procedure separately to photos taken with different cameras. Once photos have been loaded in the program, PhotoScan automatically divides them into calibration groups

\footnotetext{
32 ISPRS Journal of Photogrammetry and Remote Sensing. Elsevier. 2008. Page. 10-40 33 Agisoft PhotoScan User Manual, Professional Edition, Version 1.2,“Downloads User Manuals.” Agisoft PhotoScan, www.agisoft.com/downloads/user-manuals

34 Agisoft PhotoScan User Manual, Professional Edition, Version 1.2,“Downloads User Manuals.” Agisoft PhotoScan, www.agisoft.com/downloads/user-manuals
}

35 Fraser, Clive S. "Digital Camera Self-Calibration." ISPRS Journal of Photogrammetry and Remote Sensing, vol. 52, no. 4, 1997, Page. 149-159 
according to the image resolution and/or .EXIF metadata. The distortion of the lenses used to capture the photo series is simulated in the software with the Brown's distortion model. Unfortunately, fisheye and ultra-wide angle lenses are poorly modelled by the PhotoScan base settings, requiring to specification whenever a fish eye lens is used. This can be done in the camera calibration dialog prior to processing.

\subsection{Alignment - Image processing}

The photogrammetric workflow begins with feature matching, followed by external orientation and dense matching based on pixels. ${ }^{36}$ For this process to be as effective as possible, the images can be optimized prior to loading them into the photogrammetry software. As per the Agisoft PhotoScan user manual, the images were taken at maximum resolution with a low ISO value, where permitted, to reduce noise. ${ }^{37}$ As the photographs were taken underwater under overcast skies, light was limited. To ensure the images were bright enough a lower aperture was used. This was achieved by locking the exposure values on the camera prior to submersion and data capture.

Unfortunately the available underwater cameras used in this project did not support the use of RAW files; as a result the images are automatically compressed to .JPG format. Optimization was carried out through a batching process in Adobe Photoshop \& Adobe Bridge. To ensure the optimal number of feature matches between photos, each photo was enhanced to best recreate a clear and true image. To achieve this, details were manually adjusted to normalize exposure, gamma levels and brightness. Colour adjustments were also made to balance and average hues between cameras to correct inconsistencies between photos that can be noticeable when building textures.

36 Mikhail, Edward M., et al. Introduction to Modern Photogrammetry. Wiley, 2001.

37 Agisoft PhotoScan User Manual, Professional Edition, Version 1.2,“Downloads User Manuals.” Agisoft PhotoScan, www.agisoft.com/downloads/user-manuals 


\subsection{Alignment - Camera Calibrations}

iPhone 7 Plus : Tie Point Matches

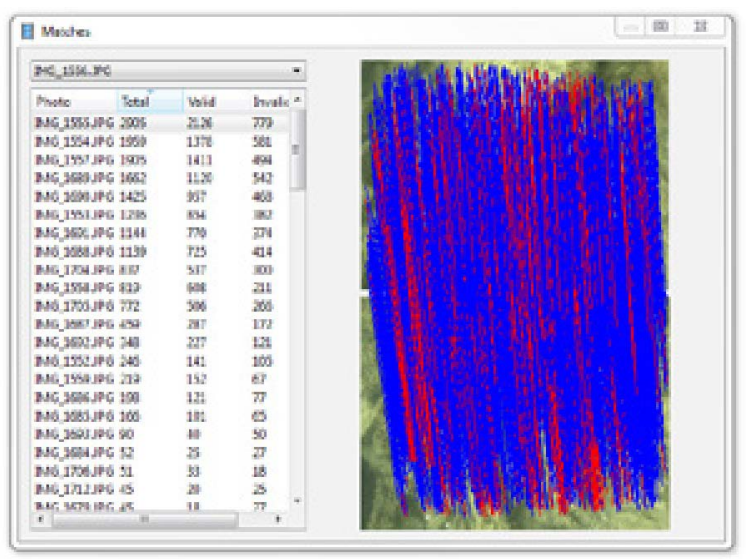

Tie Point Match Examples

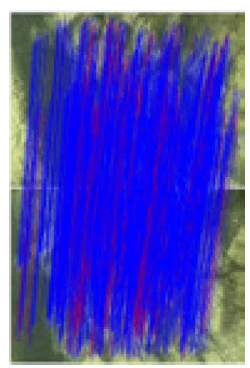

VALID 1846

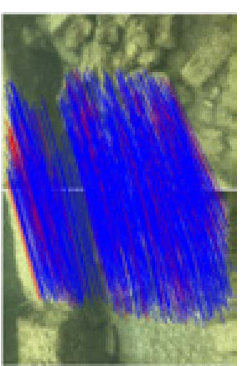

VALID 987

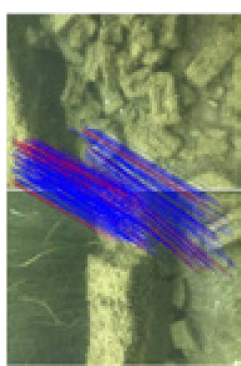

VALID 412

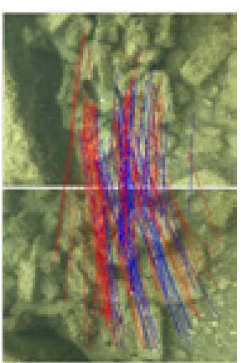

VALID 52

INVALID 352

INVALID 373

INVALID 91

INVALID 62

The processed data was loaded into PhotoScan to estimate camera positions and to define calibration parameters. During this process the software identifies a set number of feature points (Key Points) for each photo. This generates a list of common features (Tie Points) between source images. The accuracy of this process mainly depends on the amount of overlap between source photos and the number of identifiable key points per image. To avoid a diminishing return, the maximum key point value was set at 20,000 key points with a maximum value of 10,000 tie points. At this point, the identified tie points are visualized in the scene as a sparse point cloud. 


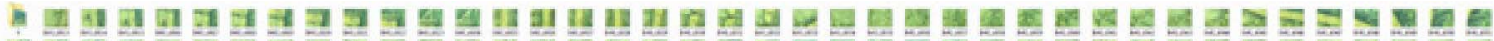

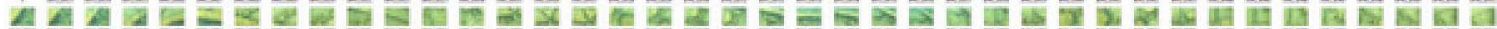

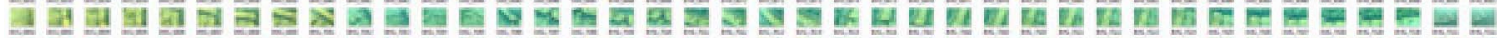

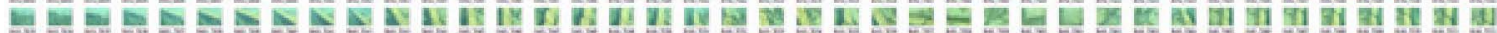

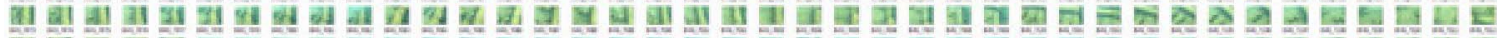

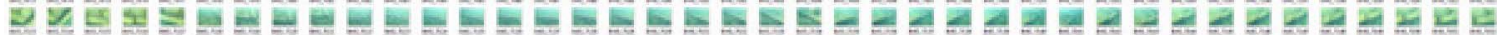

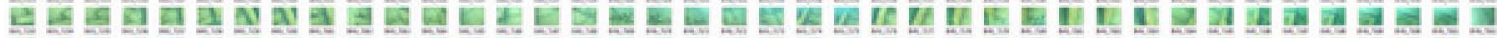

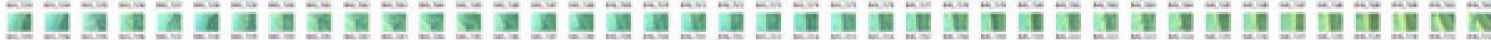

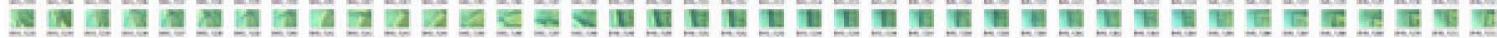

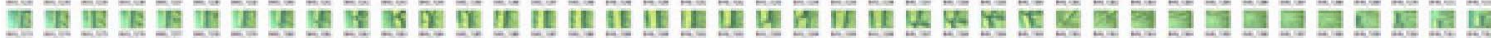

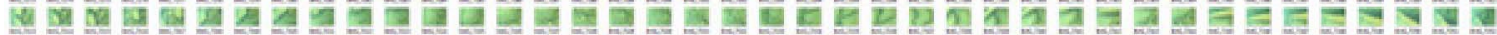

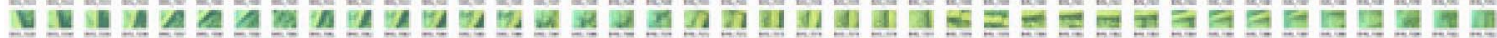

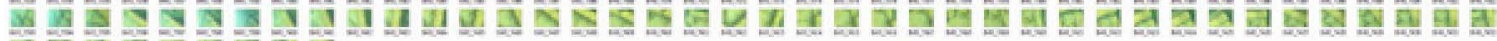

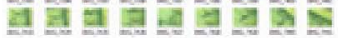

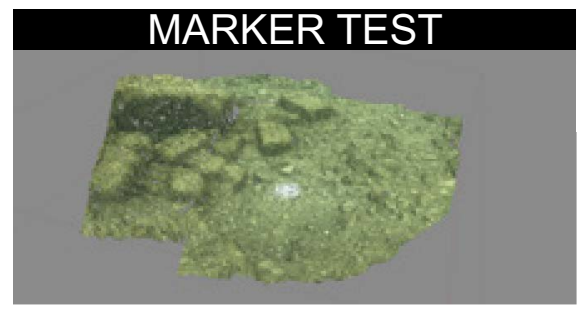

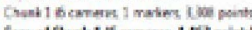

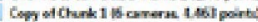

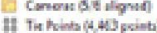

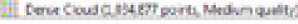

DIV 441 images, First test animation with point cloud

JUNE 302017

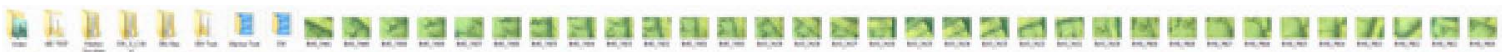

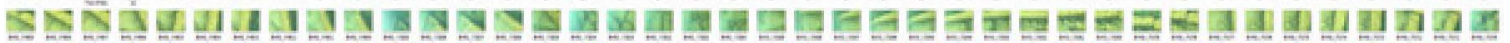

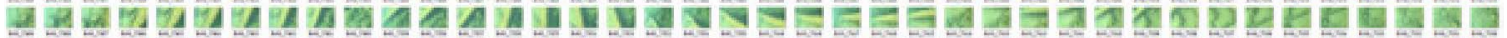

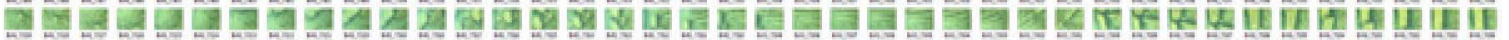

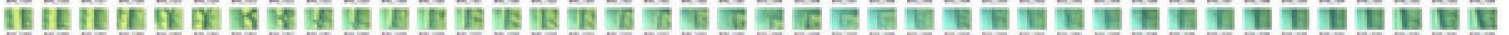

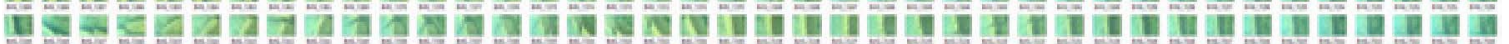

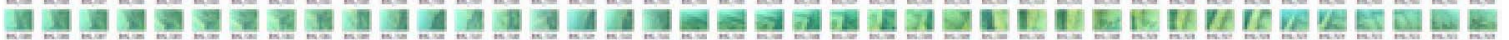

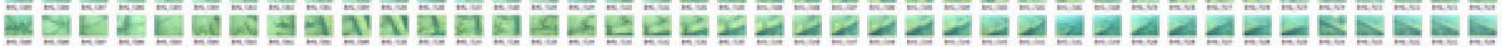

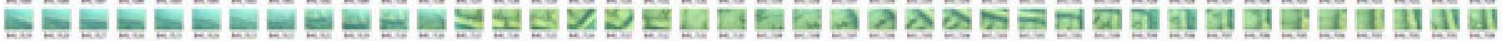

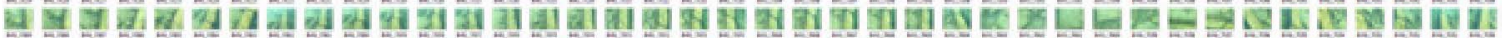

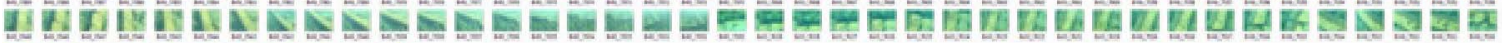

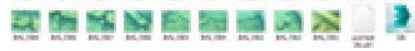

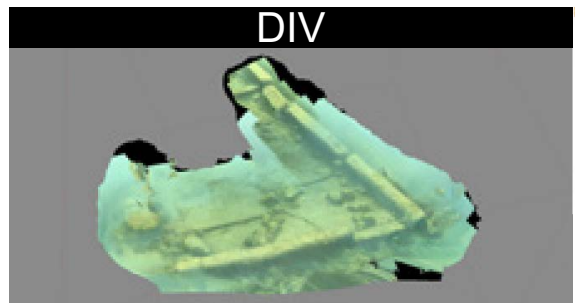

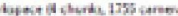

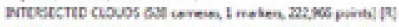

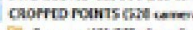

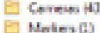

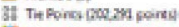

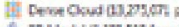

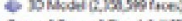

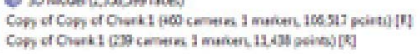




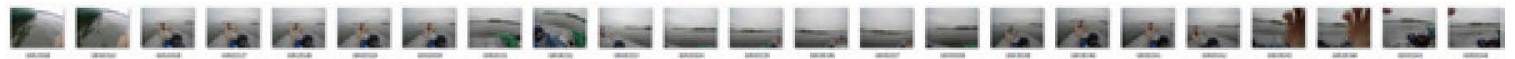

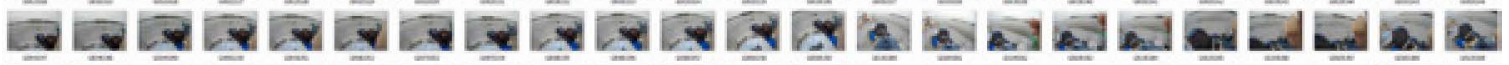

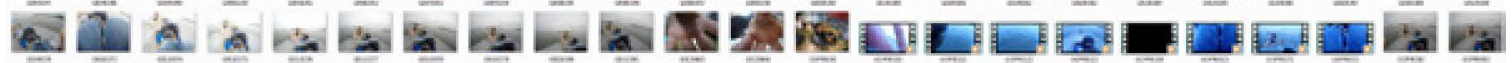

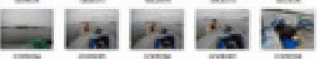

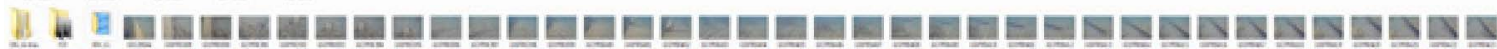

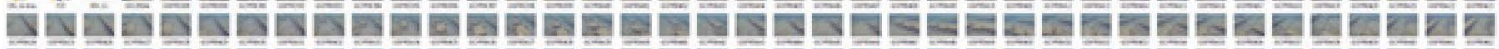

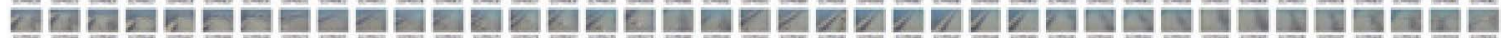

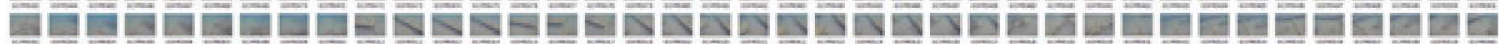

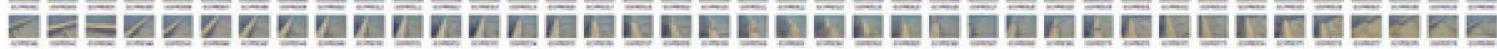

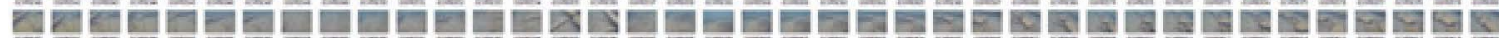

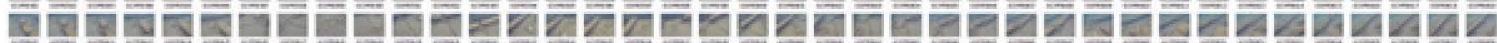

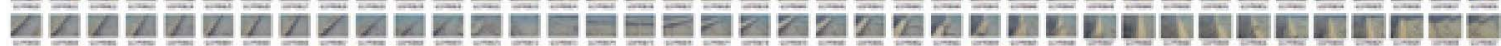

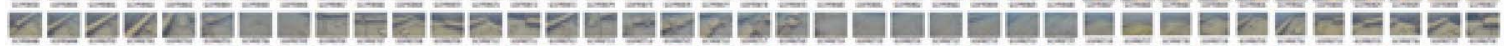

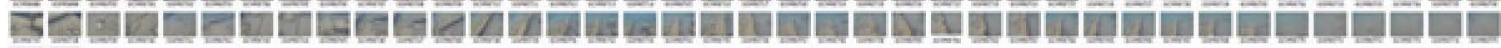
믐므
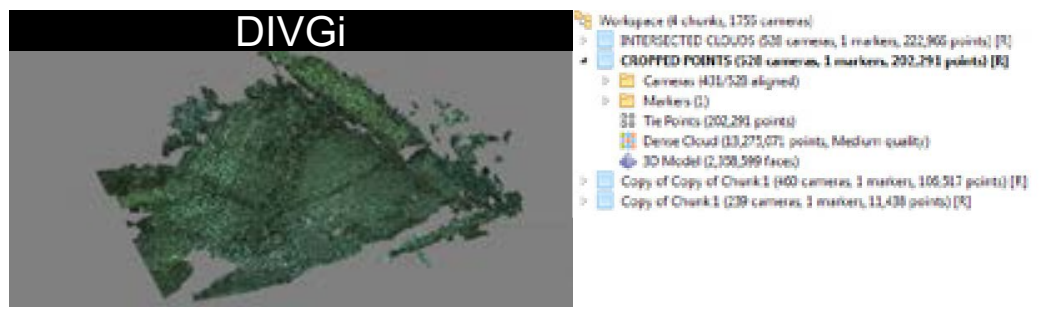

DIVii 850 images, Iphone 7 Plus

SEP 012017

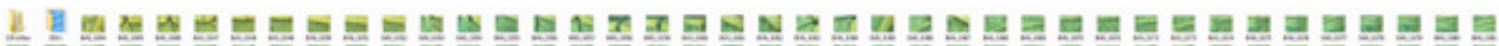

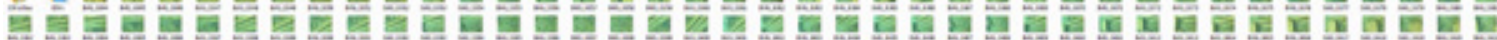

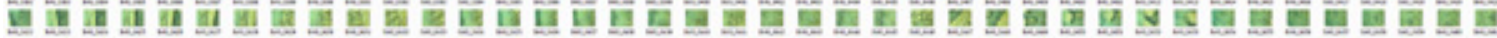

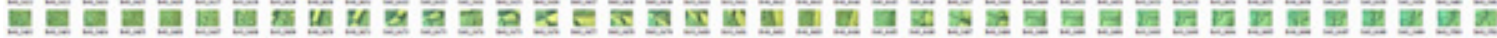

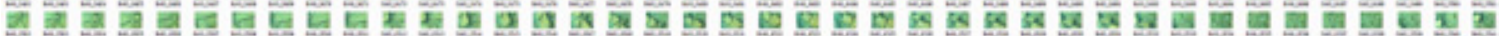

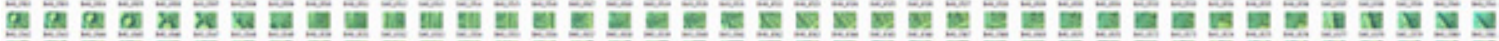

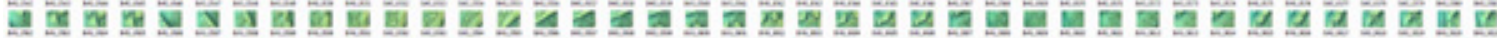

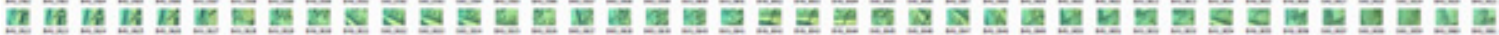

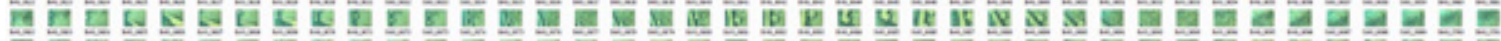

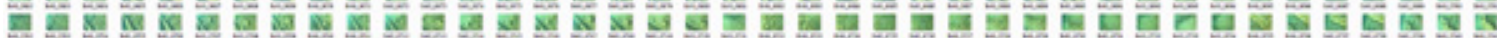

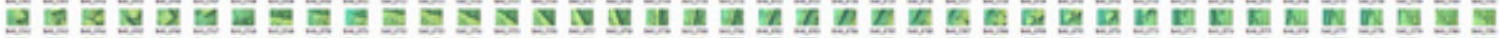

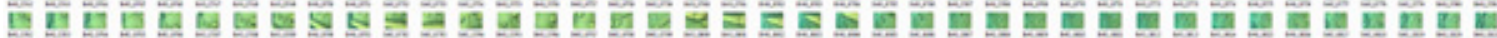

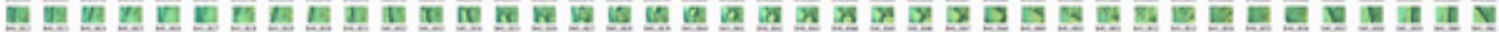

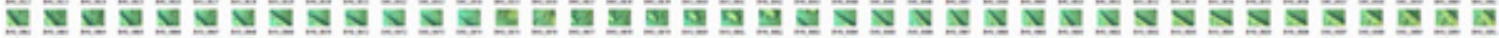

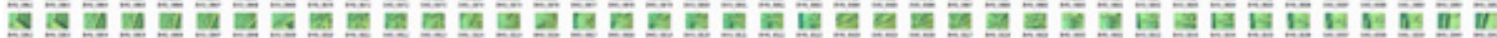

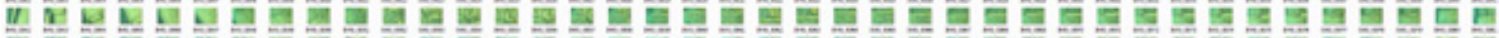

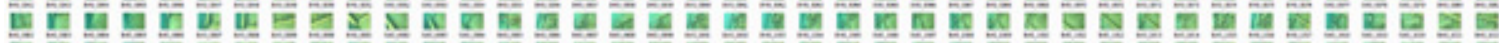

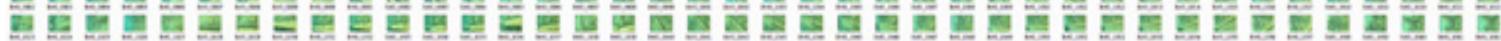

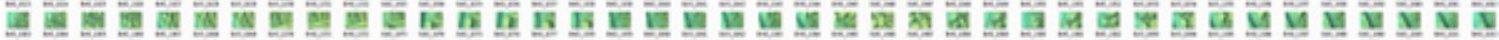

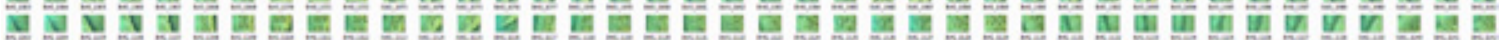

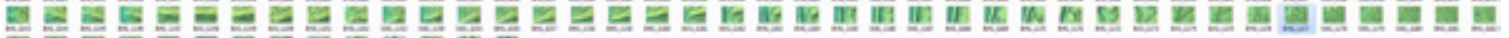

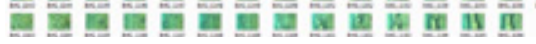
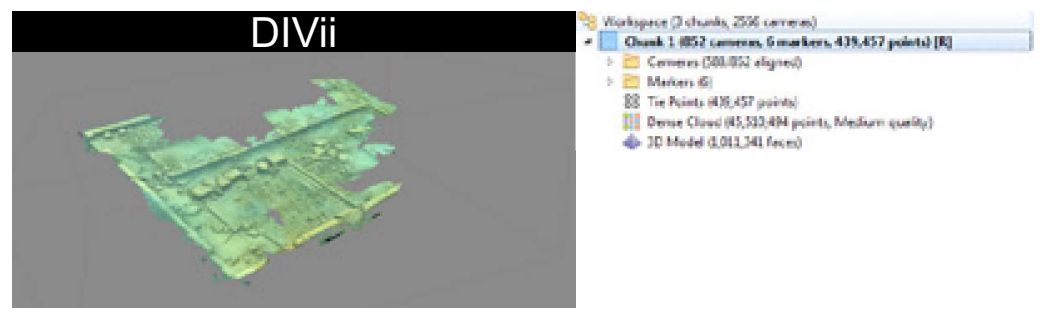
Camera A 417 images, GoPro Hero 5

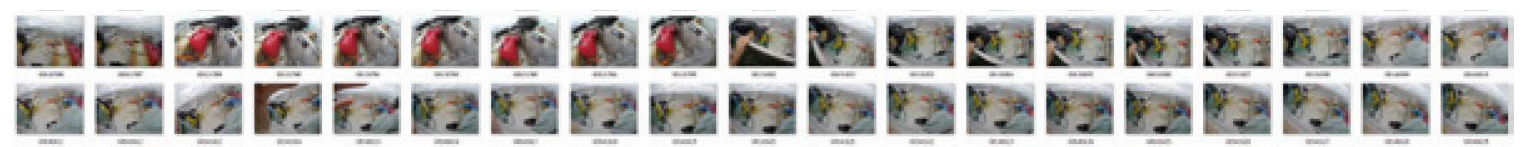

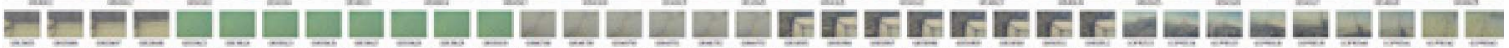

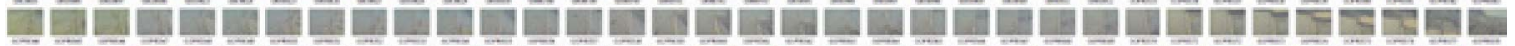

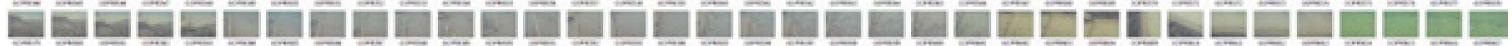

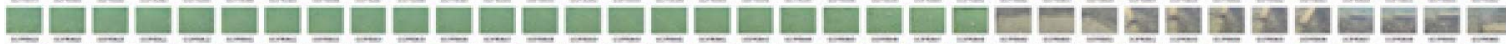

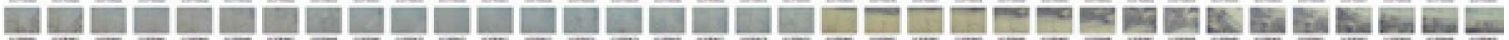

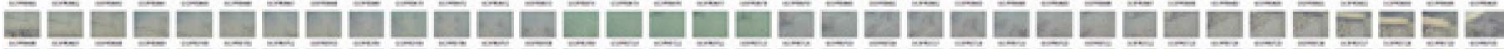

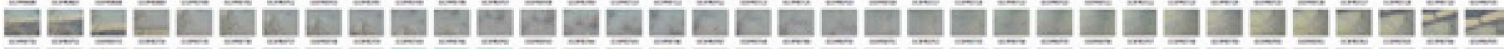

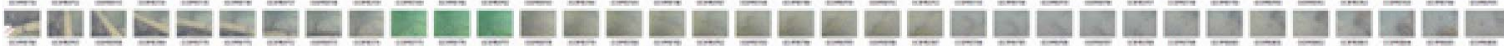

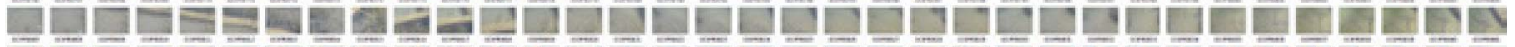
므므모ำง

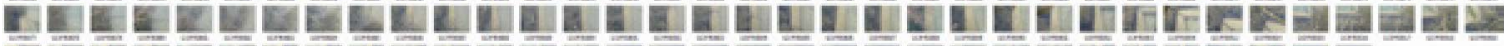

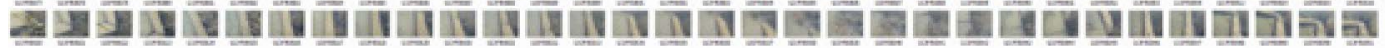

\section{Camera B 673 images, GoPro Hero 5}

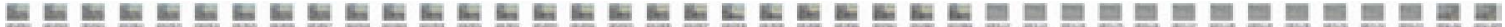

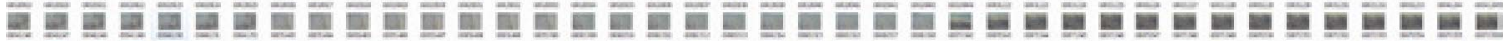

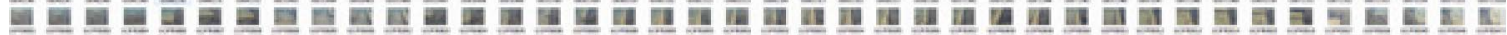

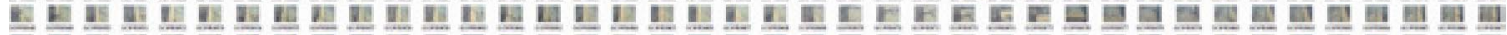

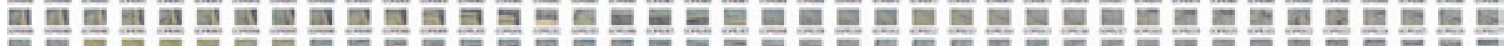

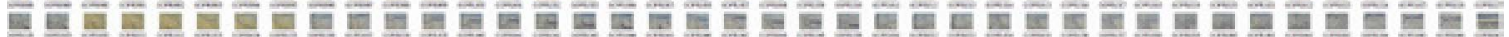

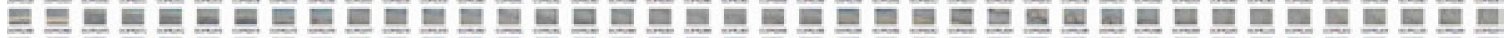

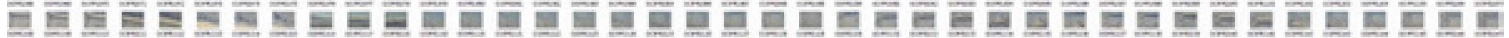

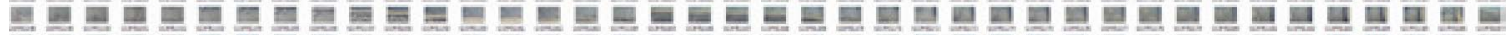

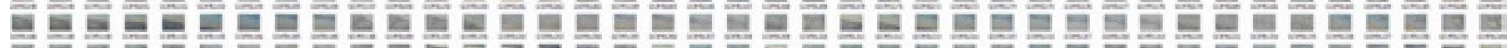

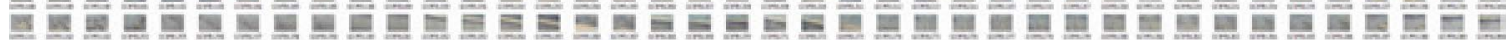

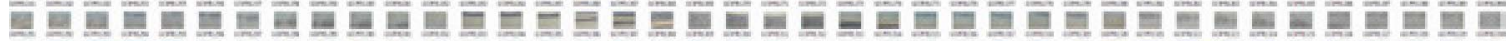

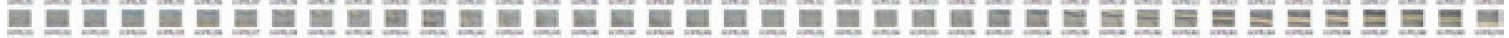

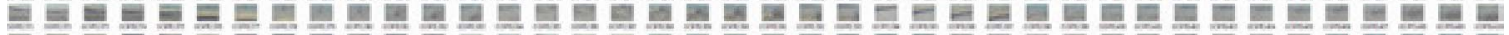

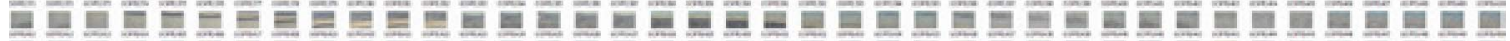

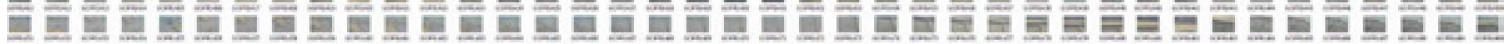

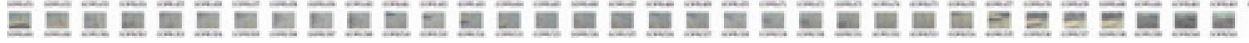
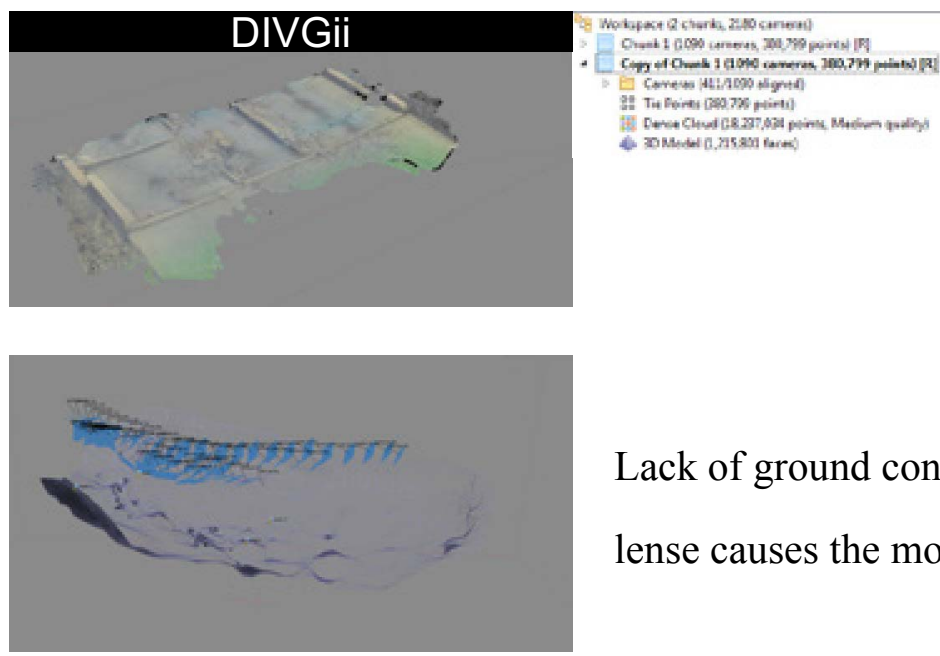

Lack of ground control points + curvature of the

lense causes the model to curl. 
Camera A 285 images, GoPro Hero 5
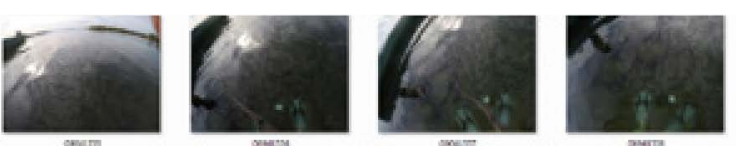
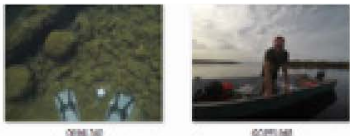

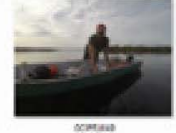

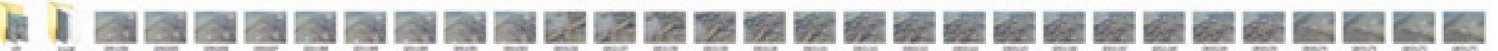

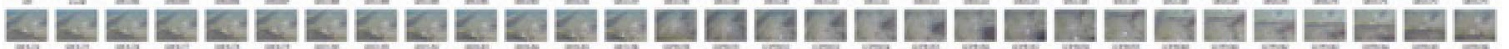

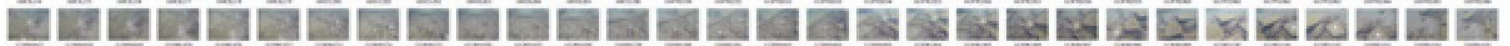

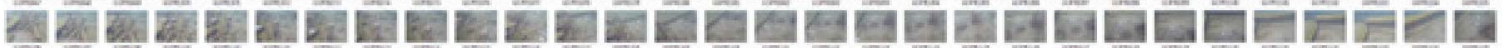

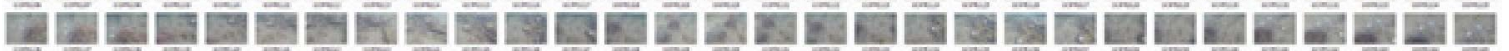

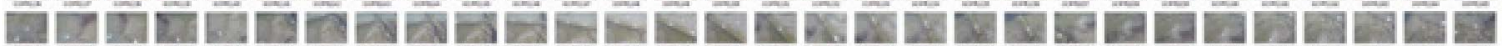

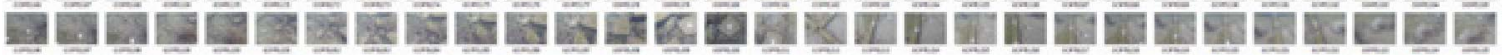

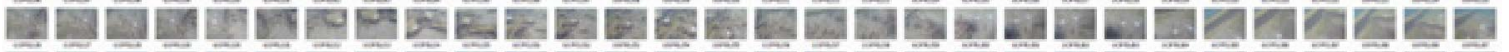

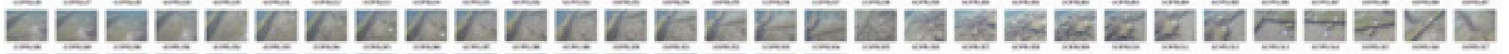

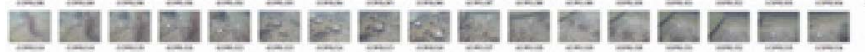
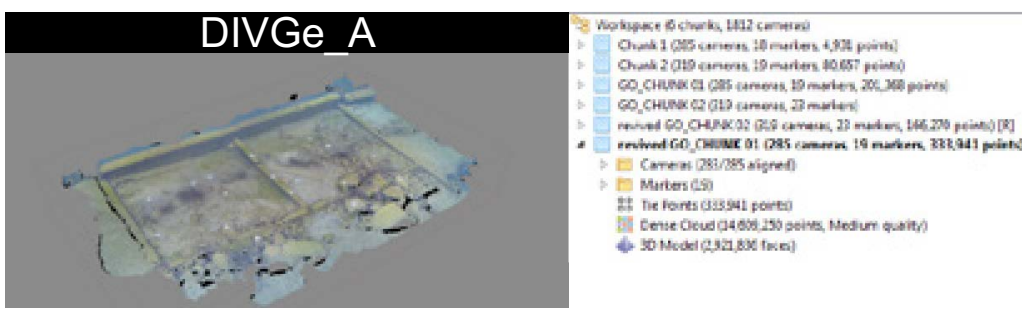

Camera B 320 images, GoPro Hero 5

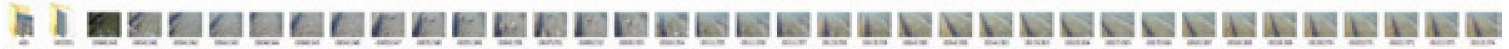

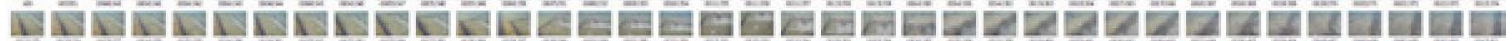

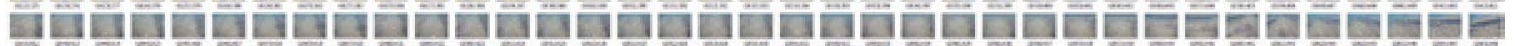

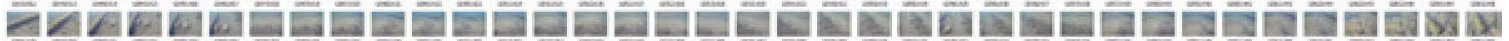

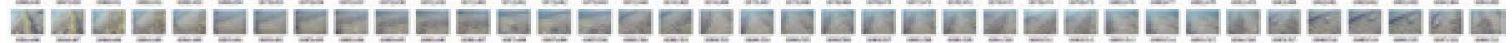

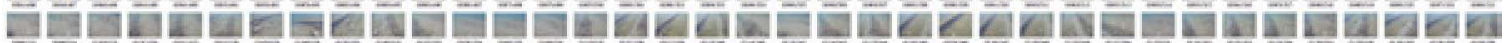

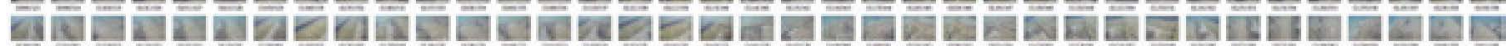

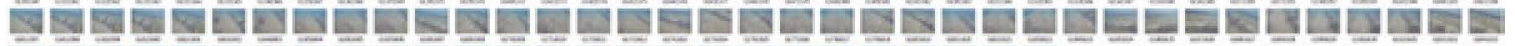

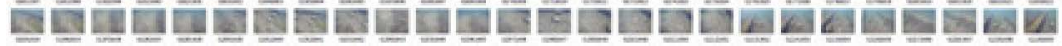

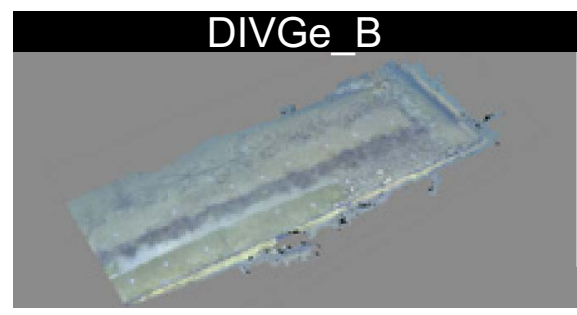

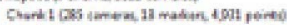

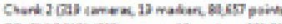

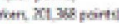

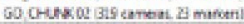

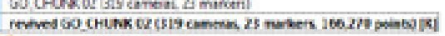

conter cos 319 atques

1 Mether

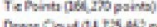

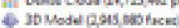

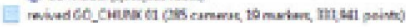




$$
\text { DIVi } 1304 \text { images, Iphone } 7 \text { Plus }
$$

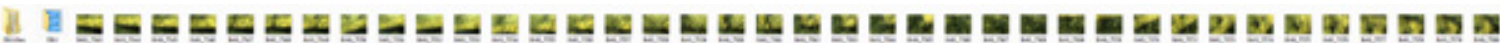

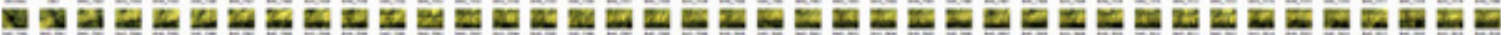

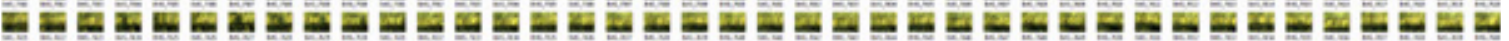

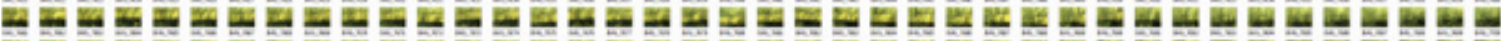

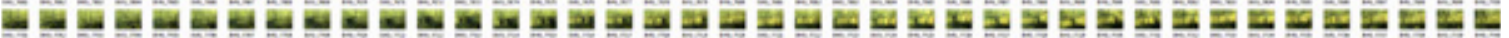

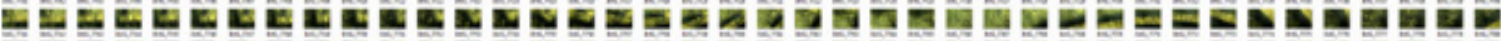

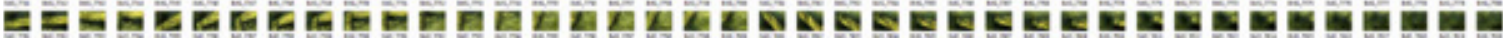

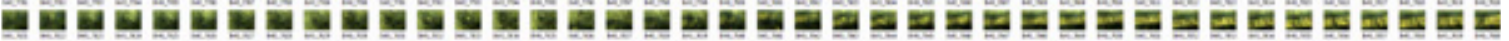

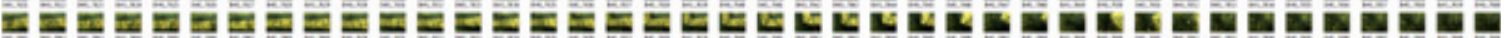

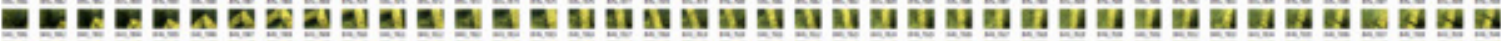
พ

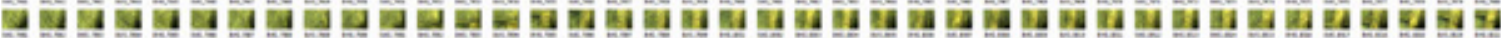

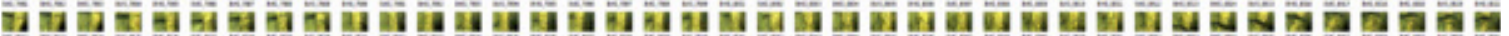

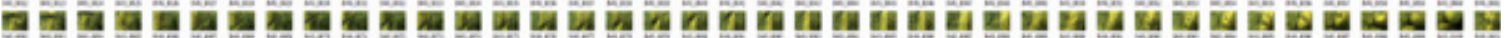

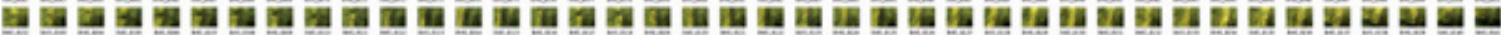

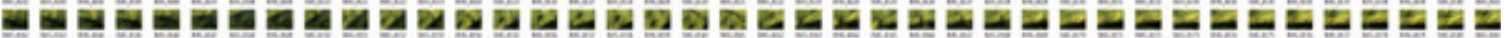

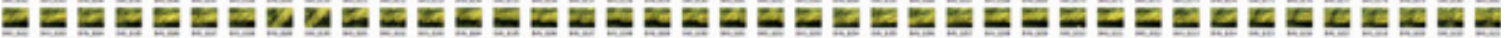

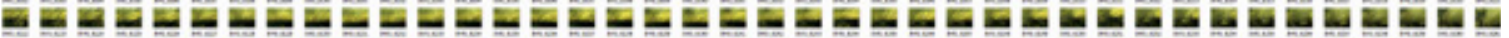

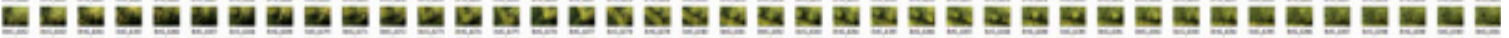

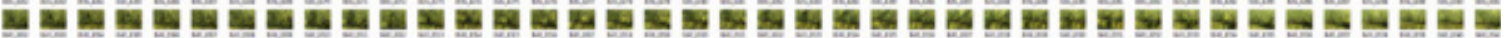

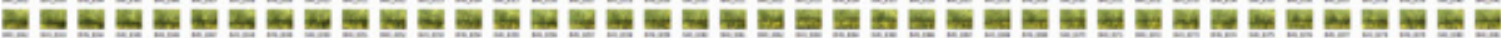

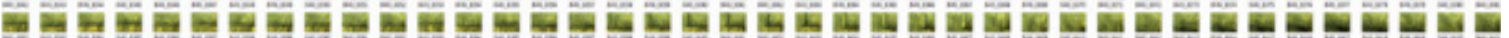

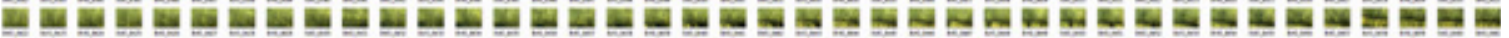

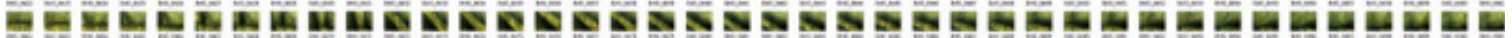

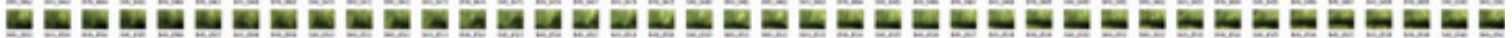

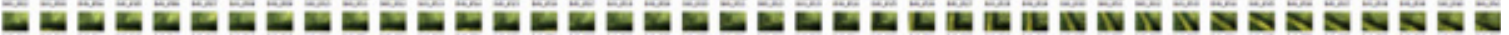

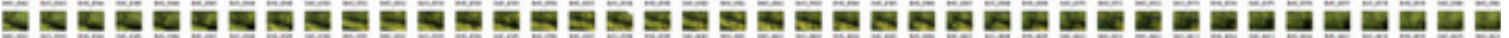

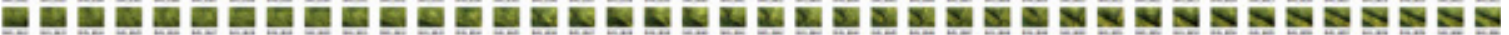

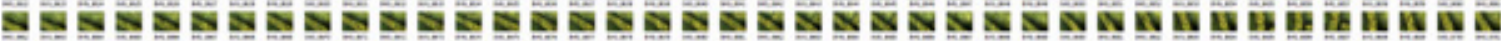

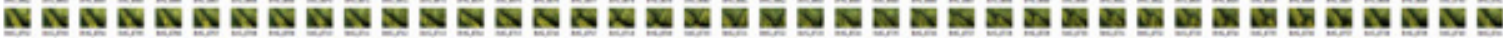

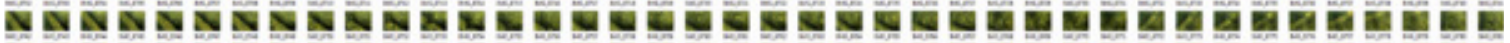

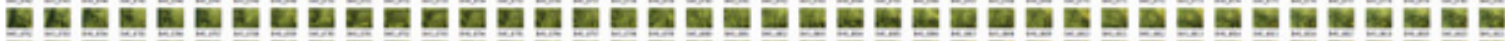

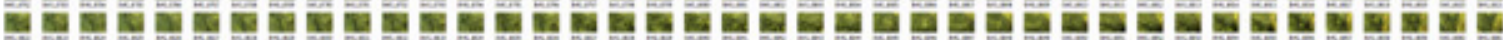

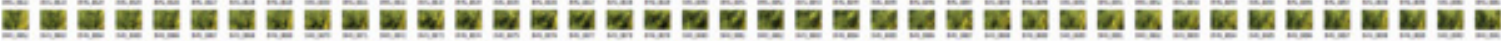

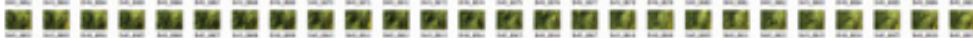

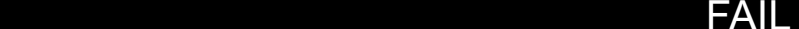

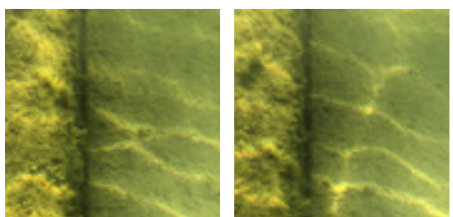

Example A

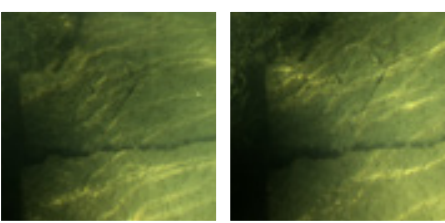

Example B

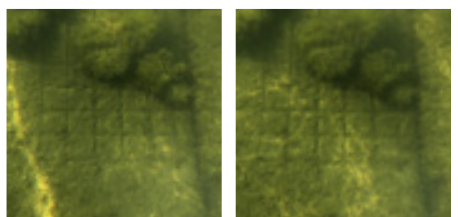

Example C

Unfortunately the clouds parted and the sun came out. As a result irregularities

created by waves and refracted light prevented image alignment in Agisoft

Photoscan. 


\section{DIViii 4236 images, Iphone 7 Plus}

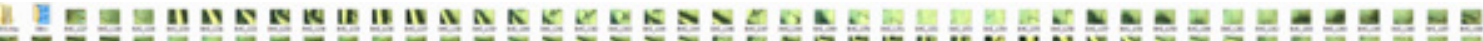

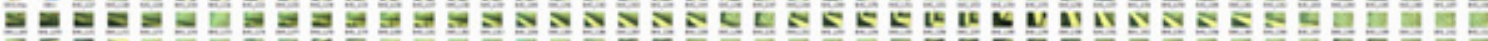

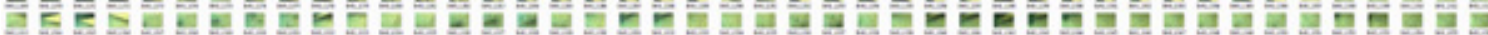

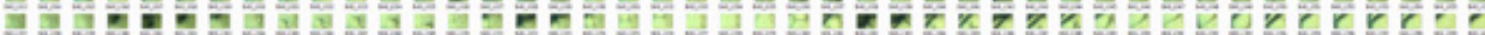
гог

I.

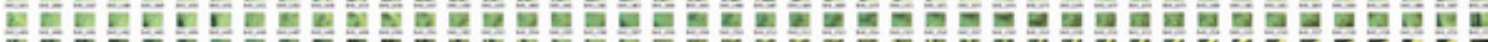

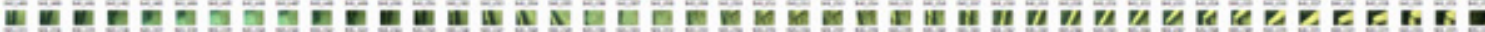

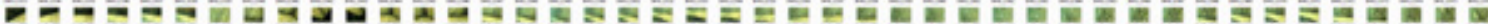

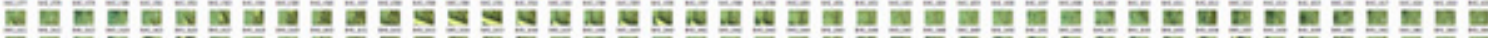

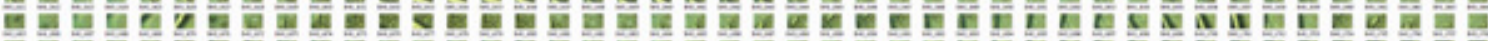
눌

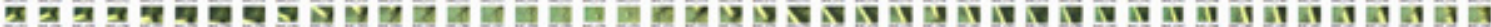

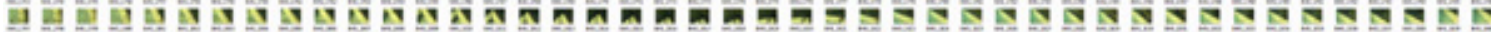

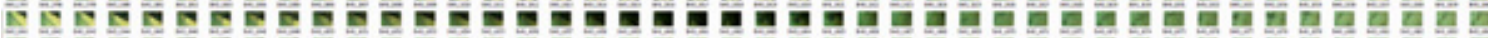

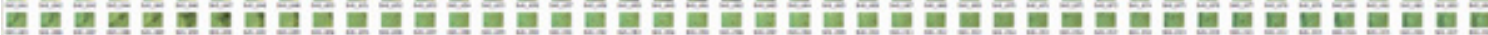

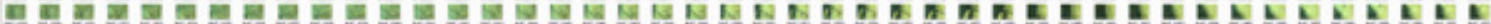

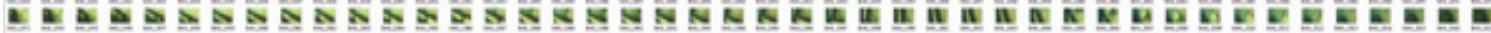

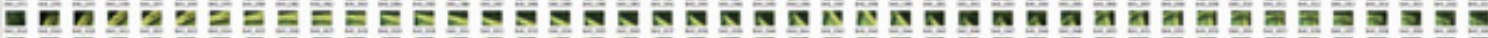

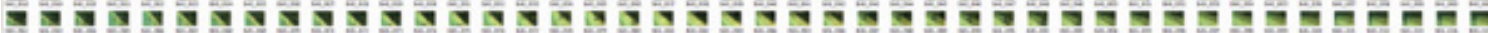

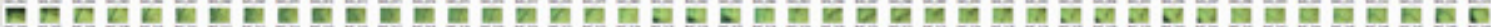

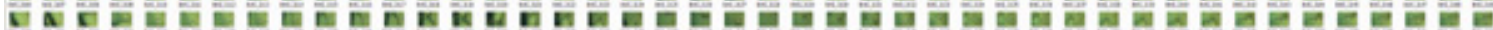

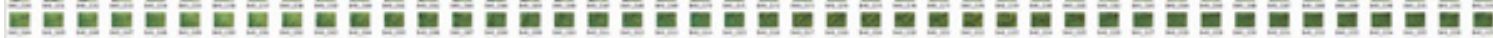

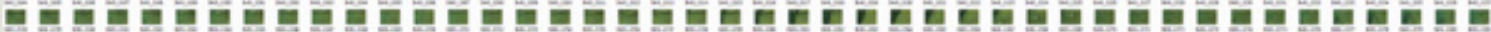

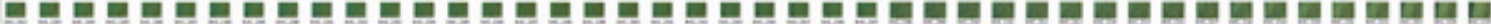

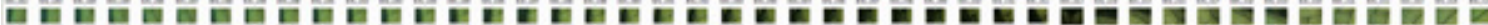

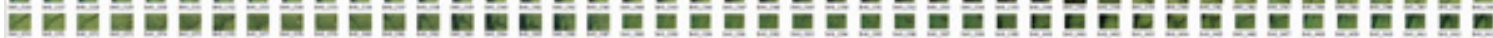

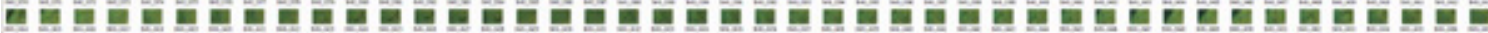

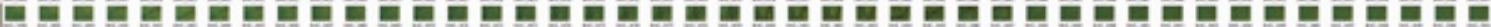

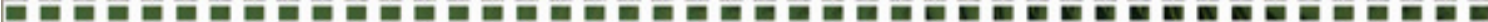

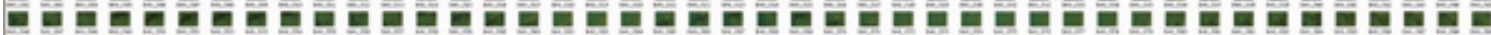

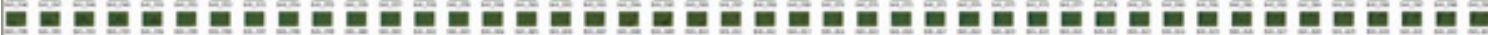

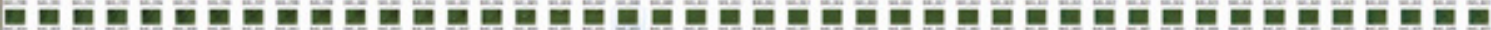

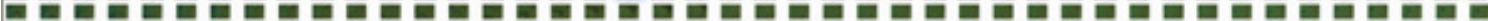

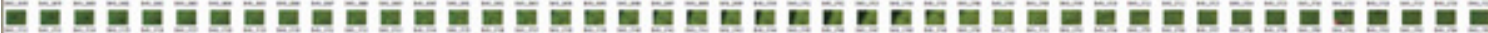

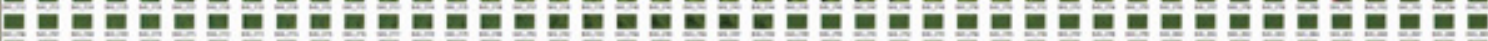

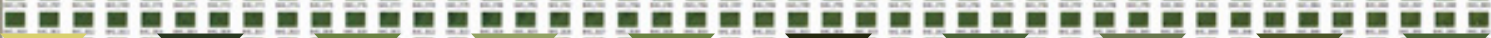

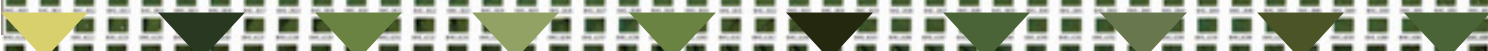

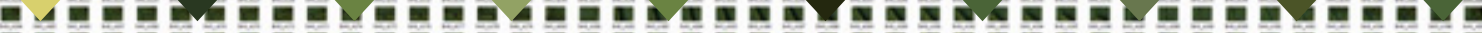

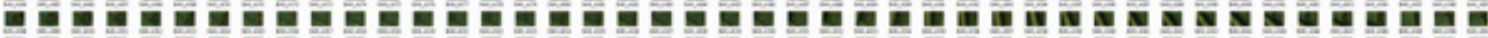

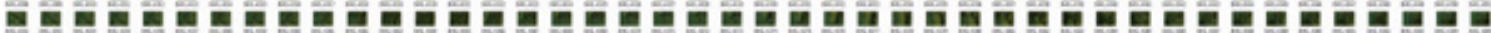

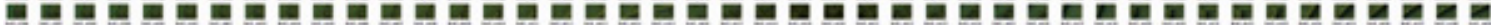

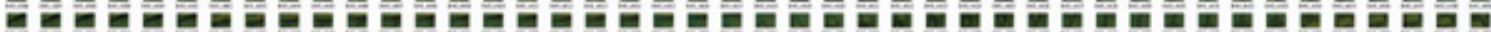

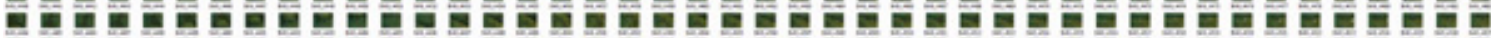

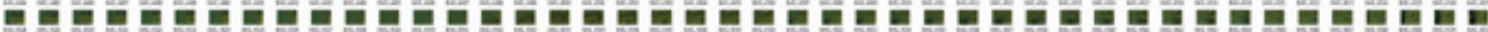

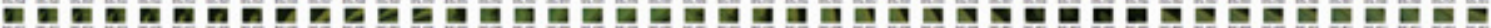

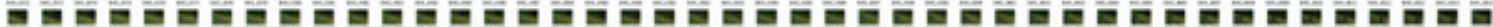

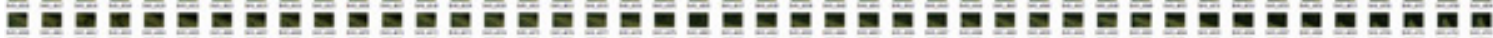

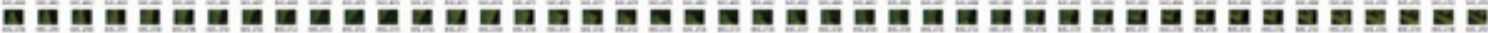

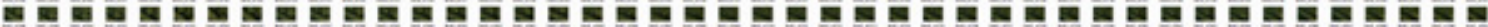

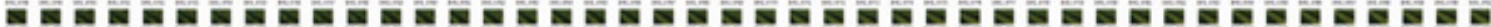

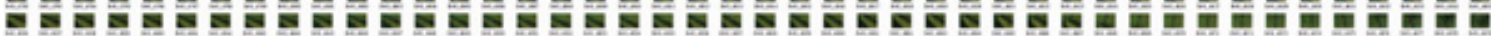

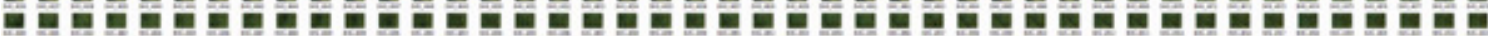

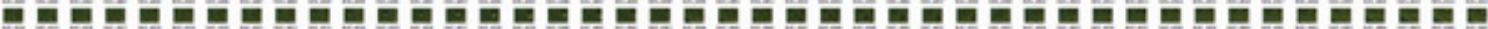

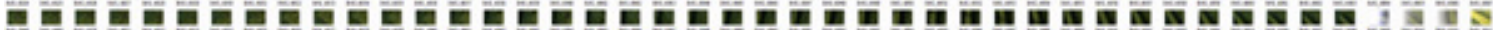

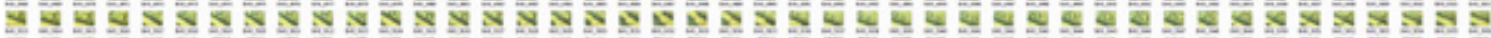

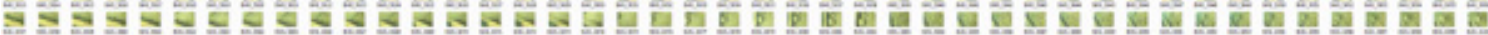

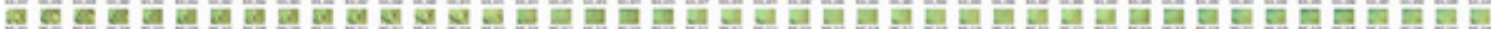

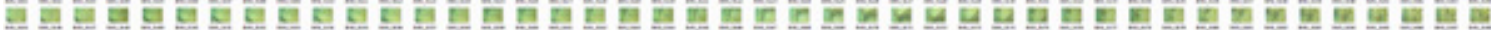

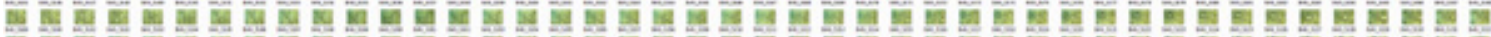

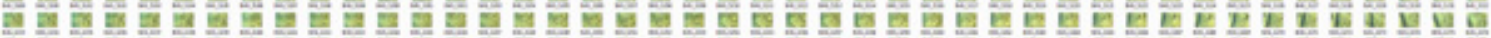

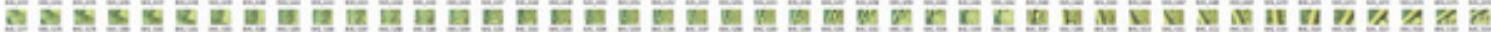

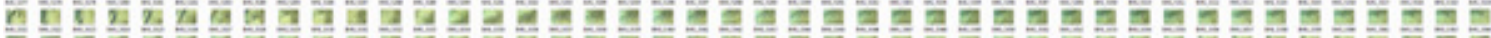

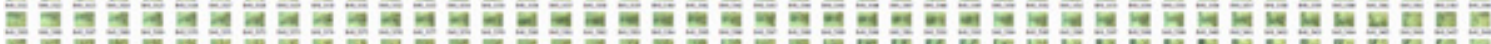

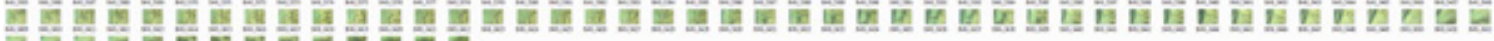

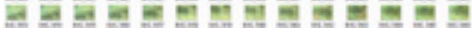

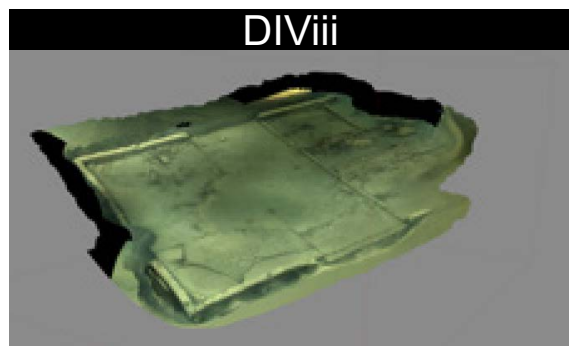

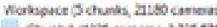

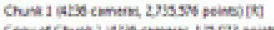

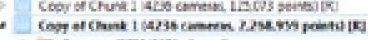
Tientions

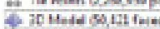

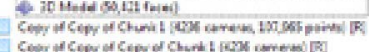


It was important to manually remove falsely aligned camera estimates in the sparse point cloud to prevent reprojection errors and non-linear deformations. After refining the camera projections, the point cloud is re-adjusted based off of the remaining cameras and the known GCPs. A second alignment is conducted for a homogeneous result. As a final optimization, a bundle adjustment is performed to optimize image orientation. During this optimization, PhotoScan adjusts the estimated tie point coordinates and camera parameters in an attempt to reduce reprojection errors and reference coordinate misalignments. The resulting point cloud was then further refined by deleting any additional mis-located points as these errors can also lead to deformations.

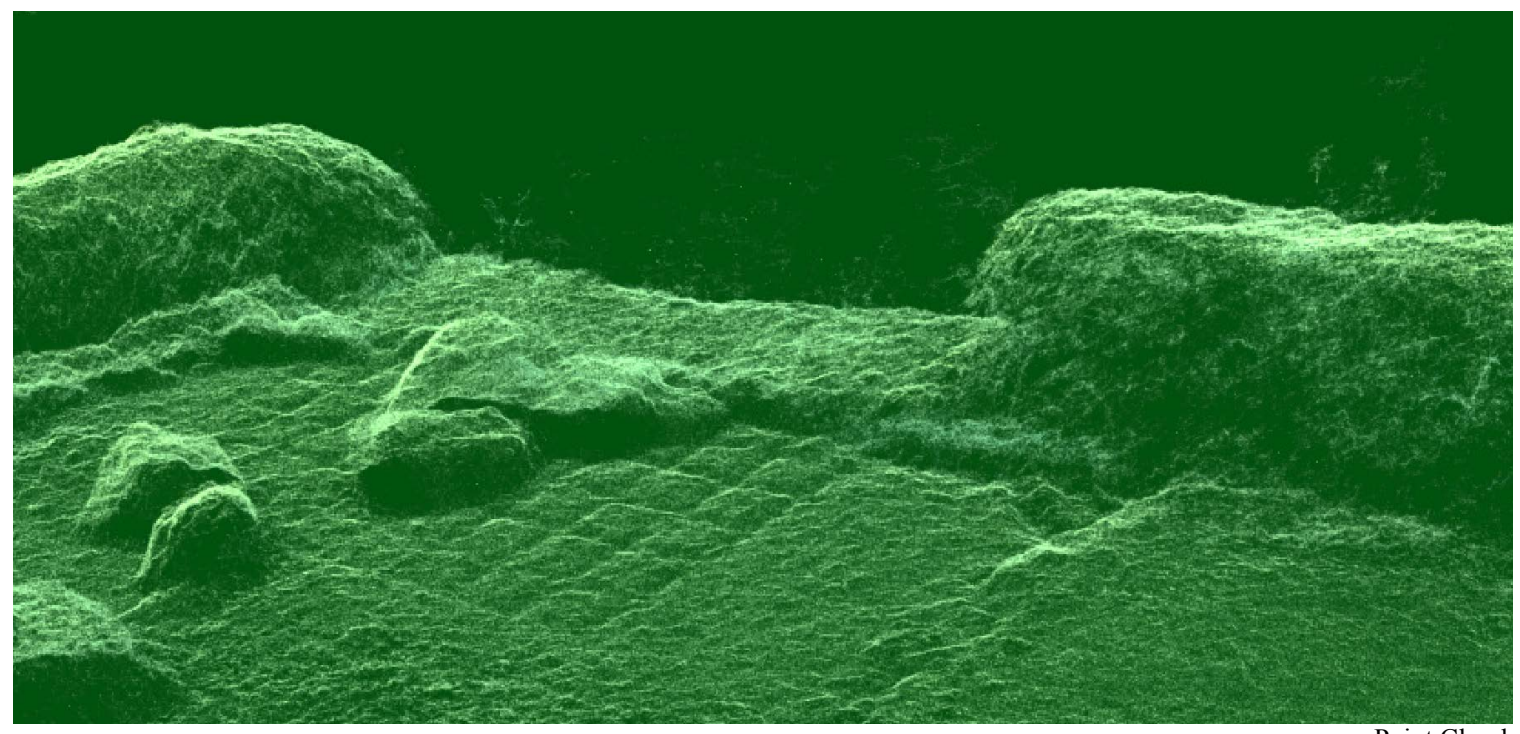

\subsection{Building Dense Clouds}

Point Cloud

Dense point cloud reconstruction was calculated by the individual depth maps extracted from every image. After the cameras are aligned, the software calculates depth information for each camera and generates a dense point cloud based off of their positions. ${ }^{38}$ Similar to the density a LIDAR scan, the dense point cloud was then used to provide an accurate representation of the data used to define the proceeding mesh topology. ${ }^{39}$

38 Mikhail, Edward M., et al. Introduction to Modern Photogrammetry. Wiley, 2001.

39 Agisoft PhotoScan User Manual, Professional Edition, Version 1.2,"Downloads User Manuals.” Agisoft PhotoScan, www.agisoft.com/downloads/user-manuals 

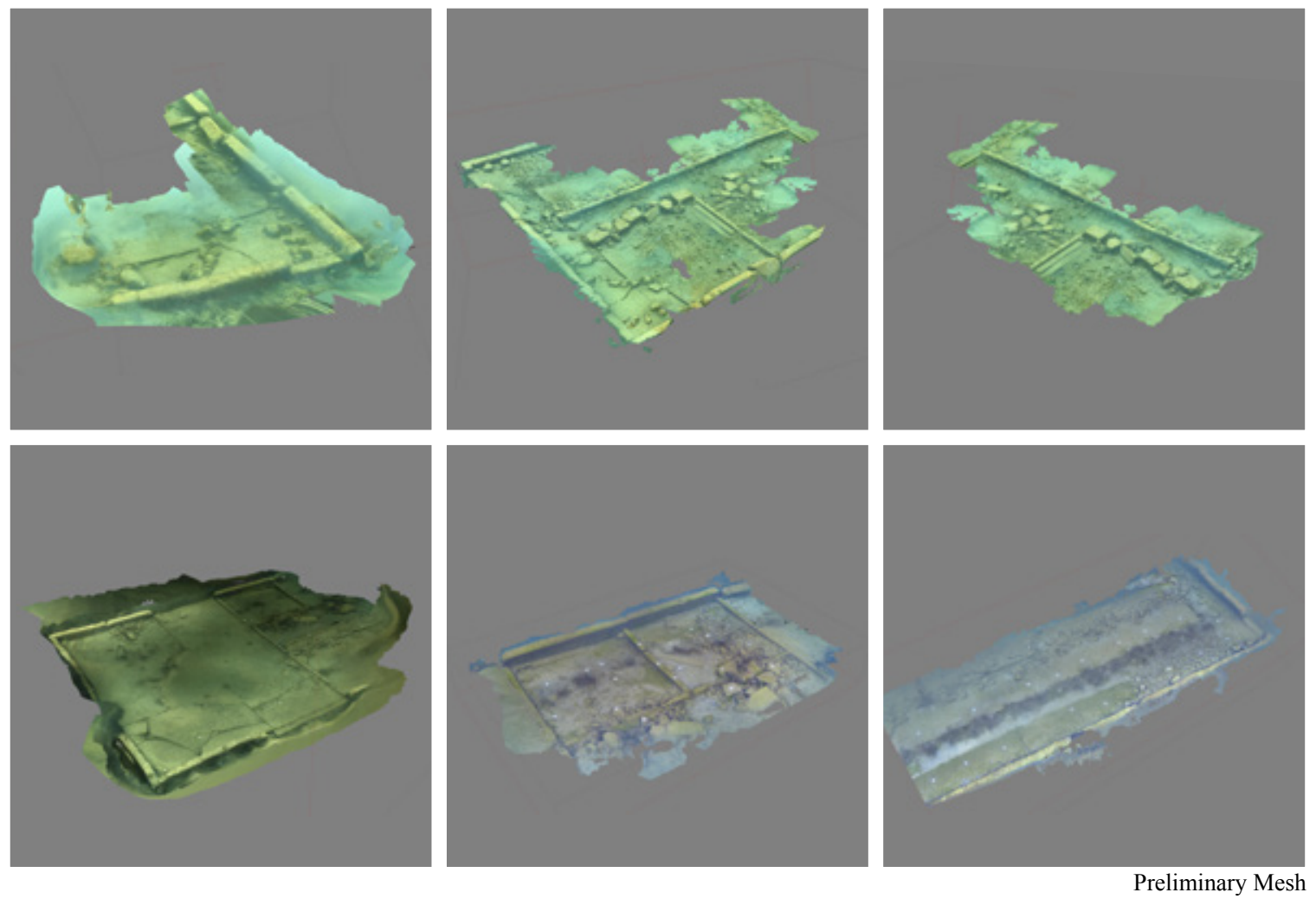

\subsection{Building Meshes}

The maximum number of polygons in the final mesh was determined by the number of products desired for end use purposes. Suggested values for visualization products are then calculated based off of the medium which the end user has identified as an appropriate method of dissemination. For the purpose of this project, the assets are to be viewed as a real time visualization in a head mounted display (HMD) and as a scaled representational model for display purposes. For this purpose a lower number of polygons are required. ${ }^{40}$ Unfortunately, if the mesh topology is set to a lower polygon count, the mesh is likely to lack surface details. While if the polygon count is too high (over 10 million polygons), the mesh is likely to cause visualization problems in external software. To overcome this issue the mesh was optimized in a set of external softwares. ${ }^{41}$

40 A. Chalk, B. Fisher. Normal Mapping Solutions for Oculus Rift Development.

41 Verhoeven, G. J. "Computer Graphics Meets Image Fusion:The Power Of Texture Baking To Simultaneously Visualise 3DSurface Features And Colour." ISPRS Annals of Photogrammetry, Remote Sensing and Spatial Information Sciences, IV-2/W2, 2017, Page 295-302 

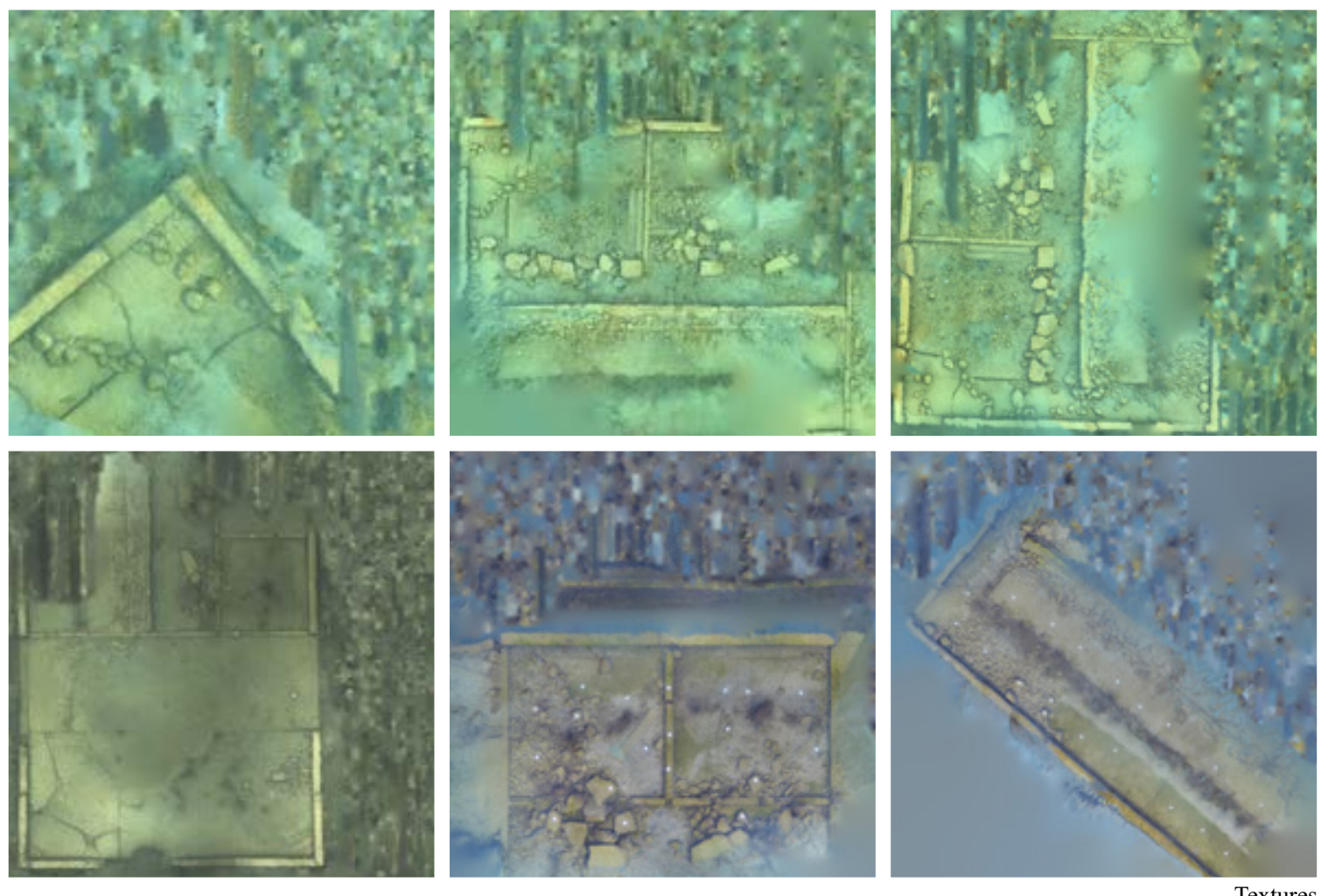

\subsection{Building Textures}

Textures

Proper texture mapping facilitates the optimal texture packing for visualizations. ${ }^{42}$ For the textures generated on this project, the adaptive-orthophoto mode was chosen. In the adaptive orthophoto mode, the mesh is split into planar and vertical regions. The planar regions of the surface are textured using an orthographic projection, while vertical regions are textured separately. ${ }^{43}$ This method maps planar surface topologies, such as the foundation floor, with a more compact texture representation which is easier to edit and view. The remaining vertical surfaces, such as walls or overhanging features, where the orthographic projection can't reach, are then mapped separately in smaller chunks. ${ }^{44}$

42 Verhoeven, G. J. "Computer Graphics Meets Image Fusion:The Power Of Texture Baking To Simultaneously Visualise 3DSurface Features And Colour." ISPRS Annals of Photogrammetry, Remote Sensing and Spatial Information Sciences, IV-2/W2, 2017, Page 295-302

43 Agisoft PhotoScan User Manual, Professional Edition, Version 1.2,"Downloads User Manuals.” Agisoft PhotoScan, www.agisoft.com/downloads/user-manuals

44 Agisoft PhotoScan User Manual, Professional Edition, Version 1.2,“Downloads User Manuals.” Agisoft PhotoScan, www.agisoft.com/downloads/user-manuals 


\section{Adaptive Orthographic Texture Mapping}

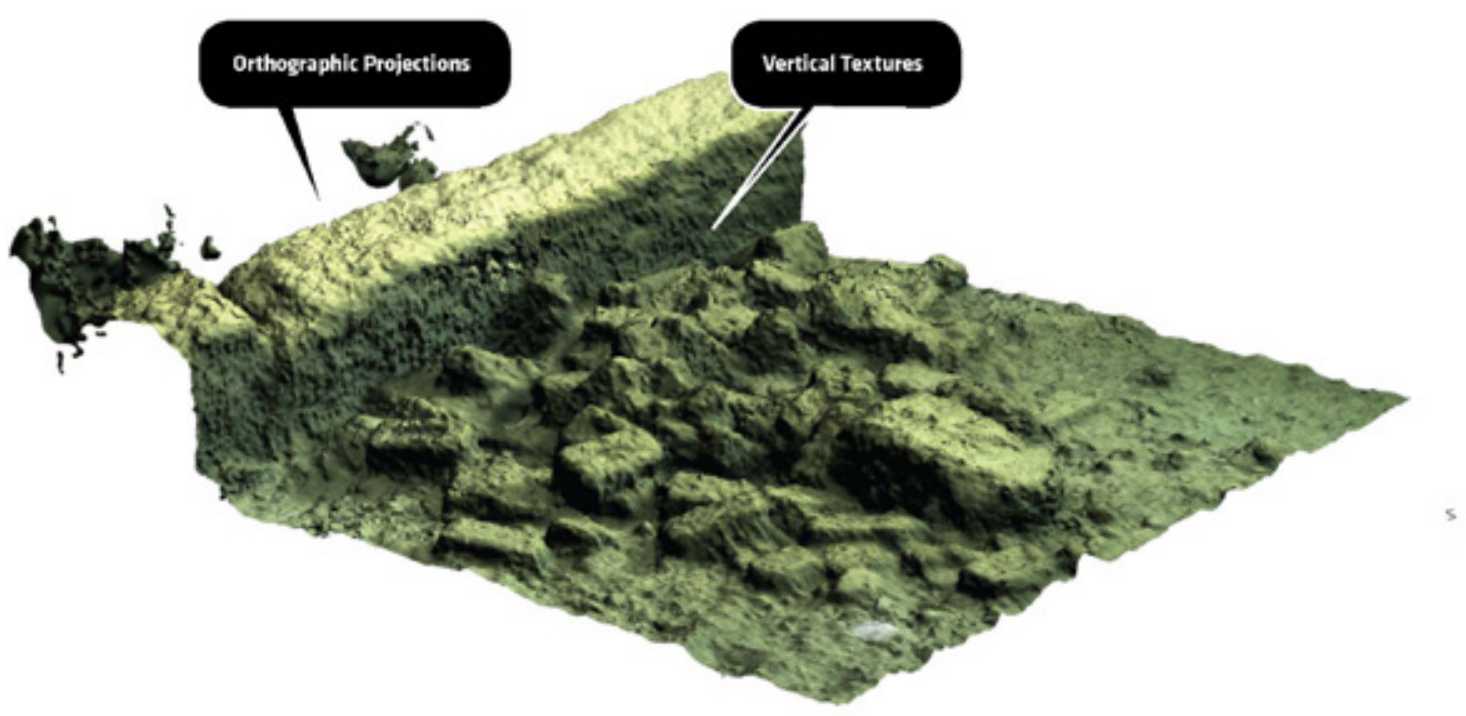

Adaptive Orthographic Texture

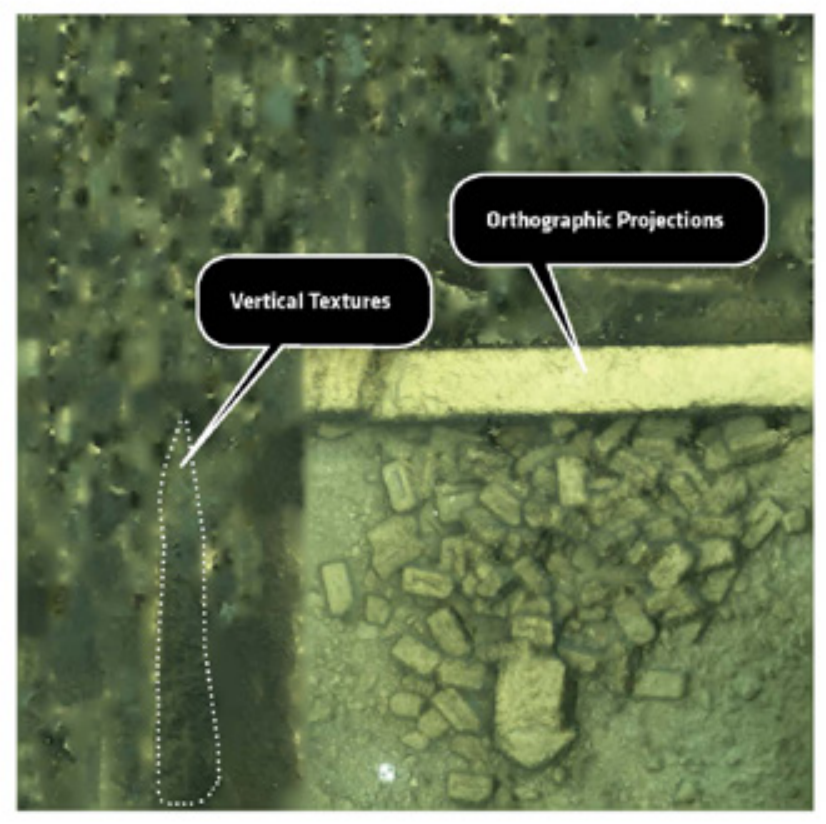



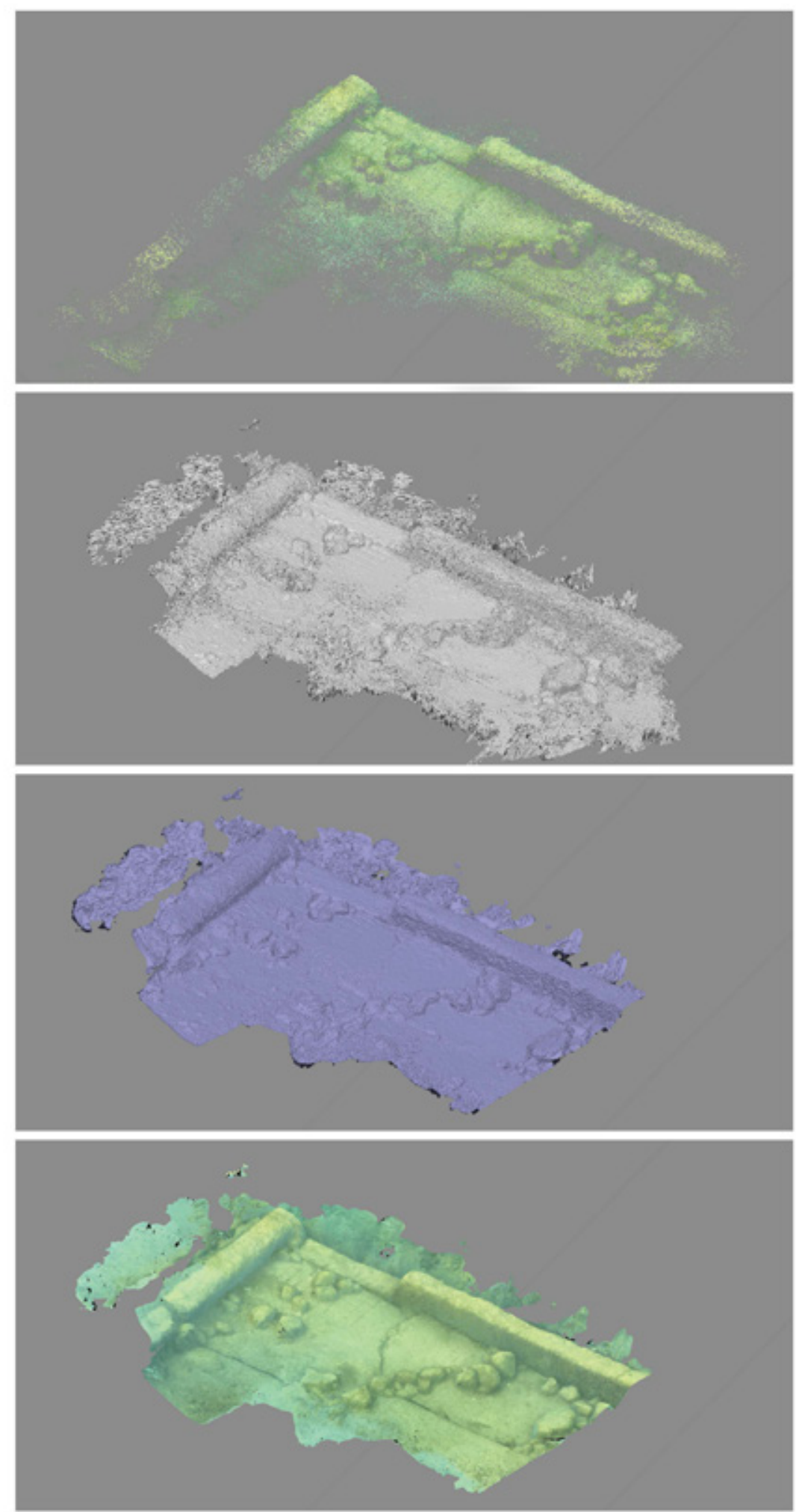

Photoscan Workflow 


\subsection{Stereo Images}

\subsection{Gopro-Stereo}

In addition to capturing data for digital restitution, a number of documenting methods were explored in order to identify any appropriate methods disseminating this process. A prototype for filming the environment in a stereoscopic 3D format was created by mounting two GoPro Hero5s to a stand, and submerging the equipment underwater. In human vision, the distance between each eye is between $5 \mathrm{~mm}$ and $10 \mathrm{~mm}$. To recreate this condition, each camera represents one eye. The resulting media when viewed in a head mounted display creates a 3D stereoscopic composition that is comfortably viewed in $\mathrm{L} / \mathrm{R}$ format.

To achieve the correct 3D effect, the distance between the cameras must be calculated by determining the depth budget. This is determined by the sum of the negative parallax (the maximum value of separation between the nearest items in the composition) and the positive parallax (the maximum value of the furthest items in the composition). By altering this dimension, the stenographer can control the compositions converging point, thus controlling the focus and attention of the viewer. 
DIVGo_01 Video Captured with one GoPro Hero 5 + Iphone 7 Plus
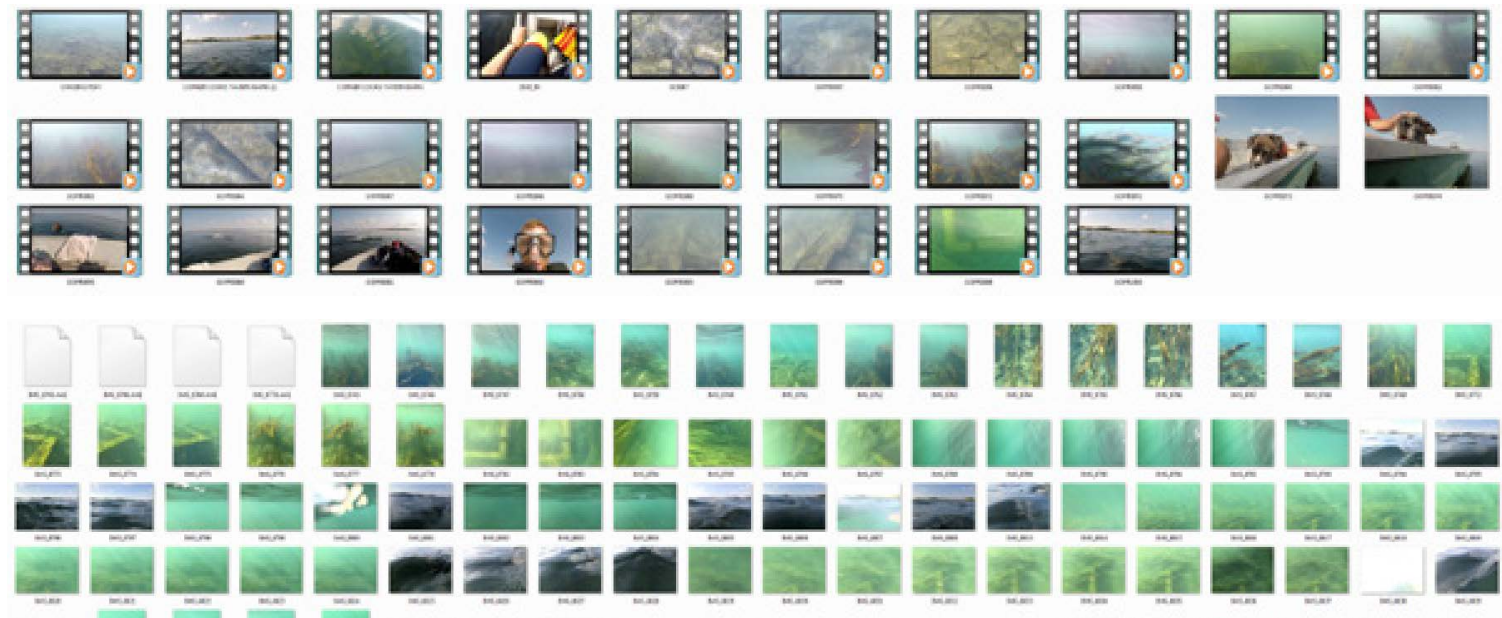

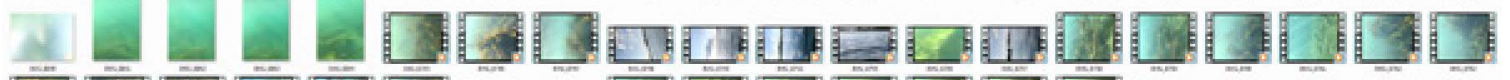
LOH 제은

DIVGo_02 Video Captured with one GoPro Hero 5
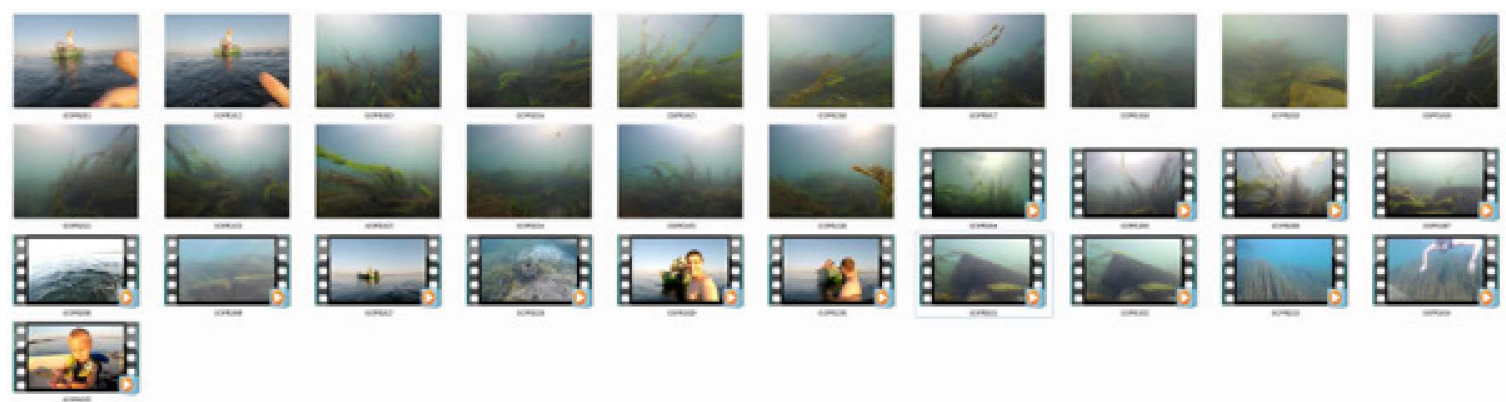

DIV_03_STEREO Stereo Video with Dual GoPro Hero 5s

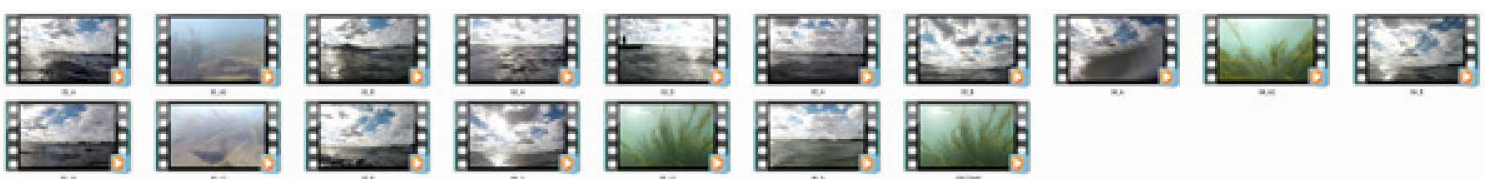




\section{Thank You}

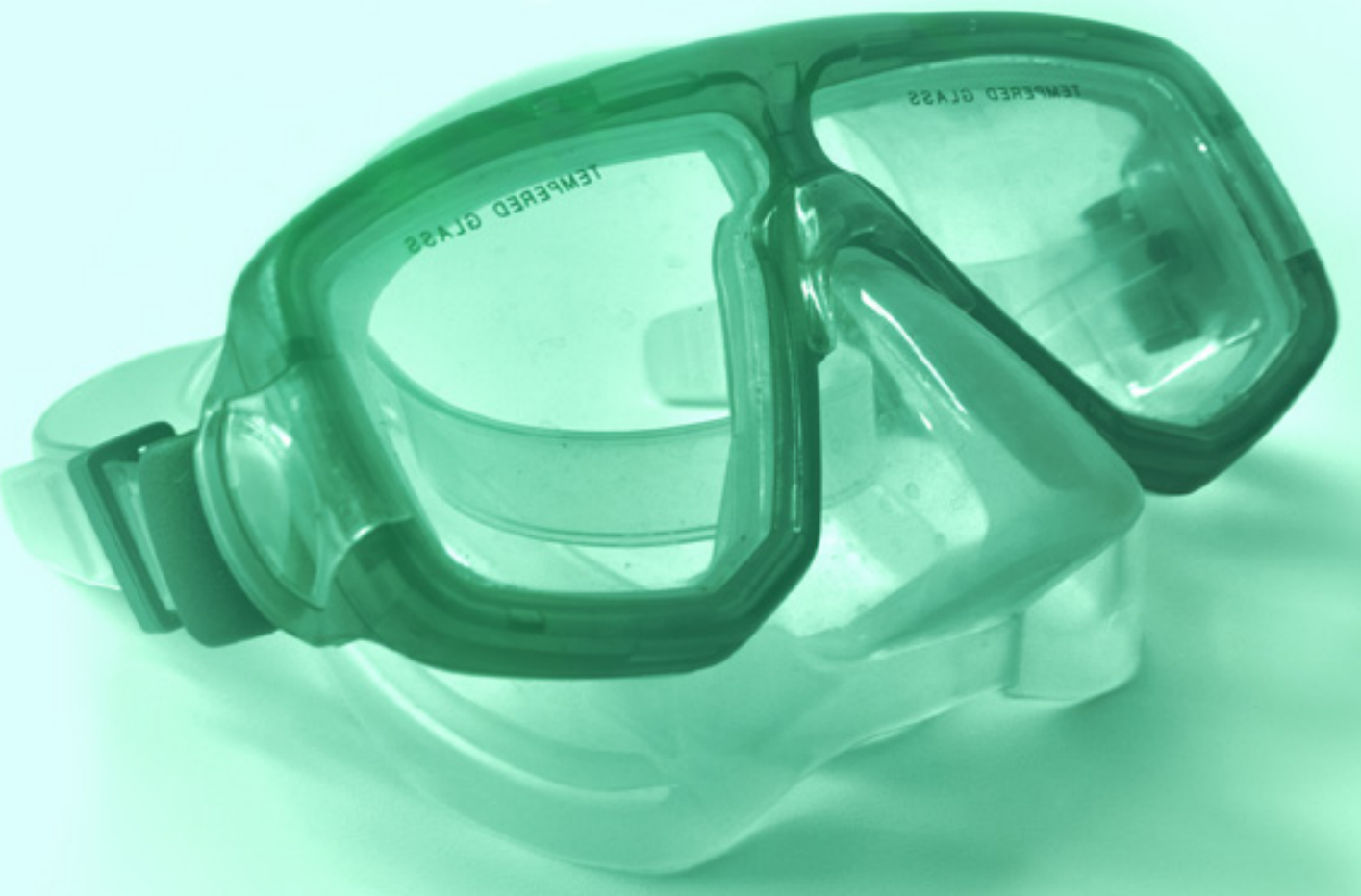




\section{Works Cited}

"1 Introduction." Close-Range Photogrammetry and 3D Imaging, pp. 1-27., doi:10.1515/9783110302783.1.

3Agrafiotis, P., and A. Georgopoulos. "Camera Constant In The Case Of Two Media Photogrammetry." ISPRS - International Archives of the Photogrammetry, Remote Sensing and Spatial Information Sciences, XL-5/W5, 2015, pp. 1-6., doi:10.5194/ isprsarchives-xl-5-w5-1-2015.

"About the Village - St. Lawrence Parks Commission.” Eastern Ontario Morrisburg Historical Attractions Plan Your Visit - St. Lawrence Parks Commission, www.uppercanadavillage.com/ about-the-village/.

Barazzetti, L. "Network Design In Close-Range Photogrammetry With Short Baseline Images." ISPRS Annals of Photogrammetry, Remote Sensing and Spatial Information Sciences, IV-2/W2, 2017, pp. 17-23., doi:10.5194/isprs-annals-iv-2-w2-17-2017.

Bouchette, Joseph. The British Dominions in North America. 1832.

The Canadian Inventory of Historic Buildings. National and Historic Parks Branch, Dept of Indian Affairs and Northern Development, 1971.

Corsane, Gerard. Heritage, Museums and Galleries: an Introductory Reader. Routledge, 2005.

Corsane, Gerard. Heritage, Museums and Galleries: an Introductory Reader. Routledge, 2010.

Creighton, Donald, and Christopher Moore. The Empire of the St. Lawrence: a Study in Commerce and Politics. University of Toronto Press, 2017.

Creighton, Donald Grant. The Commercial Empire of the St. Lawrence, 1760-1850. Ryerson Press, 1937.

Damelio, S., et al. "3D Modeling For Underwater Archaeological Documentation: Metric Verifications.” ISPRS - International Archives of the Photogrammetry, Remote Sensing and Spatial Information Sciences, XL-5/W5, 2015, pp. 73-77., doi:10.5194/ isprsarchives-xl-5-w5-73-2015.

Damme, T. Van. "Computer Vision Photogrammetry For Underwater Archaeological Site Recording In A Low-Visibility Environment.” ISPRS - International Archives of the Photogrammetry, Remote Sensing and Spatial Information Sciences, XL-5/W5, 2015, pp. 231-238., doi:10.5194/ isprsarchives-xl-5-w5-231-2015.
"Downloads User Manuals." Agisoft PhotoScan, www.agisoft. com/downloads/user-manuals/.

Fraser, Clive S. "Digital Camera Self-Calibration.” ISPRS Journal of Photogrammetry and Remote Sensing, vol. 52, no. 4, 1997, pp. 149-159., doi:10.1016/s0924-2716(97)00005-1.

Heritage Conservation Districts: a Guide to District Designation under the Ontario Heritage Act. Ministry of Culture, 2006.

Hickman, Angela. "Photographer Explores the St. Lawrence's Sunken Villages." National Post, 26 May 2011, nationalpost.com/ canada/photographer-explores-the-st-lawrences-sunken-villages.

Ioannides, Marinos. Progress in Cultural Heritage Preservation 4th International Conference, EuroMed 2012: Limassol, Cyprus, October 29-November 3, 2012: Proceedings. Springer, 2012.

Ioannides, Marinos. Progress in Cultural Heritage Preservation: Proceedings. Springer, 2012.

ISPRS / CIPA Workshop "UNDERWATER 3D RECORDING \& MODELING", 3dom.fbk.eu/repository/files/underwater/ UW_technical_sessions.html.

ISPRS Journal of Photogrammetry and Remote Sensing. Elsevier.

Journault, Marc, et al. "High Precision Hydrography in Canada, the ST. Lawrence River Channel, HD Bathymetry, Production, Distribution and Updating." Hydro12 - Taking Care of the Sea, 2012, doi:10.3990/2.221.

Klamkin, Charles. Barns: Their History, Preservation, and Restoration. Bonanza, 1979.

Kloeden, Paul, and Mark Staniforth. Cultural Mapping and Survey: Port Adelaide Waterfront:

Stage 2: Jenkins Street Boatyards, Precinct 2B, Precinct 2C. Land Management Corp., 2010.

Leacock, and Stephen Leacock. "CANADA. The Foundations Of Its Future by Stephen Leacock on TBCL The Book Collector's Library." TBCL The Book Collector's Library, Privately Printed, 1941., www.tbclrarebooks.com/pages/books/30694/ stephen-leacock/canada-the-foundations-of-its-future.

Legislative Services Branch. "Consolidated Federal Laws of Canada, International Rapids Power Development Act." Loi Sur Les Sports Nationaux Du Canada, 27 Apr. 2018, laws-lois. justice.gc.ca/eng/acts/I-19.8/page-1.html. 
"Louis Helbig: Sunken Villages.” AJ - Canada's Environmental Voice, 8 Sept. 2013, www.alternativesjournal.ca/community/ reviews/louis-helbig-sunken-villages.

Luhmann, Thomas, et al. Close Range Photogrammetry: Principles, Techniques and Applications. Whittles Publishing, 2014.

Macfarlane, Daniel. Negotiating a River: Canada, the US, and the Creation of the St. Lawrence Seaway. UBC Press, 2014.

Macfarlane, Daniel. Negotiating a River: Canada, the US, and the Creation of the St. Lawrence Seaway. UBC Press, 2014.

Macfarlane, Daniel. "Watershed Decisions: the St. Lawrence Seaway and Sub-National Water Diplomacy." Canadian Foreign Policy Journal, vol. 21, no. 3, 2015, pp. 212-223., doi:10.1080/1 1926422.2015.1051069.

Maas, H.-G. "A Modular Geometric Model For Underwater Photogrammetry." ISPRS - International Archives of the Photogrammetry, Remote Sensing and Spatial Information Sciences, XL-5/W5, 2015, pp. 139-141., doi:10.5194/ isprsarchives-xl-5-w5-139-2015.

Menna, Fabio, et al. "Optical Aberrations in Underwater Photogrammetry with Flat and Hemispherical Dome Ports." Videometrics, Range Imaging, and Applications XIV, 2017, doi:10.1117/12.2270765.

Mikhail, Edward M., et al. Introduction to Modern Photogrammetry. Wiley, 2001.

Murtiyoso, A., et al. “Acquisition And Processing Protocols For Uav Images:3D Modeling Of Historical Buildings Using Photogrammetry." ISPRS Annals of Photogrammetry, Remote Sensing and Spatial Information Sciences, IV-2/W2, 2017, pp. 163-170., doi:10.5194/isprs-annals-iv-2-w2-163-2017.

PADI Open Water Diver Manual. BPADI, 1990.

Parks Canada Agency, and Government of Canada. "Canadian Register of Historic Places (CRHP).” Parcs Canada | Parks Canada, 8 June 2017, www.pc.gc.ca/en/culture/rclp-crhp.

Pine, B. Joseph., and James H. Gilmore. Welcome to the Experience Economy. Harvard Business Review Press, 1998.

Rempel, John I. Building with Wood: and Other Aspects of Nineteenth-Century Building in Central Canada. University of Toronto Press, 1986.

Richardson, Ronald E. Developing Water Resources: the St. Lawrence Seaway and the Columbia - Peace Power Projects. Ryerson Press, 1969.
Schoenherr, John. The Barn. Little, Brown, 1968.

Stone, Peter G., and Philippe G. Planel. The Constructed Past: Experimental Archaeology, Education and the Public. Routledge, 2012.

Sunken Villages St Lawrence River, www.louishelbig.com/ sunkenvillagesst.html.

"The Sunken Villages Story.” SUNKEN VILLAGES, sunkenvillages.ca/story/.

Troisi, S., et al. "3D Models Comparison Of Complex Shell In Underwater And Dry Environments.” ISPRS - International Archives of the Photogrammetry, Remote Sensing and Spatial Information Sciences, XL-5/W5, 2015, pp. 215-222., doi:10.5194/ isprsarchives-xl-5-w5-215-2015.

Verhoeven, G. J. "Computer Graphics Meets Image Fusion:The Power Of Texture Baking To Simultaneously Visualise 3DSurface Features And Colour." ISPRS Annals of Photogrammetry, Remote Sensing and Spatial Information Sciences, IV-2/W2, 2017, pp. 295-302., doi:10.5194/isprs-annals-iv-2-w2-295-2017.

Weilberg, Matt. Photogrammetry and Remote Sensing. Syrawood Publishing House, 2016.

Wynn, Graeme. Canada and Arctic North America: an Environmental History. ABC-CLIO, 2007. 